Universidade de São Paulo

Instituto de Física

\title{
Desenvolvimento de Detectores a Gás de Padrão Microscópico para Experimentos com Raios X
}

\author{
Eraldo de Sales

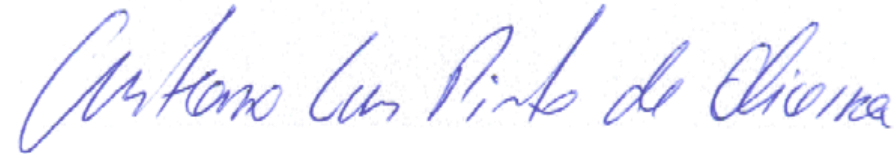 \\ Orientador: Prof. Dr. Cristiano Luis Pinto de Oliveira \\ Co-Orientador: Prof. Dr. Alexandre Alarcon do Passo Suaide
}

\begin{abstract}
Tese de doutorado apresentada ao Instituto de Física como requisito parcial para a obtenção do título de Doutor em Ciências.
\end{abstract}

Banca Examinadora:

Prof. Dr. Cristiano Luis Pinto de Oliveira (IFUSP)

Profa. Dra. Marcia C. Abreu Fantini (IFUSP)

Prof. Dr. Gustavo Pamplona Rehder (EPUSP)

Prof. Dr. Jean Rinkel (UNICAMP)

Prof. Dr. Guinther Kellermann (UFPR) 


\section{FICHA CATALOGRÁFICA \\ Preparada pelo Serviço de Biblioteca e Informação do Instituto de Física da Universidade de São Paulo}

Sales, Eraldo

Desenvolvimento de detectores a gás de padrão microscópico para experimentos com raios X. São Paulo, 2020.

Tese (Doutorado) - Universidade de São Paulo. Instituto de Física. Depto. de Física Experimental.

Orientador: Prof. Dr. Cristiano Luis Pinto de Oliveira

Área de Concentração: Física Experimental

Unitermos: 1. Simulação; 2. Física computacional; 3. Física experimental; 4. Detecção de partículas; 5. Modelagem computacional. 
University of São Paulo

Physics Institute

\title{
Development of Microscopic Pattern Gas
}

\section{Detectors for X-Ray Experiments}

\author{
Eraldo de Sales \\ Supervisor: Prof. Dr. Cristiano Luis Pinto de Oliveira \\ Co-supervisor: Prof. Dr. Alexandre Alarcon do Passo Suaide \\ Thesis submitted to the Physics Institute of the \\ University of São Paulo in partial fulfillment of the \\ requirements for the degree of Doctor of Science.
}

Examining Committee:

Prof. Dr. Cristiano Luis Pinto de Oliveira (IFUSP)

Profa. Dra. Marcia C. Abreu Fantini (IFUSP)

Prof. Dr. Gustavo Pamplona Rehder (EPUSP)

Prof. Dr. Jean Rinkel (UNICAMP)

Prof. Dr. Guinther Kellermann (UFPR) 

à minha querida Samara, que tanto me inspirou e motivou nessa empreitada. 



\section{Agradecimentos}

Primeiramente a Deus que me deu a inspiração necessária nos momentos mais difíceis das etapas mais duras dessa empreitada.

Quero agradecer enormemente aos meus pais. A eles nunca deixarei de agradecer ao me lembrar de todas as dificuldades que tiveram na criação dos dez filhos, sempre se esforçando para dar o melhor para cada um, sem deixar de dar a oportunidade de estudar, em um tempo em que isso não era assim tão comum em uma realidade dura. Tenho muito orgulho deles e nunca deixarei de lembrar da minha mãe Eva que nos deixou tão cedo, mas cuja passagem na Terra sempre será um legado para mim. Ao meu pai, José que tanto lutou para a criação dos seus filhos com muita gana e sempre me incentivou demais nos estudos, mesmo que ele próprio mal tenha aprendido a ler e escrever em três anos que permaneceu na escola nos anos 1940. Me lembro dele uma vez triste porque eu estava mal na escola me dizer: "meu filho, você não vai mais faltar na escola para ajudar nos afazeres, pois isso está prejudicando você na escola...". Essas palavras me marcaram para sempre e por isso sempre agarrei com unhas e dentes cada oportunidade que a vida me deu.

Agradeço de um modo muito especial à minha querida Samara que sempre me deu o apoio para seguir na luta e concluir essa etapa na vida. Lembro-me de diversas vezes querer desanimar e pensar que não seria capaz de lidar com tamanho desafio. Contudo, agindo como uma verdadeira companheira, amável e paciente, sempre torcendo pelo meu sucesso e caminhando junto nessa jornada. Tenho muito a agradecer por todo carinho, amor e compreensão e dizer que sem você eu não teria chegado até o final desse caminho...

Quero agradecer à minha segunda família, os pais, irmãos, tios, primos por parte de minha esposa: Marli, minha querida sogra, Rubem (o carismático "Rubão") meu querido sogro, Suelen, Washington, Marluce, Marilene, Solange, Miguel, Michele, muito obrigado!

Agradeço aos meus familiares que sempre me incentivaram de uma maneira muito especial, em especial aos meus irmãos e irmãs: Gildete, minha primeira professora e incentivadora e que viu algum potencial em mim; Gilvanete que esteve comigo e me ajudou muito nessa jornada, compartilhando bons e maus momentos; Maria, com seu jeito sempre calmo e sapiente para dar um conselho (e foram muitos!!); Egnaldo, que sempre me tratou com muito carinho; Edson com seu jeito simples a carinhoso; Elivonaldo e Everaldo, ambos 
com muito bom humor que me alegraram nos momentos mais complicados da vida. Erivaldo e Jaidete, aqueles mais próximos a mim em idade e que ajudaram muito também, especialmente na época da infância e adolescência. Meus sinceros agradecimentos também a todos meus sobrinhos que conviveram comigo e me incentivaram das mais diversas maneiras possíveis. Difícil citar todos, mas mesmo assim devo tentar me lembrar das (os) queridas (os) Julliana, Jackeline, Isabela, Gustavo, Guilherme, Sueli, Emerson, Vitor, Kaline, Robson, Remilson, Renan, Arthur, Jhuan, Julio, Cauã, Josieli, Josevaldo.

Não posso esquecer-me de mencionar minha querida tia Celina... Ela que foi minha segunda mãe na infância, me acolhendo sempre com muito amor em sua casa. Acolheu-me nos momentos mais difíceis da minha vida, quando perdi minha mãe... A você tia, desejo todas as bênçãos de Deus, pois você merece!

Ao professor Cristiano só tenho a agradecer por toda ajuda, especialmente naqueles momentos nebulosos onde a dúvida batia forte. Muito mais que um orientador, atuou como um amigo onde diversas vezes me forneceu conselhos valiosos que de fato contribuíram demais para minha formação desde a iniciação científica e Mestrado, mas de um modo ainda mais marcante no presente trabalho, que considero o mais difícil que já fiz na vida. Graças a ele estou nessa etapa final desse processo tão importante para mim.

Ao professor Alexandre Suaide, que forneceu toda infraestrutura computacional fundamental através do cluster SAMPA que foi decisivo para o desenvolvimento do trabalho. Isso para não falar das importantes discussões que foram determinantes para uma maior compreensão e para o avanço da pesquisa.

Um agradecimento especial também aos técnicos do Grupo de Fluídos Complexos (GFCx), especialmente ao Társis, sempre muito prestativo para ajudar nas pesquisas dos alunos do grupo. Também quero mencionar os membros da Bioengenharia do InCor, nas pessoas de Marcelo Mazzetto e Professora Idágene Cestari, sempre dispostos a me ajudar a concluir essa difícil missão.

Agradeço aos membros do grupo HEPIC: Hugo e ao professor Marco Bregant, que me ajudaram em diversos momentos, deram sugestões e forneceram acesso aos equipamentos no laboratório. Também a todos os colegas do GFCx pelas discussões que ajudaram demais a rever os problemas, que auxiliou de modo crucial na estratégia de busca por soluções. 


\section{Resumo}

Foram realizadas simulações de várias características do funcionamento de um triplo GEM (Gas Electron Multiplier) de geometria bicônica padrão, incluindo o ganho efetivo, o estudo do movimento dos íons positivos e a resolução em energia e espacial. Considerando que as simulações foram desenvolvidas em softwares livres, que nem sempre são amigáveis a novos usuários, foi desenvolvida uma ferramenta que as automatiza e facilita o uso, dispensando a exigência de configurar todos os arquivos necessários para executar cada programa. No intuito de fazer a validação das simulações, foi efetuada uma comparação da curva de ganho simulada com uma curva experimental de um triplo GEM padrão do CERN, com uma boa concordância. Foi simulado um detector com geometria alternativa (cônica, máscara simples), onde se explorou a variação das características estudadas em função do diâmetro dos furos e do espaçamento entre os mesmos. Nessas simulações foram identificados parâmetros ótimos para cada característica estudada, como o diâmetro ou espaçamento que maximiza o ganho ou minimiza o movimento retrógrado de íons, por exemplo. Aplicando os parâmetros geométricos que maximizam o ganho, com espaçamento entre orifícios de $120 \mu \mathrm{m}$, diâmetro superior de $60 \mu \mathrm{m}$ e inferior de $70 \mu \mathrm{m}$, foi encontrada uma configuração de um GEM cônico (máscara simples) que pode chegar a um ganho até 75\% maior em relação à configuração usual (espaçamento de $140 \mu \mathrm{m}$, diâmetro superior de $70 \mu \mathrm{m}$ e inferior de $60 \mu \mathrm{m})$. Essas propostas de melhorias podem ser empregadas em uma nova versão desse detector que pode vir a ser efetivamente construído. Foram realizados também experimentos com um detector multifilar e um GEM de geometria alternativa utilizando uma fonte de ${ }^{55} \mathrm{Fe}$. Nesses experimentos, pôde-se caracterizar a resolução em energia e a curva de ganho, cujos comportamentos estão de acordo com aqueles estimados pelas simulações.

Palavras-chaves: Detecção de Partículas; Raios X; Detectores a Gás; Simulação Computacional. 


\begin{abstract}
Simulations of several characteristics of a standard biconical triple GEM (Gas Electron Multiplier) operation were performed, including effective gain, the study of positive ions movement, spatial and energy resolution. Considering that the simulations were developed using free software that are not always friendly to new users, a tool was developed that automates them and facilitates its use, eliminating the requirement to configure all the files necessary to run each program. In order to validate the simulations, a comparison of the simulated gain curve with an experimental curve of a standard CERN triple GEM was performed, with a good agreement. A detector with alternative geometry (conical, single mask) was simulated, where the variation of the studied characteristics was explored according to the diameter of the holes and its pitch. In these simulations, optimal parameters were identified for each characteristic studied, such as the diameter or pitch that maximizes the gain or minimizes the ion back flow, for example. Applying the geometric parameters that maximize the gain, with hole pitch of $120 \mu \mathrm{m}$, top diameter of $60 \mu \mathrm{m}$ and bottom of $70 \mu \mathrm{m}$, was found a conical GEM (single mask) configuration that can reach a gain up to $75 \%$ greater in relation to the usual configuration (pitch of $140 \mu \mathrm{m}$, top diameter of 70 $\mu \mathrm{m}$ and bottom of $60 \mu \mathrm{m})$. These improvements suggested can be used in a new version of this detector that can be effectively made. Experiments were also performed with a multiwire detector and an alternative geometry GEM using a ${ }^{55} \mathrm{Fe}$ source. In these experiments it was possible to characterize the energy resolution and gain curve, whose behaviors are in accordance with those estimated by simulations.
\end{abstract}

Keywords: Particle Detection; X Ray; Gas Detectors; Computational Simulation. 


\section{Sumário}



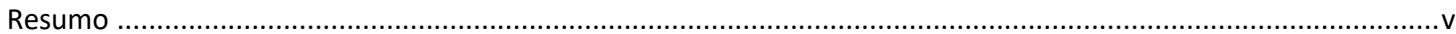



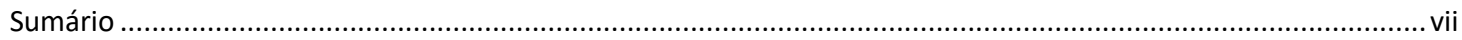

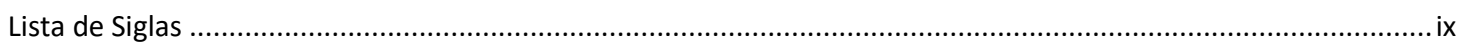

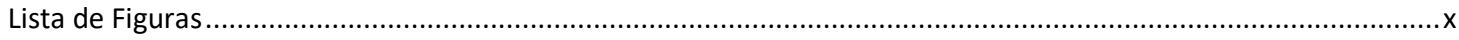

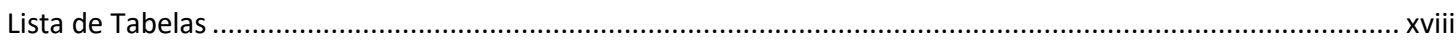

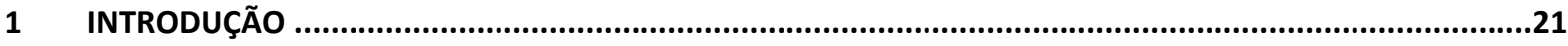

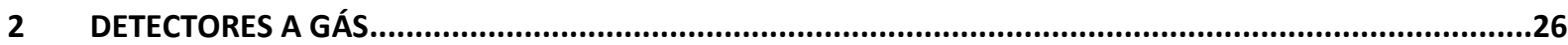

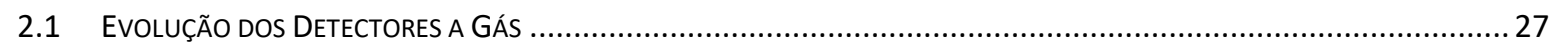

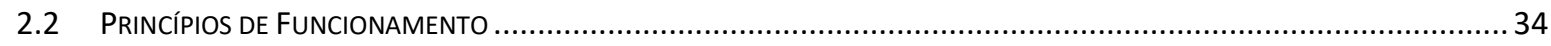

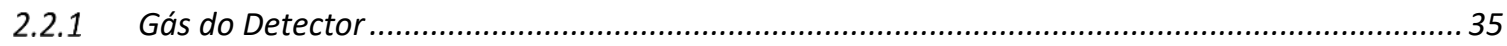

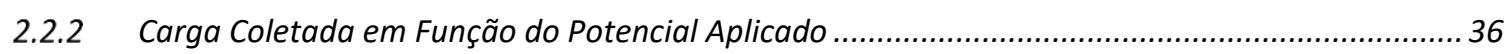

2.2.3 Número de Pares de Elétrons e ĺons Produzidos no Gás..............................................................37



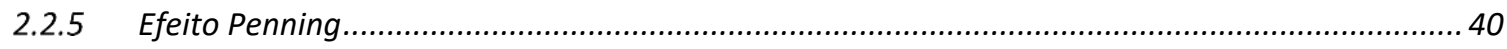

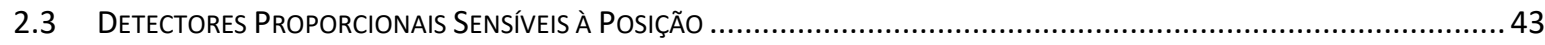





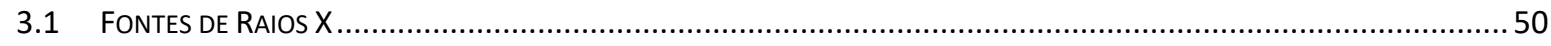

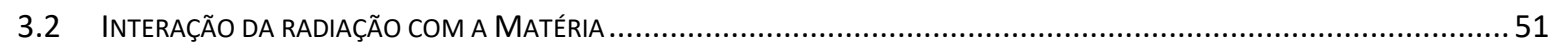

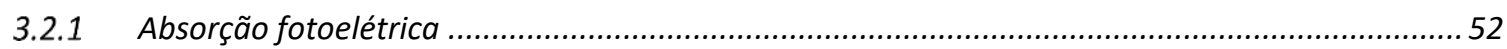

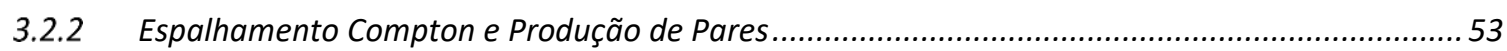

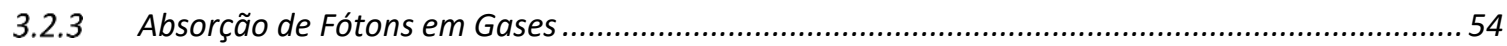

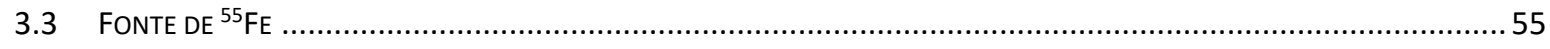

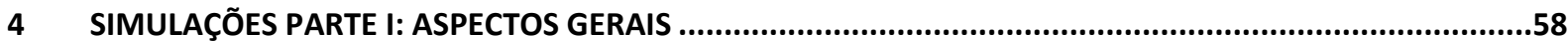



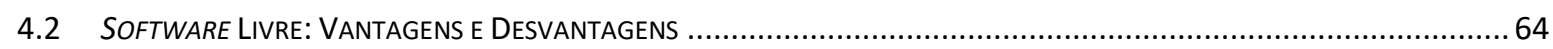

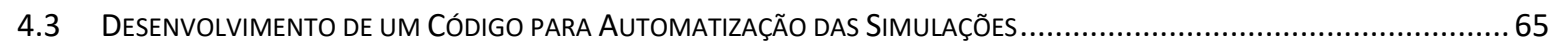

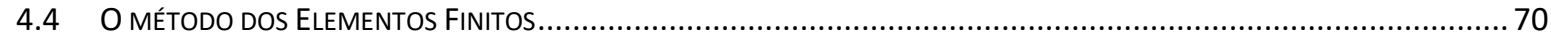

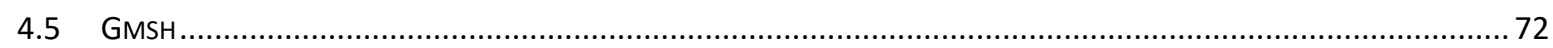

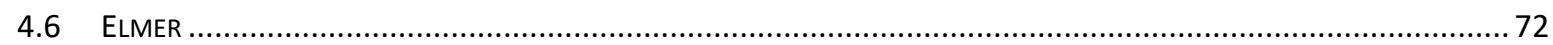



4.6.2 Metodologia para Resolução do Problema ..................................................................... 74

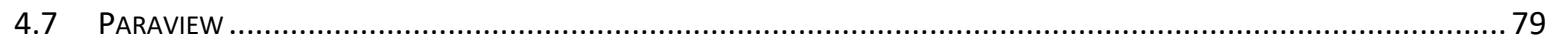

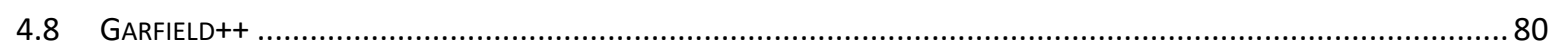




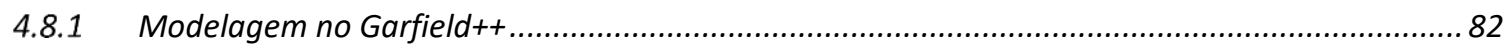

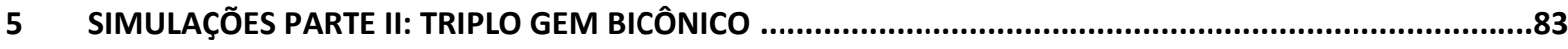

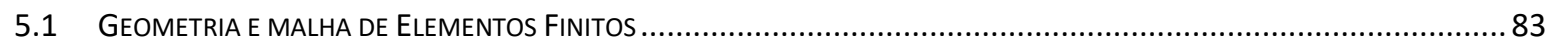

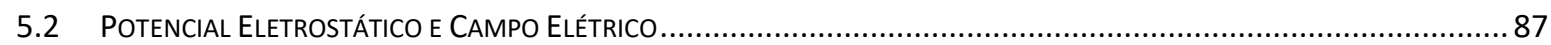

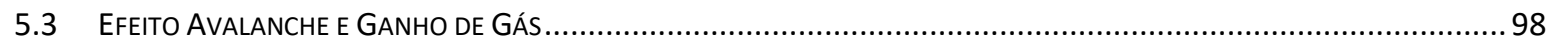

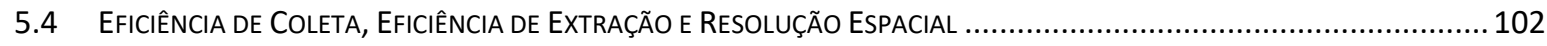

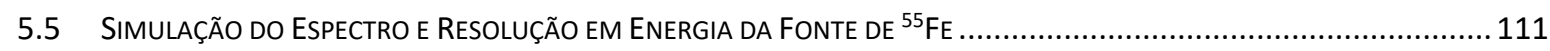

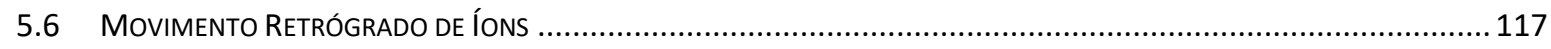

6 SIMULAÇÕES PARTE III: O GEM CÔNICO DE MÁSCARA SIMPLES .................................................126

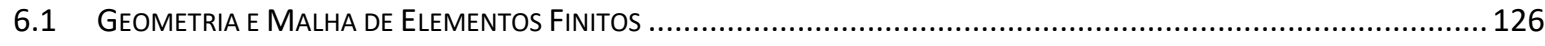

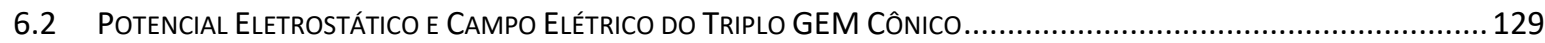

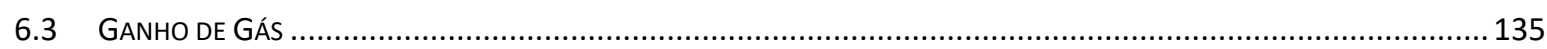

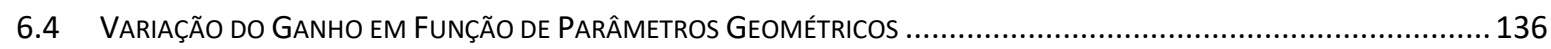

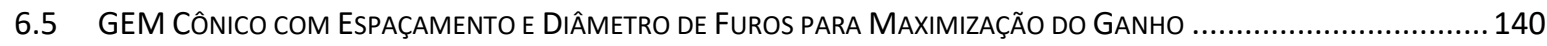

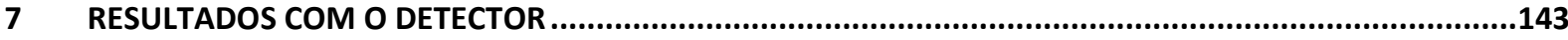

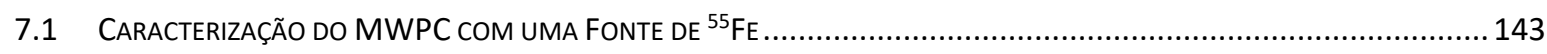



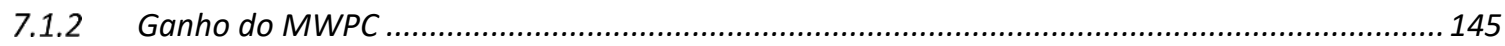

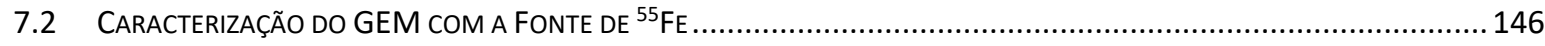

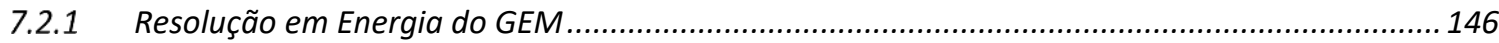

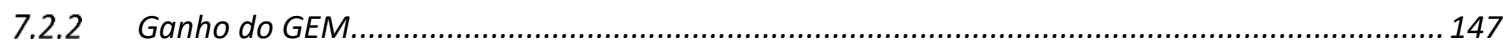



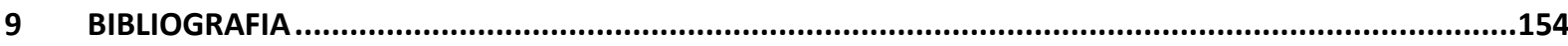

10 APÊNDICE A - CONFIGURAÇÕES DE POTENCIAL E CAMPO ELÉTRICO DO TRIPLO GEM PADRÃO ...........165

11 APÊNDICE B - AJUSTE DA DISTRIBUIÇÃO DO NÚMERO DE ELÉTRONS NA AVALANCHE........................168

12 APÊNDICE C - EXEMPLOS DE UTILIZAÇÃO DA ROTINA DE AUTOMATIZAÇÃO DAS SIMULAÇÕES...........171 


\section{Lista de Siglas}

B

BiCG - Biconjugate Gradient $\quad 76$

$\begin{array}{ll}\text { BiCGSTAB - BiConjugate Gradient Stabilized } & 78\end{array}$

C

CG - Conjugate Gradient $\quad 75$

$\begin{array}{ll}\text { CGS - Conjugate Gradient Squared } & 78\end{array}$

$\boldsymbol{F}$

FWHM - Full Width at Half Maximum

G

GEM - Gas Electron Multiplier

I

IBF - Ion Back Flow

M

MEF - Método dos Elementos Finitos

MICROMEGAS - MICRO-MEsh-GAseous Structure

MSGC - Micro-Strip Gas Counter

MWPC - Multi-Wire Proportional Counter

$S$

SAXS - Small Angle X-ray Scattering

$x$

XRD - X-Ray Diffraction 


\section{Lista de Figuras}

FIGURA 2.1: ESQUEMA DE UM DETECTOR A GÁS, COMPOSTO POR DOIS ELETRODOS (ANODO E CATODO) E UMA CÂMARA PREENCHIDA COM GÁs.

FIGURA 2.2: EXEMPLO DE IMAGEM DE UMA FOLHA DE GEM OBTIDA POR MICROSCÓPIO, MOSTRANDO OS FUROS NA FOLHA DE KAPTON QUE É REVESTIDA COM COBRE. O DIÂMETRO TíPICO DOS FUROS É DE $70 \mu \mathrm{M}$ NA SUPERFÍCIE E DE $50 \mu \mathrm{M}$ NO CENTRO, DE MODO QUE FORMAM UM PERFIL BICÔNICO. A ESPESSURA DO KAPTON É DE $50 \mu \mathrm{M}$ E O ESPAÇAMENTO ENTRE FUROS É DE 140 $\mu$ M. FIGURA OBTIDA DE ROPELEWSKI (ROPELEWSKI, 2011A).

FIGURA 2.3: ESQUEMA DO TRIPLO GEM, ONDE PODE-SE OBSERVAR UM DIVISOR DE TENSÕES (RESISTORES) RESPONSÁVEL POR ESTABELECER UMA DIFERENÇA DE POTENCIAL ENTRE CADA ESTÁGIO DO DETECTOR. NESSA CONFIGURAÇÃO, ELÉTRONS SÃO ACELERADOS PELO CAMPO ELÉTRICO EM DIREÇÃO AO READOUT, ONDE OS SINAIS SÃO COLETADOS.

FIGURA 2.4: CARGA COLETADA EM FUNÇÃO DA DIFERENÇA DE POTENCIAL APLICADA NOS ELETRODOS. NOTA-SE AS DIFERENTES REGIÕES DE OPERAÇÃO DOS DETECTORES A GÁS, COMO A REGIÃO DAS CÂMARAS DE IONIZAÇÃO (II), DOS DETECTORES PROPORCIONAIS (III) E REgIÃo dos CONTAdores Geiger-Mueller (V). Figura AdAPTADA de G. F. KNOLL (KNOLL, 1979).

FIGURA 2.5: ESQUEMA DOS NÍVEIS DE ENERGIA E DA CONFIGURAÇÃO ELETRÔNICA DO ARGÔNIO EM COMPARAÇÃO COM A ENERGIA PARA IONIZAR UMA MOLÉCULA DE CO 2 . NOTA-SE COMO UM ÁTOMO DE AR NO TERCEIRO ESTADO EXCITADO POSSUI ENERGIA SUFICIENTE PARA IONIZAR UMA MOLÉCULA DE DIÓXIDO DE CARBONO. FIGURA ADAPTADA DE NEMALlAPUDI (NEMALLAPUDI, 2012), Dildick (DILDICK, 2011) E SAHIN ET AL. (SAHIN ET AL., 2010).

FiguRA 2.6: DeTECTOR MULTIFILAR SENSíVEL À POSIÇÃO UTILIZADO NOS TESTES MOSTRADOS NA SEÇÃO 7.1. HÁ CINCO CONECTORES CORRESPONDENTES AOS CINCO SINAIS DE INTERESSE, SENDO AS DUAS EXTREMIDADES DE CADA CATODO (EIXO X E Y) E UMA DO ANODO (PARA MENSURAR A ENERGIA DA PARTíCULA), ALÉM DO CONECTOR PARA APLICAÇÃO DA ALTA TENSÃO.

FIGURA 2.7: ESQUEMA DO MÉTODO DE DETERMINAÇÃO DA LOCALIZAÇÃO ESPACIAL DOS EVENTOS POR CADEIA RESISTIVA. OS ELÉTRONS PROVENIENTES DA IONIZAÇÃO PELA RADIAÇÃO SÃO ACELERADOS ATÉ O FIO DO ANODO MAIS PRÓXIMO, GERANDO UMA AVALANCHE ELETRÔNICA NAS SUAS PROXIMIDADES. O PULSO SE DIVIDE IGUALMENTE E SEGUE NOS DOIS SENTIDOS DA CADEIA DE RESISTORES, AO PASSO QUE AO ATRAVESSAR CADA RESISTOR ELE SOFRE ATENUAÇÃO NA AMPLITUDE DEVIDO AO EFEITO JOULE.

FIGURA 3.1: REPRESENTAÇÃO DA PROBABILIDADE DE OCORRÊNCIA DOS TRÊS DIFERENTES PROCESSOS DE INTERAÇÃO DOS FÓTONS COM A MATÉRIA. VÊ-SE QUE O EFEITO FOTOELÉTRICO É PREDOMINANTE PARA BAIXAS ENERGIAS, ENQUANTO O ESPALHAMENTO COMPTON PREDOMINA EM VALORES INTERMEDIÁRIOS DE ENERGIA, JÁ A PRODUÇÃO DE PARES É INFLUENTE PARA FÓTONS DE ENERGIA BASTANTE ELEVADA. Figura AdAPtAdA DE G. F. KNOlL (KNOLL, 1979).

FIGURA 3.2: ESQUEMA DO ESPALHAMENTO COMPTON, MOSTRANDO A DEFINIÇÃO DOS ÂNGULOS E AS RESPECTIVAS ENERGIAS DO ELÉTRON E DO FótON ANTES E APÓS O ESPALHAMENTO. FIGURA ADAPTADA DE GRUPEN \& SHWARTZ (GRUPEN \& SHWARTZ, 2008).

FIGURA 3.3: TRANSIÇÕES QUE DÃO ORIGEM ÀS LINHAS DE EMISSÃO MOSTRADAS NA TABELA 3.1. FIGURA ADAPTADA DA BASE DE DADOS XDB (X-RAY DATA BOOKLET) (THOMPSON ET AL., 2009).

FiguRA 3.4: DiagRAMA DE DECAIMENTO dO ${ }^{55}$ FE NO QUAL O NÚCLEO dO ÁTOMO DE FERRO CAPTURA UM ELÉTRON DA CAMADA K PRODUZINDO MANGANÊS EM UM ESTADO EXCITADO. QUANDO RETORNA AO ESTADO FUNDAMENTAL, EMITE UM FÓTON 
CARACTERÍSTICO SEGUINDO AS PROBABILIDADES RELATIVAS INDICADAS NA TABELA 3.1. FIGURA ADAPTADA DE GRUPEN \& SHWARTZ (GRUPEN \& SHWARTZ, 2008)

FIGURA 4.1: DIAGRAMA REPRESENTATIVO DAS ETAPAS NECESSÁRIAS PARA SE CONSTRUIR AS SIMULAÇÕES DO DETECTOR BASEADAS EM SOFTWARES DE LICENÇA LIVRE. OS ELEMENTOS NA COR PRETA REPRESENTAM OS PASSOS ENTRE OS DIFERENTES SOFTWARES, AQUELES NA COR VERMELHA INDICAM AÇÕES E/OU ESCOLHAS QUE DEVEM SER TOMADAS PELO USUÁRIO, ENQUANTO AQUELES DE COR VERDE INDICAM OS RESULTADOS OBTIDOS NA RESPECTIVA ETAPA DA SIMULAÇÃO.

FIGURA 4.2: PARÂMETROS GEOMÉTRICOS DO GEM DE REFERÊNCIA (BICÔNICO), INCLUINDO O DIÂMETRO EXTERNO (SUPERFÍCIE DA FOLHA DE KAPTON), DIÂMETRO INTERNO (CENTRO DA FOLHA), ESPAÇAMENTO ENTRE OS FUROS E ESPESSURA DA FOLHA. A ESPESSURA DA CAMADA DE COBRE EM CADA SUPERFÍCIE É DE $5 \mu \mathrm{M}$ (NÃO MOSTRADO NA FIGURA).

FIGURA 4.3: PARÂMETROS GEOMÉTRICOS DO GEM CÔNICO, INCLUINDO O DIÂMETRO SUPERIOR E DIÂMETRO INFERIOR, ESPAÇAMENTO ENTRE OS FUROS E ESPESSURA DA FOLHA. A ESPESSURA DA CAMADA DE COBRE EM CADA SUPERFÍCIE É DE 5 MM (NÃO MOSTRADO NA FIGURA).

FIGURA 4.4: TRIPLO GEM DE REFERÊNCIA PARA VALIDAR AS SIMULAÇÕES, DESTACANDO A CONFIGURAÇÃO DOS RESISTORES PARA A DISTRIBUIÇÃO DO POTENCIAL AO LONGO DOS ELETRODOS. SÃO IDENTIFICADOS OS OITO ELETRODOS QUE COMPÕEM O SISTEMA, ALÉM DAS DISTÂNCIAS ENTRE OS MESMOS. SÃO MOSTRADOS AINDA OS CAMPOS ELÉTRICOS ENTRE OS ELETRODOS, CALCULADOS CONSIDERANDO QUE CADA CONJUNTO DE DOIS ELETRODOS SE COMPORTA COMO UM CAPACITOR DE PLACAS PARALELAS........63

FIGURA 4.5: DIAGRAMA DE BLOCOS MOSTRANDO O ESQUEMA DE FUNCIONAMENTO DO CÓDIGO DESENVOLVIDO PARA AUTOMATIZAR AS SIMULAÇÕES DE UM DETECTOR TRIPLO GEM DE FUROS CÔNICOS OU BICÔNICOS. EM CADA ETAPA ONDE O USUÁRIO PRECISA ENTRAR COM PARÂMETROS, É MOSTRADO NA TELA O RESUMO DOS VALORES DIGITADOS, ONDE É POSSÍVEL RETROCEDER E REALIZAR OS AJUSTES (CASO NECESSÁRIO).

FIGURA 4.6: TELA MOSTRANDO O FUNCIONAMENTO DA FERRAMENTA PARA AUTOMATIZAÇÃO DAS SIMULAÇÕES COM O TRIPLO GEM.

PODE-SE OBSERVAR O DIÁLOGO COM O USUÁRIO, COM SUGESTÃO DE PARÂMETROS E DICAS QUE VISAM FACILITAR SUA UTILIZAÇÃO.

Figura 5.1: CÉlULA bÁSICA do deteCtOR CRIADA NO GMSH. PODE-SE NOTAR A ESTRUTURA BÁSICA do tRIPLO GEM, COMPOSTA PELAS TRÊS FOLHAS COM OS FUROS, DELIMITADAS NA DIREÇÃO LONGITUDINAL PELOS ELETRODOS DE DERIVA E LEITURA. AS DIMENSÕES ESTÃO DADAS EM CM.

FIGURA 5.2: DETALHE DA ESTRUTURA BÁSICA DO GEM MOSTRANDO OS FUROS DA FOLHA E SUA RESPECTIVA CONICIDADE.

FIGURA 5.3: MALHA DO TRIPLO GEM CRIADA NO GMSH COMPOSTA DE UM MOSAICO DE ESTRUTURAS QUE DIVIDEM A GEOMETRIA EM PEQUENOS COMPONENTES. SÃO MOSTRADAS AS TRÊS DIFERENTES CAMADAS QUE COMPÕEM O TRIPLO GEM. ALGUMAS ESTRUTURAS IMPORTANTES PARA O FUNCIONAMENTO DA SIMULAÇÃO (ELETRODOS DE DERIVA E DE LEITURA, ALÉM DAS SUPERFÍCIES DE FRONTEIRA) FORAM OCULTADAS DA FIGURA PARA MAIOR CLAREZA DA IMAGEM.

FIGURA 5.4: CÉLULA DO GEM MOSTRANDO O MOSAICO DE ELEMENTOS CRIADOS PELO GMSH PARA A APLICAÇÃo DO MÉTODO DE ELEMENTOS FINITOS. OS PONTOS SOBRE AS LINHAS QUE DEFINEM OS ELEMENTOS REPRESENTAM OS NÓS DA MALHA.

FIGURA 5.5: CÉLULA DO GEM COMPOSTA POR DUAS SUPERFÍCIES CONDUTORAS DE COBRE ENTRE UMA PLACA DE MATERIAL DIELÉTRICO (KAPTON). ESSA CÉLULA COM DOIS QUARTOS DE FUROS E UM MEIO FURO É REPRODUZIDA ESPACIALMENTE PARA ENTÃO CRIAR TODA A ÁREA SENSÍVEL DO DETECTOR. 
FiguRA 5.6: MAPA do POTENCIAL ELETROSTÁtico (EM VoltS) AO LONGO DO TRIPLO GEM DE PADRÃO BICÔNICO. NOTA-SE COMO O VALOR DO POTENCIAL VARIA BRUSCAMENTE ENTRE AS DIFERENTES REGIÕES DEVIDO À MUDANÇA DE POTENCIAL EM CADA ELETRODO.

FIGURA 5.7: POTENCIAL ELETROSTÁtICO AO LONGO DO EIXO Z (PERPENDICULAR AO PLANO DOS ELETRODOS) PASSANDO PELO CENTRO DOS FUROS DAS TRÊS FOLHAS, PARA DUAS CONFIGURAÇÕES DE POTENCIAL DISTINTAS. AS CARACTERÍSTICAS MAIS MARCANTES DO GRÁFICO SÃO OS SEGUIMENTOS COM INCLINAÇÃO CONSTANTE NAS DIFERENTES REGIÕES DO DETECTOR. .88

FIGURA 5.8: MAPA DO CAMPO ELÉTRICO AO REDOR DO FURO DO GEM MOSTRANDO UMA PROJEÇÃO (Z-X), PERPENDICULAR AO PLANO DA FOLHA DO DETECTOR (X-Y). NOTA-SE PELO CÓDIGO DE CORES COMO O MÓDULO DO CAMPO É MAIS INTENSO NA REGIÃO INTERNA AOS FUROS EM COMPARAÇÃO COM A REGIÃO EXTERNA, PROPICIANDO A FORMAÇÃO DA AVALANCHE DE ELÉTRONS. A REGIÃO COM DESTAQUE NA COR PRETA INDICA O LIMIAR PARA FORMAÇÃO DA AVALANCHE.

FIGURA 5.9: LINHAS DE CAMPO ELÉTRICO AO REDOR DO FURO DO GEM. OS ELÉTRONS, AO SE APROXIMAREM DESSA ÁREA, SÃO DIRECIONADOS PARA O INTERIOR DOS ORIFÍCIOS, REGIÃO ONDE O CAMPO ELÉTRICO ACELERA ESSAS CARGAS O SUFICIENTE PARA PROMOVER IONIZAÇÕES E ASSIM GERAR UMA AVALANCHE ELETRÔNICA.

FIGURA 5.10: ACIMA EM (A) É INDICADA A DIREÇÃO CORRESPONDENTE A DIR1. EM (B) É MOSTRADO o CAMPO ELÉTRICO AO LONGO DESSA DIREÇÃO PERPENDICULAR AO PLANO DAS FOLHAS DO GEM, PASSANDO PELO CENTRO DOS FUROS.

FIGURA 5.11: EM (A) É INDICADA A DIREÇÃO CORRESPONDENTE A DIR2. JÁ EM (B) MOSTRA-SE O CAMPO ELÉTRICO AO LONGO DESSA DIREÇÃO, PARALELA AO PLANO DO DETECTOR E NAS PROXIMIDADES DO GEM1. PARA PLANOS CUJA COORDENADA Z É MAIOR QUE ESSA $(0,210 \mathrm{CM})$, O CAMPO É UNIFORME.

FIGURA 5.12: INDICAÇÃO DE DIR3 EM (A) E DO CAMPO ELÉTRICO AO LONGO DESSA DIREÇÃO, PARALELA AO PLANO DO DETECTOR E NAS PROXIMIDADES DO GEM1 EM (B).

FIGURA 5.13: INDICAÇÃO DE DIR4 EM (A) E DO CAMPO ELÉTRICO AO LONGO DESSA DIREÇÃO, PARALELA AO PLANO DO DETECTOR E PASSANDO PELO INTERIOR DA CAMADA CONDUTORA DE COBRE EM (B).

FIGURA 5.14: DIR5 É MOSTRADA EM (A), ENQUANTO O CAMPO ELÉTRICO AO LONGO DESSA DIREÇÃO, PARALELA AO PLANO DO DETECTOR E PASSANDO PELO INTERIOR DO KAPTON É MOSTRADO EM (B).

FIGURA 5.15: DIR6 EM (A) E CAMPO ELÉTRICO AO LONGO DESSA DIREÇÃO, PARALELA AO PLANO DO DETECTOR E LOCALIZADO NO CENTRO DO GEM EM (B).

FIGURA 5.16: CAMPO ELÉTRICO NA DIREÇÃO Z PASSANDO PELO CENTRO DO ORIFÍCIO SIMILAR A DIR1, MAS DESTACANDO OS DETALHES DO CAMPO NAS PROXIMIDADES DO ORIFÍCIO DO PRIMEIRO GEM (GEM1)

FIGURA 5.17: SIMULAÇÃO DO EFEITO DE MULTIPLICAÇÃO DE CARGAS, ONDE OBSERVA-SE A FORMAÇÃO DA AVALANCHE QUANDO O ELÉTRON PENETRA NO FURO DO GEM E A DERIVA DOS ELÉTRONS RESULTANTES NA DIREÇÃO DO ELETRODO GERADOR DO CAMPO DE TRANSFERÊNCIA (NÃO MOSTRADO NA FIGURA).

FIGURA 5.18: EXEMPLO DA DISTRIBUIÇÃO DO NÚMERO DE ELÉTRONS NA AVALANCHE, MOSTRANDO O NÚMERO DE OCORRÊNCIAS (CONTAGENS) EM FUNÇÃO DO TAMANHO DA AVALANCHE (NÚMERO DE ELÉTRONS NA MESMA). NESSE EXEMPLO, FOI APLICADA UMA DIFERENÇA DE POTENCIAL DE 417 V NA FOLHA DO GEM, UM CAMPO DE DERIVA (ACIMA DO GEM) DE 2,162 KV/CM E UM CAMPO DE INDUÇÃO (ABAIXO DO GEM) DE 2,925 kV/CM. 100

FIGURA 5.19: AJUSTE DA DISTRIBUIÇÃO DO NÚMERO DE ELÉTRONS NA AVALANCHE ATRAVÉS DE UMA DISTRIBUIÇÃO DE POLYA REALIZADA COM A ROTINA DESENVOLVIDA NESSE TRABALHO 
FIGURA 5.20: GANHO EFETIVO SIMULADO DE UM TRIPLO GEM PADRÃO BICÔNICO DO CERN E A RESPECTIVA COMPARAÇÃO COM AQUELE OBTIDO EXPERIMENTALMENTE SOB AS MESMAS CONFIGURAÇÕES DE CAMPO E POTENCIAL. NOTA-SE COMO A SIMULAÇÃO SEM LEVAR EM CONTA O EFEITO PENNING (RPEN = 0) NÃO É CAPAZ DE SE AJUSTAR AOS DAdOS EXPERIMENTAIS, MOSTRANDO VALORES MENORES PARA O GANHO. O VALOR DO GANHO NAS SIMULAÇÕES É DADO PELO NÚMERO MÉDIO DE ELÉTRONS NA AVALANCHE, DETERMINADO A PARTIR DO AJUSTE PELA DISTRIBUIÇÃO DE POLYA.

FIGURA 5.21: PosIÇÃo FINAL dOS ELÉTRONS EM UMA VISÃO EM 3D, MOSTRANDO O AUMENTO dA AVALANCHE ATÉ CHEGAR NO PLANO DE LEITURA DE SINAIS. PERCEBE-SE QUE NENHUM ELÉTRON SE DIRIGE AO PLANO DE DERIVA (Z = 7 MM).

FIGURA 5.22: POSIÇÃO FINAL DOS ELÉTRONS NO PLANO X-Y NA SUPERFÍCIE SUPERIOR DO PRIMEIRO GEM. ESSA DISTRIBUIÇÃO MOSTRA OS ELÉTRONS QUE FORAM ARREMESSADOS CONTRA A PARTE SUPERIOR DO PRIMEIRO GEM PELO CAMPO DE DERIVA E, ASSIM, NÃO CONTRIBUEM PARA O SINAL OBSERVADO PELA ELETRÔNICA, QUE GERALMENTE CAPTA O SINAL DO READOUT OU DO GEM3 BOTTOM, APENAS.

FIGURA 5.23: DISTRIBUIÇÃO DOS ELÉTRONS NO KAPTON DO PRIMEIRO GEM 1. PARTE DOS ELÉTRONS SE DISTRIBUI NA CAMADA DO POLÍMERO QUE FORMA A CONICIDADE DOS ORIFÍCIOS.

FIGURA 5.24: DISTRIBUIÇÃO DA POSIÇÃO FINAL DOS ELÉTRONS NA SUPERFÍCIE INFERIOR DO PRIMEIRO GEM. NESSE CASO, É OBSERVADO QUE OS ELÉTRONS SE DISTRIBUEM NAS PROXIMIDADES DOS ORIFÍCIOS DEVIDO AO REARRANJO DE CARGAS QUE



FIGURA 5.25: POSIÇÃO FINAL DOS ELÉTRONS NA SUPERFÍCIE SUPERIOR DO SEGUNDO GEM. OS ELÉTRONS ARREMESSADOS PELO CAMPO CONTRA A SUPERFÍCIE SUPERIOR ACABAM SE DISTRIBUINDO CONTINUAMENTE, ENQUANTO QUE NA SUPERFÍCIE INFERIOR TENDEM A SE CONCENTRAR NAS PROXIMIDADES DOS ORIFÍCIOS. 105

FIGURA 5.26: DISTRIBUIÇÃO DOS ELÉTRONS NO KAPTON DO SEGUNDO GEM. NOTA-SE UM AUMENTO NA DISPERSÃO TRANSVERSAL NO PLANO X-Y, AUMENTANDO O NÚMERO DE FUROS AO REDOR DOS QUAIS AS CARGAS ACABAM SENDO DEPOSITADAS....... 106

FIGURA 5.27: POSIÇÃO FINAL DOS ELÉTRONS NO PLANO X-Y NA SUPERFÍCIE INFERIOR DO SEGUNDO GEM. SÃO OBSERVADAS AS MESMAS CARACTERÍSTICAS APRESENTADAS NA RESPECTIVA FIGURA DO PRIMEIRO GEM, MAS COM MAIOR ALARGAMENTO DA DISTRIBUIÇÃO REFLETINDO UM AUMENTO ESPACIAL DA AVALANCHE NO PLANO. 106

FIGURA 5.28: Posição FINAL dOS ELÉTRONS NA SUPERFíCIE SUPERIOR DO TERCEIRO GEM. CONFORME SE AVANÇA NOS ELETRODOS AO LONGO DO EIXO Z, OBSERVA-SE UM AUMENTO NA DISPERSÃO TRANSVERSAL NO PLANO, ELEVANDO A QUANTIDADE DE FUROS AO REDOR DOS QUAIS OS ELÉTRONS SÃO DEPOSITADOS. 107

FIGURA 5.29: POSIÇÃO FINAL DOS ELÉTRONS NO KAPTON DO TERCEIRO GEM. É NOTÁVEL UMA CONCENTRAÇÃO MAIOR NO CENTRO DA IMAGEM, CUJA INTENSIDADE SE ATENUA CONFORME SE AFASTA DO CENTRO DA DISTRIBUIÇÃO. 107

FIGURA 5.30: POSIÇÃO FINAL DOS ELÉTRONS NO PLANO X-Y NA SUPERFÍCIE INFERIOR DO TERCEIRO GEM. 108

FIgURA 5.31: PosIÇÃo FINAL dOS ELÉTRONS NO PLANO X-Y NO ELETRODO DE LEITURA (READOUT). PODE-SE OBSERVAR QUE NESSE ELETRODO A DISTRIBUIÇÃO ESPACIAL OBTIDA NÃO MOSTRA A POSIÇÃO DOS FUROS, DIFERENTEMENTE DOS ANTERIORES. ......108

FIGURA 5.32: PROJEÇÃO NA DIREÇÃO X DA DISTRIBUIÇÃO DA POSIÇÃO FINAL DOS ELÉTRONS OBSERVADA NA FIGURA 5.31. A RESOLUÇÃO OBTIDA PARA ESSA CONFIGURAÇÃO FOI DE $(558 \pm 3) \mu \mathrm{M}$.

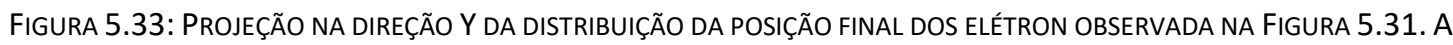
RESOLUÇÃO OBTIDA PARA ESSA CONFIGURAÇÃO FOI DE $(560 \pm 2) \mu \mathrm{M}$. 
FIGURA 5.34: PSEUDOCÓDIGO UTILIZADO PARA REPRODUZIR NAS SIMULAÇÕES O ESPECTRO DA FONTE DE ${ }^{55} \mathrm{FE}$. A VARIÁVEL PROB REPRESENTA A INTENSIDADE RELATIVA DE OCORRÊNCIA OBTIDA A PARTIR DA FUNÇÃO RNDMUNIFORM (QUE RETORNA UM VALOR DOUBLE COM IGUAIS PROBABILIDADES ENTRE 0 E 1), MULTIPLICADA PELO VALOR 181 (SOMA DAS INTENSIDADES RELATIVAS PARA TODAS AS ENERGIAS POSSÍVEIS).

FIGURA 5.35: LINHAS DE INTENSIDADE RELATIVA PARA TODAS AS POSSÍVEIS ENERGIAS DEPOSITADAS NO GÁS PELA FONTE DE ${ }^{55} \mathrm{FE} . .112$ FIGURA 5.36: NÚMERO DE OCORRÊNCIAS (CONTAGENS) EM FUNÇÃO DO NÚMERO DE ELÉTRONS CRIADOS PELA DEPOSIÇÃO DA ENERGIA DA RADIAÇÃO NO GÁS (CARGAS PRIMÁRIAS), PARA A MISTURA DE 70\% DE AR E 30\% DE CO2.

FIGURA 5.37: ESPECTRO DA FONTE DE ${ }^{55}$ FE CRIADA A PARTIR DA LIBERAÇÃO DOS PARES DE CARGAS PRIMÁRIAS ESTIMADAS PARA A DEPOSIÇÃO DE ENERGIA PELOS FÓTONS NO GÁS.

FigURA 5.38: AJUSTE GAUSSIANO dO PICO PRINCIPAL DO ESPECTRO SIMULADO DA FONTE DE RAIOS X DE ${ }^{55}$ FE PARA CÁLCULO DA RESOLUÇÃO EM ENERGIA.

FIGURA 5.39: TRECHO DE CÓDIGO UTILIZADO PARA REPRODUZIR O ESPECTRO DA FONTE DE RAIOS X COM ALARGAMENTO DO MESMO DEVIDO A FONTES DE RUÍDO QUE NÃO ESTÃO LIGADAS DIRETAMENTE AOS PROCESSOS ESTATÍSTICOS NO GÁS, COMO RUÍDO ELETRÔNICO, POR EXEMPLO.

FIGURA 5.40: ESPECTROS DA FONTE DE RAIOS X COM DIFERENTES NÍVEIS DE RUÍDO BRANCO GAUSSIANO CAUSANDO ALARGAMENTO DOS MESMOS. NOTA-SE UM PROGRESSIVO ALARGAMENTO DA CURVA COM O RESPECTIVO AUMENTO DO NíVEL DE RUÍDO. NO CASO DE $20 \%$ DE FLUTUAÇÃO DO VALOR ESPERADO, PRATICAMENTE NÃO É POSSÍVEL DISTINGUIR O PICO PRINCIPAL DA FONTE DE ${ }^{55}$ FE DO PICO DE ESCAPE DO ARGÔNIO.

FiguRA 5.41: PosiçÃo FINAL dos ÍONS POSITIVOS AO LONGO DO TRIPLO GEM. PERCEBE-SE QUE NENHUMA DESSAS CARGAS CHEGA ATÉ O PLANO DE LEITURA ( $Z=-2 \mathrm{MM})$

FIGURA 5.42: DISTRIBUIÇÃO DA POSIÇÃO FINAL DOS ÍONS NO KAPTON DO TERCEIRO GEM. OS ÍONS SE DISTRIBUEM AO LONGO DO POLÍMERO EM CADA ORIFÍCIO DE MODO QUE A MAIOR PARTE DAS CARGAS SE CONCENTRA NO CENTRO DA IMAGEM.

FIGURA 5.43: DISTRIBUIÇÃO DOS ÍONS QUE PARAM NA SUPERFÍCIE SUPERIOR DO TERCEIRO GEM, SENDO PARADAS NAS PROXIMIDADES DOS FUROS.

FIGURA 5.44: POSIÇÃO FINAL DOS ÍONS NA SUPERFÍCIE INFERIOR DO SEGUNDO GEM. NESSE CASO, AS CARGAS SE DISTRIBUEM CONTINUAMENTE AO LONGO DA SUPERFÍCIE DE COBRE, COM MAIOR CONCENTRAÇÃO NO CENTRO DA DISTRIBUIÇÃO. 120

FIGURA 5.45: POSIÇÃO FINAL dOS ÍONS NO KAPTON DO SEGUNDO GEM. AS CARACTERÍSTICAS SÃO SIMILARES ÀQUELA OBSERVADA NO KAPTON DO TERCEIRO GEM, CONTUDO A DISTRIBUIÇÃO POSSUI UM ALARGAMENTO NO PLANO MENOR NESSE CASO..... 121

FIGURA 5.46: DISTRIBUIÇÃO DOS ÍONS NA SUPERFÍCIE SUPERIOR DO SEGUNDO GEM. FORAM OBSERVADAS CARACTERÍSTICAS SIMILARES COM A DISTRIBUILÇÃO EQUIVALENTE NO TERCEIRO GEM, MAS COM MENOR ALCANCE AO LONGO DO PLANO, REFLETINDO O FATO DA AVALANCHE AUMENTAR ESPACIALMENTE NO PLANO X-Y CONFORME SE DIRIGE AO ELETRODO DE LEITURA.

FIGURA 5.47: POSIÇÃO dOS ÍONS NA SUPERFÍCIE INFERIOR DE COBRE DO PRIMEIRO GEM. CARACTERÍSTICAS SEMELHANTES FORAM OBSERVADAS NO SEGUNDO GEM, MAS COM MAIOR ALCANCE NO PLANO X-Y NAQUELE CASO.

FIGURA 5.48: POSIÇÃO FINAL dOS ÍONS NO KAPTON DO PRIMEIRO GEM. A AMPLITUDE REDUZIDA AO LONGO DO PLANO REFLETE O FATO DA AMPLITUDE DA AVALANCHE SER MENOR NO PRIMEIRO GEM. NOTA-SE QUE EM TODOS OS GEM'S O NÚMERO DE ÍONS COLETADOS NO POLÍMERO É MUITO MENOR QUE AQUELE COLETADO NAS RESPECTIVAS SUPERFÍCIES DE COBRE. 
FIGURA 5.49: ÍONS COLETADOS NA SUPERFÍCIE SUPERIOR DO PRIMEIRO GEM, MOSTRANDO UMA CONCENTRAÇÃO NO CENTRO DA IMAGEM AO LONGO DE UM INTERVALO DE CERCA DE 0,4 MM NAS DIREÇÕES X E Y.....

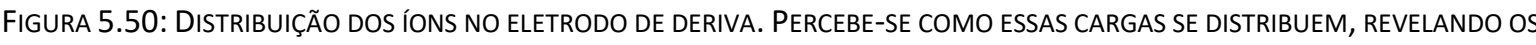
CONTORNOS DOS FUROS, OU SEJA, NÃO DERIVAM DE MANEIRA CONTÍNUA COMO FAZEM OS ELÉTRONS NO READOUT, ESTANDO ASSIM RELACIONADA COM OS FUROS NO GEM.

FIGURA 5.51: FRAÇÃO DE ÍONS NA REGIÃO DE DERIVA (IBF) SEGUNDO A EQUAÇÃO (5.3) EM FUNÇÃO DA CORRENTE APLICADA PELA FONTE DE ALTA TENSÃO. PODE-SE VERIFICAR COMO HÁ UMA TENDÊNCIA DE QUEDA NO IBF CONFORME AUMENTA-SE O GANHO DO DETECTOR

FIGURA 6.1: CÉLULA BÁSICA DO TRIPLO GEM CÔNICO CRIADA NO GMSH. OBSERVAM-SE AS TRÊS FOLHAS COM OS FUROS, DELIMITADAS NA DIREÇÃo LONGITUdINAL PELOS ELETROdOS DE DERIVA E LEITURA (READOUT). AS DIMENSÕES ESTÃo EM CENTÍMETRO

FIGURA 6.2: DETALHE DA ESTRUTURA BÁSICA DO GEM CÔNICO MOSTRANDO OS FUROS DA FOLHA

FIGURA 6.3: MALHA DO GEM CÔNICO CRIADA NO GMSH COMPOSTA DE UM MOSAICO DE ESTRUTURAS QUE DIVIDEM A GEOMETRIA EM PEQUENOS COMPONENTES. OS ELETRODOS DE DERIVA, DE LEITURA E AS SUPERFÍCIES DE FRONTEIRA FORAM OCULTADAS DA FIGURA PARA MAIOR CLAREZA DA IMAGEM.

FiguRA 6.4: CÉlULA DO GEM MOSTRANDO O MOSAICO DE ELEMENTOS CRIADOS PELO GMSH PARA A APLICAÇÃO DO MÉTODO DE ELEMENTOS FINITOS (A). ALÉM DA MESMA IMAGEM SEM MOSTRAR OS CONTORNOS DOS ELEMENTOS, DESTACANDO APENAS A GEOMETRIA (B).

FIGURA 6.5: MAPA DO CAMPO ELÉTRICO AO REDOR DO FURO DO GEM CÔNICO ATRAVÉS DE UMA PROJEÇÃO NO PLANO Z-X, PERPENDICULAR AO PLANO DA FOLHA DO DETECTOR. O CÓDIGO DE CORES REVELA COMO O MÓDULO CAMPO É MAIS INTENSO NA REGIÃO DOS ORIFÍCIOS EM COMPARAÇÃO COM O CAMPO NA REGIÃO EXTERNA. A REGIÃO MARCADA COM A COR PRETA INDICA O LIMIAR PARA FORMAÇÃO DA AVALANCHE (SAULI, 2014)

FIGURA 6.6: CAMPO ELÉTRICO DAS DUAS GEOMETRIAS AO LONGO DA DIREÇÃO PERPENDICULAR AO PLANO DAS FOLHAS DO GEM, PASSANDO PELO CENTRO DOS FUROS (DIR1).

FIGURA 6.7: CAMPO ELÉTRICO PARA AS DUAS GEOMETRIAS DO GEM AO LONGO DA DIREÇÃO X, PARALELA AO PLANO DO DETECTOR E NAS PROXIMIDADES DO GEM1 (DIR2). PARA PLANOS CUJA COORDENADA Z MAIORES O CAMPO TORNA-SE UNIFORME PARA AMBAS. .

FIGURA 6.8: CAMPO ELÉTRICO PARA AS DUAS GEOMETRIAS ESTUDADAS AO LONGO DA DIREÇÃO X, PARALELA AO PLANO DO DETECTOR E NAS PROXIMIDADES DO GEM1 (DIR3).

FIGURA 6.9: CAMPO ELÉTRICO AO LONGO DA DIREÇÃO X, PARALELA AO PLANO DO DETECTOR E PASSANDO PELO INTERIOR DA CAMADA CONDUTORA DE COBRE PARA O GEM CÔNICO E BICÔNICO (DIR4).

FIGURA 6.10: CAMPO ELÉTRICO AO LONGO DA DIREÇÃO X, PARALELA AO PLANO DO DETECTOR E PASSANDO PELO INTERIOR DO KAPTON (DIR5).

FiguRA 6.11: CAMPO ELÉTRICO AO LONGO dA DIREÇÃO X, PARALELA AO PLANO DO DETECTOR E LOCALIZADO NO CENTRO DO GEM (DIR6).

FIGURA 6.12: CAMPO ELÉTRICO NA DIREÇÃO Z, PASSANDO PELO CENTRO DO ORIFÍCIO SIMILAR A DIR1, MAS DESTACANDO OS DETALHES DO CAMPO NAS PROXIMIDADES DO ORIFÍCIO DO PRIMEIRO GEM (GEM1). A DIFERENÇA ENTRE O MÓDULO DO 
CAMPO ELÉTRICO DAS DUAS GEOMETRIAS NO CENTRO DA CURVA FOI DE CERCA DE 6 KV/CM, SENDO MAIOR NO CASO DO GEM CÔNICO.

FIGURA 6.13: GANHO SIMULADO DO TRIPLO GEM DE GEOMETRIA CÔNICA EM COMPARAÇÃO COM A BICÔNICA. NOTA-SE COMO O GANHO DO GEM CÔNICO É MAIOR EM COMPARAÇÃO COM O BICÔNICO PARA UMA MESMA CONFIGURAÇÃO DE POTENCIAL, CONSIDERANDO OS PARÂMETROS GEOMÉTRICOS MOSTRADOS NAS FIGURAS FIGURA 4.2 E FIGURA 4.3.

FIGURA 6.14: GANHO DO GEM CÔNICO EM FUNÇÃO DA DIFERENÇA ENTRE OS RAIOS SUPERIOR E INFERIOR (R RESULTADO É RELATIVO AO GEM BICÔNICO PADRÃO, ISTO É, O GANHO OBTIDO FOI NORMALIZADO PELO GANHO DESSE DETECTOR (SEÇÃO 5.3). O ESPAÇAMENTO ENTRE OS FUROS FOI MANTIDO CONSTANTE, ASSIM COMO A CONFIGURAÇÃO DE POTENCIAIS E CAMPOS, UTILIZANDO AQUELA MOSTRADA NA TABELA 10.2

FIGURA 6.15: FRAÇÃO DE ÍONS NA ZONA DE DERIVA EM FUNÇÃO DA VARIAÇÃO RELATIVA ENTRE O DIÂMETRO DOS ORIFÍCIOS DO GEM CÔNICO. NOTA-SE QUE QUANTO MAIOR O VALOR DO RAIO DO FURO INFERIOR EM RELAÇÃO AO SUPERIOR, MAIS EFICIENTE SERÁ O DETECTOR EM EVITAR QUE AS CARGAS POSITIVAS CHEGUEM ATÉ A REGIÃO DE DERIVA.

FIGURA 6.16: GANHO EM FUNÇÃO DO ESPAÇAMENTO ENTRE OS ORIFÍCIOS PARA O TRIPLO GEM CÔNICO NORMALIZADO PELO GANHO

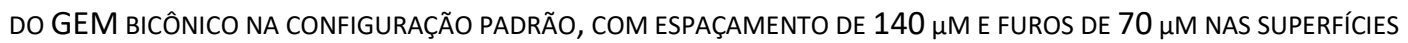
SUPERIOR E INFERIOR E DE $50 \mu M$ NO CENTRO DA FOLHA DE KAPTON.

FIGURA 6.17: IBF EM FUNÇÃO DO ESPAÇAMENTO ENTRE OS FUROS. A FRAÇÃO DE ÍONS NA ZONA DE DERIVA NORMALIZADA PELO GANHO É TANTO MENOR QUANTO MAIOR O ESPAÇAMENTO ENTRE OS FUROS.

FIGURA 6.18: GEOMETRIA DO GEM CÔNICO APRIMORADO PARA MAXIMIZAÇÃO DO GANHO, COM DIÂMETRO SUPERIOR DE 60 M E INFERIOR DE $70 \mu \mathrm{M}$, ENQUANTO O ESPAÇAMENTO ENTRE FUROS É DE $120 \mu \mathrm{M}$.

FIGURA 6.19: GANHO DO GEM DE GEOMETRIA APRIMORADA PARA MAXIMIZAÇÃO DESSA GRANDEZA EM COMPARAÇÃO COM O GEM BICÔNICO PADRÃO E CÔNICO COM ESPAÇAMENTO DE $140 \mu \mathrm{M}$, RAIO DO ORIFÍCIO SUPERIOR DE 35 M E INFERIOR DE $30 \mu \mathrm{M}$.

FIGURA 6.20: ÍNDICE DE ÍONS NA REGIÃO DE DERIVA NORMALIZADO PELO GANHO, PARA O GEM PROPOSTO PARA OTIMIZAÇÃO DE GANHO, E GEM PADRÃO CÔNICO E BICÔNICO. OS TRÊS DETECTORES SE MOSTRARAM SIMILARES EM RELAÇÃO A ESSA GRANDEZA, COM PEQUENA VANTAGEM PARA O GEM CÔNICO PADRÃO.

FIGURA 7.1: ESPECTRO DE ENERGIA DA FONTE DE ${ }^{55} \mathrm{FE}$ COM UM AJUSTE GAUSSIANO DO PICO PRINCIPAL DESSA FONTE DE RADIAÇÃO.

O AJUSTE FORNECE O DESVIO PADRÃO E A LARGURA A MEIA ALTURA (NÃO MOSTRADOS NA FIGURA), QUE FORAM EMPREGADOS NO CÁLCULO DA RESOLUÇÃO EM ENERGIA.

FIGURA 7.2: RESOLUÇÃO EM ENERGIA DO DETECTOR MULTIFILAR EM FUNÇÃO DA DIFERENÇA DE POTENCIAL ENTRE OS ELETRODOS. A PARTIR DO AJUSTE GAUSSIANO DO ESPECTRO DE ENERGIA DA FONTE DE FERRO, OBTEVE-SE A LARGURA A MEIA ALTURA, QUE EMPREGADA NA EQUAÇÃO (2.17) FORNECEU A RESOLUÇÃO.

FIGURA 7.3: GANHO MEDIDO NO MWPC EM FUNÇÃO DA DIFERENÇA DE POTENCIAL APLICADA. PODE-SE NOTAR QUE ESSA GRANDEZA É BEM DESCRITA POR UM AJUSTE EXPONENCIAL, MOSTRANDO QUE O DETECTOR SE ENCONTRA NA REGIÃO PROPORCIONAL. . 145

FIGURA 7.4: DETECTOR TRIPLO GEM UTILIZADO PARA MEDIDAS DE GANHO DE GÁS E RESOLUÇÃO EM ENERGIA. NO CENTRO DO DISPOSITIVO PODE-SE PERCEBER A FONTE DE ${ }^{55} \mathrm{FE}$ UTILIZADA NO EXPERIMENTO.

FIGURA 7.5: RESOLUÇÃO EM ENERGIA EM FUNÇÃO DO POTENCIAL GLOBAL APLICADO NO TRIPLO GEM DO GRUPO HEPIC EM COMPARAÇÃO COM A OBTIDA PELO TRIPLO GEM PADRÃO DO CERN (SALES, 2015). 


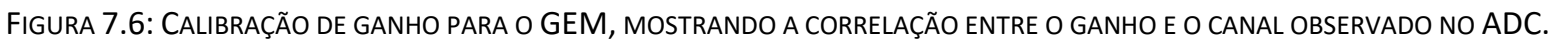

FIGURA 7.7: GANHO DO GEM EM FUNÇÃO DO POTENCIAL GLOBAL APLICADO NO TRIPLO GEM...........................................149

FIGURA 11.1: HISTOGRAMA DA DISTRIBUIÇ̃̃o DO NÚMERO DE ELÉTRONS NA AVALANCHE PARA UMA DIFERENÇA DE POTENCIAL DE 400

V NA FOLHA DO GEM, UM CAMPO DE DERIVA DE 500 V/CM E UM CAMPO DE INDUÇÃO DE 1 KV/CM. 168

FIGURA 11.2: UM EXEMPLO DO AJUSTE DA DISTRIBUIÇÃO DO NÚMERO DE ELÉTRONS NA AVALANCHE ATRAVÉS DE UMA DISTRIBUIÇÃO De Polya ReAlizada no programa desenVolvido nesse trabalho. 169 


\section{Lista de Tabelas}

TABela 2.1: VALOR DE RPen ENCONTRAdo NA LITERATURA PARA A TRANSFERÊNCIA DE ENERGIA PELO EFEITO PENNING UTILIZADO NAS SIMULAÇÕES COM O PROGRAMA GARFIELD++.

TABELA 3.1: ENERGIAS DOS FÓTONS E INTENSIDADES RELATIVAS DAS PRINCIPAIS LINHAS DE EMISSÃO DAS CAMADAS K E L DO MANGANÊS, ORDENADAS PELO AUMENTO DE ENERGIA. OS RAIOS X PROVENIENTES DAS EMISSÕES A PARTIR DA CAMADA L (CERCA DE 0,6 KEV), GERALMENTE NÃO PODEM SER MEDIDOS E ASSIM NÃO APARECEM EM UM ESPECTRO USUAL DA FONTE DE ${ }^{55} \mathrm{FE}$ (SCHÖTZIG, 2000). UMA INTENSIDADE RELATIVA DE 100 É ATRIBUÍDA À LINHA MAIS INTENSA EM CADA CAMADA. ADAPTADO DA BASE DE DADOS XDB (X-RAY DATA BOOKLET) (THOMPSON ET AL., 2009).

TABELA 4.1: VALORES DOS RESISTORES APRESENTAdOS NA FIGURA 4.4. A PARTIR DESSA CONFIGURAÇÃO, FOI POSSÍVEL CALCULAR O VALOR DO POTENCIAL EM CADA ELETRODO DO TRIPLO GEM APLICANDO A LEI DE OHM.

TABELA 4.2: EXEMPLOS DAS GRANDEZAS EXPRESSAS NA EQUAÇÃO (4.2) PARA DIFERENTES TIPOS DE PROBLEMAS. ADAPTADO DE WECK \& KIM (WECK \& KIM, 2005).

TABELA 4.3: RESUMO DAS TÉCNICAS ITERATIVAS UTILIZADAS PARA A RESOLUÇÃO NUMÉRICA DE SISTEMAS LINEARES.

TABELA 4.4: RESUMO DOS SOFTWARES QUE FAZEM PARTE DO PACOTE GARFIELD++ OU SÃO UTILIZADOS POR ESSE PROGRAMA, FORNECENDO SUPORTE PARA AS DIFERENTES CARACTERÍSTICAS DAS SIMULAÇÕES DE UM DETECTOR A GÁS.

TABELA 5.1: CORTES ESCOLHIDOS PARA PLOTAGEM DAS CURVAS DO CAMPO ELÉTRICO. AS COORDENADAS QUE DEFINEM O SEGUIMENTO DE RETA DE PLOTAGEM ESTÃO EM CENTÍMETROS.

TABELA 5.2: NÚMERO DE PARES DE ELÉTRONS-ÍONS PRODUZIDOS NO GÁS EM FUNÇÃO DA ENERGIA DEPOSITADA. CÁLCULO REALIZADO SEGUNDO A EQUAÇÃO (2.1) PARA AS ENERGIAS CORRESPONDENTES ÀS TRANSIÇÕES KA1, KA2 E KB1 DO MANGANÊS, ALÉM DO PICO DE ESCAPE DO ARGÔNIO.

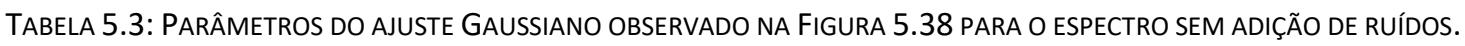

TABELA 5.4: RESUMO DOS PARÂMETROS DE AJUSTE, LARGURA A MEIA ALTURA E RESOLUÇÃO EM ENERGIA DOS ESPECTROS PARA OS DIFERENTES NÍVEIS DE RUÍDO GAUSSIANO CONSIDERADOS.

TABELA 10.1: CONFIGURAÇÃO DE POTENCIAIS E CAMPOS PARA O PRIMEIRO PONTO DA CURVA DE GANHO EFETIVO (CORRENTE APLICADA DE $641 \mu \mathrm{A})$.

TABELA 10.2: CONFIGURAÇÃO DE POTENCIAIS E CAMPOS PARA O SEGUNDO PONTO DA CURVA DE GANHO EFETIVO (CORRENTE APLICADA DE $650 \mu \mathrm{A})$.

TABELA 10.3: CONFIGURAÇÃO DE POTENCIAIS E CAMPOS PARA O TERCEIRO PONTO DA CURVA DE GANHO EFETIVO (CORRENTE APLICADA DE $659 \mu \mathrm{A})$.

TABELA 10.4: CONFIGURAÇÃO DE POTENCIAIS E CAMPOS PARA O QUARTO PONTO DA CURVA DE GANHO EFETIVO (CORRENTE APLICADA $\mathrm{DE} 668 \mu \mathrm{A})$.

TABELA 10.5: CONFIGURAÇÃO DE POTENCIAIS E CAMPOS PARA O QUINTO PONTO DA CURVA DE GANHO EFETIVO (CORRENTE APLICADA DE $677 \mu \mathrm{A})$.

TABELA 10.6: CONFIGURAÇÃO DE POTENCIAIS E CAMPOS PARA O SEXTO PONTO DA CURVA DE GANHO EFETIVO (CORRENTE APLICADA $\mathrm{DE} 686 \mu \mathrm{A})$.

TABELA 10.7: CONFIGURAÇÃO DE POTENCIAIS E CAMPOS PARA O SÉTIMO PONTO DA CURVA DE GANHO EFETIVO (CORRENTE APLICADA DE $695 \mu \mathrm{A})$. 
TABELA 10.8: CONFIGURAÇÃO DE POTENCIAIS E CAMPOS PARA O OITAVO PONTO DA CURVA DE GANHO EFETIVO (CORRENTE APLICADA DE $704 \mu \mathrm{A})$. 



\section{Introdução}

O anseio da humanidade por conhecer os constituintes elementares da matéria teve início, provavelmente, com os filósofos gregos, mas foi apenas no século XVI que reais progressos foram feitos nesse campo de pesquisa (Sundaresan, 2001). O principal motivo que leva o cientista a novas descobertas e a compreensão da natureza é a curiosidade humana; porém, os avanços na ciência são alcançados geralmente através de questionamentos cuidadosamente dirigidos à natureza, com auxílio de experimentos (Grupen \& Shwartz, 2008). Grandes contribuições foram promovidas nesse sentido através da formulação das leis do movimento por Galileu e Newton possibilitando o estudo quantitativo do movimento de partículas (Sundaresan, 2001).

Esse acontecimento marca o início de uma era científica, onde houve progressos tanto no campo da teoria quanto dos experimentos, como no entendimento das propriedades dos gases em termos do movimento das partículas constituintes do gás, por meio dos trabalhos de Daniel Bernoulli no início do século XVIII (1738). Já em 1803, progressos no entendimento da estrutura da matéria foram realizados com as pesquisas de John Dalton que formulou a hipótese atômica. Outras grandes conquistas no mesmo século foram o desenvolvimento da lei de Avogadro em 1811 e a formulação da lei da eletrólise em 1833 pelos estudos experimentais de Michael Faraday. No final desse mesmo século, o químico Dmitri Mendeleev descobriu que ao se arranjar os elementos químicos de acordo com seu peso atômico, suas propriedades químicas mostram um comportamento periódico, o que levou ao desenvolvimento da tabela periódica dos elementos (Sundaresan, 2001).

Conhecimentos acerca das propriedades atômicas como massa, tamanho ou forma tiveram início apenas no final do século XIX e início do século XX, através de estudos com descargas elétricas em gases, onde se estudou o que acontece com átomos de gases quando submetidos a descargas elétricas. Além disso, se estudou as propriedades da luz emitidas pelos átomos na descarga. Os resultados desses estudos levaram a desvendar os produtos do rompimento de átomos na descarga, em particular o elétron. Estudos posteriores levaram ao desenvolvimento da espectroscopia óptica como ferramenta para estudo da estrutura atômica. O conceito do quantum, introduzido por Max Planck em 1900, a descoberta dos raios X por Wilhelm Conrad Röntgen em 1895 e da radiatividade por 
Becquerel em 1896, foram progressos que ajudaram a desvendar os mistérios da estrutura atômica (Sundaresan, 2001).

Dois aspectos devem ser considerados quando falamos na evolução experimental da física de partículas. Por um lado, a produção de partículas que serão estudadas e, por outro lado, o desenvolvimento de sistemas de detecção das mesmas (Choudhury, 1999). Para que se possa responder a muitas questões relativas à natureza, se fazem necessários dispositivos de medição precisos ou detectores que possam fornecer resultados satisfatórios (Grupen \& Shwartz, 2008).

A construção de aceleradores de partículas contribuiu bastante para obtenção de dados experimentais no ramo da Física de partículas, especialmente no período de 1950 a 1990. Foi na década de 1950 que foi criado o "Conseil Européen pour La Recherche Nucléaire" que ficou conhecido como CERN. Um de seus principais objetivos era desenvolver aceleradores de alta energia e, desde então, o CERN tem desempenhado papel de liderança no desenvolvimento de aceleradores de partículas e detectores associados para experimentos de física de partículas. Neste período, também foram construídos outros importantes aceleradores em outros lugares do mundo além da Europa, especialmente nos Estados Unidos. Esses equipamentos contribuíram com os experimentos nesse ramo da Física e, paralelamente, aos poucos foram ocorrendo avanços no desenvolvimento de detectores (Sundaresan, 2001). Pode-se destacar que essa tecnologia acabou sendo aplicada em outras áreas estratégicas, como em medicina nuclear para tratamento de tumores, em ciência de materiais, na preservação de alimentos, etc. (Grupen \& Shwartz, 2008).

Uma contribuição fundamental da Física de partículas para a sociedade moderna se deu através do desenvolvimento do sistema WWW (World Wide Web) em 1989, constituindo um componente essencial para a evolução e popularização da internet (Segal, 1995). O autor desse trabalho foi Tim Berners-Lee, um cientista britânico que proporcionou esse avanço enquanto trabalhava no CERN (CERN, 2019a). A motivação inicial da rede mundial foi atender à demanda de compartilhamento automatizado de informações entre cientistas em universidades e institutos em todo o mundo, especialmente para a física de altas energias (Berners-Lee \& Groff, 1992). Berners-Lee aperfeiçoou a proposta inicial com o engenheiro de sistemas belga Robert Cailliau em 1990. Nesse ano, os dois pesquisadores publicaram uma proposta formal descrevendo os principais conceitos e definindo termos 
importantes por trás da web. O documento descrevia um "projeto de hipertexto" chamado "World Wide Web", no qual uma "rede" de "documentos de hipertexto" poderia ser vista por "navegadores". Ainda neste ano, um protótipo de software para um sistema web básico já estava sendo demonstrado. Foi fornecida uma interface para incentivar a sua adoção e aplicada à documentação do centro de computação do CERN, sendo os primeiros exemplos desta interface desenvolvidos em computadores NeXT (CERN, 2019b).

Para realizar o estudo de partículas do ponto de vista experimental é fundamental a construção de aceleradores que sejam capazes de produzi-las, assim como o desenvolvimento de detectores que possam realizar tais medições. No campo dos aceleradores, as primeiras máquinas criadas (como geradores Cockcroft-Walton, Van de Graaff, etc.) utilizavam basicamente a alta tensão aplicada entre eletrodos para acelerar partículas. Esse tipo de dispositivo limitava a energia das partículas em alguns $\mathrm{MeV}$, pois não se pode aumentar a tensão indefinidamente devido ao surgimento de descargas elétricas. Para atingir energias maiores, máquinas baseadas em geometrias circulares (cíclotrons, sincrotrons, etc.) e aceleradores lineares que usam uma combinação de campo magnético e campos elétricos de rádio frequência para acelerar as partículas foram criados. No caso dos aceleradores lineares, a aplicação do campo elétrico de rádio frequência repetidamente na fase e no momento correto eleva gradativamente a energia das partículas. Já no caso dos sincrotrons, por exemplo, a variação no fluxo magnético induz o campo elétrico que por sua vez promove a aceleração. No caso do sincrotron há ainda a aplicação de um campo magnético que é responsável pela mudança de direção das partículas ao longo do percurso circular (Sundaresan, 2001).

No campo dos detectores, o desenvolvimento de sistemas de detecção complexos se fez necessário. O aperfeiçoamento desses sistemas, capazes de medir energia, momento, posição, massa, etc., levou ao surgimento de volumes cada vez maiores de dados e a consequente necessidade do desenvolvimento de potência computacional para processar as informações (Sundaresan, 2001).

A complexidade e tecnologias envolvidas nos princípios de funcionamento dos detectores foram sendo ampliadas no decorrer do tempo, conforme a necessidade da aplicação, como pode-se ver na seção 2.1 através de uma breve descrição de alguns dos principais tipos de detectores já desenvolvidos. No Capítulo 2 são mostrados também alguns 
dos princípios de funcionamento dos detectores a gás, como efeito avalanche e ganho de gás. Apresenta-se ainda os detectores sensíveis à posição, que são capazes de localizar as partículas em um plano e assim construir imagens. Já no Capítulo 3 destacam-se algumas características dos raios $\mathrm{X}$ e a fonte de ${ }^{55} \mathrm{Fe}$, assim como a interação dessa radiação com a matéria.

Esse trabalho tem como um de seus principais objetivos a concepção de um detector a gás para raios $X$ baseado na tecnologia GEM com capacidade para realizar a aquisição de dados em experimentos como espalhamento de raios $\mathrm{X}$ a baixos ângulos - SAXS (small angle $x$-ray scattering) e difração de raios X - XRD (X-ray diffraction), por exemplo. Destaca-se que esses experimentos são bastante utilizados para caracterização de materiais. Para se atingir esse objetivo, estudaram-se diferentes designs para o detector GEM por meio de simulações utilizando as ferramentas disponíveis em se tratando de softwares de livre acesso, como o Garfield++, Elmer e Gmsh, como apresentado no Capítulo 4.

Nesse estudo, buscou-se inicialmente definir as condições experimentais do sistema real (geometria, composição, pressão e temperatura do gás, configuração dos potenciais elétricos aplicados, etc.). Procurou-se fazer uma validação das simulações realizadas nesse trabalho por meio da comparação dos resultados obtidos com resultados experimentais da literatura (Bencivenni et al., 2002; Benlloch, Bressan, Buttner, et al., 1998; Murtas, 2002; Sauli, 1999; Zuydtwyck, 2010) ou com dados obtidos pelo próprio autor em outro trabalho (Sales, 2015) com um sistema bastante consolidado, como é o triplo GEM bicônico padrão desenvolvido no CERN (Ropelewski, 2011a). Esses softwares que estão sendo usados possibilitam simulações de campo e potencial, deriva de cargas no gás, e muitas outras características que ajudam a determinar o desempenho do detector. Isso é possível para geometrias praticamente arbitrárias graças à interface com programas de métodos de elementos finitos (Geuzaine \& Remacle, 2009; Mukhopadhay \& Majumdar, 2009; Veenhof, 1984), propriedades de misturas de gases (Biagi, 1995) e cálculo detalhado da perda de energia de partículas carregadas no gás (Smirnov, 1995), entre outras características (C. A. B. Oliveira, 2011; Veenhof, 1984).

Os resultados obtidos com o triplo GEM padrão de geometria bicônica são mostrados no Capítulo 5, enquanto simulações com um GEM de geometria cônica são apresentadas no Capítulo 6, onde é estudado o desempenho do dispositivo em função da variação de 
parâmetros geométricos. Nesses estudos, são levantados parâmetros que otimizam o funcionamento do detector, maximizando o ganho. É proposta uma configuração de espaçamento entre furos, além de diâmetros dos mesmos, que maximizam o ganho em relação a uma configuração usual (ver Figura 2.2).

Já no Capítulo 7, são mostrados alguns resultados obtidos com um detector multifilar e um triplo GEM de geometria e configuração alternativa, cujas folhas possuem diferentes espaçamentos entre os furos. Destaca-se a resolução em energia dos dois dispositivos e a curva de ganho.

Para finalizar, apresentam-se as conclusões do trabalho, assim como as perspectivas para trabalhos futuros, incluindo o desenvolvimento de um protótipo aplicando os parâmetros ótimos encontrados pelas simulações. Essa estratégia tem como objetivo obter um design que aperfeiçoe as características desejadas, como maximização do ganho ou minimização do movimento retrógrado dos íons.

Por fim, é importante destacar a importância do desenvolvimento de detectores no Brasil, principalmente levando-se em conta que são escassas iniciativas para fabricação desse tipo de sistema de detecção em território nacional. Isso se torna ainda mais relevante quando consideramos que esses dispositivos são equipamentos comerciais importados de custo elevado, tornando-se crucial que se desenvolvam projetos para a fabricação e manutenção desses dispositivos no país. 


\section{Detectores a Gás}

Detectores a gás são dispositivos capazes de operar em experimentos que exigem altas taxas de contagens e podem ser utilizados para medir a energia ou a posição de partículas que atravessam o meio sensível, isto é, o gás que preenche o detector. Ele pode detectar partículas carregadas ou mesmo fótons e nêutrons. Um exemplo de um detector a gás pode ser observado na Figura 2.1, no qual a interação da radiação que penetra o dispositivo com uma molécula do gás provoca uma ionização. As cargas produzidas na ionização serão direcionadas aos eletrodos pelo campo elétrico. O sinal coletado nos eletrodos, por sua vez, dependerá da diferença de potencial aplicada entre os mesmos (Knoll, 1979).

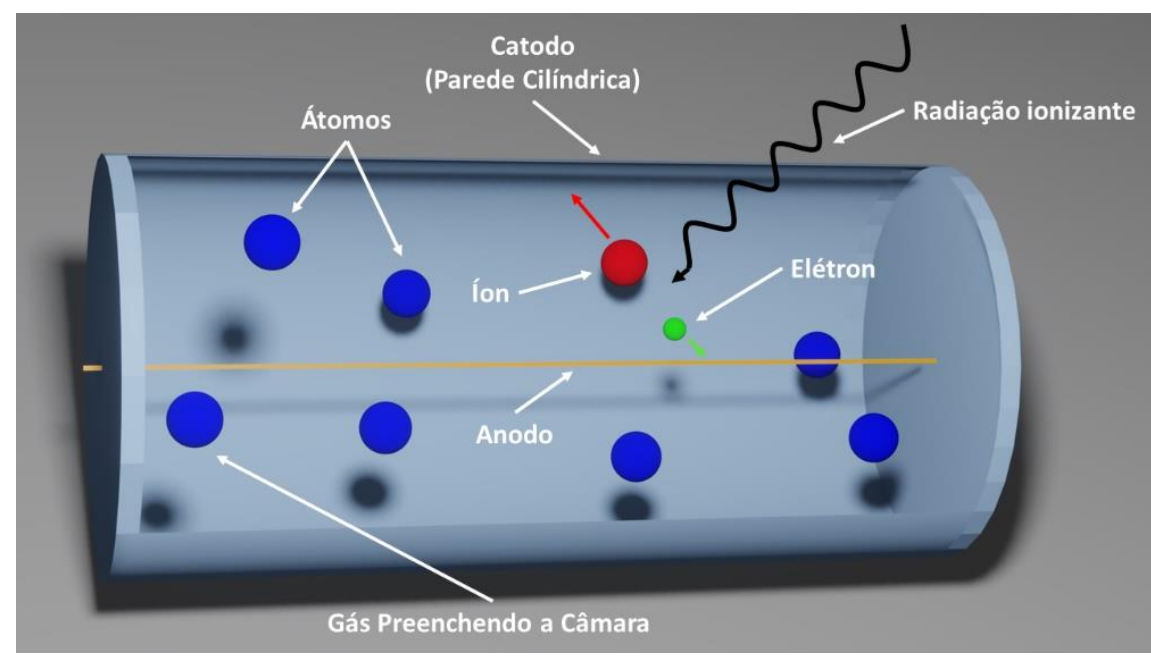

Figura 2.1: Esquema de um detector a gás, composto por dois eletrodos (anodo e catodo) e uma câmara preenchida com gás.

Uma característica importante desse tipo de dispositivo é seu relativo baixo custo, mesmo para detectores que possuam grandes dimensões (Stéphan, 1997). Algumas das principais desvantagens e limitações desse tipo de detector dizem respeito à limitação na resolução em energia (pelo menos em detectores proporcionais) em comparação com detectores de estado sólido, pelo fato desta ser limitada pelas flutuações na produção de cargas e sua multiplicação (Grupen \& Shwartz, 2008; Zuydtwyck, 2010). Os detectores semicondutores, por exemplo, são capazes de fornecer apenas a ionização primária como sinal elétrico. Esse modo de operação é possível devido à baixa energia necessária para produzir um sinal (3,6 eV em silício, em comparação com cerca de 30 eV em gases), além da 
disponibilidade de uma eletrônica de baixo ruído. Isso evita a dependência na variação de ganho do detector (Lutz 2007). Os detectores a gás enfrentam também problemas com o gás na câmara (vazamentos, alta pureza necessária para operação, etc.) (Stéphan, 1997). Como exemplo de problemas com o gás, pode-se destacar o surgimento de produtos de recombinação das moléculas poliatômicas (ver seção 2.2.1) que dão origem a polímeros que, por sua vez, se depositam nos eletrodos. Esse efeito adverso cria uma fina camada isolante que aos poucos irá reduzir o ganho no detector (Grupen \& Shwartz, 2008).

\subsection{Evolução dos Detectores a Gás}

Um dos primeiros detectores desenvolvidos para medição de trajetória e ionização foi a câmara de nuvem. Esse dispositivo é composto por um recipiente preenchido com uma mistura de gás e vapor (por exemplo, vapor de ar e água, ou álcool e argônio) à pressão de saturação de vapor. Se uma partícula carregada atravessa a câmara da nuvem, ela produz um rastro de ionização através de condensação ao longo do caminho da partícula formando gotículas (Grupen \& Shwartz, 2008). Essas gotas, ao serem iluminadas, revelam o caminho percorrido pela partícula carregada. Aplicando-se um campo magnético uniforme na câmara, as partículas carregadas irão descrever uma curva. Isso pode ser utilizado para determinar o momento da partícula carregada através da análise da curvatura do caminho, aplicando-se as leis do movimento de uma partícula carregada em um campo magnético uniforme. Por outro lado, a contagem das gotículas condensadas ao longo do caminho pode ser empregada na determinação da energia da partícula que, por sua vez, juntamente com a medida do momento pode ser usada para determinar a massa da mesma (Sundaresan, 2001).

A câmara de bolhas é um detector similar à câmara de nuvem, sendo que o meio sensível é composto por um material em estado líquido $\left(\mathrm{H}_{2}, \mathrm{D}_{2}, \mathrm{Ne}, \mathrm{C}_{3} \mathrm{H}_{8}\right.$, Freon, etc.), mantido sob pressão na câmara próximo de seu ponto de ebulição. Esse detector exige gravação óptica de eventos, método que inclui a tediosa análise das imagens da câmara, o que limita as estatísticas dos experimentos (Grupen \& Shwartz, 2008). Nesse dispositivo, quando uma partícula carregada atravessa a câmara, bolhas são formadas ao redor do caminho da ionização promovida pela mesma. O caminho da partícula através da câmara pode ser reconstruído com o auxílio de fotografias tiradas por diferentes câmeras, em 
diferentes posições. Uma das principais limitações desse tipo de detector está no fato de sua taxa de repetição ser bastante lenta, inviabilizando sua aplicação em experimentos com alta taxa de contagem (Sundaresan, 2001). Um fato problemático sobre a câmara de bolhas está relacionado aos riscos envolvidos em sua operação devido à grande quantidade de gases armazenados nas câmaras com hidrogênio, que pode ser potencialmente perigoso no caso do gás escapar da câmara. No caso de operação com líquidos orgânicos também pode haver riscos, pois estes devem ser aquecidos para a operação, representando um risco devido à sua inflamabilidade (Grupen \& Shwartz, 2008). Com o passar do tempo, as câmaras de bolhas foram substituídas por detectores eletrônicos, pois: elas não possuem possibilidade de trigger (gatilho de eventos); para energias elevadas não são capazes de parar as partículas produzidas; experimentos que exigem muita estatística não são práticos devido à análise demorada das imagens da câmara de bolha; entre outros motivos (Grupen \& Shwartz, 2008).

A câmara de ionização é um dispositivo que mede a energia depositada por partículas carregadas ou fótons atravessando o meio sensível do detector. Quando a partícula é contida e não sai do meio, a energia medida é equivalente à sua energia total. Esse tipo de detector pode ser construído em uma geometria planar, onde possui dois eletrodos na forma de planos paralelos. Uma diferença de potencial é aplicada entre os planos a fim de criar um campo elétrico uniforme na região entre os mesmos. Esse dispositivo é geralmente preenchido com uma mistura de gases ou um gás nobre em estado líquido, que servirá como meio onde ocorrerá a interação com as partículas incidentes que, por sua vez, proporcionará ionização do meio. Nesse caso, o campo elétrico não é intenso o suficiente para promover ionizações secundárias. Os elétrons e os íons resultantes seguem então na direção dos eletrodos, onde induzem uma carga nos mesmos, que por sua vez formam um capacitor de placas paralelas. Essa carga induzida cria um pulso de tensão que pode ser medido através de um circuito eletrônico associado ao detector. Esse dispositivo pode ser criado ainda em uma geometria cilíndrica, formada por um cilindro (catodo) e um fio (anodo) ao longo do eixo do mesmo. O meio entre o anodo e o catodo é preenchido da mesma maneira e serve como meio de interação com a radiação incidente (meio sensível). É aplicada uma diferença de potencial entre os eletrodos para a criação do campo elétrico entre os mesmos. Nesse 
caso, o campo não é uniforme, mas varia na proporção $1 / r$, onde $r$ é a distância radial a partir do fio (no eixo do cilindro) (Sundaresan, 2001).

O detector de micro fitas de silício é um dispositivo que usa um sólido como meio sensível, o que proporciona a detecção de partículas de energias muito maiores que os detectores a gás, uma vez que o sólido em geral tem uma capacidade maior de absorver totalmente a energia da radiação incidente. Por esse motivo, é possível construir detectores mais compactos em comparação com detectores a gás, que necessitam de maior camada absorvedora. Esse detector de estado sólido é construído através da criação de uma região de condutividade intrínseca entre camadas do tipo $\mathrm{p}$ e do tipo $\mathrm{n}$ bastante finas e separadas por várias centenas de micrometros. As fitas são colocadas em regiões do tipo $p$ e separadas de outra fita por $20 \mu \mathrm{m}$, aplicando-se um potencial negativo nas fitas. A incidência de partículas e interação com o meio cria pares elétron-buraco, que vão gerar um sinal mensurável. As fitas podem ser subdivididas em uma matriz de pads que são lidos individualmente, possibilitando a obtenção de uma imagem bidimensional. Um detector desse tipo é conhecido como CCD (Sundaresan, 2001).

O contador proporcional, desenvolvido por Ernest Rutherford juntamente com Hans Geiger em 1908, consistia de um fio de metal (anodo) bastante fino e coaxial com um catodo cilíndrico preenchido com gás. Quando uma diferença de potencial é estabelecida entre esses eletrodos, os elétrons são acelerados pelo campo elétrico na direção do anodo. Esse dispositivo é capaz de detectar radiação ao amplificar o fraco sinal de ionizações primárias, pois nele o campo elétrico é intenso o bastante para gerar ionizações secundárias a partir das cargas primárias. Para tanto, é necessário que o fio do anodo seja fino o suficiente (Knoll, 1979; Sauli, 2014). Além disso, esse efeito só ocorre nas vizinhanças do fio, quando o módulo do campo atinge o valor necessário para permitir a ocorrência desse fenômeno, conhecido como efeito avalanche (ver seção 2.2.4). Ele proporciona a criação de cargas a partir de ionizações secundárias que podem atingir números tipicamente de $10^{6}$ para cada elétron primário. Quando a intensidade do campo não é demasiada alta nas proximidades do fio, o fator de amplificação é constante e assim o sinal gerado é proporcional ao número de cargas primárias, isto é, à energia das partículas incidentes (Sundaresan, 2001).

O contador Geiger (desenvolvido por Hans Geiger e Walther Müller em 1928) é um detector a gás que opera nos casos onde o campo é demasiado intenso nas proximidades do 
fio (acima daquela utilizada nos contadores proporcionais). Nessa situação, um grande número de fótons é criado durante o efeito avalanche, o que leva ao surgimento de muitos outros elétrons pelo efeito fotoelétrico. Esse efeito faz com que o número de fotoelétrons produzidos por elétron na avalanche inicial cresça muito rápido devido à contribuição de avalanches secundárias. Como resultado disso, o sinal observado não é proporcional ao número de ionizações primárias, mas depende apenas da diferença de potencial aplicada. Nos contadores Geiger, tipicamente o número de cargas devido ao processo de amplificação chega a até $10^{10}$ por elétron primário (Sundaresan, 2001). Além disso, seu relativo baixo custo, capacidade de fazer a contagem de partículas, simplicidade e facilidade de operação faz com que ainda sejam muito usados para monitorar radiação (Knoll, 1979; Sauli, 2014).

O contador proporcional multifilar (MWPC) é um dispositivo baseado no contador proporcional, mas formado por vários fios de anodo dispostos em um plano localizado entre outros dois planos de catodos. Ele foi desenvolvido em 1967 por Georges Charpak (Charpak, Bouclier, Bressani, Favier, \& Zupancic, 1968). Esse trabalho, devido à sua enorme contribuição para a deteç̧ão de partículas e para a pesquisa fundamental, fez com que Charpak fosse laureado com o prêmio Nobel de Física de 1992 (Sauli, 2014). O diâmetro dos fios tipicamente varia de $10 \mu \mathrm{m}$ até $30 \mu \mathrm{m}$ separados por uma distância da ordem de alguns milímetros. Esse dispositivo é capaz de medir a energia depositada por partículas no meio sensível e fazer a sua localização espacial. Esse tipo de detector revolucionou o campo dos detectores sensíveis à posição, possuindo desempenho jamais obtido até aquele momento em relação à resolução em tempo, em posição e capacidade para a taxa de contagens exigidas na época (Sauli, 2014).

Outras contribuições importantes nessa área foram dadas nos anos seguintes com o desenvolvimento de dispositivos similares ao MWPC de Charpak e colaboradores (Bateman, Connolly, Stephenson, \& Tappern, 1981; Gabriel, 1977; Gabriel, Dauvergne, \& Rosenbaum, 1978). Porém, desvantagens intrínsecas aos MWPC juntamente com o respectivo aumento nas exigências experimentais motivaram a busca por dispositivos otimizados em relação à capacidade para altas taxas de contagem e resolução em posição e energia. Algumas das principais desvantagens dos MWPC que podem ser destacadas são o surgimento de carga espacial (gerada pelos íons positivos ao redor dos fios do anodo devido à sua baixa 
mobilidade) e a estrutura frágil dos fios, além de estarem sujeitos ao envelhecimento ${ }^{1}$. 0 efeito de carga espacial se torna mais importante quanto maior for a taxa de contagens, causando alterações no campo elétrico, tendo como principal consequência diminuir o ganho (Fourme, 1997).

Visando superar as limitações dos detectores MWPC, a partir do trabalho de Anton Oed com o desenvolvimento do detector a gás de micro fitas (MSGC) (Oed, 1988), surgiu uma nova família de dispositivos baseados em padrão microscópico. Esse dispositivo contribuiu significativamente no campo dos detectores de radiação, obtendo um ganho significativo na resolução espacial e na taxa de contagem, estimulando imediatamente o desenvolvimento de novos dispositivos nessa classe de detectores a gás (Guérard, 2019). Ele é baseado no MWPC onde os fios do anodo são substituídos por fitas muito finas que são depositadas em um material como cerâmica, quartzo ou substrato plástico. Ele é capaz de operar em altas taxas de contagens (da ordem de $\mathrm{MHz}$ por $\mathrm{mm}^{2}$ ) e ao mesmo tempo possuir resolução submilimétrica, sendo possível graças ao estreito passo entre as tiras que compõem os planos de detecção (Oed, 1988; Sauli, 2014). O anodo e o catodo formam uma estrutura intercalada no substrato de modo que as distâncias entre os eletrodos são da ordem de algumas centenas de micrometros (contra alguns milímetros no MWPC), com a distância entre as fitas de um eletrodo da ordem de algumas dezenas de micrometros. Os eletrodos estão contidos em um recipiente preenchido com uma mistura de gases, que atua como meio sensível. Algumas vantagens desse detector é o baixo tempo morto, uma vez que as distâncias entre anodo e catodo são pequenas, isso viabiliza a rápida deriva e consequente coleta de todas as cargas (inclusive os íons), o que levaria muito mais tempo em um MWPC. Apesar de suas excelentes características, ele apresentava um grave problema por ser eletronicamente frágil. Isso se deve ao fato dos campos elétricos gerados serem demasiado intensos pela proximidade entre catodo e anodo (tipicamente uma distância da ordem de 100 um entre esses eletrodos) (Sauli, 2014).

\footnotetext{
${ }^{1}$ No processo de formação da avalanche de elétrons, os gases da câmara (além de pequenas quantidades de contaminantes) são parcialmente decompostos, com a consequente formação de fragmentos de moléculas. Esses fragmentos (radicais livres) podem então formar longas cadeias, originando assim um efeito de polimerização. Esses polímeros podem se fixar à superfície dos fios, causando assim o "envelhecimento" dos mesmos.
} 
Essa desvantagem no MSGC motivou a busca por soluções mais sofisticadas que possuíssem maior robustez (Guérard, 2019). Como resultados dessa busca, surgem alguns conceitos de detectores que buscaram superar as limitações do MSGC e que simultaneamente tivessem ao menos as mesmas capacidades de detecção desse dispositivo (Sauli, 2014).

Um dos dispositivos que surgiu desse contexto foi o MICROMEGAS (Micro-MEsh Gaseous Structure) (Giomataris, Rebourgeard, Robert, \& Charpak, 1996), um detector também baseado em tecnologia microeletrônica (assim como o MSGC), mas nesse caso os eletrodos são compostos por uma malha microscópica. A malha é composta por uma grade metálica com $3 \mu \mathrm{m}$ de espessura e fios de níquel espaçados de $25 \mu \mathrm{m}$. Nesse conceito, a amplificação de cargas ocorre entre o plano da malha e um plano de micro fitas, separados por $3 \mathrm{~mm}$ e distanciamento entre as fitas de $100 \mu \mathrm{m}$, permitindo um campo elétrico muito intenso na região de amplificação (cerca de $100 \mathrm{kV} / \mathrm{cm}$ ) ao mesmo tempo em que há um campo relativamente baixo na região de deriva, características estas necessárias para um bom funcionamento do dispositivo (Giomataris et al., 1996; Sauli, 2014).

Outro exemplo desses novos detectores é o chamado GEM (Gas Electron Multiplier), um dispositivo também baseado em microeletrônica que foi desenvolvido por Fabio Sauli em 1997 (Sauli, 1997). Nesse dispositivo, duas camadas de metal (geralmente cobre) separadas por uma folha fina de um polímero isolante (geralmente Kapton) são usadas para formar o design do detector. Uma técnica que perfura quimicamente a folha é aplicada de modo a formar uma grade com uma densidade de orifícios da ordem de 50 a 100 furos por $\mathrm{mm}^{2}$ em um padrão muito bem definido (Benlloch, Bressan, Capeans, et al., 1998; Ropelewski, 2011a, 2011b). Um exemplo de uma folha de GEM é mostrado na Figura 2.2. 


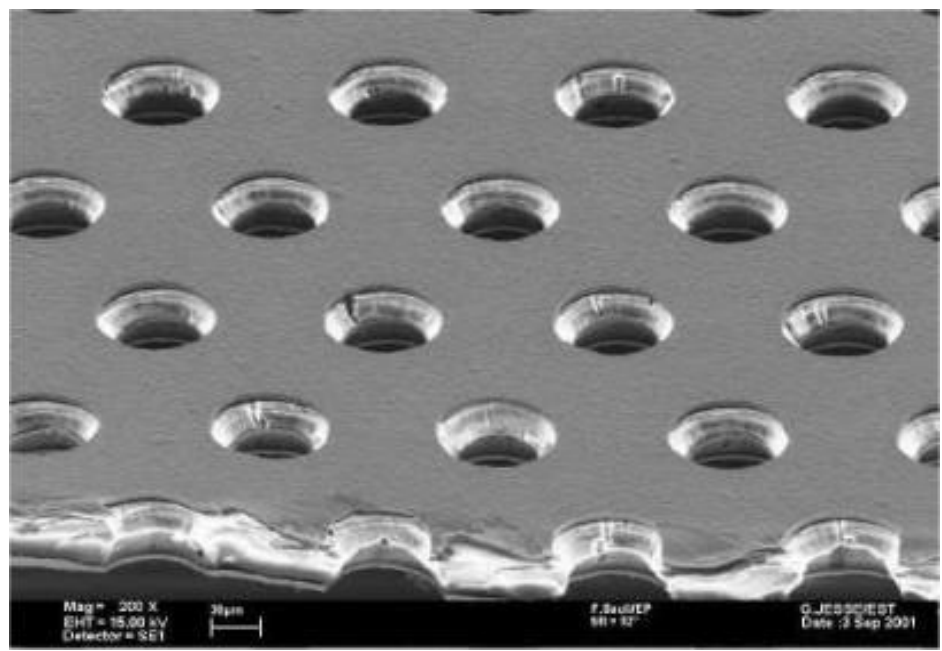

Figura 2.2: Exemplo de imagem de uma folha de GEM obtida por microscópio, mostrando os furos na folha de Kapton que é revestida com cobre. O diâmetro típico dos furos é de $70 \mu \mathrm{m}$ na superfície e de $50 \mu \mathrm{m}$ no centro, de modo que formam um perfil bicônico. A espessura do Kapton é de $50 \mu \mathrm{m}$ e o espaçamento entre furos é de 140 mm. Figura obtida de Ropelewski (Ropelewski, 2011a).

Preenche-se o meio onde o GEM está imerso com um gás conveniente e aplica-se uma diferença de potencial entre as duas superfícies da folha do GEM de modo que a radiação interage com o gás e ioniza suas moléculas. Os elétrons gerados por essa interação são acelerados na direção da folha. Quando se aproximam da mesma, estes são direcionados pelo campo elétrico até o interior dos furos, onde ocorre uma amplificação do sinal (Sauli, 1997). Esse efeito de amplificação do sinal (efeito avalanche, similar ao ocorrido no MWPC) ocorre pelo fato de o campo elétrico se intensificar na região interna dos furos. 0 efeito avalanche é gerado quando os elétrons recebem energia cinética suficiente para ionizar moléculas do gás que preenche o meio, provocando a formação de elétrons secundários.

Pode-se dispor as folhas de GEM em conjunto, constituindo uma espécie de "wafer" formando diversos estágios de amplificação do sinal, como ocorre no caso do detector triplo GEM. Essa configuração permite que se atinjam ganhos da ordem de até $10^{5}$ elétrons secundários para cada primário (dependendo da configuração), pois em cada estágio ocorre o fenômeno de formação de uma avalanche de cargas (Sauli, 1997). O esquema de um triplo GEM pode ser observado na Figura 2.3. 


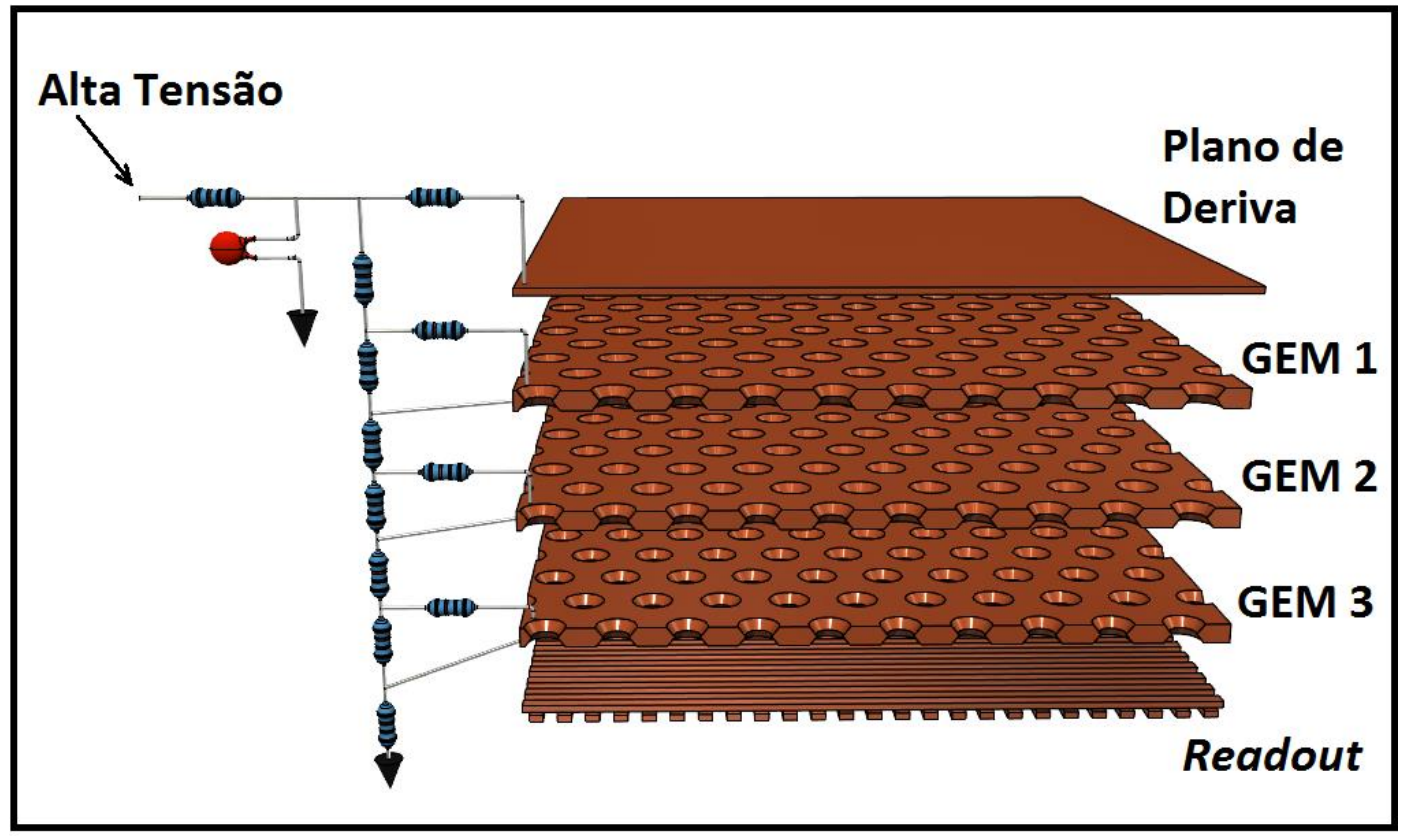

Figura 2.3: Esquema do triplo GEM, onde pode-se observar um divisor de tensões (resistores) responsável por estabelecer uma diferença de potencial entre cada estágio do detector. Nessa configuração, elétrons são acelerados pelo campo elétrico em direção ao Readout, onde os sinais são coletados.

O desempenho do GEM é similar ao apresentado pelo MSGC, mas com uma grande vantagem de a distância entre os eletrodos de multiplicação e coleta das cargas ser muito maior (100 $\mu \mathrm{m}$ no MSGC e $2 \mathrm{~mm}$ no GEM), reduzindo drasticamente a probabilidade de danos ao equipamento devido descargas elétricas, o que era bastante comum dos dispositivos MSGC (Sauli, 2014).

\subsection{Princípios de Funcionamento}

Os detectores a gás são compostos por uma câmara preenchida com um gás (geralmente uma mistura de gases), de modo que esses dispositivos utilizam esse material como meio sensível, uma vez que a radiação ioniza as moléculas do gás ao atravessá-lo (Knoll, 1979; Sauli, 2014). A ionização, por sua vez, origina cargas que podem ser coletadas através de eletrodos depois de aplicada uma diferença de potencial entre os mesmos (Knoll, 1979). Já o número de pares de elétrons e íons criados pela ionização das moléculas do gás, assim como sua distribuição, dependem ambos da natureza da radiação (partículas carregadas, fótons ou nêutrons) e de sua respectiva energia (Sauli, 2014). 


\subsubsection{Gás do Detector}

A escolha do gás apropriado para a operação do detector varia de acordo com a aplicação, ou seja, dependerá do tipo de partícula a ser detectada assim como de sua energia (de Moura et al., 1999; Gabriel et al., 1978). No caso dos detectores proporcionais (caso tanto do GEM quanto do detector multifilar) a escolha é limitada devido a requisitos experimentais contraditórias, como a necessidade de alto ganho, com baixa voltagem de trabalho (a menor possível para evitar descargas), rápida recuperação, entre outras (Sauli, 1977). Uma vez que não existe nenhuma família de gases que por si só suprem todos os requisitos simultaneamente, geralmente a escolha é feita utilizando uma mistura de diferentes famílias de gases, cada uma delas atendendo a algumas das características necessárias para a operação desses dispositivos (Stéphan, 1997).

Os gases nobres oferecem ganho através da multiplicação de cargas devido ao efeito avalanche a baixos campos elétricos; por outro lado, os gases compostos por moléculas poliatômicas necessitam de altos valores de campos elétricos, uma vez que os modos rotacionais e vibracionais são capazes de absorver energia sem causar ionizações (Sauli, 1977). Gases nobres operando sozinhos não oferecem ganhos satisfatórios, pois entram em um regime de descarga permanente, onde átomos excitados retornam ao estado fundamental emitindo fótons que interagem com o catodo, iniciando uma nova avalanche causada pelos fotoelétrons extraídos no eletrodo. Por outro lado, gases compostos por moléculas poliatômicas absorvem os fótons emitidos por átomos excitados, diminuindo a probabilidade das emissões secundárias. Nesse caso, a energia é dissipada por processos típicos desse tipo de molécula, como colisões, dissociação ou polimerização. Portanto, a solução encontrada para a escolha do gás de operação ideal é uma mistura entre essas duas famílias de gases, utilizando a propriedade de operação com baixos campos dos gases nobres e do efeito inibidor (conhecido como quencher) característico das moléculas poliatômicas (Stéphan, 1997).

Um problema em relação à utilização do gás do detector é o grande grau de pureza necessário, uma vez que a amplitude do sinal é bastante sensível a impurezas, que acabam agindo como inibidor. Alguns dos principais poluentes são o oxigênio, nitrogênio e água. Apesar de a qualidade dos gases vendidos comercialmente normalmente serem capazes de atender à pureza necessária para operação do detector, os poluentes podem surgir na 
câmara devido a alguns processos como adsorção de moléculas nos materiais da câmara, degradação dos gases devido à irradiação, entre outros fatores. Esses problemas geram a necessidade de troca do gás ou uma purificação do mesmo (Stéphan, 1997).

\subsubsection{Carga Coletada em Função do Potencial Aplicado}

Há uma correlação entre a carga total coletada nos eletrodos do detector e a diferença de potencial que é aplicada entre os mesmos. Isso define cinco regiões de operação onde a amplitude do sinal varia em função da tensão aplicada, como mostra a Figura 2.4. Nela são observadas as regiões de operação da câmara de ionização, detectores proporcionais e contadores Geiger-Mueller (Knoll, 1979; Stéphan, 1997), que são três conhecidos tipos de detectores a gás brevemente descritos na seção 2.1.

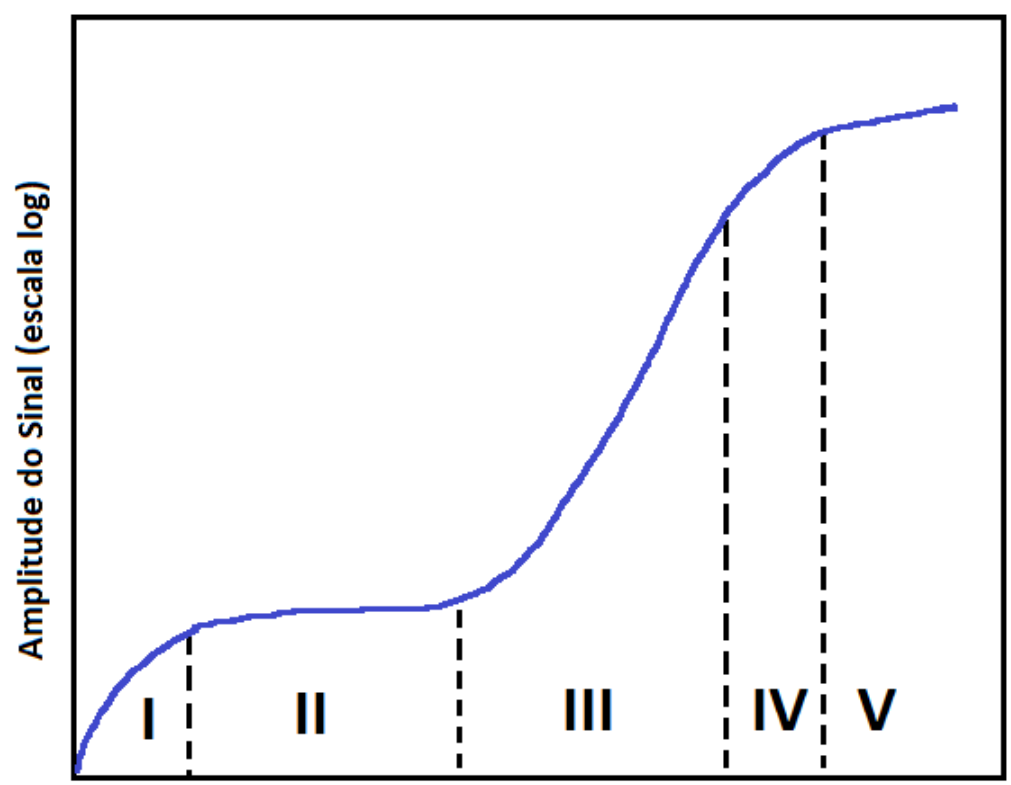

Diferença de Potencial Aplicada

Figura 2.4: Carga coletada em função da diferença de potencial aplicada nos eletrodos. Nota-se as diferentes regiões de operação dos detectores a gás, como a região das câmaras de ionização (II), dos detectores proporcionais (III) e região dos contadores Geiger-Mueller (V). Figura adaptada de G. F. Knoll (Knoll, 1979).

Resumidamente, podemos dizer que na região I da Figura 2.4 a tensão aplicada entre os eletrodos é baixa, de modo que há a probabilidade de haver recombinação de elétrons com moléculas do gás, não contribuindo para o sinal observado. Algumas características que influenciam na probabilidade de recombinação (além da diferença de potencial entre os eletrodos) é a densidade dos portadores de carga e pressão do gás (Stéphan, 1997). 
Já na região II da Figura 2.4, a diferença de potencial é suficiente para suprimir as recombinações, de modo que as cargas coletadas são aproximadamente iguais às produzidas pela ionização. Nessa região atuam as câmaras de ionização (Knoll, 1979).

A região III é conhecida como região proporcional, pois o campo elétrico é capaz de fornecer energia suficiente para que os elétrons ionizem outras moléculas do gás. Essas ionizações secundárias dão origem ao fenômeno de multiplicação de cargas no gás conhecido como efeito avalanche (seção 2.2.4), cuja localização mantém uma correlação com a posição da ionização. Nessa região, o número de cargas coletadas é proporcional ao número devido às ionizações primárias (provenientes da interação da radiação com as moléculas do gás), fato que caracteriza os contadores proporcionais (Knoll, 1979).

Na região de proporcionalidade limitada (região IV) não há uma dependência linear entre o número de cargas coletadas e a tensão aplicada, apesar de ainda haver informações sobre o número inicial de cargas pelo aumento do sinal observado com o respectivo aumento da tensão aplicada (Knoll, 1979).

Por fim, na região $V$ da Figura 2.4 o campo elétrico é bastante intenso de modo que a avalanche formada é completamente independente da carga inicial. Esse fato é o que faz com que os contadores Geiger-Mueller sejam incapazes de distinguir diferentes valores de energia (Knoll, 1979).

\subsubsection{Número de Pares de Elétrons e Íons Produzidos no Gás}

Uma vez que uma partícula interage com as moléculas do gás depositando sua energia no mesmo, ela cria um número discreto de pares de elétrons e íons. Esse número é dependente de mecanismos de absorção de energia sem ionização, como excitação atômica. Esse efeito faz com que a energia média para produção de um par de elétron e íon seja maior que a energia de ionização (Stéphan, 1997). Por exemplo, a energia média para ionização no argônio é de $15 \mathrm{eV}$, enquanto a energia média para produção de um par elétron-íon é de $26 \mathrm{eV}$ (Grupen \& Shwartz, 2008). O mecanismo que produz a maior parte dos pares é baseado no fato dos elétrons ejetados dos átomos terem energia suficiente para ionizar outros átomos e através desse processo criam outros pares de íons. 
Esse número de pares de elétrons e íons gerados pela radiação (também chamado de cargas primárias) pode ser calculado para o caso da mistura entre argônio e $\mathrm{CO}_{2}$ pela seguinte expressão (Sauli, 1977):

$$
n=E\left(\frac{r_{A r}}{W_{A r}}+\frac{r_{\mathrm{CO}_{2}}}{W_{\mathrm{CO}_{2}}}\right)
$$

onde $\mathbf{n}$ é o número de cargas primárias, $\mathbf{E}$ é a energia da radiação que é efetivamente depositada no gás, $\boldsymbol{r}_{A r}$ e $\boldsymbol{r}_{\text {Co2 }}$ são, respectivamente, as quantidades relativas de argônio e dióxido de carbono presentes no gás que preenche o detector, e $\mathbf{W}_{\mathrm{Ar}}$ e $\mathbf{W}_{\mathrm{co} 2}$ são as energias médias para produção de um par de íons para os dois gases, respectivamente (Pulkkinen, 2013; Sauli, 1977). Um fato importante de se avaliar é se a partícula depositou toda sua energia no gás ou apenas parte dela, pois o número de pares produzidos é dado em função da energia depositada no gás (Stéphan, 1997).

\subsubsection{Efeito Avalanche}

O efeito avalanche é um fenômeno que ocorre quando o campo elétrico no detector fornece energia suficiente aos elétrons livres para ionizar moléculas do gás. Os novos elétrons livres são acelerados e promovem novas ionizações, gerando um efeito em cascata cujo número de cargas cresce exponencialmente (Stéphan, 1997).

Suponhamos o caso onde os eletrodos são compostos por um fio fino (anodo), separado por uma distância $r$ de uma carcaça metálica (catodo). Considere-se um único elétron livre (proveniente da ionização de uma molécula do gás pela radiação). Ele possui energia devido à agitação térmica e também uma componente da velocidade devido à ação do campo elétrico aplicado. Essa partícula será acelerada em direção ao fio e, ao se aproximar a certa distância, a intensidade do campo elétrico fornece energia suficiente para o elétron ionizar moléculas do gás. Esse ponto marca o limiar para o início da formação da avalanche (Majewski, 1996).

Seja $\boldsymbol{\alpha}^{-1}$ a distância entre duas colisões sucessivas (livre caminho médio, $\boldsymbol{\lambda}$ ). Quando ocorre uma colisão, os dois elétrons são acelerados e produzem mais uma ionização, cada um, depois de percorrido $\boldsymbol{\alpha}^{-1}$, e assim sucessivamente, de modo que em uma dada posição o 
número total de elétrons é $\mathbf{n}$ e depois de uma distância percorrida igual a $\mathbf{d x}$ o número de elétrons será dado por (Majewski, 1996):

$$
d n=n \cdot \alpha \cdot d x
$$

Pode-se integrar a equação (2.2), a fim de obter o número de elétrons e definir o fator de multiplicação:

$$
G=\frac{n}{n_{0}}=\mathrm{e}^{\alpha \cdot x}
$$

onde $\mathbf{n}_{\mathbf{0}}$ é o número inicial de elétrons e $\mathbf{G}$ é o fator de multiplicação, também conhecido como ganho de gás (Date, Kondo, Shimozuma, \& Tagashira, 2000). Esse fator representa o número total de elétrons criado pelo efeito avalanche a partir de um único elétron. Ele está sujeito à flutuação no número de elétrons primários, assim como às flutuações inerentes do próprio fator de multiplicação (Stéphan, 1997).

Em um caso geral, onde o campo elétrico não é uniforme, o parâmetro $\boldsymbol{\alpha}$ não é constante, variando em função da distância até o fio (Majewski, 1996). É conhecido na literatura que o campo é uniforme em pontos distantes dos fios em um detector MWPC e possui simetria radial nas proximidades dos mesmos (Knoll, 1979). Nessa situação, o fator de multiplicação G pode ser calculado da seguinte forma:

$$
G=\mathrm{e}^{\int_{a}^{r_{c}} \alpha(r) d r}
$$

onde a é o raio do fio e $\mathbf{r}_{c}$ é a distância onde ocorre o limiar na intensidade do campo para formação da avalanche.

O número médio de ionizações por unidade de comprimento ( $\boldsymbol{\alpha}$ ) também é conhecido como coeficiente de Townsend e pode ser definido como:

$$
\alpha=\frac{1}{\lambda}
$$

onde $\boldsymbol{\lambda}$ é o livre caminho médio entre duas colisões sucessivas. 
A probabilidade de formar-se a avalanche eletrônica ou a recombinação das cargas depende tanto da intensidade do campo quanto do gás que preenche o detector. A mistura de gases deve ser escolhida convenientemente e são necessários alguns cuidados como a pureza do mesmo, como discutido em 2.2.1.

O número de elétrons produzidos na avalanche é bem descrito por uma distribuição de probabilidades de variável aleatória discreta, conhecida como distribuição de Polya (Ferretti, De Nardo, \& Lombardi, 2009; Takada et al., 2013). Essa distribuição é capaz descrever o número de objetos (elétrons, no caso) que ocorrem em aglomerados. Os aglomerados seguem uma distribuição de Poisson com um dado parâmetro de forma, enquanto que o número de objetos (elétrons) dentro de um aglomerado segue uma distribuição geométrica com outro parâmetro de forma. Uma aplicação dessa distribuição pode ser vista na seção 5.3 no estudo do ganho de gás, enquanto os detalhes sobre essa distribuição são mostrados no Apêndice B.

\subsubsection{Efeito Penning}

O fenômeno que ficou conhecido como efeito Penning é um mecanismo que possibilita a utilização da energia de excitação de moléculas de gases para ionizar outras moléculas. Esse efeito foi observado por Frans Michel Penning (Penning, 1928, 1934) enquanto estudava descargas em gases e observou que o potencial de descarga em misturas de neon, argônio e mercúrio é menor do que em gases nobres puros, atribuindo esse efeito a estados metaestáveis (Druyvesteyn \& Penning, 1940).

A importância desse fenômeno no presente trabalho se dá pelo fato de ter sido reportado na literatura uma discrepância entre o valor do ganho do gás dado pelo efeito avalanche apenas considerando o coeficiente de Townsend (implementado por padrão no Garfield++) em relação ao observado em experimentos, sendo este último maior que nas simulações (Azevedo, Correia, Carramate, Silva, \& Veloso, 2016; Sipaj, 2012). A fim de superar essa limitação, há no software a possibilidade de incluir as ionizações dadas através do efeito Penning (Schindler, 2019).

O efeito Penning ocorre quando a energia de excitação do átomo de um dos gases que compõe a mistura é maior que o potencial de ionização do gás secundário inibidor (quencher, ou extintor). No nosso caso, estamos interessados no estudo do átomo de 
argônio (que pode receber energia da radiação e ser ionizado ou excitado), já o gás inibidor de baixo potencial de ionização trata-se do $\mathrm{CO}_{2}$. No caso de uma colisão entre eles, transferências de energia são possíveis, resultando em um elétron extra que irá contribuir para o ganho do detector (Azevedo et al., 2016; Sahin, Tapan, Ozmutlua, \& Veenhof, 2010).

Um esquema dos níveis de energia e da configuração eletrônica do átomo de argônio e da energia para ionização da molécula de $\mathrm{CO}_{2}$ é mostrado na Figura 2.5. Nessa figura pode ser observado como um átomo de Ar no terceiro estado excitado possui energia suficiente para ionizar uma molécula de dióxido de carbono. O átomo de um gás nobre, quando excitado, é altamente reativo devido ao fato de ter apenas um elétron na camada de valência, tendo propriedades químicas semelhantes às dos metais alcalinos. Essas propriedades fazem com que na maior parte dos casos o gás nobre excitado ser o responsável pela ionização da mistura (Sahin et al., 2010).

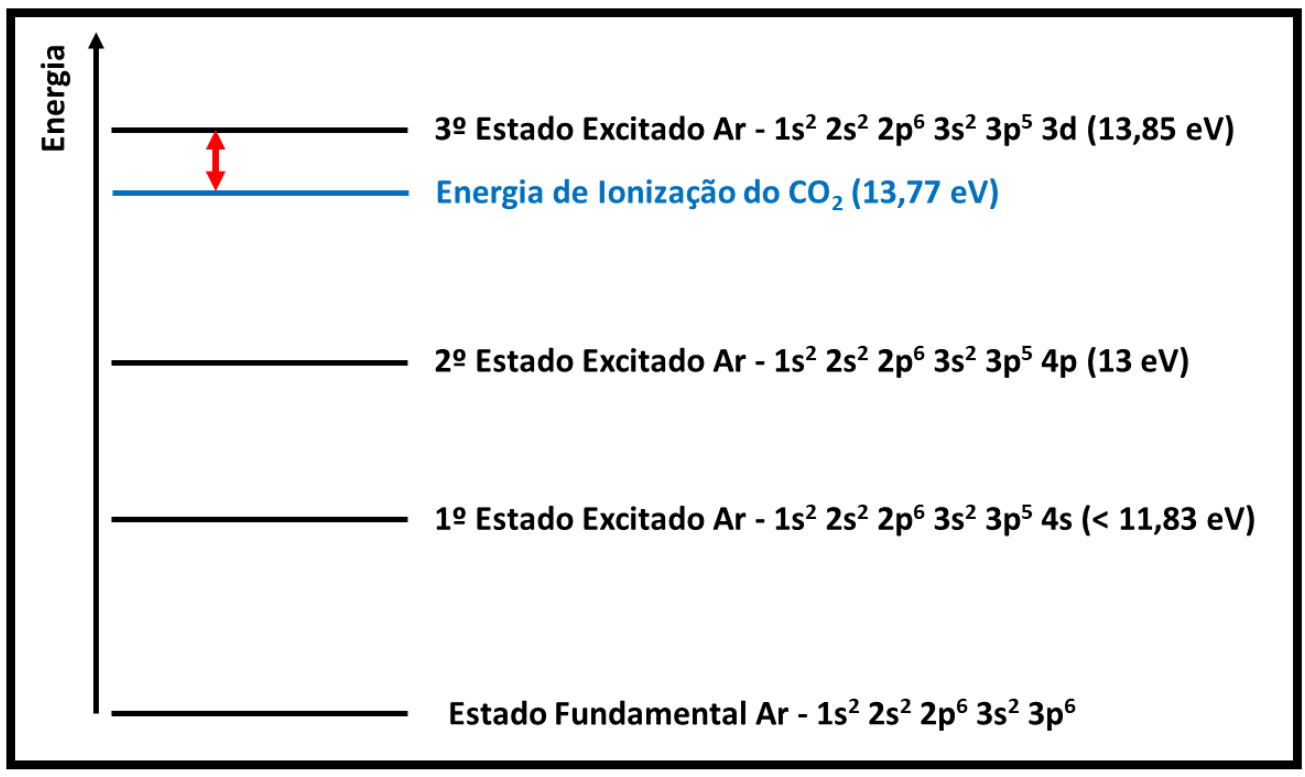

Figura 2.5: Esquema dos níveis de energia e da configuração eletrônica do argônio em comparação com a energia para ionizar uma molécula de $\mathrm{CO}_{2}$. Nota-se como um átomo de Ar no terceiro estado excitado possui energia suficiente para ionizar uma molécula de dióxido de carbono. Figura adaptada de Nemallapudi (Nemallapudi, 2012), Dildick (Dildick, 2011) e Sahin et al. (Sahin et al., 2010).

O ganho de gás extra devido à colisão do átomo excitado de argônio ( $\mathrm{Ar}^{*}$ ) com o dióxido de carbono, resultando em um elétron livre, pode ser expresso da seguinte maneira:

$$
\mathrm{Ar}^{*}+\mathrm{CO}_{2} \rightarrow \mathrm{Ar}+\mathrm{CO}_{2}^{+}+e^{-}
$$


Devido ao efeito Penning, o coeficiente de multiplicação de Townsend pode ser corrigido da seguinte maneira (Sipaj, 2012):

$$
\alpha_{\text {Efetivo }}=\alpha\left(1+r_{\text {Pen }} \frac{V_{E x c}}{V_{\text {Ion }}}\right)
$$

onde $\boldsymbol{r}_{P e n}$ é a probabilidade de o átomo excitado ionizar a molécula do gás secundário, já $\boldsymbol{V}_{E x c}$ e $V_{\text {Ion }}$ são as frequências de excitação e ionização (colisões por intervalo de tempo, geralmente em MHz e conhecidas na literatura) (Sahin et al., 2010).

Nas simulações, pode-se escolher o valor de $r_{\text {Pen }}$ entre 0,00 e 1,00 de modo que o ganho do gás simulado possa ser análogo ao observado experimentalmente, a fim de representar da melhor maneira possível o sistema real. Na Tabela 2.1 são mostrados os valores da literatura de $r_{p e n}$ utilizados em diferentes trabalhos de simulação de detectores com o programa Garfield++, destacando a mistura e proporção de gases estudada. Esse levantamento serviu como uma referência para saber se a escolha do valor de $r_{P e n}$ que foi empregado nas simulações no presente trabalho condizem com os valores adotados em outros trabalhos.

Tabela 2.1: Valor de $r_{\text {Pen }}$ encontrado na literatura para a transferência de energia pelo efeito Penning utilizado nas simulações com o programa Garfield++.

\begin{tabular}{|l|c|c|}
\hline rPen & Mistura (Proporção) & Referência \\
\hline 0,55 & $\mathrm{Ar} / \mathrm{CO}_{2}(70 \% / 30 \%)$ & (Dildick, 2011) \\
\hline 0,70 & $\mathrm{Ar} / \mathrm{CO}_{2}(70 \% / 30 \%)$ & (Nemallapudi, 2012) \\
\hline 0,45 & $\mathrm{Ar} / \mathrm{CO}_{2}(90 \% / 10 \%)$ & (Nemallapudi, 2012) \\
\hline 0,51 & $\mathrm{Ar} / \mathrm{CO}_{2}(80 \% / 20 \%)$ & (Sipaj, 2012) \\
\hline 0,57 & $\mathrm{Ar} / \mathrm{CO}_{2}(70 \% / 30 \%)$ & (Azevedo et al., 2016) \\
\hline 0,51 & $\mathrm{Ar} / \mathrm{CO}_{2}(70 \% / 30 \%)$ & (Malinowski et al., 2018) \\
\hline 0,32 & $\mathrm{Ar} / \mathrm{Isobutano} \mathrm{(95 \%} \mathrm{/} \mathrm{5 \% )}^{\text {(Ogawa \& Aoki, 2017) }}$ \\
\hline
\end{tabular}




\subsection{Detectores Proporcionais Sensíveis à Posição}

Os detectores proporcionais operam fazendo uso das ionizações secundárias devido ao efeito avalanche, descrito na seção 2.2.4. Nessa classe se encaixam tanto o detector MWPC quanto o GEM, ambos abordados nesse trabalho. No MWPC o fator de multiplicação do número de cargas iniciais é da ordem de $10^{5}$ até $10^{6}$ (Price, 1964), além de ser proporcional à energia depositada pela partícula incidente, o que permite medir a energia das mesmas (Stéphan, 1997). Nesse dispositivo, o anodo precisa ser formado por um fio bastante fino (da ordem de dezenas de $\mu \mathrm{m}$ ) visando à maximização da intensidade do campo para que ocorra a multiplicação no gás, como mostra a equação (2.8) (Stéphan, 1997). Para o caso onde o catodo é uma câmara cilíndrica e o anodo é composto por um fio fino no centro, o campo elétrico em função da distância ao fio $\mathbf{E}(\mathbf{r})$, à distância $\mathbf{r}$ do centro do fio é dado por:

$$
E(r)=\frac{\Delta V}{r \ln \left(\frac{r_{b}}{r_{a}}\right)}
$$

onde $\boldsymbol{\Delta} \boldsymbol{V}$ é a diferença de potencial, $\mathbf{r}_{\mathrm{a}}$ é o raio do fio e $\mathbf{r}_{\mathrm{b}}$ é o raio interno do catodo.

Uma partícula incidente nesse detector cilíndrico ioniza as moléculas do gás de modo que íons positivos derivam em direção ao catodo e os elétrons em direção ao anodo. Uma vez que a avalanche se forma nas proximidades do fio, a posição desta indica com certa precisão a posição onde ocorreu a ionização. Efeitos que são intrínsecos do detector ou dos processos físicos envolvidos na detecção como ruído eletrônico, espalhamento múltiplo, flutuações na perda de energia, etc. definem uma resolução em posição finita (Stéphan, 1997). A aplicação de detectores a gás sensíveis à posição diminuiu consideravelmente os tempos necessários para coleta de dados, uma vez que permitiram medidas de diferentes ângulos simultaneamente (Gabriel, 1977).

Para fazer a determinação da posição em detectores unidimensionais (ao longo do fio) pode-se empregar o método de divisão de cargas. Isso é realizado levando-se em conta que o anodo é constituído por um fio bastante fino e que possui alta resistência, fazendo com que a amplitude do sinal seja atenuada por efeito Joule ao atravessar o mesmo. Esse efeito faz com que a amplitude do pulso seja proporcional à posição relativa da avalanche, 
sendo assim capaz de localizar espacialmente os eventos ao longo do eixo definido pela direção do fio do anodo (Knoll, 1979).

Os detectores proporcionais unidimensionais apresentavam resposta rápida na detecção de partículas, mas colocar vários deles lado a lado em um mesmo volume e combinar seus dados a fim de ter-se um sistema bidimensional não parecia uma ideia interessante do ponto de vista prático. Por outro lado, antes de se construir uma estrutura com vários fios paralelos (multifilar), acreditava-se que o sinal adquirido em um fio (ao redor do qual se formou a avalanche) se espalharia por todos os fios devido o acoplamento capacitivo (Stéphan, 1997). Entretanto, Charpak e colaboradores (Charpak et al., 1968) mostraram que formavam-se sinais induzidos em todos os fios vizinhos de modo a compensar os sinais devido ao acoplamento capacitivo (Stéphan, 1997).

O MWPC foi o detector bidimensional desenvolvido por Charpak consistindo de fios finos igualmente espaçados entre dois planos de catodos. Nesse dispositivo, o processo para formação da avalanche eletrônica ocorre basicamente da mesma maneira que em um contador proporcional (Grupen \& Shwartz, 2008). Porém, características desse dispositivo como variações no campo elétrico e capacitância dependem fortemente de parâmetros geométricos (Sauli, 1977; Stéphan, 1997).

Parte do presente trabalho se deu fazendo-se testes utilizando o detector multifilar mostrado na Figura 2.6, composto por uma câmara metálica preenchida com a mistura de argônio (70\%) e $\mathrm{CO}_{2}$ (30\%), sendo essa composição utilizada em vários trabalhos (Croci, Ropelewski, Sauli, \& Solevi, 2007a, 2007b; Gabriel et al., 1978; Ropelewski, 2011a). Com esse dispositivo pode-se obter a energia que a partícula depositou no gás, além de ser possível obter a localização espacial dos eventos (ionizações) em duas dimensões. O design desse detector é composto por uma grade de fios central (anodo), colocada entre outras duas grades perpendiculares entre si (catodos). Essas duas últimas são utilizadas para se fazer a localização espacial ao longo das direções $X$ e $Y$, enquanto o anodo é aplicado para obtenção do espectro de energia da radiação incidente, além de servir como gatilho de eventos (trigger) (de Moura et al., 1999).

Os fios de cada grade possuem $25 \mu \mathrm{m}$ de diâmetro, feitos de tungstênio e cobertos por uma fina camada de ouro (de Moura et al., 1999). O detector possui área ativa de $10 \mathrm{x}$ 
$10 \mathrm{~cm}^{2}$ (80 fios igualmente espaçados de 1,25 mm) e a distância entre as grades de fios é de $3 \mathrm{~mm}$ (Sales, 2015).

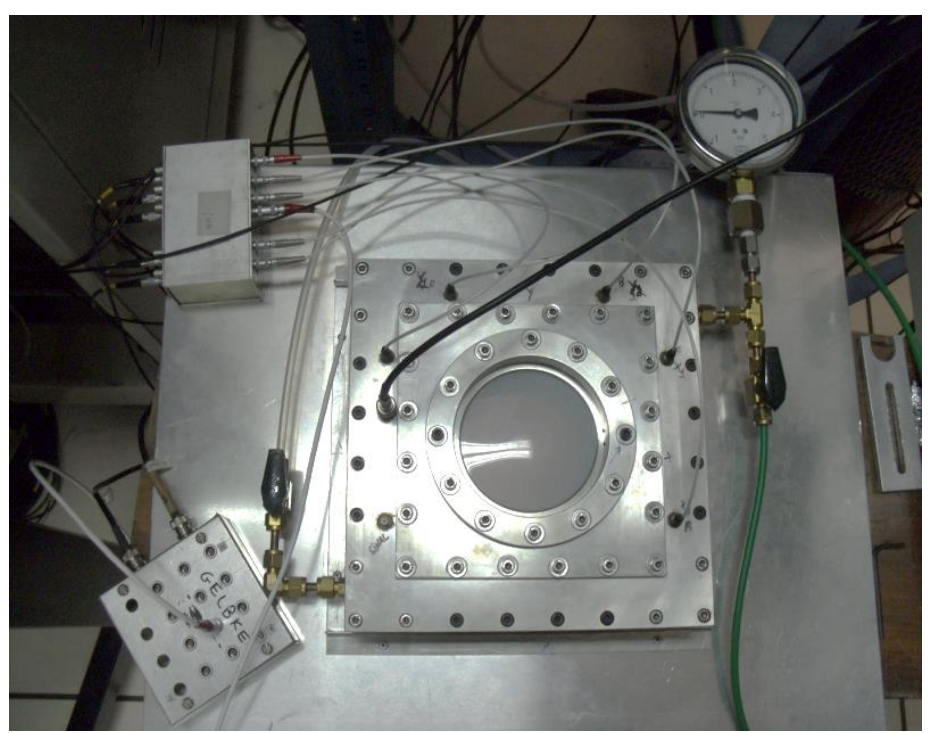

Figura 2.6: Detector multifilar sensível à posição utilizado nos testes mostrados na seção 7.1. Há cinco conectores correspondentes aos cinco sinais de interesse, sendo as duas extremidades de cada catodo (eixo $\mathrm{x} e$ y) e uma do anodo (para mensurar a energia da partícula), além do conector para aplicação da alta tensão.

Nesse MWPC, o sistema para determinação das posições das ionizações é baseado no método de divisão de cargas através de uma cadeia resistiva, onde há um resistor de $100 \Omega$ (com tolerância de $\pm 1 \%$ ) entre cada fio nos catodos. Nesse sistema ocorre atenuação da amplitude do pulso conforme este se desloca através dos resistores. Esse arranjo é uma alternativa ao sistema de linhas de retardo (Boulin, Kempf, Gabriel, \& Koch, 1988) e tem como objetivo ser de mais fácil operação e manutenção em comparação com as linhas de retardo (de Moura et al., 1999; Sales, 2015).

Nesse esquema há um deslocamento de cargas até os fios mais próximos à ocorrência da ionização, enquanto que o campo elétrico é idêntico para todos os fios à mesma grade, já que são idênticos e encontram-se sob o mesmo potencial. Esse método de localização espacial dos eventos utiliza o fato da amplitude do pulso elétrico sofrer atenuação por efeito Joule conforme se desloca através dos resistores, como esquematizado na Figura 2.7. 


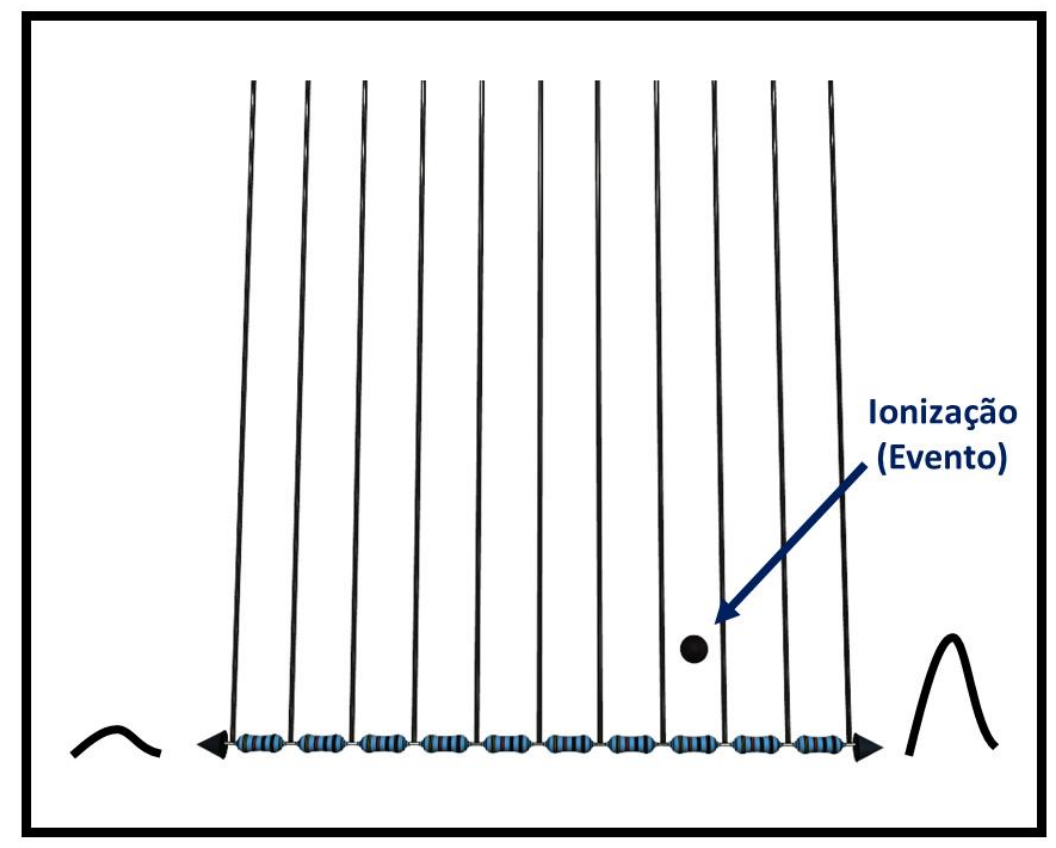

Figura 2.7: Esquema do método de determinação da localização espacial dos eventos por cadeia resistiva. Os elétrons provenientes da ionização pela radiação são acelerados até o fio do anodo mais próximo, gerando uma avalanche eletrônica nas suas proximidades. O pulso se divide igualmente e segue nos dois sentidos da cadeia de resistores, ao passo que ao atravessar cada resistor ele sofre atenuação na amplitude devido ao efeito Joule.

A determinação da posição ao longo de um eixo é feita através da comparação entre as amplitudes dos sinais que chegam a cada uma das duas extremidades (esquerda e direita) da mesma grade de fios. Com esse método, duas amplitudes similares representam um fóton que interagiu com o gás em um ponto na região central. Já uma amplitude bastante diferente de outra representa um fóton que ionizou o gás próximo da extremidade do detector, e assim por diante.

A posição ao longo de uma direção pode ser calculada através da seguinte expressão (de Moura et al., 1999):

$$
P=\frac{A_{E}-A_{D}}{A_{E}+A_{D}} f
$$

onde $\boldsymbol{P}$ é a posição ao longo de uma direção (X ou $\mathrm{Y}$ ), $\boldsymbol{A}_{E}$ e $\boldsymbol{A}_{\boldsymbol{D}}$ são, respectivamente, as amplitudes dos sinais medidos na extremidade esquerda e direita da mesma cadeia resistiva, e $f$ é uma constante. 
Utilizando e equação (2.9) para as direções $X$ e $Y$ de modo a combinar as informações de ambos em um histograma bidimensional é possível obter-se uma imagem com a localização dos fótons (de Moura et al., 1999; Sales, 2015).

A constante $f$ na equação (2.9) pode ser escolhida de forma arbitrária ou respeitar algum critério de modo que a imagem obtida tenha unidades físicas. Nessa expressão, o resultado pode variar entre -1 e 1 , pois para eventos nas extremidades uma das amplitudes é máxima enquanto a outra tende a zero. Conhecendo-se o comprimento real (L) da lateral do detector, pode-se escolher $\boldsymbol{f}$ de modo que o resultado ( $\boldsymbol{X}$ ou $\boldsymbol{Y}$ ) esteja dentro do intervalo entre $-\mathrm{L} / 2$ e $\mathrm{L} / 2$. No caso do MWPC utilizado no presente trabalho, ambos os lados do detector medem $100 \mathrm{~mm}$, de modo que colocando no programa $f=50$ o resultado estará no intervalo entre -50 e 50 . Nessas condições, supondo que o detector possua uma relação linear entre $P$ e a posição real, a imagem será dada em unidades de comprimento $(\mathrm{mm}$, nesse caso).

\subsection{Resolução em Energia}

O efeito avalanche, característico de todos os tipos de detectores proporcionais, é um processo de natureza estatística que acaba por inserir flutuações no ganho de gás do detector. Essas flutuações, por sua vez, promovem um efeito bastante importante na determinação da resolução em energia dos detectores proporcionais, especialmente na detecção de raios $X$ de baixa energia, tal como aqueles provenientes de uma fonte de ${ }^{55} \mathrm{Fe}$ (Sauli, 2014).

Seja $\boldsymbol{n}$ o número médio de pares elétron-íon criados no gás (cargas primárias) e $\mathbf{G}$ o ganho do detector. A resolução relativa da altura do sinal elétrico $(\boldsymbol{S})$ em termos da variância no número de elétrons e do fator de multiplicação (ganho) será dada por (Sauli, 2014):

$$
\left(\frac{\sigma_{S}}{S}\right)^{2}=\left(\frac{\sigma_{n}}{n}\right)^{2}+\left(\frac{\sigma_{G}}{G}\right)^{2}
$$

Supondo que cada um dos elétrons primários dará origem a uma avalanche independente, pode-se fazer uma média sobre as $\boldsymbol{n}$ avalanches de tamanho $\boldsymbol{T}_{\boldsymbol{i}}$. Nesse caso, o ganho $\boldsymbol{G}$ será: 


$$
G=\frac{1}{n} \sum_{i=1}^{n} T_{i}=\bar{T}
$$

Enquanto a variância será:

$$
\left(\frac{\sigma_{G}}{G}\right)^{2}=\frac{1}{n}\left(\frac{\sigma_{T}}{\bar{T}}\right)^{2}
$$

Considerando uma distribuição de Polya (Apêndice B) para o tamanho da avalanche, a variância pode ser escrita como (Sauli, 2014):

$$
\left(\frac{\sigma_{T}}{\bar{T}}\right)^{2}=\frac{1}{\bar{T}}+\frac{1}{1+\theta}
$$

onde $\boldsymbol{\theta}$ é um parâmetro de forma da distribuição (Ver Apêndice B).

A partir de (2.13), podemos notar que a flutuação no tamanho da avalanche $\left(\sigma_{T}\right)$ aumenta em função do tamanho da mesma, isto é, com o ganho do detector.

Considerando o caso de toda a energia dos raios $X$ depositada no gás ${ }^{2}$ e levando em conta as estatísticas para essa deposição, a flutuação estatística no número de pares elétron-íon pode ser escrita como:

$$
\sigma_{n}^{2}=F \cdot n
$$

onde $\boldsymbol{F}$ é conhecido como fator de Fano e cujo valor depende do gás que preenche o detector (Fano, 1963). A partir de (2.14), observa-se então que a resolução em energia é incrementada pelo fator $\sqrt{F \cdot n}$.

Seja uma medição cujo intervalo de tempo seja tal que o número de eventos registrados seja muito grande, de tal modo que possamos considerar a estatística desses eventos como uma distribuição de Poisson. Havendo ainda um considerável número de contagens por canal, pode-se descrever essa distribuição como uma Gaussiana, cujo erro

\footnotetext{
2 É importante distinguir a flutuação da perda de energia (flutuações de Landau), que ocorrem nos casos de camadas absorvedoras finas, da flutuação do número de pares elétrons-íons produzidos por partículas que depositam toda sua energia no volume sensível do detector (raios $X$ da fonte ${ }^{55} \mathrm{Fe}$, por exemplo) (Grupen \& Shwartz, 2008).
} 
associado a uma medida é dado pelo desvio padrão $(\sigma)$ em função do número de contagens (N) (C. L. P. Oliveira, 1998):

$$
\sigma=\sqrt{N}
$$

É interessante descrever os dados através de uma função Gaussiana para fazer-se uso de propriedades da mesma, como a largura a meia altura do pico (full width at Half maximum - FWHM), muito utilizada na definição de resolução (Grupen \& Shwartz, 2008). A largura a meia altura pode ser calculada em função do desvio padrão (obtido a partir do ajuste dos dados com a função Gaussiana) através da seguinte expressão:

$$
F W H M=2,35 \cdot \sigma
$$

Quando um feixe de radiação monoenergética incide sobre o detector, este apresenta como resposta uma distribuição de altura de pulso diferencial. A resolução em energia do detector é uma característica que representa a função de resposta do dispositivo submetido a essa radiação, de modo que quanto mais larga for a distribuição, pior será a resolução em energia e vice-versa (Knoll, 1979).

Matematicamente, a resolução em energia $(\mathbf{R})$ do detector pode ser definida por (Knoll, 1979; Marinho, 2001):

$$
R=\frac{F W H M}{H_{0}}
$$

onde $\boldsymbol{F W H M}$ é a largura à meia altura da distribuição, enquanto $\boldsymbol{H}_{\boldsymbol{0}}$ representa o valor mais provável para a energia depositada no gás, ou seja, o valor médio do ajuste em torno do pico do espectro. 


\section{Raios X}

Desde que foram observados pela primeira vez em 1895 pelo físico alemão Wilhelm Conrad Röntgen, viu-se que os raios $\mathrm{X}$ podiam ser empregados em aplicações médicas, pois se podiam ver os ossos sem os músculos ou mesmo uma bala alojada no corpo. O próprio Röntgen acidentalmente colocou sua mão em frente à válvula de Hittorf com a qual trabalhava, observando os ossos na tela. Devido a essa descoberta, Röntgen foi laureado com o Prêmio Nobel de Física de 1901 (Segrè, 1987).

Apesar de não haver uma definição precisa que faça distinção entre raios $X$ e gama, por serem ambas radiação eletromagnética ionizante (Tsoulfanidis, 1995), geralmente se considera que os raios $\mathrm{X}$ são causados por transições atômicas, enquanto que raios gama são emitidos nas reações nucleares (Price, 1964; Tsoulfanidis, 1995). Há ainda um critério que considera que os fótons de raios $X$ estão compreendidos entre a faixa de energia que vai de $10^{2} \mathrm{eV}$ até $10^{5} \mathrm{eV}$ (Delaney \& Finch, 1992).

\subsection{Fontes de Raios $X$}

Na ocasião do experimento de Röntgen, os raios $X$ surgiram a partir do processo de excitação dada pela aceleração e desaceleração dos elétrons nos tubos de raios catódicos, seguida do movimento de um elétron para preencher a vacância em uma camada interna do átomo (Delaney \& Finch, 1992). Isso ocorre devido à liberação da energia conforme o átomo retorna ao estado fundamental na forma de raios $X$ característicos, cuja energia varia de alguns elétron volts a cerca de 0,1 MeV (Price, 1964). O processo de excitação pode ainda ser originado a partir de radiações externas (partículas alfa, beta, gama, etc.), ou ainda devido processos de decaimento radioativo do núcleo (Delaney \& Finch, 1992). Pode haver produção de fótons de outros modos, como aplicando aceleradores de partículas ou mesmo provenientes de fontes extraterrestres, como no caso dos raios cósmicos (Price, 1964).

É interessante destacar que partículas relativísticas carregadas podem interagir com o campo de Coulomb dos núcleos do meio ao qual atravessam. Nessa interação, elas eventualmente são desaceleradas. Dessa forma, uma parcela de sua energia cinética diminui e então será emitido um fóton. Esse tipo de radiação é conhecido como radiação de freamento (Bremsstrahlung) (Grupen \& Shwartz, 2008). 


\subsection{Interação da radiação com a Matéria}

Podem ocorrer diferentes tipos de interações da radiação com a matéria de acordo com o tipo de radiação em questão (partículas carregadas, nêutrons, radiação eletromagnética, etc.) ou da energia da mesma (Price, 1964).

A interação dos fótons com a matéria se dá basicamente através da absorção fotoelétrica (ou efeito fotoelétrico), espalhamento Compton e produção de pares (Knoll, 1979). Tanto a energia do fóton quanto a densidade e o número atômico do meio definem a probabilidade de ocorrer cada um desses processos (Sauli, 2014), como esquematizado na Figura 3.1. Os fótons interagem com a matéria em encontros individuais, ao contrário das partículas carregadas, que depositam energia continuamente ao longo de sua trajetória criando um caminho de ionizações (Sauli, 2014).

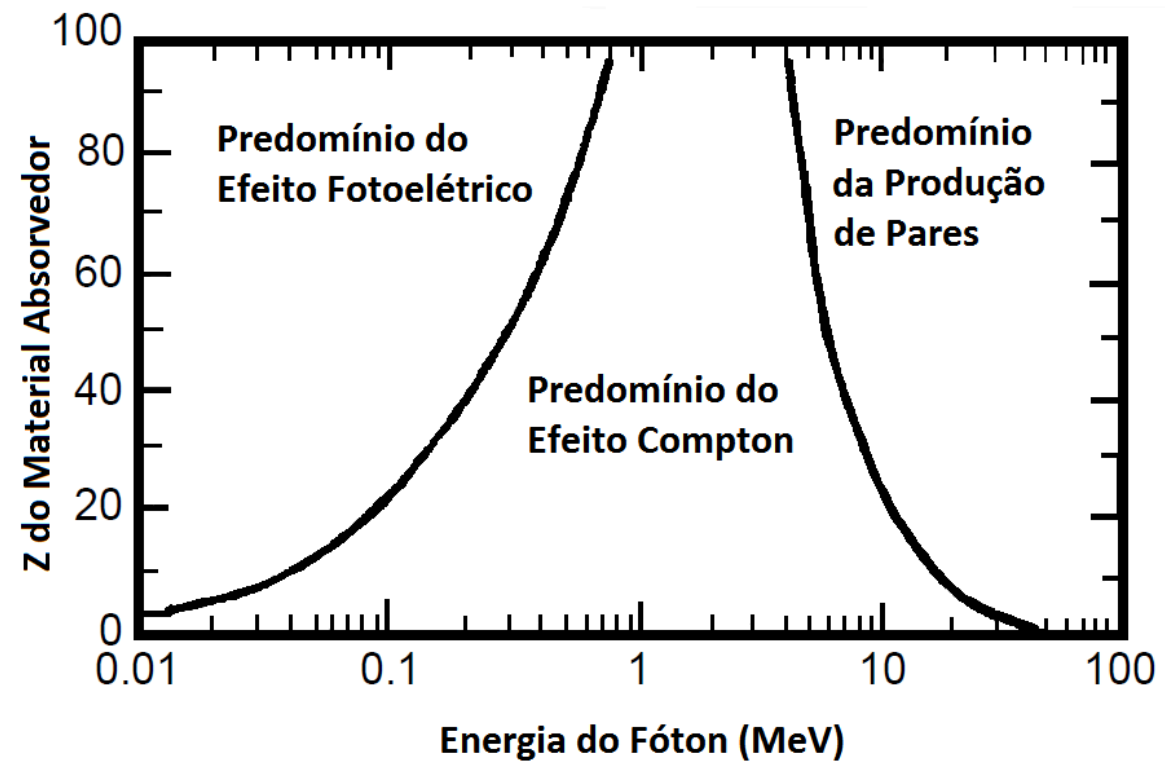

Figura 3.1: Representação da probabilidade de ocorrência dos três diferentes processos de interação dos fótons com a matéria. Vê-se que o efeito fotoelétrico é predominante para baixas energias, enquanto o espalhamento Compton predomina em valores intermediários de energia, já a produção de pares é influente para fótons de energia bastante elevada. Figura adaptada de G. F. Knoll (Knoll, 1979).

A probabilidade de ocorrência do efeito fotoelétrico é dominante para fótons de baixa energia (mas suficiente para ionização) a até algumas dezenas de keV (Sauli, 2014), além disso, depende amplamente do número atômico do material absorvedor. Já o efeito Compton predomina na faixa dos fótons de energia intermediária. A produção de pares, por sua vez, apenas é possível quando o fóton possui energia igual ou maior a duas vezes a 
energia de repouso do elétron $(\sim 2 x \quad 0,511 \mathrm{MeV})$, tornando-se o fenômeno de interação predominante para fótons de alta energia (Stéphan, 1997).

No contexto da detecção dos fótons, esta se dá de forma indireta através da interação dos mesmos com o material que compõe o detector (Grupen \& Shwartz, 2008). Dessa maneira, é relevante ressaltar que a aplicação de gases como meio sensível do detector é bastante ineficaz para fótons de energia maior que algumas dezenas de keV. Isso se deve ao fato de que esses materiais se tornam gradualmente transparentes para a radiação conforme o aumento da energia dos fótons (Sauli, 2014).

Os fótons são partículas que possuem tanto massa de repouso quanto carga elétrica nulas e se deslocam à velocidade da luz (Tsoulfanidis, 1995). A energia dessas partículas é dada em função do seu comprimento de onda ou de sua frequência, pela expressão:

$$
E=h \cdot v=h \cdot \frac{c}{\lambda}
$$

onde $\boldsymbol{E}$ é a energia do fóton, $\boldsymbol{v}$ sua frequência, $\lambda$ seu comprimento de onda, $\mathbf{h}$ é a constante de Planck e $c$ é a velocidade da luz no vácuo (Grupen \& Shwartz, 2008).

\subsubsection{Absorção fotoelétrica}

A absorção fotoelétrica é um processo idêntico ao efeito fotoelétrico usualmente observado com fótons de luz incidindo na superfície de um metal, no qual há ejeção de elétrons da superfície do material (Delaney \& Finch, 1992). Contudo, no caso da absorção fotoelétrica, um fóton interage com as camadas mais internas do átomo de modo que sua energia é transferida para um elétron de uma dessas camadas (Delaney \& Finch, 1992; Price, 1964). Como consequência dessa transferência de energia, o elétron é ejetado do átomo com uma energia cinética $E_{c}$ dada pela seguinte expressão (Price, 1964):

$$
E_{C}=h \cdot v-E_{L}
$$

onde $E_{L}$ representa a energia de ligação do elétron.

Em decorrência do processo de absorção fotoelétrica, tem-se um átomo ionizado com uma lacuna em uma camada, que é preenchida pela captura de um elétron do meio 
(recombinação) ou rearranjo dos elétrons de outras camadas do próprio átomo (Knoll, 1979).

\subsubsection{Espalhamento Compton e Produção de Pares}

O efeito Compton é o espalhamento inelástico de fótons em elétrons nos átomos (Stéphan, 1997), sendo que esses elétrons atômicos se encontram em estado quase livres (fracamente ligados ao átomo) (Grupen \& Shwartz, 2008). Nesse efeito, o fóton incidente com energia $E_{0}$ é espalhado por um elétron fracamente ligado segundo um ângulo $\boldsymbol{\theta}$ com energia $\boldsymbol{E}_{1}$. $\mathrm{O}$ elétron recebe uma parte da energia do fóton e emerge com uma energia $\mathbf{E}_{\mathbf{0}}-$ $\mathbf{E}_{1}$ com um ângulo $\boldsymbol{\phi}$ (Figura 3.2) segundo as seguintes expressões (Sauli, 2014):

$$
\begin{gathered}
\frac{1}{E_{1}}-\frac{1}{E_{0}}=\frac{(1-\cos \theta)}{m c^{2}} \\
\cot \phi=\left(1+\frac{E_{0}}{m c^{2}}\right) \tan \frac{\theta}{2}
\end{gathered}
$$

onde $\mathbf{m c}^{2}$ é a energia de repouso do elétron $(0,511 \mathrm{MeV})$.

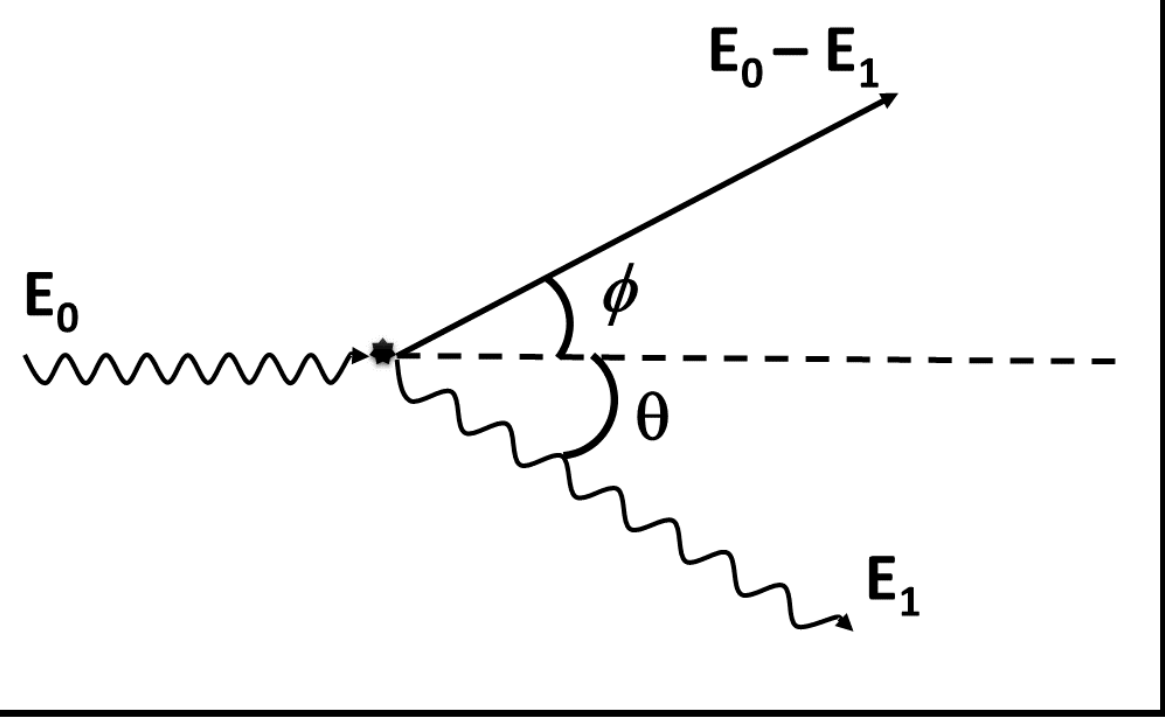

Figura 3.2: Esquema do espalhamento Compton, mostrando a definição dos ângulos e as respectivas energias do elétron e do fóton antes e após o espalhamento. Figura adaptada de Grupen \& Shwartz (Grupen \& Shwartz, 2008).

É interessante ressaltar que, com exceção de detectores muito espessos e densos, é bastante improvável que o fóton espalhado seja absorvido novamente no detector. Dessa 
maneira, a energia depositada depende do ângulo de espalhamento (geralmente desconhecido), de modo que não é possível alcançar uma resolução de energia na região de Compton (Sauli, 2014).

Como mencionado anteriormente, a produção de pares elétron-pósitron pode ocorrer por uma interação no campo nuclear em fótons cujas energias estão acima do limiar de 1,02 MeV (duas vezes a energia de repouso do elétron) (Sauli, 2014; Stéphan, 1997). Todavia, esse processo de interação torna-se mais provável para fótons de energia da ordem de vários MeV (Knoll, 1979).

No contexto dos detectores a gás, é importante ressaltar que, tanto no espalhamento Compton quanto na produção de pares, a probabilidade de interação geralmente é muito pequena. Todavia, esses efeitos podem ocorrer nas paredes do dispositivo ou em conversores devidamente adicionados (Sauli, 2014).

\subsubsection{Absorção de Fótons em Gases}

O fenômeno de absorção se inicia para fótons no ultravioleta distante, onde a sua energia excede o limiar para ocorrência de interações inelásticas com átomos ou moléculas do gás. Por outro lado, os gases são basicamente transparentes para fótons na região do visível e no ultravioleta próximo (Sauli, 2014).

Uma camada de um material de espessura $\boldsymbol{x}$ absorve um feixe monoenergético segunda a seguinte equação:

$$
I=I_{0} \cdot e^{-\mu \cdot x}
$$

onde $I_{0}$ é a intensidade inicial do feixe, $\boldsymbol{I}$ é a intensidade do feixe após atravessar a camada do material e $\boldsymbol{\mu}$ é o coeficiente de atenuação linear do absorvedor, que representa a probabilidade de interação por unidade de comprimento do material (Sauli, 2014).

Tendo em vista que o coeficiente de atenuação linear é dado em função de duas variáveis (densidade do material e energia do fóton), é interessante contornar essa situação através da normalização desse coeficiente pela densidade. Desse modo, tem-se o coeficiente de atenuação de massa $\left(\boldsymbol{\mu}_{m}\right)$, que depende apenas da energia do fóton (Knoll, 1979): 


$$
\mu_{m}=\frac{\mu}{\rho}
$$

onde $\boldsymbol{\rho}$ a densidade do material, dado em $\mathrm{g} / \mathrm{cm}^{3}$. O coeficiente de atenuação de massa é dado em $\mathrm{cm}^{2} / \mathrm{g}$.

Podemos reescrever a equação (3.5) em função do coeficiente $\boldsymbol{\mu}_{\boldsymbol{m}}$ e obtemos:

$$
I=I_{0} \cdot e^{-\mu_{m} \cdot \rho \cdot x}
$$

A absorção de raios $X$ é um processo quântico envolvendo uma ou mais transições nas camadas eletrônicas do átomo e ocorre somente nos casos onde a energia do fóton é maior que a energia de ligação das mesmas. A absorção atinge o máximo logo acima do nível da camada e diminui rapidamente com a energia (Sauli, 2014).

\section{$3.3 \quad$ Fonte de ${ }^{55} \mathrm{Fe}$}

Fontes de ${ }^{55} \mathrm{Fe}$ são bastante empregadas na calibração de diferentes tipos de detectores pelo fato de possuírem uma meia vida conveniente e alta atividade disponível, além de possuírem baixo bremsstrahlung interno associado com o processo de captura eletrônica (Knoll, 1979; Schötzig, 2000). A radiação de fundo devido ao bremsstrahlung interno tem uma intensidade relativa de $3,24(6) \times 10^{-5}$ em relação à captura eletrônica de $\mathrm{K}$ e produz um espectro contínuo até 231,21 keV (Bé \& Chisté, 2006).

$\mathrm{O}$ átomo de ${ }^{55} \mathrm{Fe}$ desintegra-se quase que exclusivamente por decaimento via captura eletrônica ${ }^{3}$, no qual o núcleo captura um elétron de uma de suas camadas eletrônicas, deixando uma vacância. Desse modo, surge um átomo de manganês em um estado excitado que, ao retornar ao estado fundamental, emite um fóton característico desse material. Os valores de energia das principais linhas de emissão do $\mathrm{Mn}$ e suas respectivas intensidades relativas são mostrados na Tabela 3.1. Uma representação dos níveis de energia é apresentada na Figura 3.3.

\footnotetext{
${ }^{3}$ Foi relatado na literatura por Žlimen e colaboradores (Žlimen et al., 1992) o surgimento de uma linha fraca atribuída a uma transição gama a 126,0 keV sobreposta ao bremsstrahlung interno. A probabilidade de emissão dessa linha é baixa, sendo estimada em 1,3(1) x $10^{-7} \%$ (Schötzig, 2000; Žlimen et al., 1992).
} 




Figura 3.3: Transições que dão origem às linhas de emissão mostradas na Tabela 3.1. Figura adaptada da base de dados XDB (X-RAY DATA BOOKLET) (Thompson et al., 2009).

Tabela 3.1: Energias dos fótons e intensidades relativas das principais linhas de emissão das camadas $K$ e $L$ do Manganês, ordenadas pelo aumento de energia. Os raios X provenientes das emissões a partir da camada L (cerca de 0,6 keV), geralmente não podem ser medidos e assim não aparecem em um espectro usual da fonte de ${ }^{55} \mathrm{Fe}$ (Schötzig, 2000). Uma intensidade relativa de 100 é atribuída à linha mais intensa em cada camada. Adaptado da base de dados XDB (X-RAY DATA BOOKLET) (Thompson et al., 2009).

\begin{tabular}{|c|c|c|}
\hline Energia (eV) & Linha & Intensidade Relativa \\
\hline 637,4 & $\mathrm{~L} \alpha_{1,2}$ & 111 \\
\hline 648,8 & $\mathrm{~L} \beta_{1}$ & 77 \\
\hline 5887,65 & $\mathrm{~K} \alpha_{2}$ & 50 \\
\hline 5898,75 & $\mathrm{~K} \alpha_{1}$ & 100 \\
\hline 6490,45 & $\mathrm{~K} \beta_{1}$ & 17 \\
\hline
\end{tabular}

A reação nuclear de captura eletrônica pode ser descrita pela equação (3.8), na qual pode-se observar que a excitação apresenta a característica peculiar de que nenhuma outra 
radiação é emitida na reação (exceto um neutrino), o que acaba sendo uma vantagem para a detecção (Delaney \& Finch, 1992).

$$
{ }_{26}^{55} \mathrm{Fe}+\mathrm{e}^{-} \rightarrow{ }_{25}^{55} \mathrm{Mn}+\mathrm{v}_{\mathrm{e}}
$$

onde $\boldsymbol{v}_{\boldsymbol{e}}$ representa o neutrino emitido no processo de decaimento por captura eletrônica. Após esse fenômeno, ocorre o retorno do átomo de $\mathrm{Mn}$ ao estado fundamental com a respectiva emissão de um fóton.

Apresenta-se na Figura 3.4 o esquema de decaimento da fonte radioativa de ${ }^{55} \mathrm{Fe}$, cuja meia-vida é de 2,73 anos (Grupen \& Shwartz, 2008).

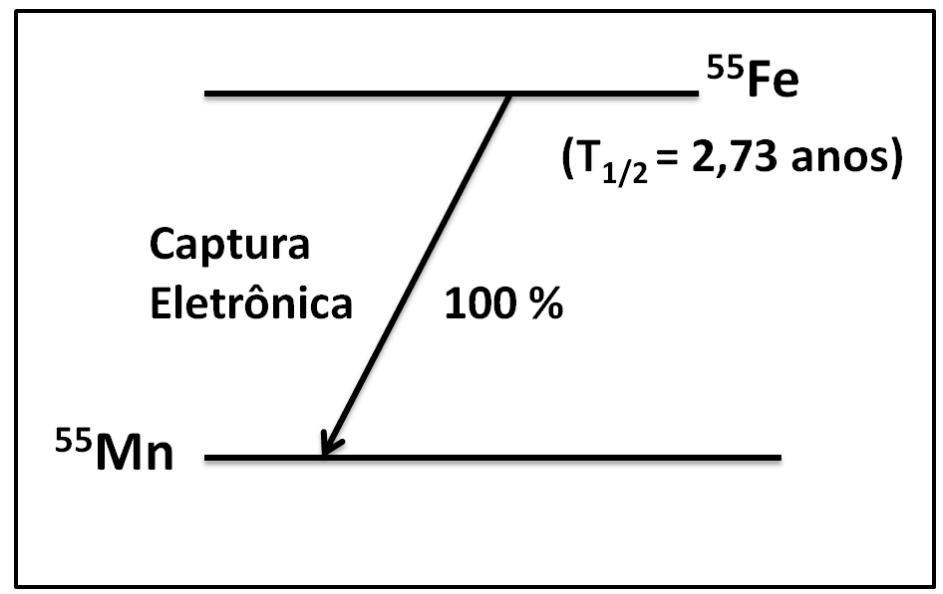

Figura 3.4: Diagrama de decaimento do ${ }^{55} \mathrm{Fe}$ no qual o núcleo do átomo de ferro captura um elétron da camada K produzindo manganês em um estado excitado. Quando retorna ao estado fundamental, emite um fóton característico seguindo as probabilidades relativas indicadas na Tabela 3.1. Figura adaptada de Grupen \& Shwartz (Grupen \& Shwartz, 2008). 


\section{Simulações Parte I: Aspectos Gerais}

Nesse capítulo são apresentados os aspectos mais gerais das simulações do GEM desenvolvidas nesse trabalho, como a motivação e a metodologia. Além disso, destaca-se a utilização dos softwares livres, com suas vantagens e desvantagens. São apresentados também os programas utilizados e alguns aspectos teóricos ligados ao método dos elementos finitos, além da modelagem do detector e do desenvolvimento de uma ferramenta que automatiza a simulação de um detector triplo GEM.

\subsection{Motivação e Metodologia}

As simulações computacionais através de modelagens de sistemas físicos reais são aplicadas normalmente para fazer previsões, indicar melhorias no arranjo experimental, ou ainda propor novos designs. Entre suas principais vantagens em relação aos testes reais no laboratório, estão a economia de tempo e principalmente de recursos. Isso porque para criar um novo projeto de um determinado arranjo é preciso despender recursos na compra de materiais, muitas vezes sem ter uma noção se esse novo conceito terá o desempenho esperado. Essa ferramenta é muito utilizada e amplamente abordada na literatura devido seu potencial e aplicabilidade em diversas áreas de pesquisa (Betts, 1996; Blum, Riegler, \& Rolandi, 2008; Filliatre, Jammes, Geslot, \& Veenhof, 2012; C. A. B. Oliveira, 2011; Ryne, 1993; Veenhof, 1998).

A abordagem por meio de simulações em se tratando de detectores de partículas é normalmente aplicada ao estudo de características de difícil observação, como por exemplo, estudo de seções de choque, a absorção de fótons no gás (Biagi, 1995; Henke, Gullikson, \& Davis, 1993), o efeito avalanche (Alkaa, Mitev, \& Segur, 2007; Azevedo et al., 2016; Purba Bhattacharya, Mohanty, Mukhopadhyay, Majumdar, \& Luz, 2017; Date et al., 2000; Matoba, Hirose, Sakae, \& Kametani, 1985), entre outras. Além dessas propriedades, há outras que são recorrentes e servem tanto para a comparação com dados experimentais quanto no estudo e proposição de novos dispositivos. Entre elas, podemos apontar o ganho de gás (Azevedo et al., 2016; Burns et al., 2017; Correia et al., 2018; Ogawa \& Aoki, 2017; Supriya, 2016), movimento retrógrado de íons (Purba Bhattacharya et al., 2017; Hallermann, 2010; Wang et al., 2019), espectro de energia de raios X (Malinowski et al., 2018), resolução espacial (Kudryavtsev, Maltsev, \& Shekhtman, 2019), dentre outras. 
No presente trabalho, estamos interessados em determinar os parâmetros ótimos para o GEM (maximização do ganho, minimização do movimento retrógrado de íons, etc.), visando o projeto para a construção de um novo detector a gás baseado na tecnologia GEM. Um detector que possua ganho de gás otimizado é capaz operar com menor diferença de potencial, a fim de diminuir a probabilidade de descargas, mantendo o mesmo valor de ganho, por exemplo. Já um dispositivo com menor índice do movimento retrógrado de íons, pode operar satisfatoriamente em experimentos com maiores taxas de contagem.

Entre as possibilidades de métodos numéricos empregados no cálculo do potencial e do campo elétrico em detectores a gás estão os métodos analíticos, de elementos finitos e de elementos de contorno. O primeiro é adequado para estruturas bidimensionais, é rápido e preciso (quando aplicável). O segundo é bastante versátil, aplicável tanto para estruturas bidimensionais quanto tridimensionais, condutores ou dielétricos, mas menos preciso para o campo elétrico. Já o último é tão versátil quanto o método de elementos finitos, incorporando uma nova formulação onde ocorrem algumas falhas no método original (Veenhof, 2009).

Os métodos analíticos são aplicáveis para detectores formados por estruturas bidimensionais de fios e planos equipotenciais e periódicos, como o MWPC, tubos, câmaras de deriva, etc. O método dos elementos finitos é capaz de lidar com as propriedades eletrostáticas de detectores baseados no padrão microscópico como MSGC, Micromegas e GEM, que combinam eletrodos e dielétricos de geometrias complexas e, portanto, são menos acessíveis à solução por métodos analíticos. O uso do método dos elementos finitos tornou-se comum no mundo da engenharia, enquanto os programas que realizam tais cálculos têm um valor comercial considerável e apenas alguns são de código aberto. 0 método dos elementos de contorno discretiza as fronteiras e não o domínio do problema, como o método dos elementos finitos. As cargas são colocadas em elementos fora do domínio do problema, de modo a reproduzir as condições de contorno. Este método, portanto, não sofre de descontinuidades de elementos. O campo é calculado usando as funções de Green que são soluções das equações de Maxwell (Veenhof, 2009).

No presente trabalho, foram realizadas simulações de detectores GEM com três estágios (triplo GEM) utilizando o programa Garfield++ (Schindler et al., 2015) e outros programas, como o Elmer (http://www.csc.fi/elmer), o Gmsh (Geuzaine \& Remacle, 2009) e 
o ParaView (Ahrens et al., 2019). Um aspecto interessante nesse trabalho é o fato de ser baseado em softwares de livre acesso, o que difere de boa parcela dos trabalhos nessa área, que optam por utilizar softwares proprietários, como o Ansys (Burns et al., 2017; Correia et al., 2018; Karadzhinova et al., 2015; Kudryavtsev et al., 2019; Maghrbi, Bouhali, \& leee, 2013; Supriya, 2016; Wang et al., 2019) ou outra solução similar (Shohani et al., 2016). Uma possível explicação para isso pode estar relacionada a problemas na interface entre o Elmer e o Garfield++, passando por escolhas pessoais ou mesmo a problemas intrínsecos aos softwares livres, cujos suportes para sanar dúvidas e resolver problemas nem sempre são os mesmos que no caso das soluções do tipo software proprietário. Mais detalhes sobre os prós e contras dos programas de livre acesso serão dados na seção 4.2.

Uma visão geral das simulações realizadas é apresentada no diagrama da Figura 4.1. Pode-se observar a sequência de etapas entre cada um dos programas utilizados, bem como as escolhas que devem ser tomadas pelo usuário em cada estágio da simulação, assim como os resultados obtidos em cada respectiva etapa.

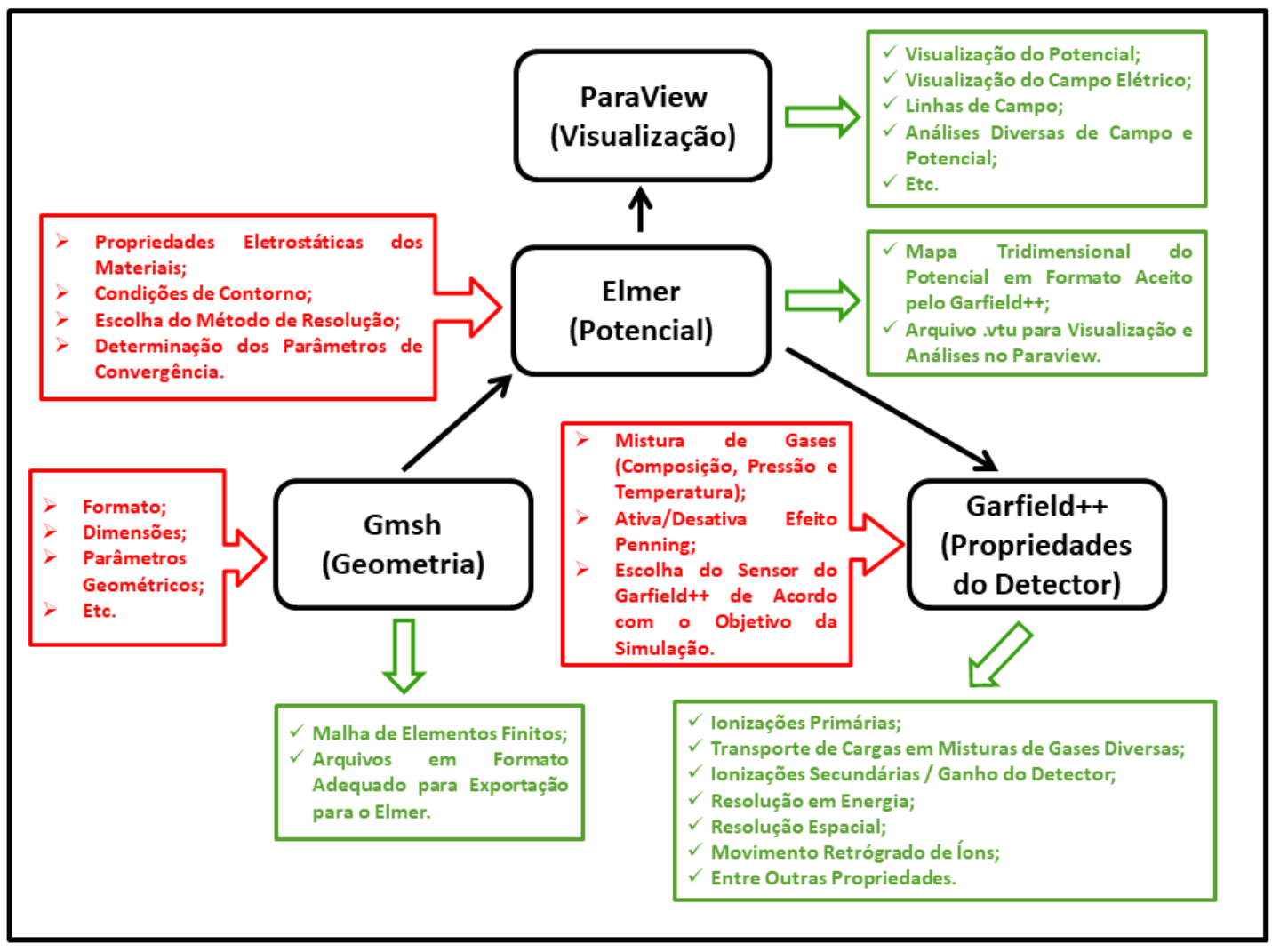

Figura 4.1: Diagrama representativo das etapas necessárias para se construir as simulações do detector baseadas em softwares de licença livre. Os elementos na cor preta representam os passos entre os diferentes softwares, aqueles na cor vermelha indicam ações e/ou escolhas que devem ser tomadas pelo usuário, enquanto aqueles de cor verde indicam os resultados obtidos na respectiva etapa da simulação. 
Para que as simulações do triplo GEM representassem o mais fielmente possível os dispositivos reais, procurou-se definir da melhor maneira possível um detector real, incluindo características dos materiais que compõem o dispositivo, configuração de potenciais e campos elétricos, parâmetros geométricos, etc. Além disso, foi necessário fazer uma validação dos resultados simulados comparando-os com experimentos. Podemos dizer que, de um modo geral, não é suficiente apenas comparar as simulações com dados da literatura, pois muitas vezes os artigos e teses não comunicam em detalhes todas as variáveis necessárias de entrada para as simulações, o que dificulta consideravelmente uma comparação fidedigna. Isso é especialmente importante no que se refere à curva de ganho, pois essa grandeza é especialmente sensível à configuração do potencial em cada eletrodo do detector, precisando ser ajustada em total acordo com aquela aplicada experimentalmente.

Foi utilizado como referência para validação um triplo GEM de furos bicônicos, pertencente ao Grupo de Desenvolvimento de Detectores do CERN (Ropelewski, 2011b). A caracterização desse dispositivo, incluindo a curva de ganho de gás, e outras características já foram descritas anteriormente (Sales, 2015). No presente trabalho, será feito uso dessas informações e do fato de possuirmos todos os parâmetros de entrada para a simulação. Poderia ser utilizado também o GEM apresentado na seção 7.2, mas este detector possui características distintas de um triplo GEM padrão, com mudanças no espaçamento dos furos e método de coleta dos sinais, de modo que será utilizado como complemento do presente estudo, mas não como referência para validação.

Os parâmetros geométricos necessários para entrada nas simulações do triplo GEM de referência de geometria bicônica são apresentados na Figura 4.2. Destaca-se que os três GEM's possuem os mesmos parâmetros geométricos (diferentemente do detector mostrado na seção 7.2). 


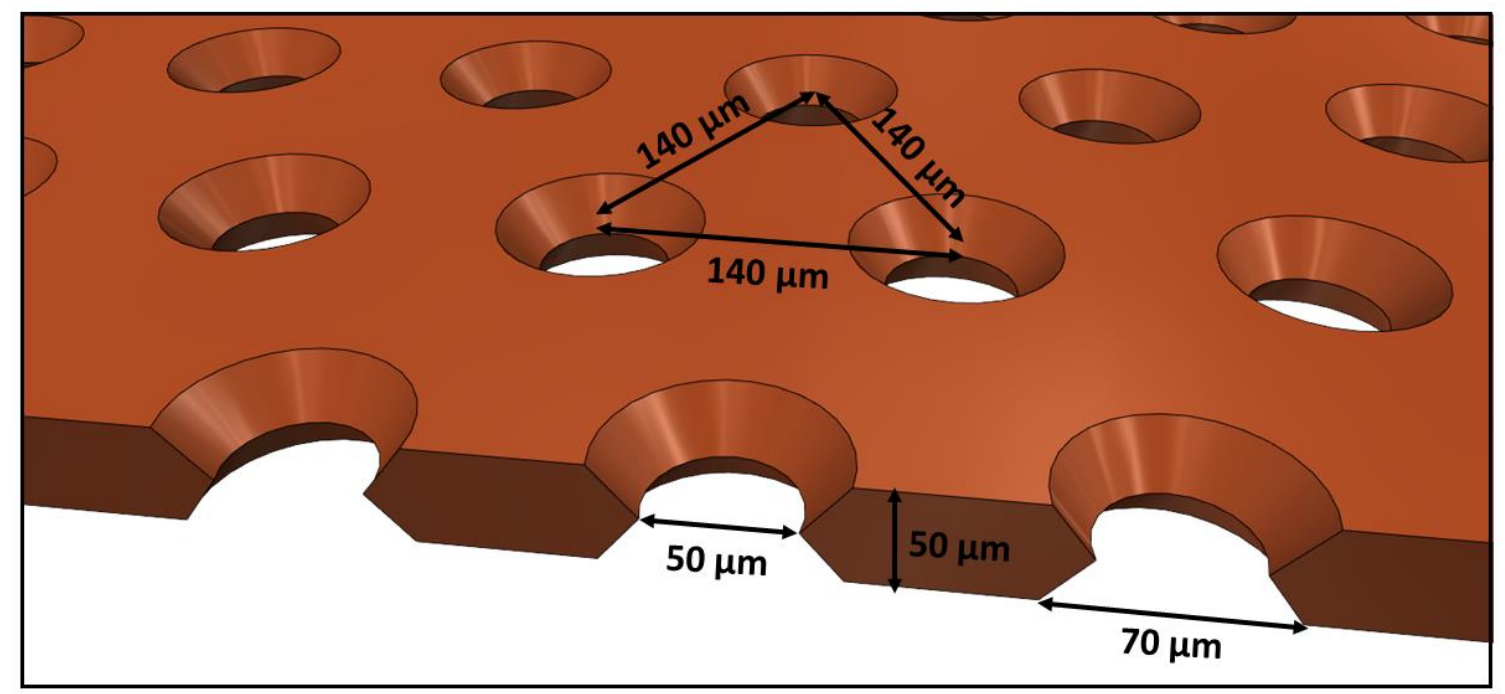

Figura 4.2: Parâmetros geométricos do GEM de referência (bicônico), incluindo o diâmetro externo (superfície da folha de Kapton), diâmetro interno (centro da folha), espaçamento entre os furos e espessura da folha. A espessura da camada de cobre em cada superfície é de $5 \mu \mathrm{m}$ (não mostrado na figura).

Os parâmetros geométricos do GEM de geometria cônica, cujos resultados serão apresentados no Capítulo 6, são mostrados na Figura 4.3.

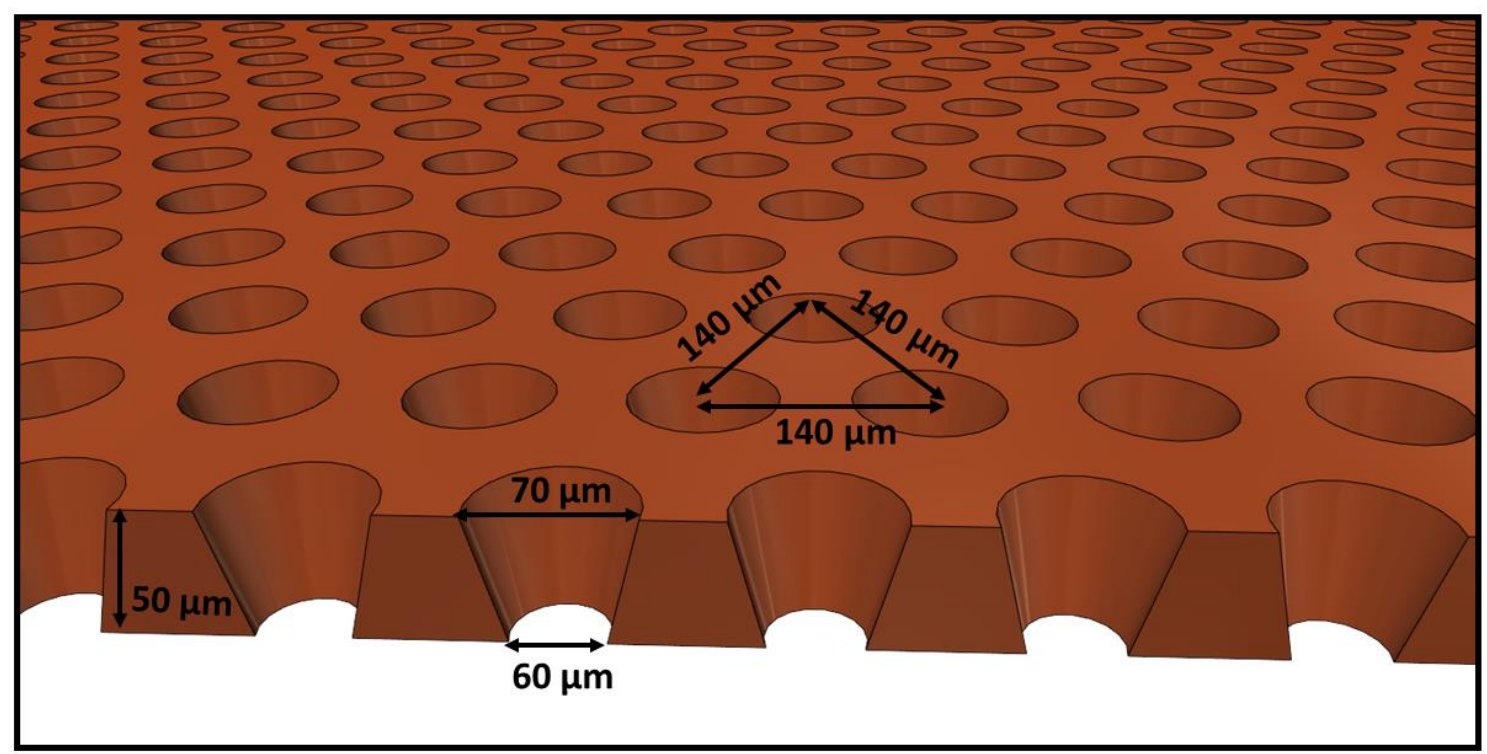

Figura 4.3: Parâmetros geométricos do GEM cônico, incluindo o diâmetro superior e diâmetro inferior, espaçamento entre os furos e espessura da folha. A espessura da camada de cobre em cada superfície é de 5 $\mu \mathrm{m}$ (não mostrado na figura).

O esquema dos resistores utilizados no circuito para aplicação da alta tensão em todos dos eletrodos, assim como a identificação dos mesmos e a indicação das distâncias 
entre eles, são mostrados na Figura 4.4. Já os valores dos respectivos resistores são apresentados na Tabela 4.1.

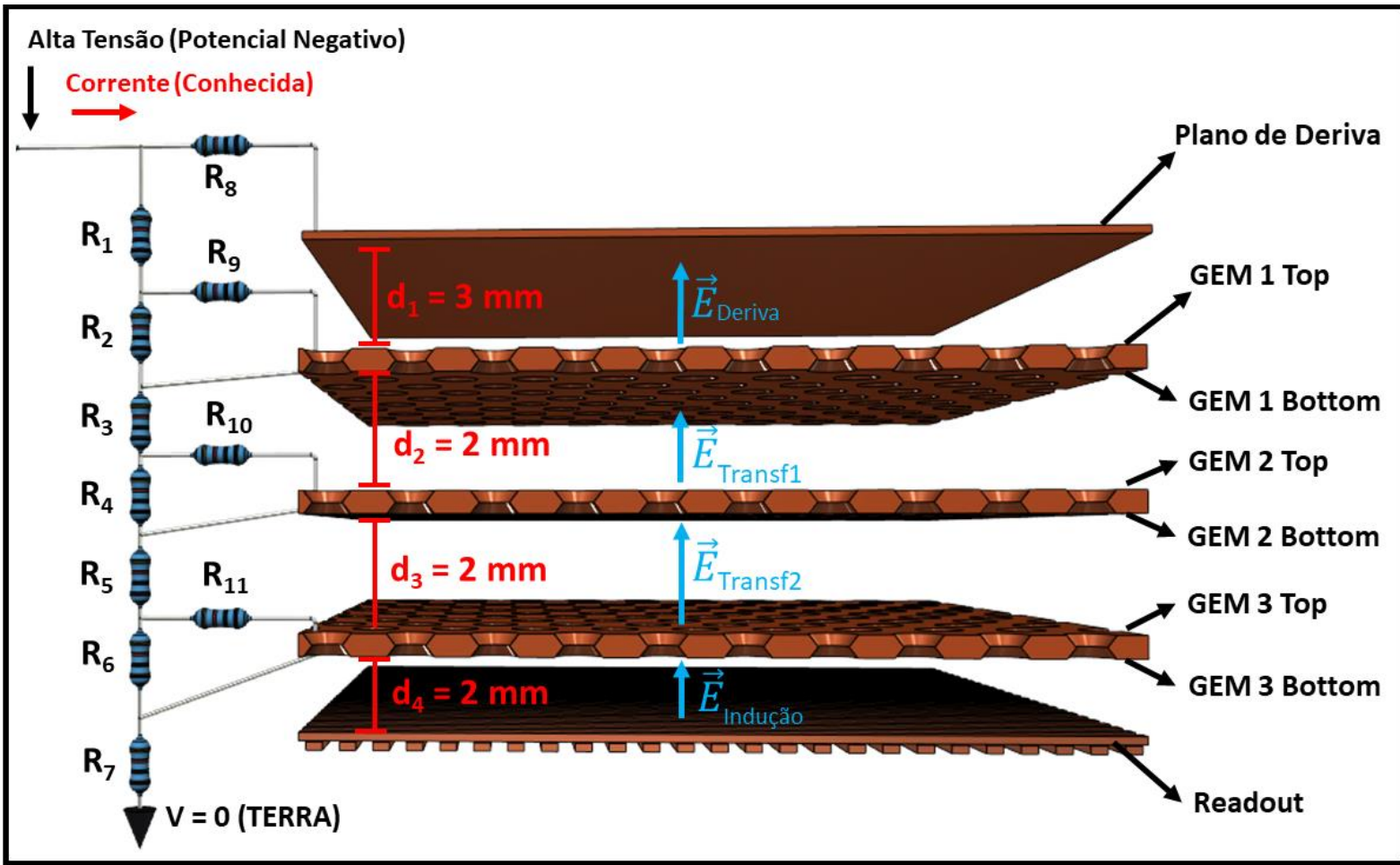

Figura 4.4: Triplo GEM de referência para validar as simulações, destacando a configuração dos resistores para a distribuição do potencial ao longo dos eletrodos. São identificados os oito eletrodos que compõem o sistema, além das distâncias entre os mesmos. São mostrados ainda os campos elétricos entre os eletrodos, calculados considerando que cada conjunto de dois eletrodos se comporta como um capacitor de placas paralelas.

Tabela 4.1: Valores dos resistores apresentados na Figura 4.4. A partir dessa configuração, foi possível calcular o valor do potencial em cada eletrodo do triplo GEM aplicando a lei de Ohm.

\begin{tabular}{|c|c|}
\hline \multicolumn{2}{|c|}{ Resistores } \\
\hline Rn & Resistência (k $\boldsymbol{\Omega})$ \\
\hline R1 & 998,0 \\
\hline R2 & 543,0 \\
\hline R3 & 999,5 \\
\hline R4 & 496,0 \\
\hline R5 & 983,0 \\
\hline R6 & 445,0 \\
\hline R7 & 986,0 \\
\hline R8 & 98,9 \\
\hline R9 & 99,2 \\
\hline R10 & 99,5 \\
\hline R11 & 103,0 \\
\hline
\end{tabular}


A partir desses valores de resistência e, aplicando a lei de Ohm, foi calculado o valor do potencial em cada um dos oito eletrodos. Isso foi possível porque o valor da corrente que flui da fonte de alta tensão até o aterramento era conhecido. Além disso, utilizando as distâncias entre os eletrodos $(d)$, foi possível estimar o valor do campo elétrico uniforme na região entre os mesmos. Para tanto, foi considerado que na região entre eletrodos (mas não muito próximo à superfície da folha de Kapton) o campo elétrico é aproximado pelo campo de um capacitor de placas paralelas, que é dado por:

$$
|\vec{E}|=\frac{\Delta V}{d}
$$

onde $\Delta V$ é a diferença de potencial aplicada entre os eletrodos.

\subsection{Software Livre: Vantagens e Desvantagens}

Em uma primeira abordagem, pode-se defender o emprego dos programas livres justamente pelo fato de não demandarem pagamento de licenças ${ }^{4}$, geralmente onerosas, para sua utilização (características de programas do tipo proprietário). No entanto, os benefícios de sua utilização em relação aos do tipo proprietário não se limitam a esse aspecto, pois esses programas possibilitam o acesso ao código fonte do mesmo (Ven, Verelst, \& Mannaert, 2008). Desse modo, é possível estudar o funcionamento do programa, sem precisar simplesmente confiar no produto oferecido pelos desenvolvedores. Além disso, são programas cujas licenças permitem aos usuários a liberdade de executar o programa para qualquer finalidade, além de poder investigar e realizar modificações no código fonte e redistribuir livremente cópias do programa original ou modificado (Wheeler, 2015).

Cabe apontar aqui uma interessante colocação e muito bem apresentada por Hippel (Hippel, 2001) no qual diz: "se você quer algo bem feito, faça você mesmo". Com esse ditado, ele defende a ideia de que por um lado os fabricantes de softwares proprietários não

\footnotetext{
${ }^{4}$ Não é correto afirmar que todo software livre é gratuito. No artigo de Đurković et al. (Đurković, Vuković, \& Raković, 2008) os autores argumentam que deve-se pensar em software livre ("free software") como sinônimo de liberdade ("freedom") para executar, estudar, modificar, aprimorar e redistribuir. Essa filosofia é baseada no conceito de software livre desenvolvido pelo ativista Richard M. Stallman, fundador do projeto GNU, e da FSF (Fundação para o Software Livre) (Lessig \& Stallman, 2004). Nesse trabalho, estamos assumindo que eles são gratuitos e de livre acesso ao código fonte, pois assim são todos os programas que foram utilizados nas simulações aqui apresentadas.
} 
sabem exatamente o que os usuários necessitam tão bem quanto eles mesmos; por outro lado, mesmo que saibam, possivelmente lhes falte o incentivo (por questões comerciais) de corresponder aos seus anseios em todos os detalhes e, assim, possam vender seus produtos para o maior número de usuários possível (Hippel, 2001).

Outra característica interessante a ser apontada são as interações que se dão nas comunidades de usuários de softwares livres. Nesses ambientes, todos podem usar o programa e realizar testes. Isso contribui de maneira eficiente para a minimização de falhas: uma vez que um número considerável de usuários o utiliza, há maior possibilidade de descobrir defeitos e facilidade no conserto dos mesmos, além de poderem sugerir novos recursos para o programa (Đurković et al., 2008). No entanto, para que isso se dê de forma eficiente, é importante que o código seja legível e auto descritivo, permitindo assim modificações e extensões frequentes (Stamelos, Angelis, Oikonomou, \& Bleris, 2002). Como resultado, são realizadas e compartilhadas modificações incorporando melhorias no código, que pode ser baixado gratuitamente, o que irá contribuir para a expansão do mesmo (Hippel, 2001).

Por outro lado, o controle sobre a qualidade dos programas livres depende basicamente do retorno através dos comentários da comunidade que o utiliza, que por vezes são incapazes de identificar falhas na arquitetura do código. Isso se torna notável nos casos de falhas que não aparecem com muita frequência e que não podem ser facilmente identificadas no processo de teste de código (Đurković et al., 2008).

Podemos destacar também que normalmente os projetos de programas livres, apesar de se esforçarem para escrever uma documentação adequada, acabam muitas vezes pecando nesse aspecto. Pode ocorrer assim que partes dos conhecimentos permaneçam ocultas e não seja devidamente documentado, o que pode levar tempo desnecessário para o aprendizado, ou até mesmo desencorajar a utilização do software (Đurković et al., 2008).

\subsection{Desenvolvimento de um Código para Automatização das Simulações}

Levando em consideração que os softwares livres nem sempre são muito amigáveis para os usuários, especialmente para aqueles que estão iniciando no ramo das simulações, foi pensado em uma maneira de facilitar os trabalhos com Garfield++, Gmsh e Elmer. A 
solução encontrada foi produzir um código que configure de maneira automatizada todos os parâmetros de entrada, prepare os arquivos necessários para utilização e organize os resultados obtidos de modo a facilitar o uso desses três programas. Desse modo, a ferramenta desenvolvida permite um fluxo facilitado entre os diferentes programas, fazendo com que não seja necessário que o usuário configure todos os arquivos de entrada manualmente, o que poderia demandar bastante tempo ou mesmo desencorajar o uso dos softwares livres.

Antes de entrar em detalhes sobre o funcionamento dessa solução, vamos destacar como funciona a utilização dos três softwares citados acima. O primeiro passo das simulações é criar a geometria do detector, que é realizada por meio de comandos com instruções detalhadas (seção 4.5) que podem ser colocados em um arquivo cuja sintaxe possa ser interpretada pelo sistema, como Perl (https://www.perl.org/), por exemplo. Uma maneira prática de fazer isso é parametrizando as coordenadas dos pontos através do diâmetro dos furos, espessura do Kapton e da camada de cobre, espaçamento entre os furos, distância entre as folhas de GEM, entre outros. Contudo, caso se deseje fazer mudanças na geometria, ainda que pequenas, é preciso fazer ajustes no código, como a redefinição das superfícies e volumes, por exemplo. É necessário também configurar uma série de arquivos para exportar a geometria (malha de elementos finitos) criada em um formato adequado para utilização no Elmer.

Na sequência, é preciso preparar um arquivo para o Elmer com a indicação das propriedades dielétricas de cada material que compõe o detector, além da correspondência de cada volume com o respectivo material. Em seguida, é obrigatório definir as condições de contorno para o problema, isto é, os valores de potencial em cada um dos eletrodos do detector e o valor do campo elétrico uniforme entre os eletrodos. Também é preciso selecionar uma série de operações que serão efetuadas aplicando o método dos elementos finitos, como a escolha do tipo de método para resolução do problema, indicação de regras de convergência, o número máximo de iterações, configurações do pré-condicionador, inserção de constantes físicas relevantes para o problema, entre outros. Esse arquivo também deve conter instruções sobre como exportar o potencial em um formato adequado para o Garfield++, além do formato como os resultados serão exportados para visualização e análise no Paraview (ou outro software de visualização dos resultados). 
Na parte posterior da simulação, deve-se criar um arquivo importando o mapa do potencial calculado na etapa anterior, definição de algumas condições como a mistura do gás que preencherá o detector, a pressão e a temperatura da mesma, inclusão (ou não) do efeito Penning, etc. Depois, deve-se escrever o respectivo código que irá simular os fenômenos que caracterizam o detector, chamando as respectivas funções para a deriva de elétrons e íons, criação da avalanche eletrônica, deposição de energia por partículas no gás, etc. Por fim, deve-se proceder com a configuração dos histogramas ou variáveis que serão utilizadas para análise do funcionamento do dispositivo, como ganho de gás, movimento retrógrado de íons, eficiência de coleta e extração de elétrons, resolução em energia e espacial, etc. Esse último arquivo deve ser compilado em uma linguagem de programação $(\boldsymbol{C}+\boldsymbol{+}$, por exemplo), dando origem a um arquivo que tanto pode ser executado localmente quanto em um cluster, quando disponível.

Parte dos requisitos citados até aqui são supridos em exemplos encontrados na página do Garfield++. Existe um valioso exemplo consistindo na aplicação dos softwares livres em uma simulação de uma avalanche eletrônica e visualização de potencial elétrico em um detector Thick-Gem (Renner, 2015). Contudo, esse exemplo não é suficiente para simular um detector do tipo GEM. Em primeiro lugar, porque para definir a conicidade do orifício do GEM (que não existe no Thick-GEM) é preciso modificar o arquivo de geometria, adicionar pontos, linhas, superfícies e adicionar essas estruturas nos volumes, o que requer certa familiaridade com o Gmsh. Em segundo lugar, para simular o triplo GEM (três estágios de amplificação) é preciso configurar o arquivo de geometria tal que as folhas sejam replicadas e o respectivo volume do gás seja redefinido, além das configurações dos potenciais necessitarem de uma nova organização. Além disso, esse exemplo faz uso de uma interface do próprio Garfield++ para visualização do potencial e do campo elétrico. Essa ferramenta ainda não alcançou um nível comparável ao Paraview, tanto no que se refere à visualização quanto para análises e exportação dos resultados dessas duas grandezas (seção 5.2).

Para utilizar o Paraview, é preciso realizar algumas alterações nos arquivos para exportação dos resultados para esse programa. E, por fim, caso se deseje modificar o tipo de geometria, como escolher entre o GEM bicônico (Capítulo 5) e o GEM de conicidade simples (Capítulo 6), será preciso modificar consideravelmente o arquivo de geometria. 
O código de automatização das simulações proposto no presente trabalho consiste de um conjunto de arquivos que suprem integralmente as necessidades que foram citadas anteriormente. Esses arquivos tratam-se de executáveis em $\boldsymbol{C}+\boldsymbol{+}$ e $\boldsymbol{P e r l}$ onde o usuário pode interagir com o programa através de escolhas feitas no terminal de comandos do Linux, que alteram o fluxo de execução, como mostrado no diagrama de blocos da Figura 4.5. As escolhas são guiadas por diálogos e observações, que aparecem na tela e tornam a utilização dessa ferramenta mais amigável. No início do processo, o usuário é questionado sobre que tipo de GEM será simulado (bicônico ou cônico), ou se deseja carregar uma solução de potencial e campo pré-existente.

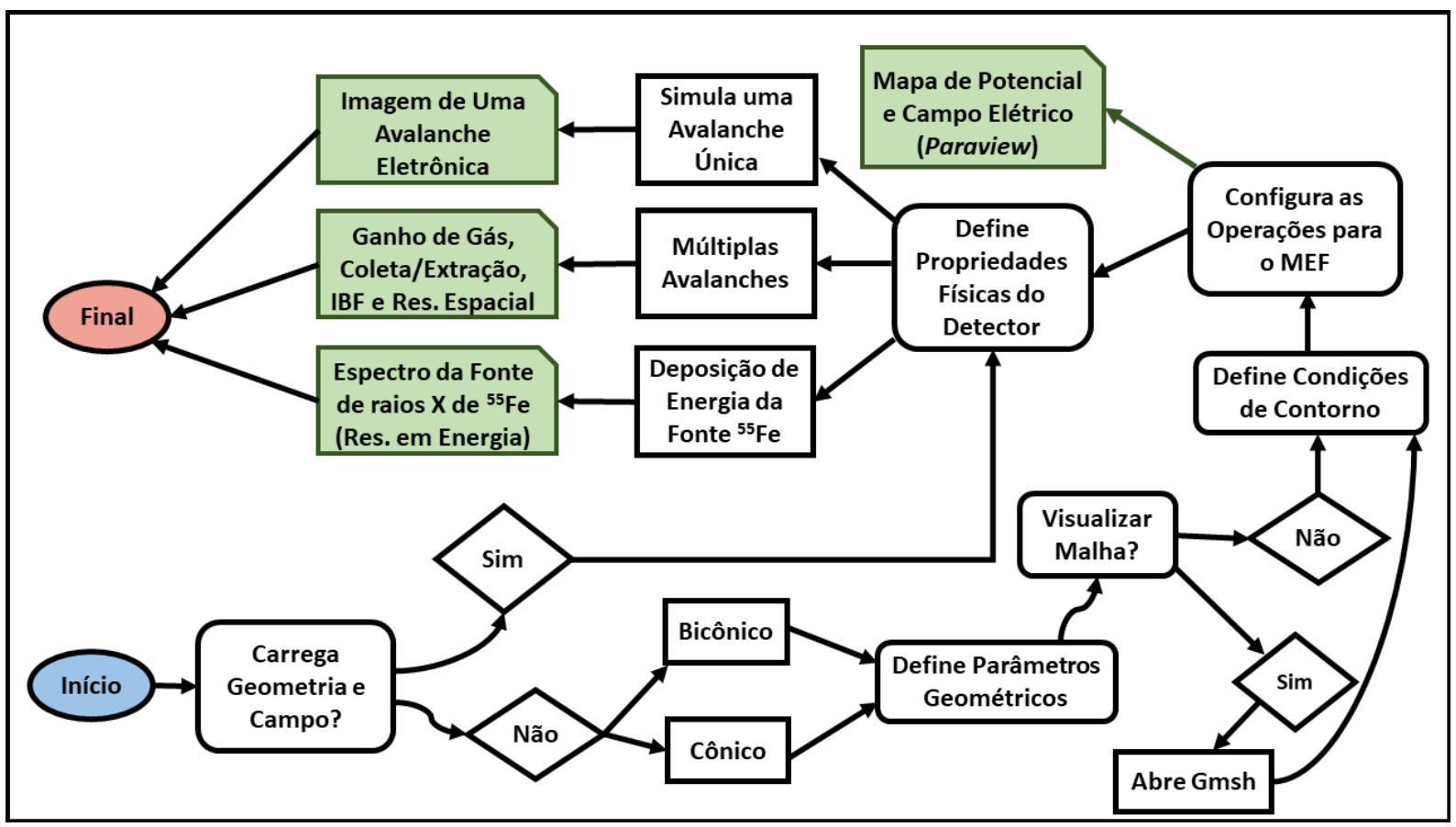

Figura 4.5: Diagrama de blocos mostrando o esquema de funcionamento do código desenvolvido para automatizar as simulações de um detector triplo GEM de furos cônicos ou bicônicos. Em cada etapa onde o usuário precisa entrar com parâmetros, é mostrado na tela o resumo dos valores digitados, onde é possível retroceder e realizar os ajustes (caso necessário).

Após essa etapa, caso selecione criar uma nova geometria, é solicitado que o usuário digite cada um dos parâmetros geométricos que irão criar a malha de elementos finitos, bem como a resolução da mesma nas proximidades de cada parâmetro. São sugeridos a cada etapa valores default baseados em uma configuração típica de um GEM como referência. Isso tem o objetivo de auxiliar o usuário na escolha dos novos parâmetros. A opção de 
carregar uma solução pré-existente é interessante pelo fato de economizar tempo na hipótese de realizar simulações diferentes para uma mesma geometria.

Na sequência, há a opção de visualizar a malha de elementos finitos recém criada ou simplesmente seguir adiante. Na etapa seguinte, é solicitada a indicação das condições de contorno, seguido dos ajustes das operações para resolução do problema. Então, a seguir devem ser definidos os parâmetros físicos do detector (mistura de gases, pressão, temperatura, etc.), cujos valores típicos também são sugeridos. Depois, deve-se selecionar qual tipo de estudo será realizado: visualização do efeito avalanche (Figura 5.17), ganho do detector, deposição de energia da radiação no gás, etc.

Para utilizar a ferramenta apresentada, é necessário ter instalado no computador um compilador $\mathbf{C + +}$, Perl e todos os programas citados acima, isto é, Gmsh, Elmer, Paraview, Garfield++ e Root. Como foi citado anteriormente, essa ferramenta é executada via linha de comando. Um exemplo com um trecho da aplicação pode ser observado na Figura 4.6, já a utilização com mais detalhes é mostrada no Apêndice C.



Figura 4.6: Tela mostrando o funcionamento da ferramenta para automatização das simulações com o triplo GEM. Pode-se observar o diálogo com o usuário, com sugestão de parâmetros e dicas que visam facilitar sua utilização. 


\subsection{O método dos Elementos Finitos}

As ideias por trás do Método dos Elementos Finitos (MEF) têm suas origens no início do século XX, sendo o cenário atual de aplicabilidade alcançado a partir da década de 1970, quando recebeu considerável atenção de cientistas e pesquisadores de todo o mundo após os últimos avanços tecnológicos e a revolução dos computadores (Polycarpou, 2006; Veenhof, 2009). Os programas que executam os cálculos através do MEF possuem valor comercial considerável, sendo poucos de código aberto (Veenhof, 2009). O MEF é um procedimento para solução numérica de problemas caracterizados por um sistema de equações diferenciais submetidas a um conjunto de restrições adicionais (condições de contorno) (Polycarpou, 2006).

A proposta do método dos elementos finitos é a divisão do domínio geométrico de um problema (contínuo) em subdomínios menores (discretos). Essas subunidades recebem o nome de elementos finitos (o que dá nome ao próprio método em si) e podem ser encarados como pequenos pedaços de uma estrutura (Cook, Witt, Malkus, \& Plesha, 2002; Polycarpou, 2006). Os elementos são conectados entre si por pontos denominados "nós" e ao conjunto de elementos e nós dá-se o nome de malha.

Uma vez que muitos fenômenos podem ser expressos em termos de equações diferenciais que governam o problema e condições de contorno, o MEF visa expressar tais equações diferenciais, juntamente com as condições de contorno associadas, como um conjunto de equações lineares que possam ser resolvidas computacionalmente usando técnicas de álgebra linear (Polycarpou, 2006; Weck \& Kim, 2005).

As equações que governam o problema podem ser expressas como (Weck \& Kim, 2005):

$$
[\mathrm{K}] u=F
$$

onde [K] é uma matriz que representa as propriedades do problema, $\boldsymbol{u}$ é o comportamento do sistema em estudo (incógnita do problema) e $\boldsymbol{F}$ trata-se da ação, isto é, o conjunto de forças ao qual o sistema está submetido.

Assumindo que a matriz de propriedades do sistema possui uma matriz inversa e aplicando as condições de contorno, tem-se: 


$$
u=[\mathrm{K}]^{-1} F
$$

Alguns exemplos da aplicação dos termos presentes na equação (4.3) podem ser observados na Tabela 4.2. Em todos os exemplos são conhecidas as forças que agem sobre o problema e a(s) propriedade(s) do sistema, desejando-se obter um determinado comportamento do mesmo. No caso das simulações do detector no presente trabalho (problema eletrostático), a carga nos eletrodos é conhecida, bem como a permissividade elétrica de cada material que compõe o GEM (cobre, Kapton ${ }^{\mathrm{TM}}$ e o gás), desejando-se saber o valor do potencial elétrico em todo espaço tridimensional.

Tabela 4.2: Exemplos das grandezas expressas na equação (4.2) para diferentes tipos de problemas. Adaptado de Weck \& Kim (Weck \& Kim, 2005).

\begin{tabular}{|c|c|c|c|}
\hline Tipo de Problema & Propriedade [K] & Comportamento u & Ação F \\
\hline Elástico & Rigidez & Deslocamento & Força \\
\hline Térmico & Condutividade & Temperatura & Fonte de Calor \\
\hline Fluido & Viscosidade & Velocidade & Força Corporal \\
\hline Eletrostático & Permissividade Elétrica & Potencial Elétrico & Carga \\
\hline
\end{tabular}

As equações são resolvidas nos nós da malha de elementos finitos para a grandeza de interesse (potencial elétrico, temperatura, velocidade, etc.), enquanto que dentro de um elemento o valor é dado por uma interpolação com base nos valores obtidos nos nós. Ou seja, a solução obtida não é exata, mas uma aproximação do valor real da grandeza. As funções de interpolação são dadas por um conjunto de polinômios, cuja precisão da solução depende da ordem dos mesmos (lineares, quadráticos, etc.) (Polycarpou, 2006). Além disso, a precisão pode ser aprimorada através do incremento no número de elementos da malha que representa o problema (Cook et al., 2002).

Entre as vantagens do MEF pode-se destacar a aplicabilidade em diversos tipos de problemas, como transferência de calor, análise de estresse em materiais, campos eletromagnéticos, fluidodinâmica, entre muitos outros. Além disso, não há restrições geométricas para o problema (a região analisada pode ter qualquer forma), a solução pode se aproximar mais da solução real com o simples incremento na resolução da malha, entre outras. É importante ressaltar que mesmo que o erro devido à discretização seja nulo, a 
solução poderá ainda não corresponder totalmente à realidade, pois também há um erro associado à modelagem do problema (Cook et al., 2002).

Uma característica importante para se levar em conta é o fato de que os programas de elementos finitos geralmente aproximam localmente o valor do potencial através de um polinômio (geralmente de segunda ordem) e tais polinômios não são soluções das equações de Maxwell. Embora o potencial possa ser razoavelmente preciso, a precisão do campo elétrico é frequentemente baixa (Veenhof, 2009).

\subsection{Gmsh}

O Gmsh (https://gmsh.info/) é um software gerador de malhas tridimensionais de elementos finitos com um mecanismo CAD embutido e pós-processador. Lançado sob licença livre, tem como um de seus principais objetivos fornecer uma ferramenta de malha que seja rápida, leve e fácil de usar, dispondo de recursos avançados de visualização. Ele foi construído em torno de quatro módulos: geometria, malha, solucionador e pósprocessamento. No módulo geometria, o Gmsh usa uma representação de fronteira para descrever geometrias. Os modelos são criados da seguinte maneira: primeiro se define pontos, em seguida estes são unidos por linhas orientadas (segmentos de linha, círculos,

elipses, splines, etc.), depois são definidas superfícies orientadas e então volumes. Grupos de entidades geométricas (chamados "grupos físicos") também podem ser definidos, com base nessas entidades geométricas elementares. A linguagem de script do Gmsh permite que todas as entidades geométricas sejam totalmente parametrizadas (Geuzaine \& Remacle, 2009).

\subsection{Elmer}

O Elmer (http://www.csc.fi/elmer) é um programa de elementos finitos para a solução de equações diferenciais parciais, podendo lidar com um grande número de equações diferentes, que podem ser acopladas de forma genérica, fazendo desse programa uma ferramenta bastante versátil. Ele é um software de código aberto que oferece meios para modificar os procedimentos de solução existentes, além da possibilidade de desenvolver novos solucionadores para equações de interesse (Råback \& Malinen, 2019). 
Em relação ao potencial eletrostático, é possível resolver o mesmo seja em material dielétrico linear ou em meio condutor. A partir da solução para o potencial, diversas outras variáveis (como o campo elétrico) e parâmetros físicos (como capacitância) podem ser calculados posteriormente (Råback, Malinen, Ruokolainen, Pursula, \& Zwinger, 2020).

\subsubsection{Teoria para o Potencial}

A partir das equações de Maxwell:

$$
\begin{gathered}
\nabla \cdot \vec{D}=\rho \\
\nabla \cdot \vec{B}=0 \\
\nabla \times \vec{E}=-\frac{\partial \vec{B}}{\partial t} \\
\nabla \times \vec{H}=\vec{J}+\frac{\partial \vec{D}}{\partial t}
\end{gathered}
$$

considera-se materiais lineares onde os campos e fluxos são simplesmente relacionados como $\mathbf{B}=\mu \mathrm{H}$ e $\mathbf{D}=\varepsilon \mathbf{E}$, onde a permissividade $\varepsilon=\varepsilon_{0} . \varepsilon_{\mathrm{r}}$ é definida através da permissividade do vácuo $\varepsilon_{0}$ e da permissividade relativa do material $\varepsilon_{\mathrm{r}}$.

No caso estacionário, o campo elétrico pode ser expresso em termos de um potencial escalar elétrico $\phi:$

$$
\vec{E}=-\nabla \phi
$$

Assumindo tratar-se de um material linear e usando a equação (4.4), obtemos:

$$
-\nabla \cdot \varepsilon \nabla \phi=\rho
$$

Para o potencial pode-se aplicar a condição de contorno de Dirichlet (onde se define o valor do potencial em fronteiras específicas) ou Neumann (para definir uma condição de fluxo em determinadas fronteiras) (Råback et al., 2020):

$$
-\varepsilon \nabla \phi \cdot \vec{n}=g
$$

onde o fluxo pode ser definido pela densidade superficial de carga: $\mathrm{g}=\sigma$. 
Para resolver o problema para o potencial, considera-se a equação de Laplace:

$$
\nabla^{2} \phi=0
$$

que, em coordenadas cartesianas, nos leva a:

$$
\frac{\partial^{2} \phi}{\partial x^{2}}+\frac{\partial^{2} \phi}{\partial y^{2}}+\frac{\partial^{2} \phi}{\partial z^{2}}=0
$$

A equação (4.12) deve ser resolvida para todo o espaço tridimensional onde o problema está definido, isto é, dentro da célula definida pelo usuário (Figura 5.1). Na realidade, como discutido na seção 4.4 , as equações são resolvidas apenas em pontos específicos da malha (nós), já o valor para os demais pontos é dado por uma interpolação polinomial com base no valor obtido em cada nó.

É necessário também impor as condições de contorno do problema: no caso da simulação do GEM, o potencial sobre cada eletrodo é conhecido e assumido constante ao longo da superfície do mesmo. Essa informação deve ser fornecida pelo usuário como parâmetro de entrada na simulação.

\subsubsection{Metodologia para Resolução do Problema}

A aplicação do MEF a problemas que envolvem condições de contorno resulta em um conjunto de equações lineares (similar à equação (4.2)) que geralmente é apresentado em forma matricial da seguinte maneira (Polycarpou, 2006):

$$
[K] \cdot u=b
$$

onde $\boldsymbol{u}$ representa o vetor de incógnitas na expansão de elementos finitos da solução estacionária ou o vetor de coeficientes para descrever a solução evolutiva de elementos finitos em um determinado momento $t=t_{k}$ (Ruokolainen et al., 2019). Já a matriz de coeficientes [ $\boldsymbol{K}$ ] representa a matriz de rigidez e $\boldsymbol{b}$ corresponde ao vetor do lado direito no sistema linear. O tamanho da matriz de coeficientes é igual ao número total de nós no domínio dos elementos finitos. Uma característica importante dessa matriz é que ela é bastante esparsa, o que significa que a maioria de seus elementos é zero (Polycarpou, 2006). 
Uma abordagem direta para resolver o sistema linear (4.13) consiste em empregar a decomposição conhecida como LU, em que a matriz [K] é decomposta em uma matriz triangular inferior [L] multiplicada por uma matriz triangular superior [U] (Golub, Greenbaum, \& Luskin, 1994; Saad, 2003). No entanto, essa abordagem irá destruir a esparsidade da matriz e assim consumir muita memória do computador. Para problemas complexos (o que acontece na maioria das aplicações), nos quais há um número muito grande de nós (incógnitas) ${ }^{5}$, será praticamente impossível resolver um sistema linear usando essa abordagem. Isso ocorre devido ao gasto exagerado da memória do computador e um extenso tempo de execução do código. Desse modo, esse tipo de abordagem é útil apenas para problemas onde a malha de elementos finitos é relativamente pequena, composta por um pequeno número de nós (Polycarpou, 2006).

Levando em conta essa deficiência para solução do sistema linear através de uma abordagem direta, surge a necessidade do emprego de técnicas iterativas. Esse tipo de técnica não destrói a esparsidade da matriz e assim o consumo de memória do computador não cresce exageradamente (Polycarpou, 2006). Técnicas iterativas usam aproximações sucessivas para obter soluções mais precisas para o sistema linear em cada etapa, buscando sempre minimizar o resíduo. A taxa na qual um método iterativo converge depende muito do espectro da matriz de coeficientes. Portanto, os métodos iterativos geralmente envolvem uma segunda matriz que transforma a matriz de coeficientes em uma com um espectro mais favorável (pré-condicionador). Um bom pré-condicionador melhora a convergência do método iterativo o suficiente para superar o custo computacional extra de construí-lo e aplicá-lo. De fato, sem esse artifício, o método iterativo pode até mesmo falhar na convergência (Barrett et al., 1994).

Abordemos alguns dos principais métodos iterativos empregados na resolução do problema. O método de gradiente conjugado (Conjugate Gradient - CG) é uma das técnicas iterativas mais conhecidas para resolver sistemas lineares simétricos positivos esparsos (Saad, 2003). Ele consiste em gerar uma sequência de vetores conjugados (ou ortogonais). Esses vetores são os resíduos das iterações, representando os gradientes de uma função

\footnotetext{
${ }^{5}$ Nas simulações do presente trabalho, as malhas geradas possuem tipicamente um número de nós da ordem de $10^{6}$
} 
quadrática cuja minimização é equivalente à solução do sistema linear. O CG é um método extremamente eficaz quando a matriz do coeficiente é definida positivamente simétrica, uma vez que embora o comprimento dessas sequências possa se tornar grande, apenas um pequeno número de vetores precisa ser mantido na memória (Barrett et al., 1994). As iterações são computáveis por meio de pequenas atualizações de vetores e, portanto, os requisitos de armazenamento e o trabalho por iteração são baixos e constantes durante toda a iteração (Golub et al., 1994).

Nesse método, os valores $u^{(i)}$ são atualizados em cada iteração por um múltiplo $\alpha_{i}$ do vetor de direção de busca $p^{(i)}$ (Barrett et al., 1994):

$$
u^{(i)}=u^{(i-1)}+\alpha_{i} \cdot p^{(i)}
$$

já os resíduos $r^{(i)}=\mathrm{b}-[\mathrm{K}] u^{(i)}$ são atualizados como:

$$
r^{(i)}=r^{(i-1)}-\alpha_{i} \cdot q^{(i)}
$$

onde $q^{(i)}=[\mathrm{K}] \cdot p^{(i)}$.

A escolha de $\alpha=\alpha_{i}=\mathrm{r}^{(\mathrm{i}-1) \top} \mathrm{r}^{(\mathrm{i}-1)} / \mathrm{p}^{(\mathrm{i}) \mathrm{T}}[\mathrm{K}] \mathrm{p}^{(\mathrm{i})}$ é tal que minimiza $\mathrm{r}^{(\mathrm{i}) \mathrm{T}}[\mathrm{K}]^{-1} \mathrm{r}^{(\mathrm{i})}$ sobre todas as opções possíveis para $\alpha$ na equação (4.15).

As direções de busca são atualizadas a partir dos residuais:

$$
p^{(i)}=r^{(i)}+\beta_{i-1} \cdot p^{(i-1)}
$$

onde a escolha de $\beta_{i}=r^{(i) T} r^{(i)} / r^{(i-1) T} r^{(i-1)}$ garante que $p^{(i)}$ e [K] $p^{(i-1)}$ são ortogonais.

O método CG não é adequado para sistemas não simétricos porque os vetores residuais não podem ser ortogonais com pequenas recorrências. Nesses casos, pode-se fazer uso do método do Gradiente Biconjugado (BiCG - BiConjugate Gradient), que atua substituindo a sequência ortogonal de resíduos por duas sequências mutuamente ortogonais (a primeira baseada na matriz $[\mathrm{K}]$ e a segunda na matriz transposta $[\mathrm{K}]^{\top}$ ) ao preço de não fornecer mais uma minimização (Barrett et al., 1994). 
A atualização para os resíduos no método Gradiente Conjugado é aumentada no método Gradiente Bi-Conjugado por relações semelhantes, mas baseadas em $[\mathrm{K}]^{\top}$ em vez de [K], levando à atualização de duas sequências de resíduos:

$$
r^{(i)}=r^{(i-1)}-\alpha_{i}[K] p^{(i)}, \quad \tilde{r}^{(i)}=\tilde{r}^{(i-1)}-\alpha_{i}[K]^{T} \tilde{p}^{(i)}
$$

assim como duas sequências de direções de busca:

$$
p^{(i)}=r^{(i-1)}+\beta_{i-1} p^{(i-1)}, \quad \tilde{p}^{(i)}=\tilde{r}^{(i-1)}+\beta_{i-1} \tilde{p}^{(i-1)}
$$

As escolhas:

$$
\alpha_{i}=\frac{\tilde{r}^{(i-1)^{T}} r^{(i-1)}}{\tilde{p}^{(i)^{T}}[K] p^{(i)}}, \quad \beta_{i}=\frac{\tilde{r}^{(i)^{T}} r^{(i)}}{\tilde{r}^{(i-1)^{T}} r^{(i-1)}}
$$

garantem as relações de bi-ortogonalidade:

$$
\tilde{r}^{(i)^{T}} r^{(j)}=\tilde{p}^{(i)^{T}}[K] p^{(j)}=0 \quad \text { se } i \neq j
$$

No método BiCG, o vetor residual $r^{(i)}$ pode ser considerado como o produto de $r^{(0)} \mathrm{e}$ um i-ésimo grau polinomial em [K] que é:

$$
r^{(i)}=P_{i}([K]) r^{(0)}
$$

onde $\mathrm{r}^{(0)}$ é o resíduo inicial (Saad, 2003). Por outro lado, esse mesmo polinômio satisfaz:

$$
\tilde{r}^{(i)}=P_{i}\left([K]^{T}\right) \tilde{r}^{(0)}
$$

tal que:

$$
p_{i}=\left(\tilde{r}^{(i)}, r^{(i)}\right)=\left(P_{i}\left([K]^{T}\right) \tilde{r}^{(0)}, P_{i}([K]) r^{(0)}\right)=\left(\tilde{r}^{(0)}, P_{i}^{2}([K]) r^{(0)}\right)
$$

Isso sugere que, se $\mathrm{P}_{\mathrm{i}}([\mathrm{K}])$ reduz $\mathrm{r}^{(0)}$ para um vetor menor $\mathrm{r}^{(\mathrm{i})}$, pode ser vantajoso aplicar esse operador de "contração" duas vezes e calcular $\mathrm{P}_{\mathrm{i}}{ }^{2}([\mathrm{~K}]) \mathrm{r}^{(0)}$. A equação (4.23) mostra que os coeficientes de iteração ainda podem ser recuperados a partir desses vetores e torna-se fácil encontrar as aproximações correspondentes para $u$. Essa abordagem conduz ao método do 
quadrado do gradiente conjugado (CGS - Conjugate Gradient Squared). Esse método foi desenvolvido visando evitar o uso de $[\mathrm{K}]^{\top}$ e obter convergência mais rápida por aproximadamente o mesmo custo computacional (Saad, 2003).

O método CGS trata-se de uma variante do BiCG baseado no quadrado do polinômio residual (Saad, 2003) que aplica as operações de atualização para [K] e [K] para os mesmos vetores (Barrett et al., 1994). Idealmente, com essa operação seria dobrada a taxa de convergência, mas na prática a convergência tende a ser muito mais irregular do que para o BiCG, o que pode levar a um acúmulo substancial de erros de arredondamento e às vezes pode levar a resultados não confiáveis (Barrett et al., 1994; Saad, 2003). Uma vantagem prática é que o método não precisa de multiplicações com a transposta da matriz de coeficientes $\left([K]^{\top}\right)$ (Barrett et al., 1994).

O método de gradiente biconjugado estabilizado (BiCGSTAB - Biconjugate Gradient Stabilized) foi desenvolvido para resolver sistemas lineares não simétricos, evitando os padrões de convergência frequentemente irregulares do método CGS. Isso é obtido através de atualizações diferentes para $[\mathrm{K}]^{\top}$ para obter uma convergência mais suave que no caso do método CGS (Barrett et al., 1994). Em vez de calcular a sequência CGS:

$$
i \mapsto P_{i}^{2}([K]) r^{(0)}
$$

o BiCGSTAB calcula:

$$
i \mapsto Q_{i}([K]) P_{i}([K]) r^{(0)}
$$

tal que:

$$
r^{(i)}=Q_{i}([K]) P_{i}([K]) r^{(0)}
$$

onde $Q_{i}$ é um novo polinômio definido recursivamente a cada etapa com o objetivo de "estabilizar" ou "suavizar" o comportamento de convergência do algoritmo original (Saad, 2003). Pelo menos localmente, um vetor residual é minimizado, o que leva a um comportamento de convergência consideravelmente mais suave (Barrett et al., 1994). 
Na Tabela 4.3 são resumidas as características dos métodos discutidos anteriormente, mostrando as vantagens e desvantagens de cada um deles.

Tabela 4.3: Resumo das técnicas iterativas utilizadas para a resolução numérica de sistemas lineares.

\begin{tabular}{|c|c|c|c|}
\hline Método & Sigla & Vantagens & Desvantagens \\
\hline $\begin{array}{c}\text { Gradiente } \\
\text { Conjugado }\end{array}$ & CG & $\begin{array}{c}\text { Baixos requisitos de } \\
\text { armazenamento por } \\
\text { iteração }\end{array}$ & $\begin{array}{c}\text { Não adequado para sistemas } \\
\text { não simétricos }\end{array}$ \\
\hline $\begin{array}{c}\text { Gradiente } \\
\text { Biconjugado }\end{array}$ & BiCG & $\begin{array}{c}\text { Aplicável a sistemas não } \\
\text { simétricos }\end{array}$ & $\begin{array}{c}\text { Mais cálculos pela utilização } \\
\text { da transposta da matriz [K] }\end{array}$ \\
\hline $\begin{array}{c}\text { Quadrado do } \\
\text { Gradiente } \\
\text { Conjugado }\end{array}$ & CGS & $\begin{array}{c}\text { Não necessita de }[K]^{\top} \text { e } \\
\text { obtém convergência mais } \\
\text { rápida }\end{array}$ & $\begin{array}{c}\text { Convergência tende a ser } \\
\text { irregular, implicando erros de } \\
\text { arredondamento }\end{array}$ \\
\hline $\begin{array}{c}\text { Gradiente } \\
\text { Biconjugado } \\
\text { Estabilizado }\end{array}$ & BiCGSTAB & $\begin{array}{c}\text { Convergência } \\
\text { consideravelmente mais } \\
\text { suave que o CGS }\end{array}$ & $\begin{array}{c}\text { Cálculos mais demorados que } \\
\text { no método CG }\end{array}$ \\
\hline
\end{tabular}

Nas simulações de potencial elétrico realizadas nesse trabalho, foi escolhido o método BiCGSTAB devido às suas características e vantagens discutidas anteriormente.

\subsection{Paraview}

O ParaView (https://www.paraview.org/) é um programa em código aberto que permite a análise e visualização de dados científicos extremamente grandes. É possível, entre outras coisas, visualizar dados de forma interativa em 3D, contornos e cortes em 2D, traçar gráficos de grandezas de interesse ao longo de uma direção específica e muitas outras ferramentas (Ahrens et al., 2019). Entre as vantagens da utilização do Paraview, podem ser citadas a capacidade de lidar com diferentes tipos de dados (por exemplo, estruturados, não estruturados, poligonais e de imagem), a incorporação de várias operações de processamento (filtros) para a produção de conjuntos de dados e a capacidade de inspecionar vetores e tensores, permitindo renderização de volume e destaque de regiões de interesse (Liu, Li, \& Liu, 2017). Paraview é uma ferramenta computacional poderosa, com capacidades de ser executada em visualização paralela em supercomputadores para grandes volumes de dados ou em computadores domésticos para dados em menor escala (Ayachit, 2015). Ele é utilizado para visualização de dados de diferentes áreas de pesquisa como simulações em cosmologia (Woodring et al., 2011), dados de estudos atmosféricos (Jucker, 
2014), deformações em estruturas mecânicas (Liu et al., 2017) e muitas outras (Lyon, Kowalkowski, \& Jones, 2017; Murello \& Milotti, 2013).

\subsection{Garfield++}

O Garfield++ (Schindler et al., 2015) é um software de simulações especializado em detectores a gás. Esse programa é baseado no trabalho de Rob Veenhof, que em 1984 desenvolveu o Garfield (Veenhof, 1984), um programa de computador escrito em Fortran e especializado em simulações detalhadas de câmaras de deriva (onde se encaixam os detectores multifilares, câmaras de ionização, etc.). O Garfield é capaz de calcular diversas características da operação de detectores a gás, podendo auxiliar na otimização das mesmas (Veenhof, 1993).

Já o Garfield++, é um programa orientado a objetos para a simulação detalhada de detectores de partículas que usam uma mistura de gás ou um material semicondutor como meio sensível. Sendo, portanto, mais abrangente que o Garfield, que considera apenas o caso gases como meio sensível. Entre as possibilidades para o cálculo de campo elétrico, no Garfield++ é possível aplicar soluções no limite de fio fino para dispositivos feitos de fios e planos (método analítico), ou ainda utilizar interfaces com programas de elementos finitos. Estes, por sua vez, podem calcular campos aproximados em configurações arbitrárias bidimensionais e tridimensionais com dielétricos e condutores, ou seja, para casos mais gerais onde a geometria é mais complexa que no caso dos planos de fios. As principais diferenças entre o Garfield e o Garfield++ são o tratamento mais atualizado do transporte de elétrons e a utilização do programa ROOT (Brun \& Rademakers, 1997) como interface com o usuário (Schindler, 2019). Como desvantagem, apresenta o fato de não possuir até o momento ${ }^{6}$ uma interface com o neBEM (Mukhopadhay \& Majumdar, 2009), que utiliza o método de elementos de contorno.

Para o cálculo das propriedades de transporte de elétrons em misturas de gases, está disponível uma interface para o programa Magboltz (Biagi, 1995). O padrão de ionização produzido ao longo do caminho de partículas relativísticas carregadas pode ser simulado usando o programa Heed (Smirnov, 1995). Já para simular a ionização produzida por íons de

\footnotetext{
${ }^{6}$ No momento da finalização desse trabalho (segundo semestre de 2020), já está disponível uma interface para o neBEM.
} 
baixa energia, é possível usar uma interface para importar resultados calculados usando o pacote de software SRIM (Ziegler, Biersack, \& Littmark, 1985).

Na Tabela 4.4 é mostrado um resumo com os diferentes programas que compõem o Garfield++, com uma sucinta descrição da funcionalidade de cada um deles para a simulação dos detectores a gás.

Tabela 4.4: Resumo dos softwares que fazem parte do pacote Garfield++ ou são utilizados por esse programa, fornecendo suporte para as diferentes características das simulações de um detector a gás.

\begin{tabular}{|c|l|}
\hline Programa & \multicolumn{1}{|c|}{ Funcionalidades } \\
\hline Magboltz & $\begin{array}{l}\text { Resolve as equações de transporte de } \\
\text { Boltzmann para elétrons em diferentes } \\
\text { misturas de gases sob a influência de } \\
\text { campos elétricos e magnéticos. }\end{array}$ \\
\hline Heed & $\begin{array}{l}\text { Simula a ionização das moléculas do gás } \\
\text { causada por uma partícula. Ele aplica um } \\
\text { modelo de foto-absorção e ionização. Além } \\
\text { disso, fornece processos de relaxamento } \\
\text { atômico e dissipação de elétrons de alta } \\
\text { energia. }\end{array}$ \\
\hline SRIM & $\begin{array}{l}\text { Pacotes que calculam muitas características } \\
\text { do transporte de íons na matéria, como } \\
\text { implantação iônica, parada e alcance em } \\
\text { alvos, entre outros. }\end{array}$ \\
\hline Root & $\begin{array}{l}\text { Fornece as funcionalidades necessárias para } \\
\text { lidar com o processamento, análise } \\
\text { estatística, visualização e armazenamento } \\
\text { de dados. É escrito em C++, mas integrado a } \\
\text { outras linguagens como Python e } \boldsymbol{R} .\end{array}$ \\
\hline
\end{tabular}

As simulações com o Garfield++ desenvolvidas nesse trabalho foram realizadas utilizando a infraestrutura do cluster SAMPA (Sistema de Análise e Multi-Processamento Avançado) localizado no Departamento de Física Nuclear do Instituto de Física da USP. Esse sistema é utilizado em análises de dados e simulação dos experimentos STAR e ALICE e também é utilizado por pesquisadores do IFUSP e da UNICAMP. O cluster dispõe atualmente de 2408 CPU's de processamento, sendo que aproximadamente 2000 são dedicadas às atividades de análise de dados e processamento. Em média, cada CPU possui 98 GB de memória RAM e cerca de 800 TB de espaço de armazenamento e encontra-se em operação desde 2007 (GRIPER, 2019). 


\subsubsection{Modelagem no Garfield++}

O processo para simular a formação e evolução de uma avalanche de elétrons no Garfield++ implica em calcular as taxas de colisão de elétrons no gás. Para tanto, é utilizado o método "microscópico" de Monte Carlo, com base nas seções transversais elétron-átomo / molécula no banco de dados do programa Magboltz (Biagi, 1995). O algoritmo toma como entrada as taxas de colisão (em função da energia cinética do elétron) para cada mecanismo de espalhamento que pode ocorrer no gás. A preparação das tabelas de taxas de colisão e a interpolação nessas tabelas é feita pela classe MediumMagboltz, que fornece uma interface para Magboltz (Schindler, 2019). Mais detalhes sobre a modelagem empregada pode ser encontrada no wesite do LXCat ( $\underline{w w w . \mid x c a t . n e t)}$ ), um site de acesso aberto para coletar, exibir e baixar seções transversais de dispersão de elétrons e íons, mobilidade, coeficiente de difusão, etc., entre muitos outros dados necessários para modelar plasmas de baixa temperatura.

A deriva de portadores de carga no gás submetidos a um campo elétrico (E) e um campo magnético (B) é descrita pela equação de movimento de primeira ordem:

$$
\frac{d \vec{r}}{d t}=\vec{v}_{d}(\vec{E}(r), \vec{B}(r))
$$

onde $\boldsymbol{v}_{\boldsymbol{d}}$ é a velocidade de deriva. Para resolver a equação (4.27), pode-se empregar a integração por Runge-Kutta-Fehlber (Fehlberg, 1969) ou Monte Carlo (Lepage, 1978).

Em relação às propriedades de transporte de íons no Garfield++, ao contrário dos elétrons, não podem ser seguidos microscopicamente. Além disso, como não existe um programa como o Magboltz que possibilite calcular propriedades macroscópicas de transporte (como a velocidade da deriva), é necessário fornecer esses dados por conta própria. Em outras palavras, o transporte de íons é realizado através da classe AvalancheMC, que recebe como entrada a velocidade de deriva macroscópica em função do campo elétrico e simula linhas de deriva usando uma técnica de Monte Carlo. Por exemplo, como utilizamos uma mistura baseada em argônio como gás de ionização, foi empregada a mobilidade dos íons $\mathrm{Ar}^{+}$em $\mathrm{Ar}$ como uma aproximação, uma vez que não há dados da literatura para a deriva na mistura $\mathrm{Ar}$ e $\mathrm{CO}_{2}$. Arquivos com dados de mobilidade para vários gases puros estão disponíveis para uso no software (Schindler, 2019). 
A deposição de energia no gás pela radiação é realizada pelo programa Heed (Smirnov, 1995) no qual há uma implementação do modelo de ionização por foto-absorção (Schindler, 2019).

\section{Simulações Parte II: Triplo GEM Bicônico}

Nesse capítulo são mostradas as simulações realizadas com o triplo GEM de furos bicônicos (com a conicidade no centro do furo), que é a geometria padrão dos primeiros GEM's desenvolvidos no CERN.

\subsection{Geometria e malha de Elementos Finitos}

A parte inicial das simulações do detector se deu com a definição da geometria desse dispositivo, isto é, a criação de seu design considerando suas dimensões e características (conicidade dos furos, espaçamentos, diâmetros, etc.). Essa tarefa foi realizada no programa Gmsh utilizando uma unidade básica (recorte, ou "célula"), que posteriormente foi reproduzida espacialmente para então criar toda a área sensível do detector (como mostra a Figura 2.2).

A metodologia aplicada para criar a geometria se deu da seguinte maneira: inicialmente foram definidos pontos de interesse (vértices, centros e bordas de arcos ou outros); em seguida, estes foram unidos por linhas (retas, circunferências, etc.); estas, por sua vez, foram unidas em laços fechados para se definir as superfícies e; estas últimas formando laços para definição de volumes. Após essa etapa, se obteve um esboço como mostrado nas Figura 5.1 e Figura 5.2, contendo apenas a definição da mesma, porém ainda sem a criação da malha de elementos finitos. 


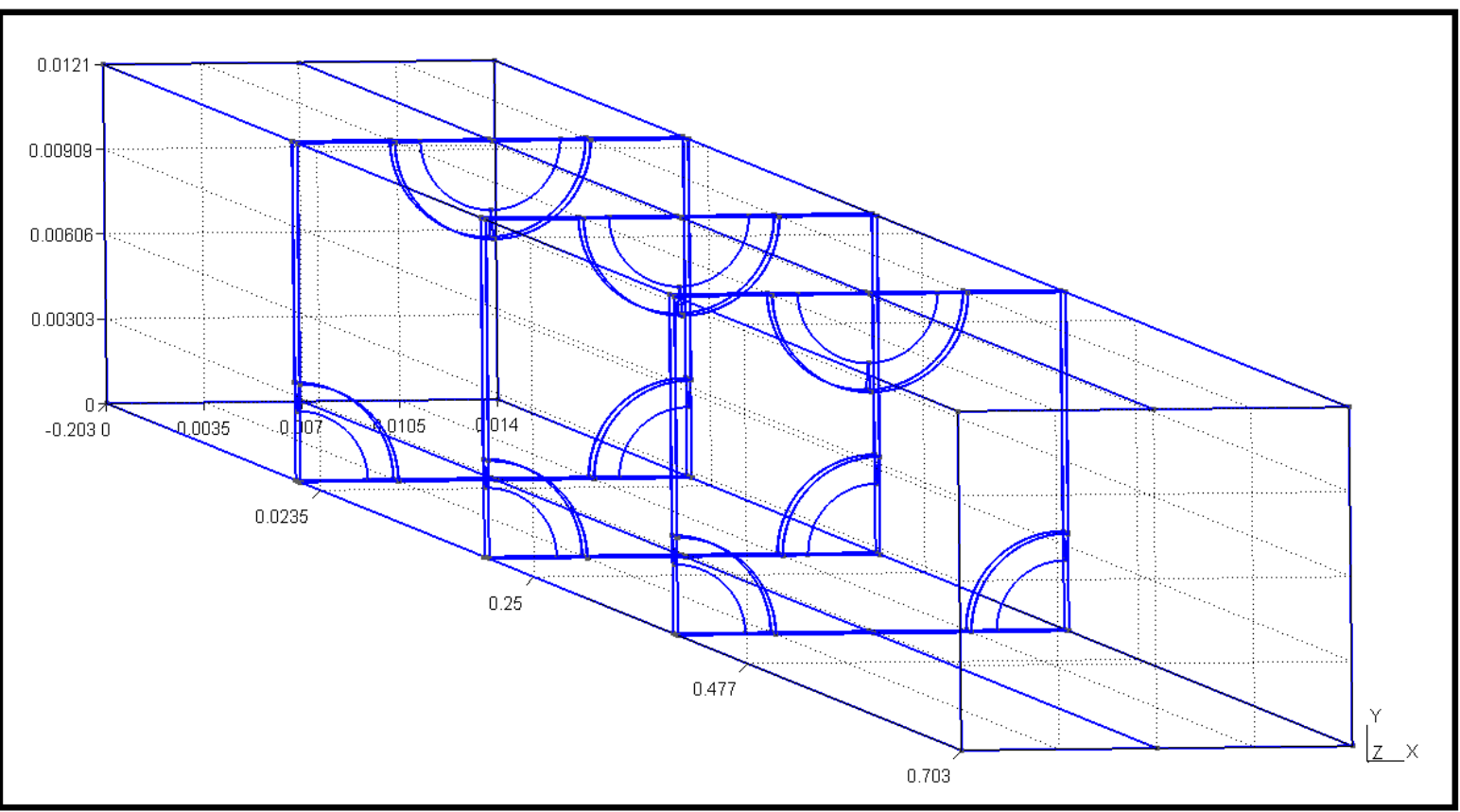

Figura 5.1: Célula básica do detector criada no Gmsh. Pode-se notar a estrutura básica do triplo GEM, composta pelas três folhas com os furos, delimitadas na direção longitudinal pelos eletrodos de deriva e leitura. As dimensões estão dadas em cm.

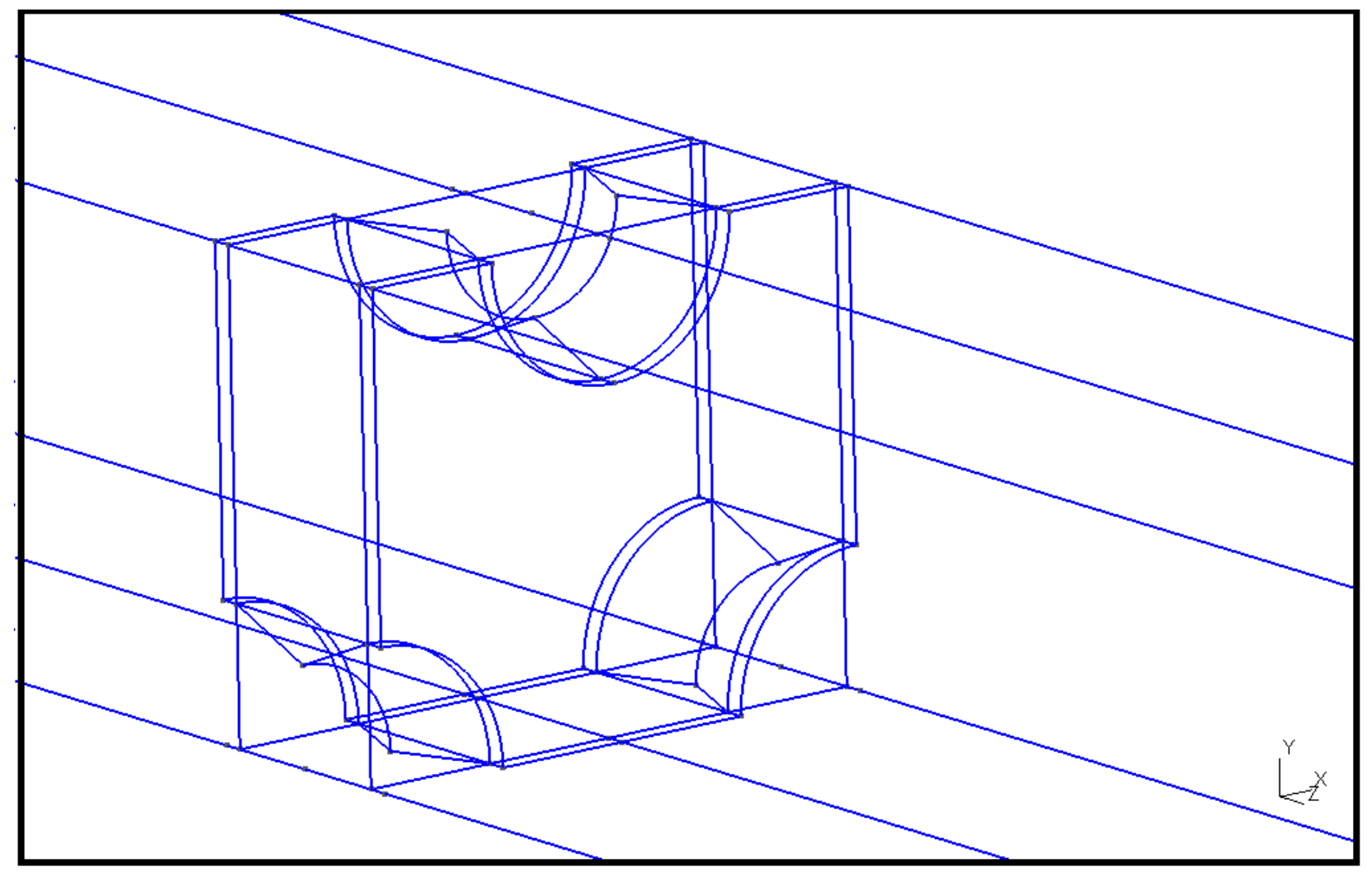

Figura 5.2: Detalhe da estrutura básica do GEM mostrando os furos da folha e sua respectiva conicidade.

Em seguida, cria-se a malha de elementos finitos (Figura 5.3), onde a geometria é dividida em pequenos componentes para que então essa estrutura possa ser exportada para 
o Elmer. Na Figura 5.4 pode-se observar o detalhe da "célula" adotada para construção do GEM, com destaque para o mosaico formado pelos elementos finitos e os nós (pontos localizados entre as linhas dos elementos). Já na Figura 5.5 pode-se ver a mesma com destaque para a geometria cônica dos furos, bem como as duas superfícies de cobre envolvendo a folha de Kapton.

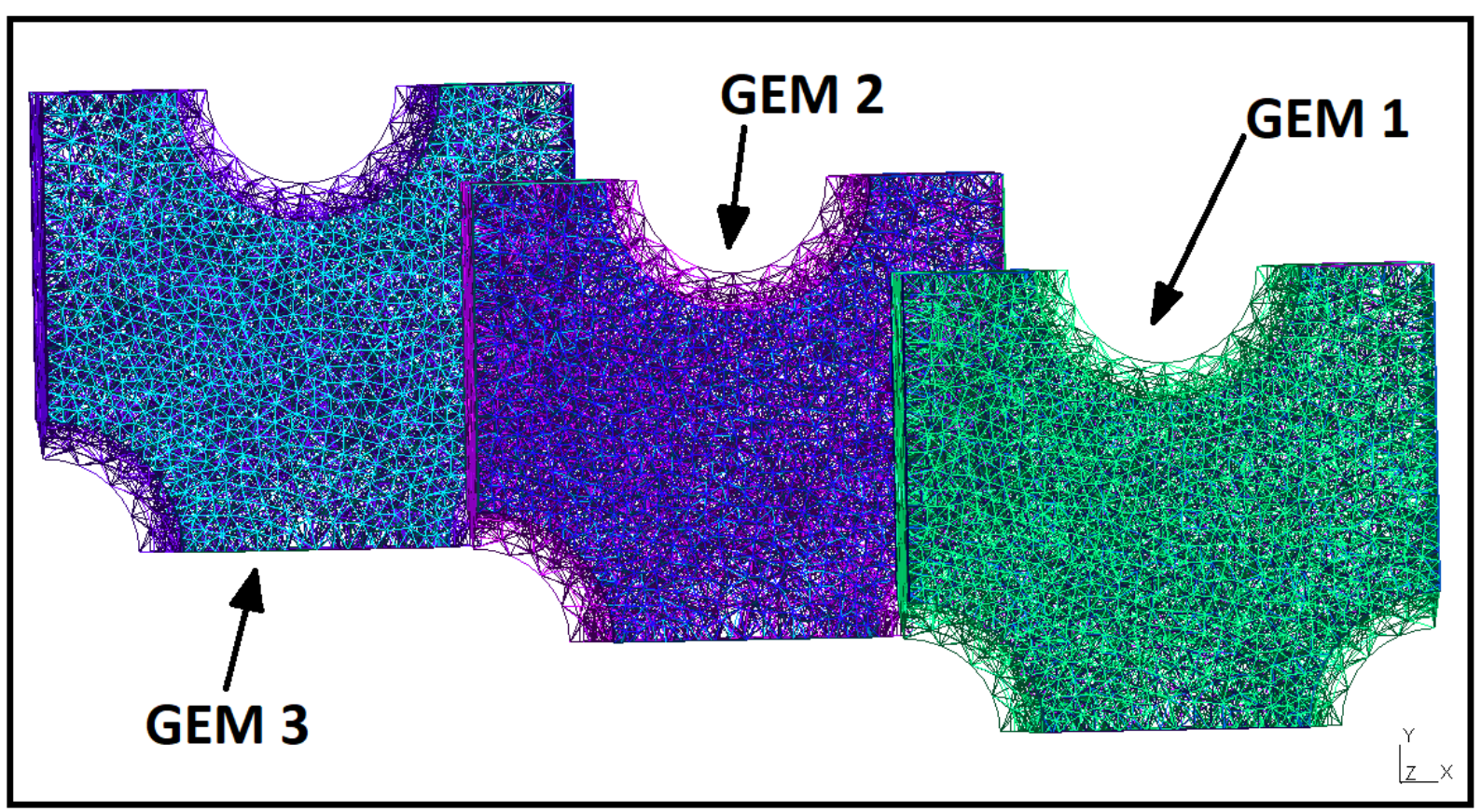

Figura 5.3: Malha do Triplo GEM criada no Gmsh composta de um mosaico de estruturas que dividem a geometria em pequenos componentes. São mostradas as três diferentes camadas que compõem o triplo GEM. Algumas estruturas importantes para o funcionamento da simulação (eletrodos de deriva e de leitura, além das superfícies de fronteira) foram ocultadas da figura para maior clareza da imagem. 


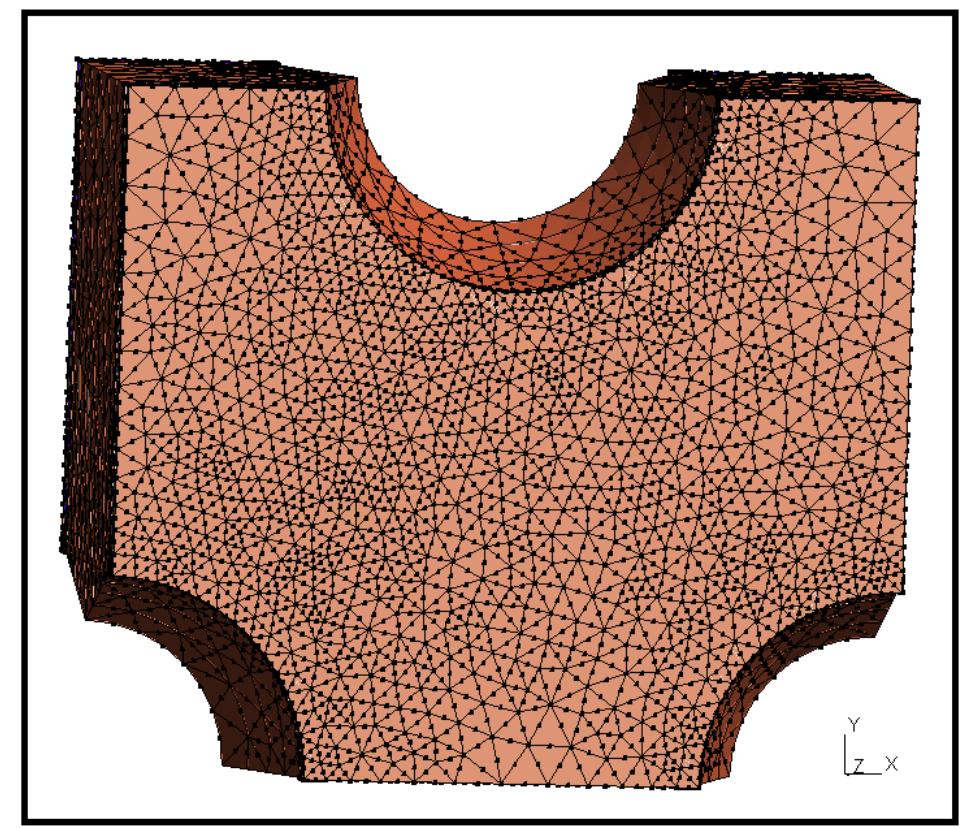

Figura 5.4: Célula do GEM mostrando o mosaico de elementos criados pelo Gmsh para a aplicação do método de elementos finitos. Os pontos sobre as linhas que definem os elementos representam os nós da malha.

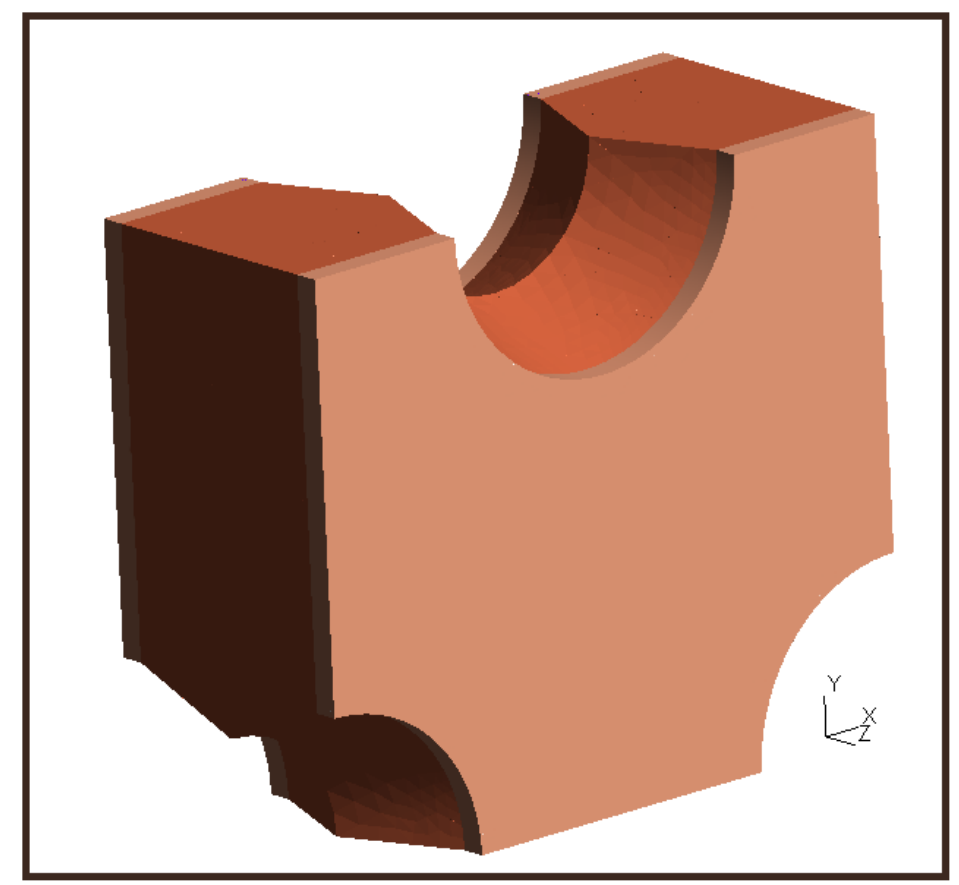

Figura 5.5: Célula do GEM composta por duas superfícies condutoras de cobre entre uma placa de material dielétrico (Kapton). Essa célula com dois quartos de furos e um meio furo é reproduzida espacialmente para então criar toda a área sensível do detector.

Resumidamente, para realizar a simulação inicia-se por definir a geometria do detector e criar uma malha da mesma no Gmsh. Esta malha é convertida pelo próprio programa em um formato legível pelo Elmer, que por sua vez aplica o cálculo dos elementos 
finitos, resultando em um valor do potencial eletrostático resolvido em cada vértice (ou nó) desses elementos, além da interpolação que é feita para os pontos no interior dos elementos. Esta lista de potenciais é então importada pelo o Garfield++, que calcula os campos eletrostáticos resultantes e realiza a simulação de características do detector.

Apresenta-se a seguir alguns exemplos de simulações de alguns aspectos relevantes para o funcionamento do detector. Nessas simulações foram reproduzidas as características do dispositivo real, como o material que o compõe, com suas características eletromagnéticas (representadas pela permissividade elétrica), mistura de gases típica, geometria, etc.

\subsection{Potencial Eletrostático e Campo Elétrico}

Para verificar se o potencial foi simulado corretamente, inicialmente foi observado seu perfil através do mapa de potencial (Figura 5.6). Nessa figura, pode-se notar uma variação gradativa em uma mesma região do detector (entre o Readout e o GEM3 bottom, entre o GEM 3 top e o GEM2 bottom, e assim por diante). Por outro lado, há alterações bruscas entre as diferentes regiões, especialmente nas áreas internas dos GEM's, como pode ser verificado na legenda com código de cores à direita da figura.

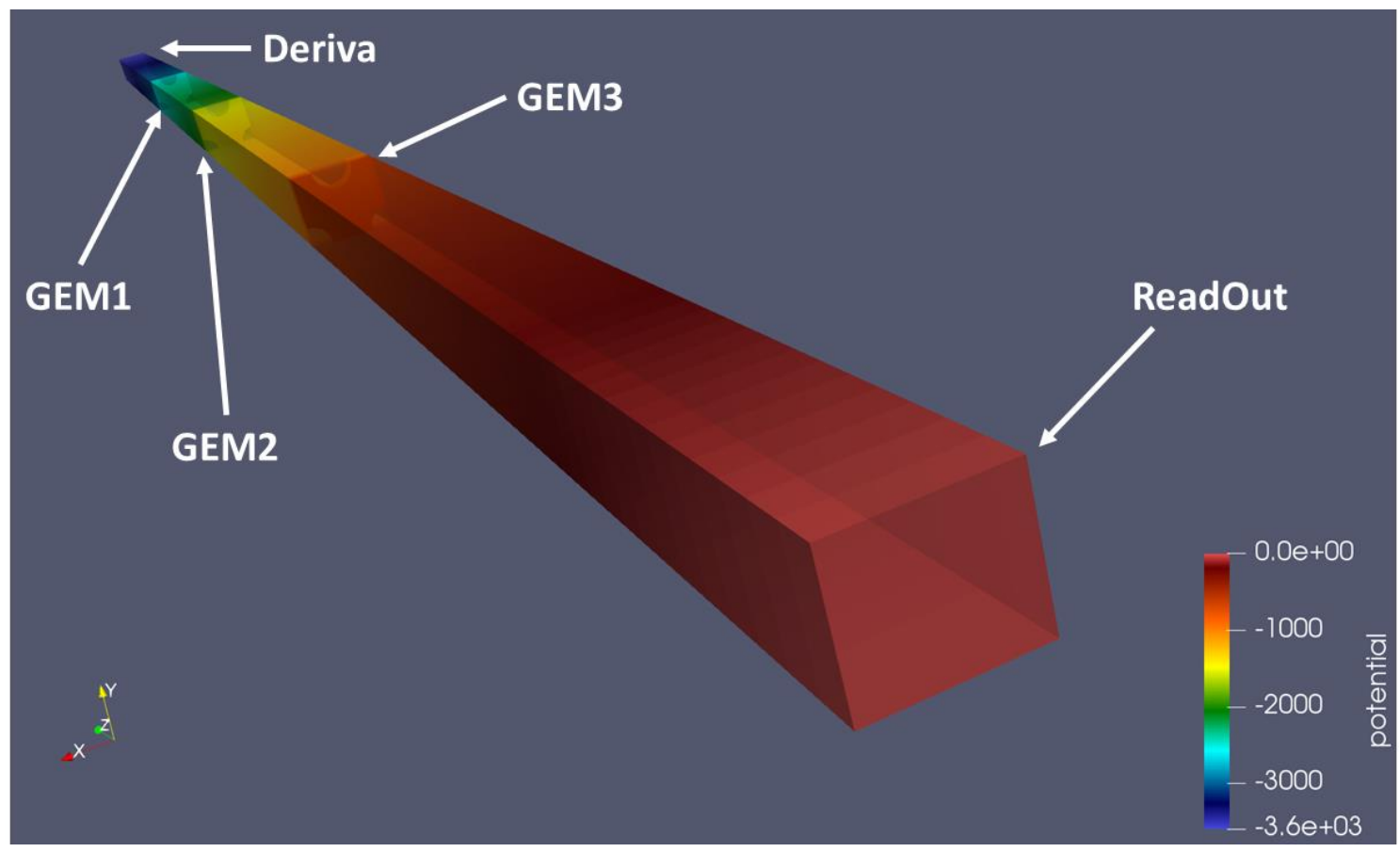

Figura 5.6: Mapa do potencial eletrostático (em Volts) ao longo do triplo GEM de padrão bicônico. Nota-se como o valor do potencial varia bruscamente entre as diferentes regiões devido à mudança de potencial em cada eletrodo. 
Esse tipo de comportamento do potencial ao longo do eixo $Z$ (perpendicular ao plano dos eletrodos) é típico de um capacitor de placas paralelas, cujo potencial varia linearmente em função da posição nessa direção. Para observar mais claramente o perfil do potencial, foi traçado um gráfico dessa grandeza ao longo dessa mesma direção, passando pelo centro do orifício do GEM. Esse gráfico pode ser observado na Figura 5.7, onde nota-se claramente a transição entre os diferentes setores do detector, destacando-se a inclinação constante em cada região. Uma vez que o campo elétrico é dado pelo negativo do gradiente do potencial, verifica-se um comportamento típico de um capacitor de placas paralelas, cujo campo é constante na região entre as placas.

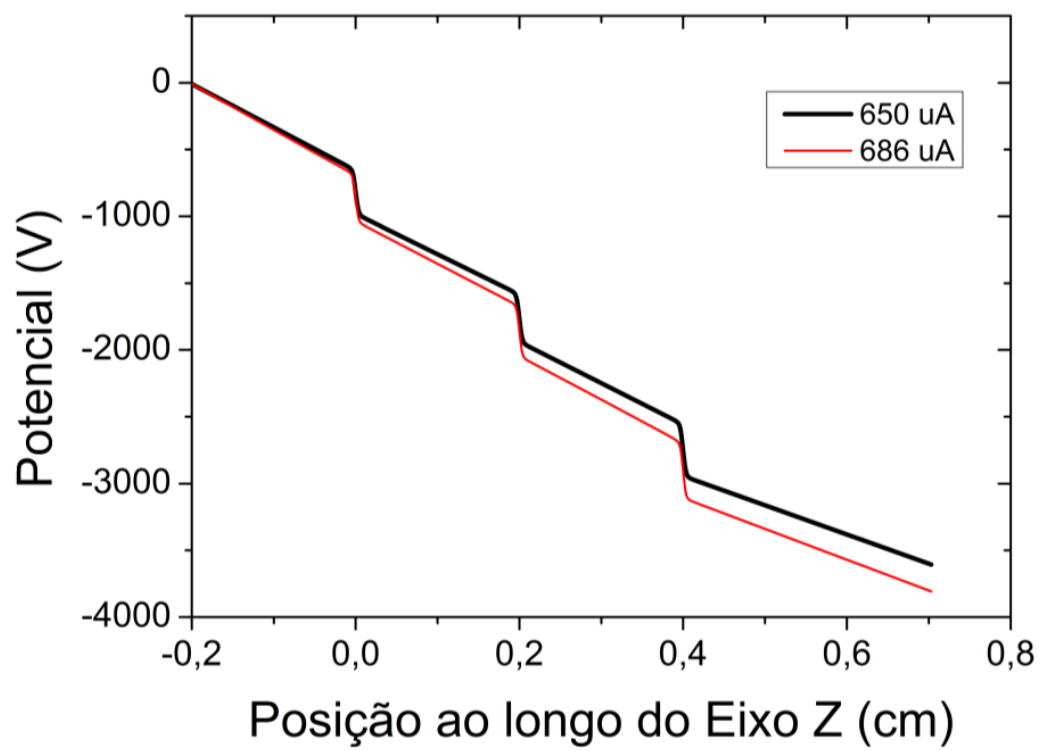

Figura 5.7: Potencial eletrostático ao longo do eixo Z (perpendicular ao plano dos eletrodos) passando pelo centro dos furos das três folhas, para duas configurações de potencial distintas. As características mais marcantes do gráfico são os seguimentos com inclinação constante nas diferentes regiões do detector.

Como discutido anteriormente, o campo elétrico é constante na região entre os eletrodos (desconsiderando as transições entre as regiões). Isso significa que a simulação está de acordo com o que já era esperado, uma vez que foram fornecidas condições de contorno estabelecendo que o potencial seja constante em cada um dos oito eletrodos do triplo GEM (superfície superior e inferior de cada um dos três GEM's, além do eletrodo de deriva e de leitura). Por outro lado, esse não é o único aspecto importante no GEM, pois esse campo uniforme é importante para direcionar os elétrons na direção do eletrodo de coleta e formação do sinal (ReadOut ou GEM3 bottom, dependendo do design do detector), constituindo assim uma região de deriva com campo constante. Desse modo, ele não é 
suficiente para proporcionar o funcionamento do dispositivo, pois é necessário haver a formação de elétrons secundários que são promovidos pelo efeito avalanche, que por sua vez carece de um campo elétrico cujo módulo seja da ordem de algumas dezenas de $\mathrm{kV} / \mathrm{cm}$ (Blum et al., 2008; Sauli, 2014). Esse regime de campo propício à formação da avalanche é alcançado apenas nas proximidades do furo do GEM, como pode ser notado na Figura 5.8, onde é apresentado o mapa do campo elétrico em uma projeção perpendicular ao plano dos eletrodos.

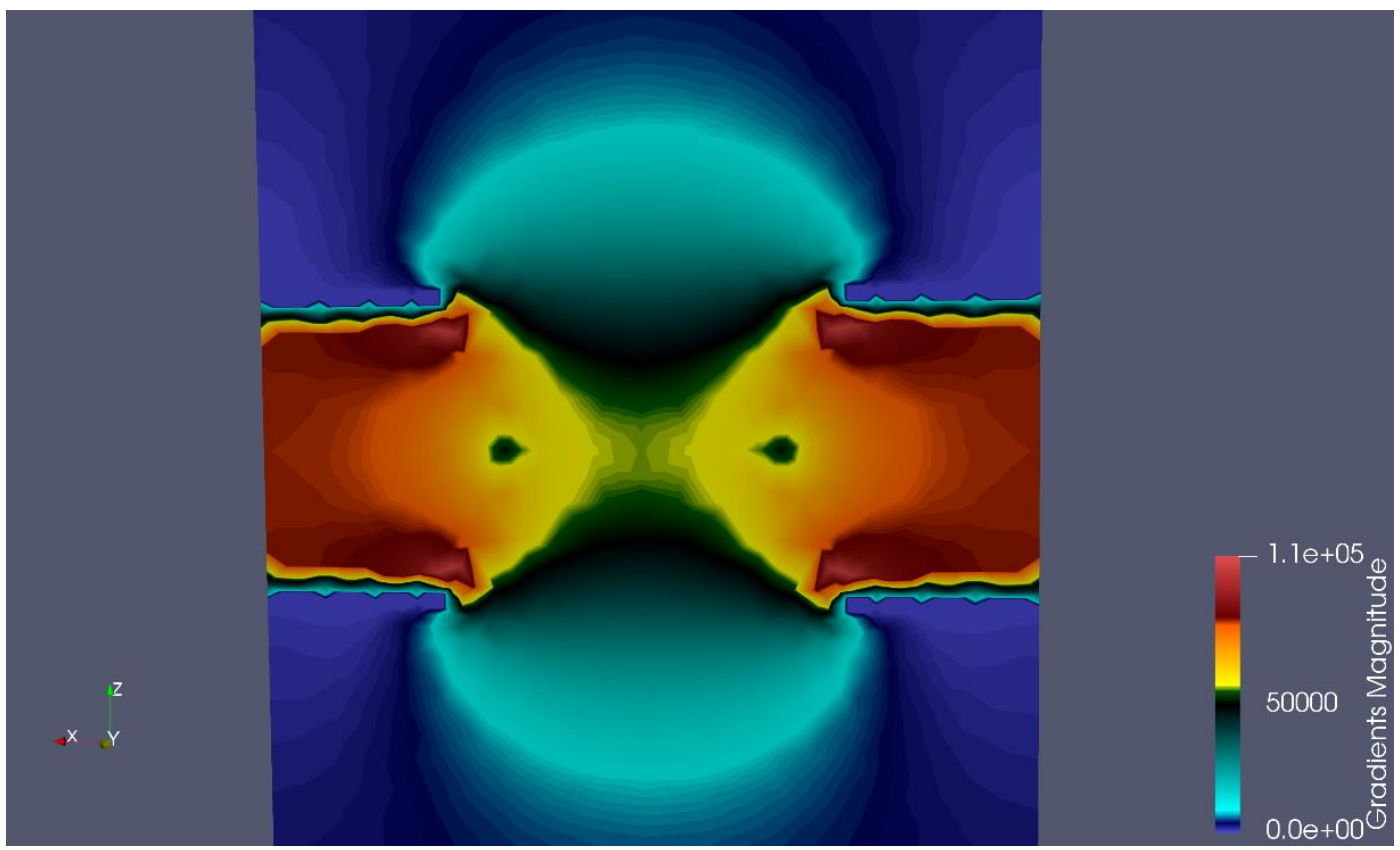

Figura 5.8: Mapa do campo elétrico ao redor do furo do GEM mostrando uma projeção (Z-X), perpendicular ao plano da folha do detector $(\mathrm{X}-\mathrm{Y})$. Nota-se pelo código de cores como o módulo do campo é mais intenso na região interna aos furos em comparação com a região externa, propiciando a formação da avalanche de elétrons. A região com destaque na cor preta indica o limiar para formação da avalanche.

Na Figura 5.9 são mostradas as linhas de campo elétrico ao redor de um furo do GEM obtidas a partir da função StreamTracer do Paraview. Essa função é capaz de gerar linhas de fluxo para campos vetoriais. Essas linhas representam curvas tangenciais ao campo vetorial no conjunto de dados. Assim, elas fornecem uma indicação da direção na qual uma partícula viajaria naquele instante quando liberadas ao longo de uma linha cuja direção é selecionada pelo usuário (não mostrada na figura). Repara-se algumas peculiaridades do campo, como a característica de direcionar os elétrons para o interior dos furos. Nessa área o campo elétrico é intenso o suficiente para promover a formação do efeito avalanche. 


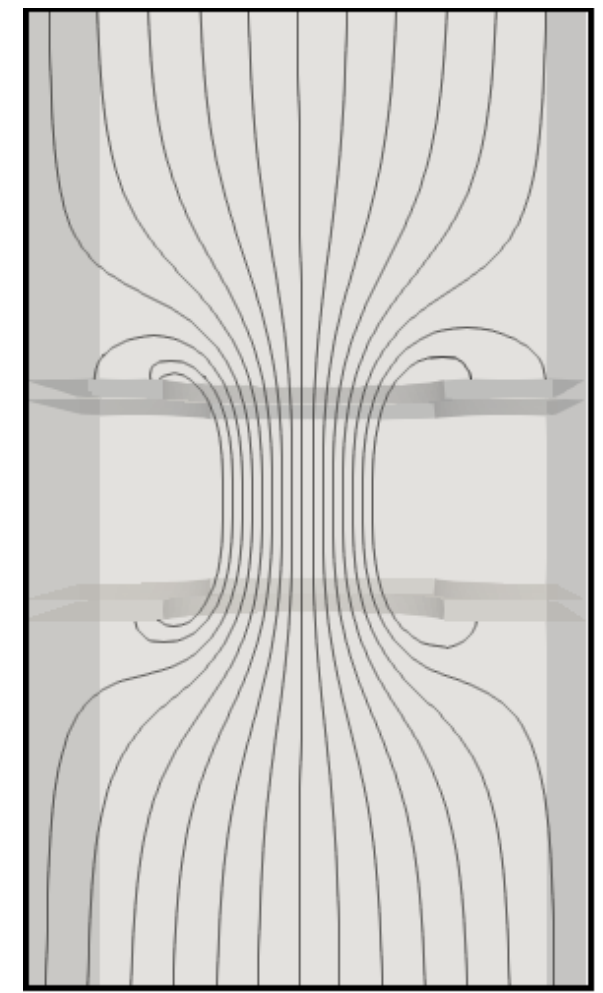

Figura 5.9: Linhas de campo elétrico ao redor do furo do GEM. Os elétrons, ao se aproximarem dessa área, são direcionados para o interior dos orifícios, região onde o campo elétrico acelera essas cargas o suficiente para promover ionizações e assim gerar uma avalanche eletrônica.

No ParaView é possível traçar gráficos unidimensionais em uma direção arbitrária, além da possibilidade de exportar os dados em alguns formatos e utilizar outro programa para realizar a plotagem. A direção em que será traçado o gráfico é dada por um seguimento de reta através da escolha de suas coordenadas cartesianas. Foram escolhidas algumas direções interessantes para comparação das simulações para diferentes configurações de campos e potenciais. As direções escolhidas são mostradas na Tabela 5.1, onde há um total de seis cortes selecionados devido a características específicas de cada um deles. 
Tabela 5.1: Cortes escolhidos para plotagem das curvas do campo elétrico. As coordenadas que definem o seguimento de reta de plotagem estão em centímetros.

\begin{tabular}{|c|c|c|c|}
\hline \multicolumn{4}{|c|}{ Direções Escolhidas para Visualização do Campo Elétrico } \\
\hline Nome & Ponto Inicial x0, y0, z0 (cm) & Ponto Final x1, y1, z1 (cm) & Direção \\
\hline DIR 1 & $(0.000,0.000,-0.203)$ & $(0.000,0.000,0.703)$ & Eixo Z \\
\hline DIR 2 & $(0.000,0.012,0.210)$ & $(0.014,0.012,0.210)$ & Eixo X \\
\hline DIR 3 & $(0.000,0.012,0.204)$ & $(0.014,0.012,0.204)$ & Eixo X \\
\hline DIR 4 & $(0.000,0.012,0.203)$ & $(0.014,0.012,0.203)$ & Eixo X \\
\hline DIR 5 & $(0.000,0.012,0.201)$ & $(0.014,0.012,0.201)$ & Eixo X \\
\hline DIR 6 & $(0.000,0.012,0.200)$ & $(0.014,0.012,0.200)$ & Eixo X \\
\hline
\end{tabular}

A seguir são apresentados os cortes selecionados e suas respectivas características que justificaram sua escolha:

- DIR 1: gráfico ao longo do eixo Z, atravessando todo o triplo GEM e passando pelo centro do furo em cada folha. Esse gráfico é interessante porque pode-se verificar a qualidade da simulação, uma vez que é averiguado se os campos nas regiões de deriva, indução e entre os GEM's são de fato constantes, como esperado dadas as condições de contorno. Além disso, podem ser observados os intensos módulos do campo elétrico no interior dos orifícios; 

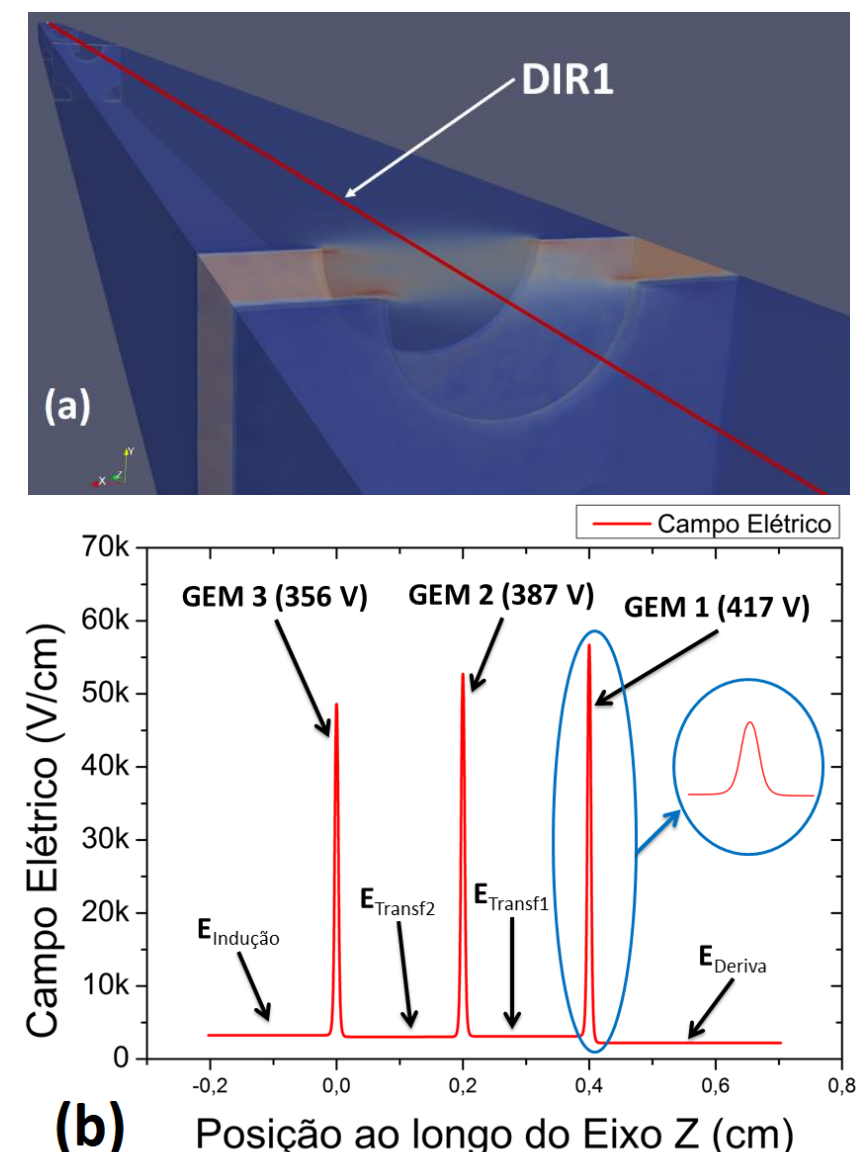

Figura 5.10: Acima em (a) é indicada a direção correspondente a DIR1. Em (b) é mostrado o campo elétrico ao longo dessa direção perpendicular ao plano das folhas do GEM, passando pelo centro dos furos.

- DIR 2: ao longo do eixo $X$, paralela à superfície da folha e acima da mesma. Para coordenadas maiores em Z $(0.210 \mathrm{~cm}$, aproximadamente) o campo elétrico é uniforme. Já para coordenadas menores em Z se iniciam as não uniformidades características nas proximidades dos furos; 


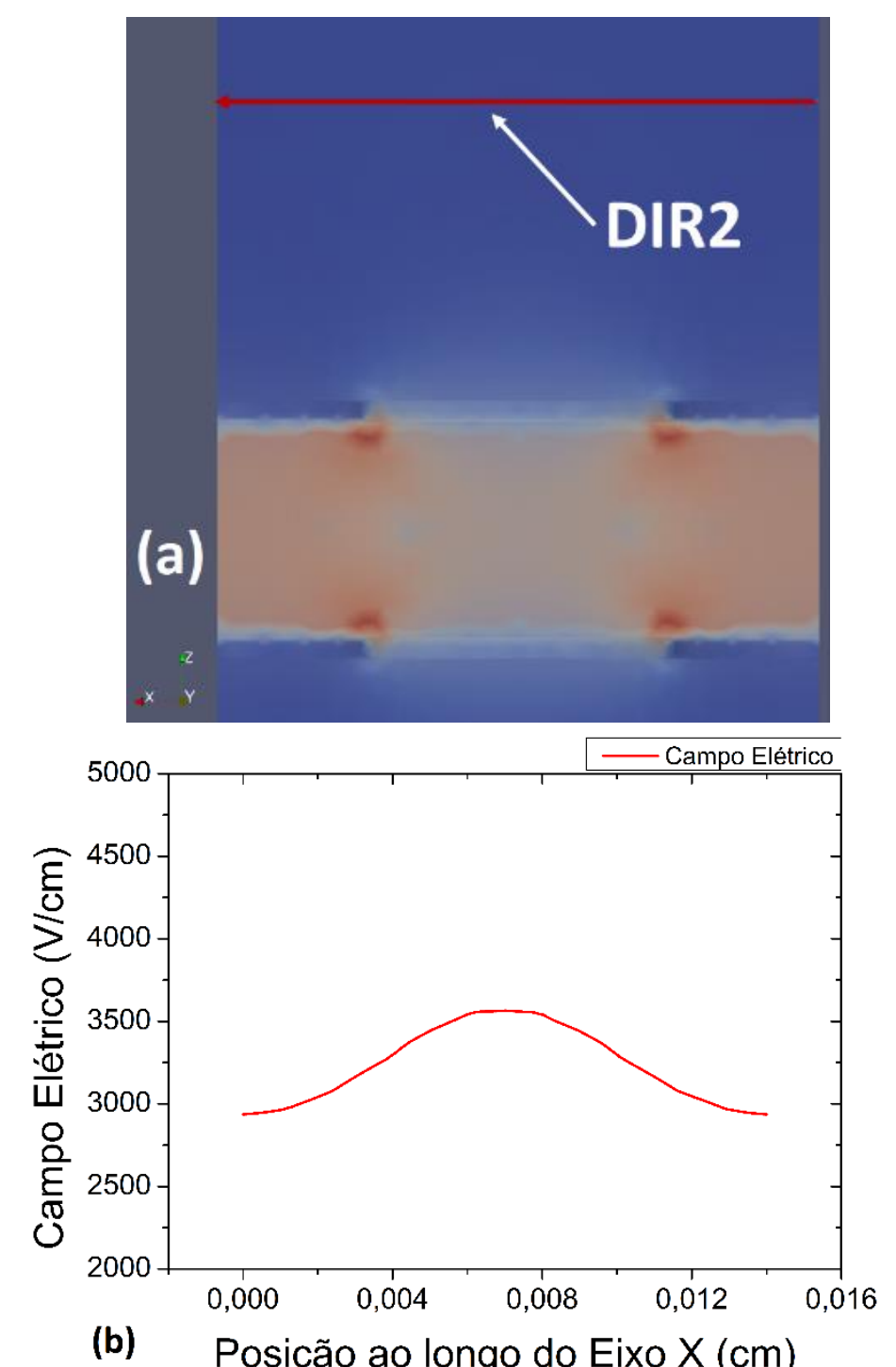

Figura 5.11: Em (a) é indicada a direção correspondente a DIR2. Já em (b) mostra-se o campo elétrico ao longo dessa direção, paralela ao plano do detector e nas proximidades do GEM1. Para planos cuja coordenada Z é maior que essa $(0,210 \mathrm{~cm})$, o campo é uniforme.

- DIR 3: ao longo do eixo $X$, paralela à superfície da folha, acima e nas proximidades da mesma. Nota-se uma intensidade muito maior no módulo do campo que em DIR 2; 

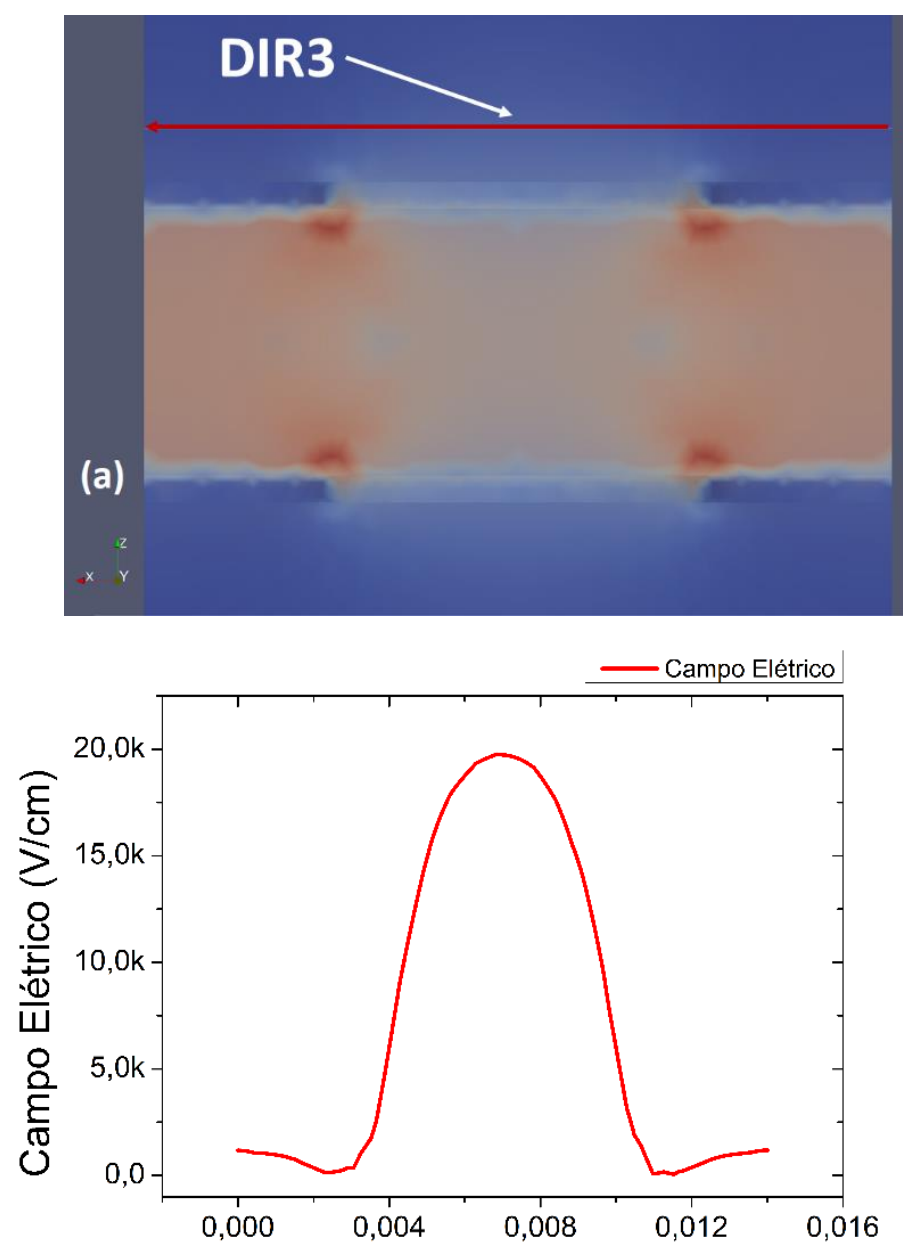

(b) Posição ao longo do Eixo $X(\mathrm{~cm})$

Figura 5.12: Indicação de DIR3 em (a) e do campo elétrico ao longo dessa direção, paralela ao plano do detector e nas proximidades do GEM1 em (b).

- DIR 4: na direção X, posicionada ligeiramente abaixo da superfície da folha, ou seja, no interior do cobre. Esse corte mostra a forte influência do campo sobre as cargas que se aproximam dessa área, ao mesmo tempo em que revela um campo nulo no interior da camada condutora, como esperado para o campo elétrico nessa região do condutor. Nas bordas do orifício o sentido do campo elétrico é invertido, pois nessa área há um rearranjo de cargas (Tikhonov \& Veenhof, 2002). Muito provavelmente é esse efeito que explica o fato de muitos elétrons serem aprisionados nessa região, especialmente nas proximidades da superfície inferior do GEM (veja Figura 5.24, por exemplo); 

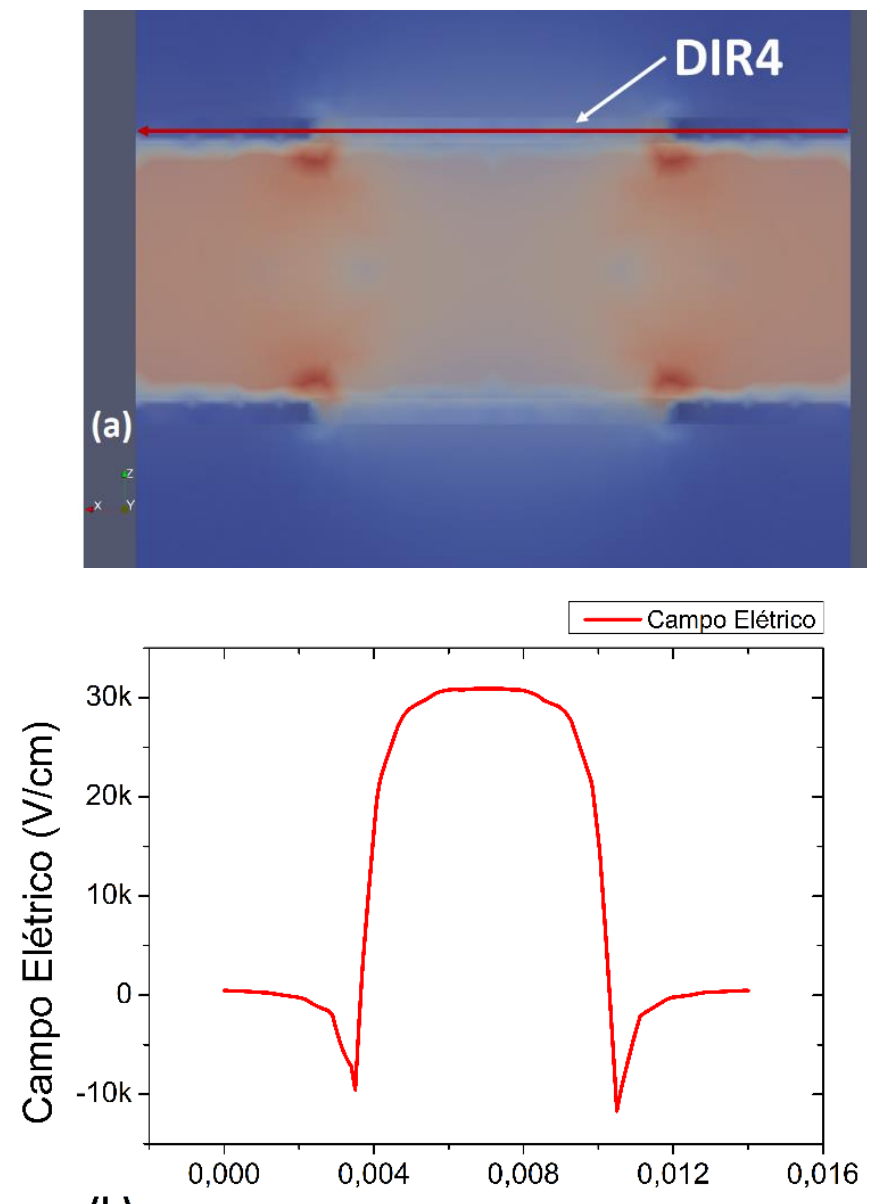

(b) Posição ao longo do Eixo $X(\mathrm{~cm})$

Figura 5.13: Indicação de DIR4 em (a) e do campo elétrico ao longo dessa direção, paralela ao plano do detector e passando pelo interior da camada condutora de cobre em (b).

- DIR 5: na direção X posicionado no interior do Kapton e acima do centro do furo. 0 módulo do campo nesse corte é bastante intenso, atingindo valores da ordem de $10^{5}$ $\mathrm{V} / \mathrm{cm}$ ou superiores em algumas configurações. É interessante notar uma transição entre a região do gás nas proximidades do centro e a região do Kapton nas bordas (lembrando que há a conicidade dos furos nessa área). Além disso, pode ser notado que o módulo do campo no Kapton é maior que no gás, característica esperada devido às características de rigidez dielétrica desse polímero. No entanto, pelo fato dos elétrons entrarem na região dos furos com energia cinética considerável, a maior parte dessas cargas acaba atravessando os furos sem serem direcionados para essa região de campo mais intenso (Veenhof, 2014); 


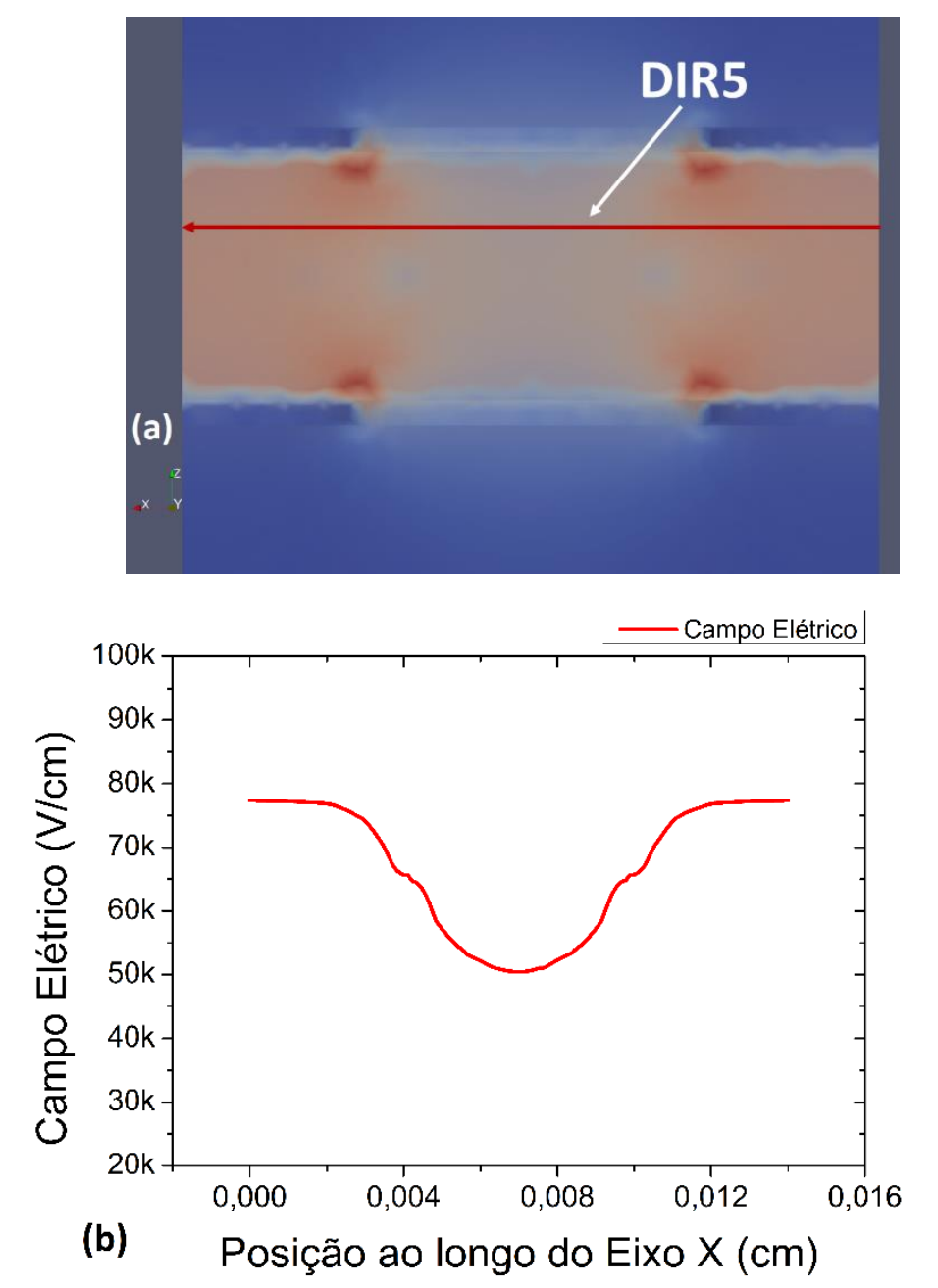

Figura 5.14: DIR5 é mostrada em (a), enquanto o campo elétrico ao longo dessa direção, paralela ao plano do detector e passando pelo interior do Kapton é mostrado em (b).

- DIR 6: gráfico ao longo do eixo X, posicionado no centro na folha de Kapton. Nota-se semelhança com a curva em DIR 5, com um campo que não chega a ser uniforme nas proximidades do centro do furo, mas apresenta uma variação suave até chegar no Kapton. 

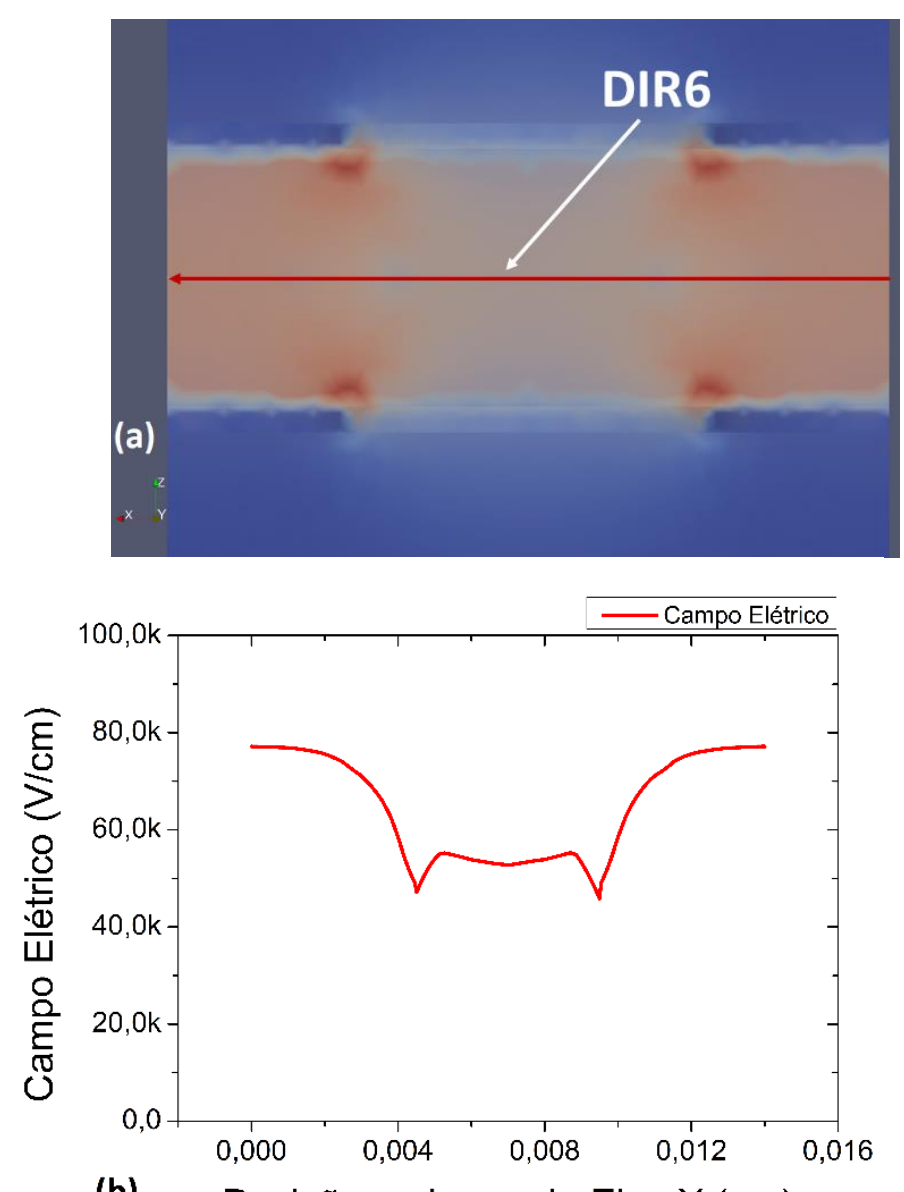

(b) Posição ao longo do Eixo $X(\mathrm{~cm})$

Figura 5.15: DIR6 em (a) e campo elétrico ao longo dessa direção, paralela ao plano do detector e localizado no centro do GEM em (b).

Para cortes com coordenadas Z abaixo de DIR 6 os resultados são similares aos cortes anteriores, dada a simetria da geometria em relação ao eixo Z. É interessante destacar que o perfil do campo elétrico nas proximidades dos furos já foi reportado na literatura e as características aqui apresentadas estão em acordo com o que já foi descrito ( $P$. Bhattacharya, Mukhopadhyay, Majumdar, \& Bhattacharya, 2012).

Na sequência (Figura 5.16) é mostrada uma projeção similar a DIR 1, mas exibindo apenas o campo nas proximidades do GEM1. O objetivo desse gráfico é expor em detalhe o perfil do campo elétrico nas proximidades dos orifícios, com destaque para a variação dessa grandeza em função da diferença de potencial aplicada no GEM. O gráfico mostra apenas o campo próximo ao orifício do GEM1, porém para os demais não foi observada nenhuma diferença sob a mesma diferença de potencial. 


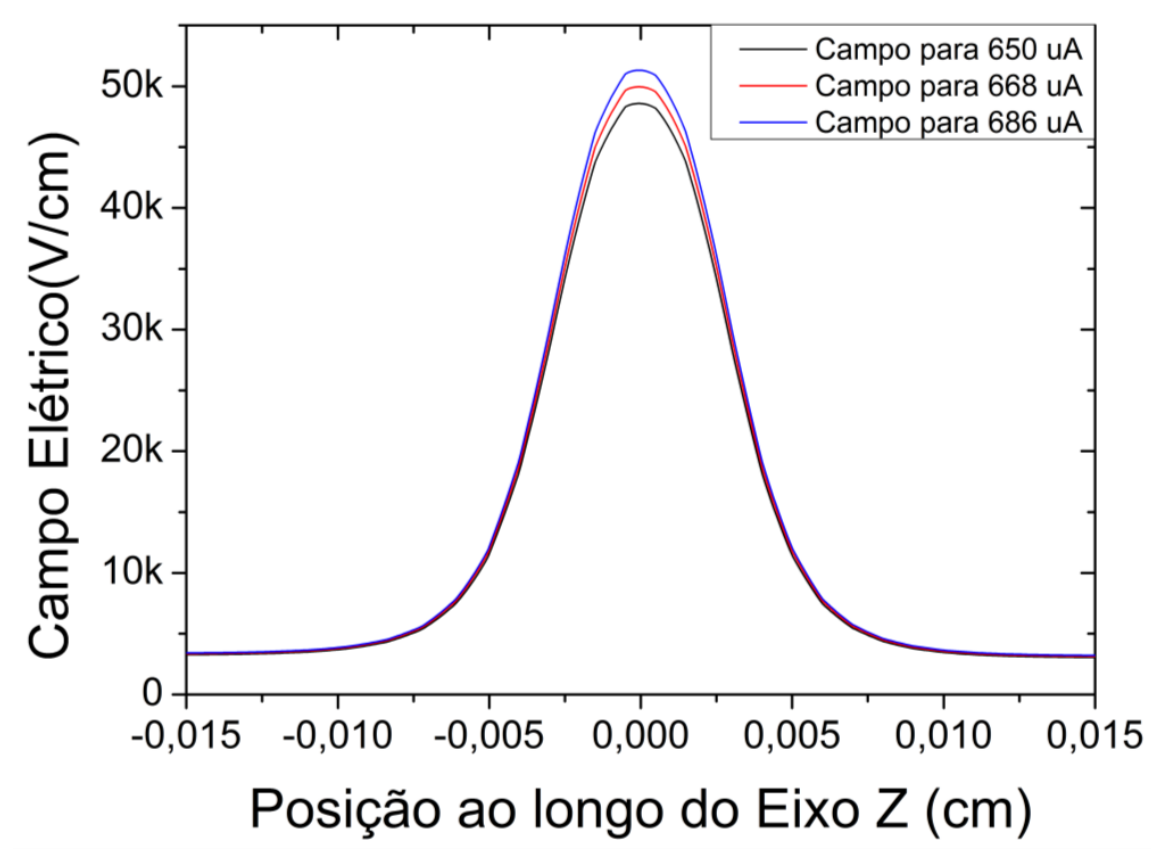

Figura 5.16: Campo elétrico na direção Z passando pelo centro do orifício similar a DIR1, mas destacando os detalhes do campo nas proximidades do orifício do primeiro GEM (GEM1).

\subsection{Efeito Avalanche e Ganho de Gás}

Uma vez que o número de cargas criado pela radiação no gás é geralmente insuficiente para se obter uma boa qualidade do sinal em relação ao ruído, os detectores proporcionais, tal como o GEM, fazem uso do efeito avalanche (descrito na seção 2.2.4). Como se sabe, esse efeito tem a interessante propriedade de amplificar o número de cargas coletadas e assim amplificar a amplitude do sinal (Blum et al., 2008). No GEM esse efeito ocorre apenas nas proximidades dos furos, onde o campo elétrico se intensifica o suficiente fazendo com que o número de elétrons cresça exponencialmente (Benlloch, Bressan, Buttner, et al., 1998; Sauli, 1997).

As simulações de ganho de gás no detector (número de ionizações produzidas pelo efeito avalanche) foram realizadas através da liberação de um elétron de uma dada posição inicial $\left(x_{0}, y_{0}, z_{0}\right)$ contida no meio sensível. Em seguida, no Garfield++ foi simulada a trajetória dessa carga primária e registradas suas interações com moléculas do gás. $\mathrm{Na}$ Figura 5.17 apresenta-se a simulação do efeito avalanche, onde se vê a trajetória de um elétron até o interior do furo do GEM, com a respectiva formação da avalanche eletrônica nessa região. O campo de deriva (acima do GEM) foi de $2,162 \mathrm{kV} / \mathrm{cm}$, enquanto aquele 
abaixo da folha foi de $2,925 \mathrm{kV} / \mathrm{cm}$. Foi aplicada uma diferença de potencial de $417 \mathrm{~V}$ entre as duas superfícies da folha nesse exemplo.

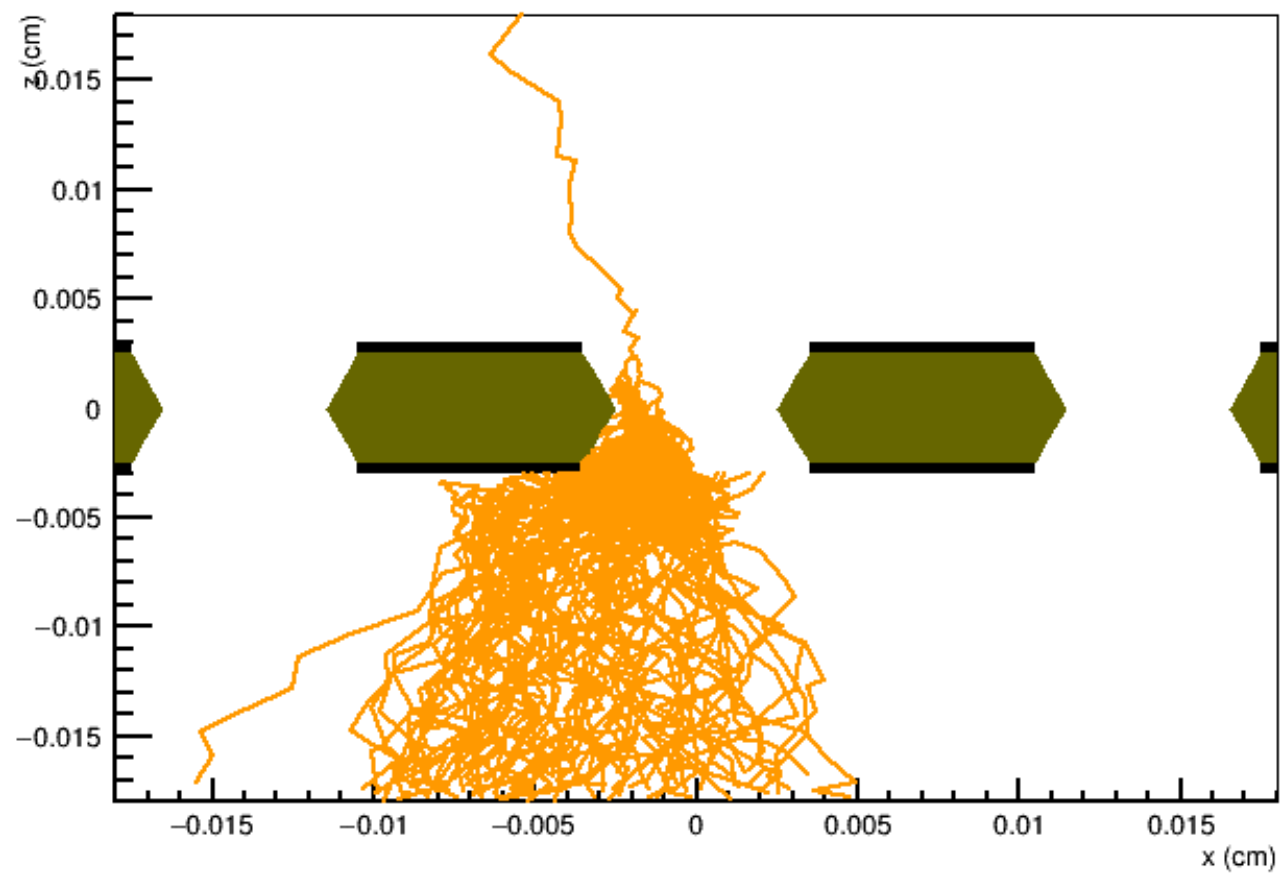

Figura 5.17: Simulação do efeito de multiplicação de cargas, onde observa-se a formação da avalanche quando o elétron penetra no furo do GEM e a deriva dos elétrons resultantes na direção do eletrodo gerador do campo de transferência (não mostrado na figura).

A grandeza conhecida como ganho de gás é dada pelo tamanho da avalanche, isto é, pelo número de elétrons presentes na mesma. Ela depende principalmente de parâmetros intrínsecos do detector, da diferença de potencial aplicada e da pressão do gás (Charles, 1972; Stéphan, 1997). Neste trabalho, foi simulado o ganho de um detector triplo GEM, composto por três estágios de amplificação. Em todas as simulações, foi aplicada uma pressão de 760 torr ( $1 \mathrm{~atm})$ e uma temperatura de $293,15 \mathrm{~K}\left(20^{\circ} \mathrm{C}\right)$.

Um dos parâmetros que pode ser obtido pela simulação de uma avalanche microscópica no Garfield++ é o número de elétrons criado pelo efeito avalanche. Desse modo, programou-se a liberação de elétrons $\mathbf{n}$ vezes, um de cada vez, a partir de uma dada posição inicial afastada da folha (tal como mostra o início da trajetória do elétron da Figura 5.17). Permitiu-se que o elétron tivesse um pequeno valor randômico em sua velocidade inicial e na posição no plano X-Y, cuja distância máxima em relação ao centro da distribuição foi da ordem do diâmetro dos furos $(70 \mu \mathrm{m})$. A partir da liberação dos elétrons, foi registrada a posição final de cada um daqueles presentes na avalanche, sendo que apenas aqueles que 
passaram pelos furos de todos os GEM's e chegaram à zona de indução (abaixo do GEM3 bottom) contribuíram efetivamente para o ganho (ganho efetivo) do detector. Em seguida, construiu-se um histograma com a distribuição do número de elétrons na avalanche que chegaram ao eletrodo de leitura (Readout), como mostra a Figura 5.18.

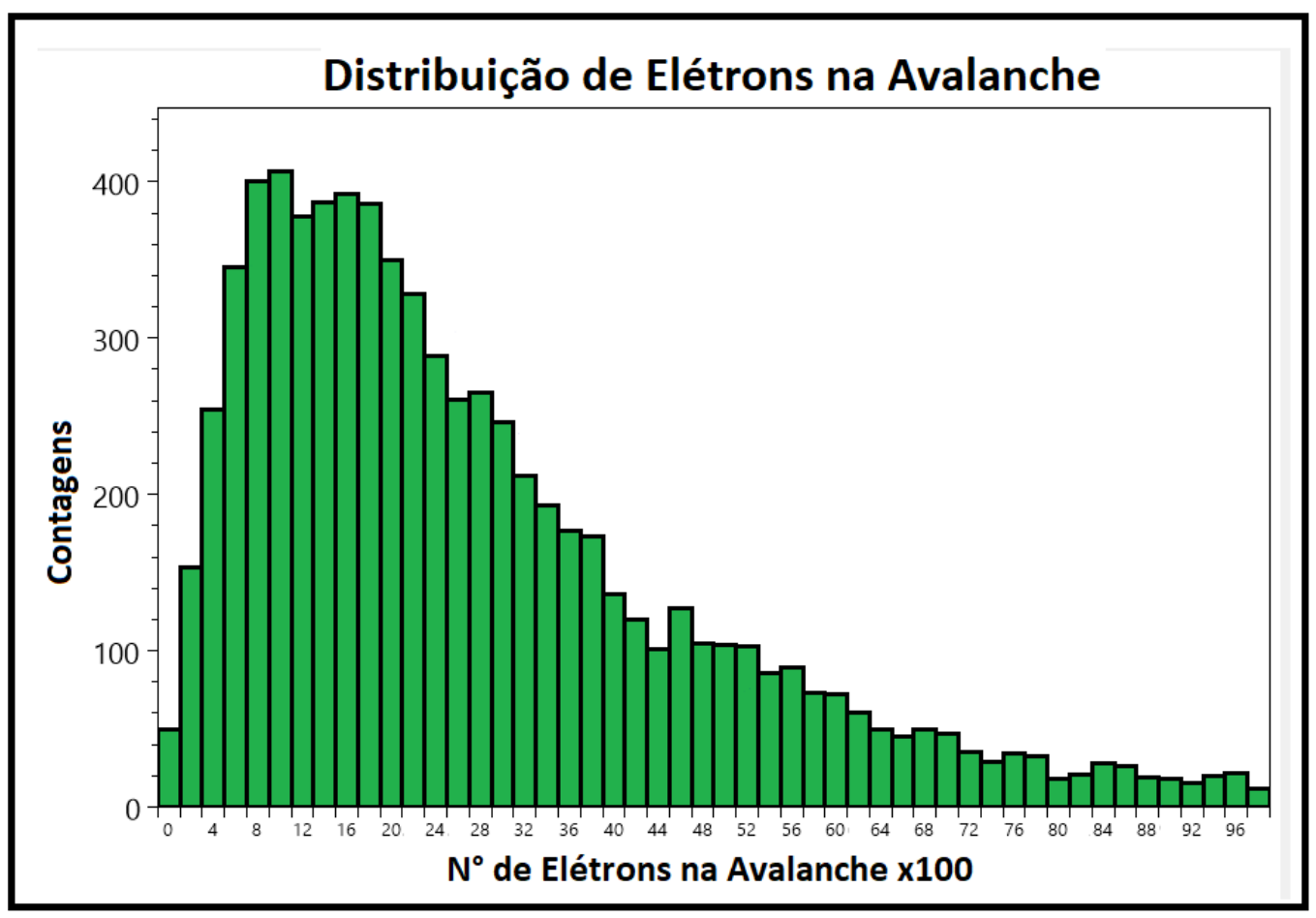

Figura 5.18: Exemplo da distribuição do número de elétrons na avalanche, mostrando o número de ocorrências (contagens) em função do tamanho da avalanche (número de elétrons na mesma). Nesse exemplo, foi aplicada uma diferença de potencial de $417 \mathrm{~V}$ na folha do GEM, um campo de deriva (acima do GEM) de 2,162 kV/cm e um campo de indução (abaixo do GEM) de $2,925 \mathrm{kV} / \mathrm{cm}$.

Como apontado ao final da seção 2.2.4, a distribuição do número de elétrons na avalanche segue uma distribuição conhecida como distribuição de Polya. Dessa maneira, para encontrar o número médio de elétrons na avalanche e assim determinar o ganho de gás, foi realizado um ajuste com essa distribuição utilizando uma rotina desenvolvida especificamente para essa finalidade, como mostra a Figura 5.19. Mais detalhes sobre a distribuição de Polya, bem como os parâmetros dos ajustes, podem ser observados no Apêndice B. 


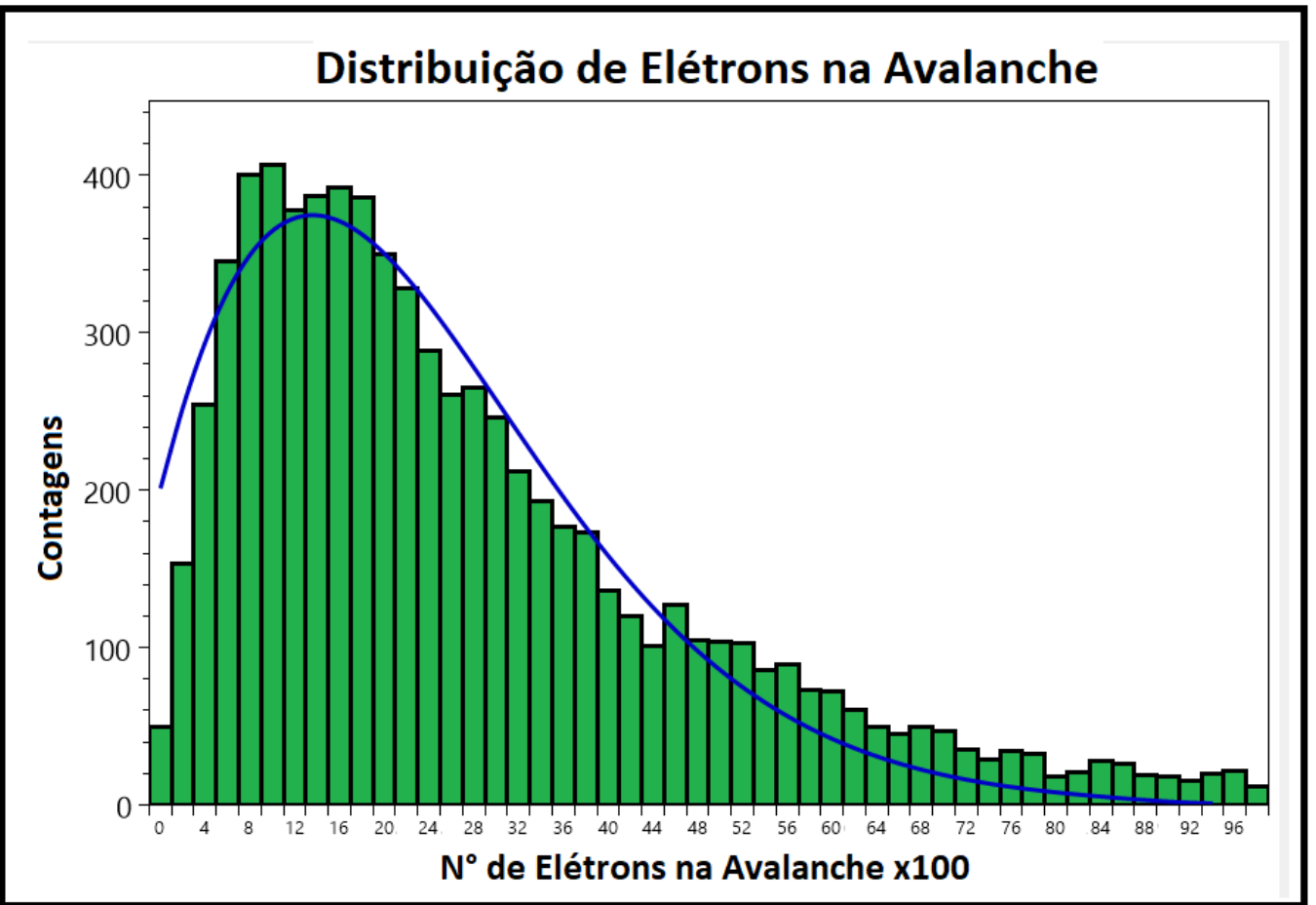

Figura 5.19: Ajuste da distribuição do número de elétrons na avalanche através de uma distribuição de Polya realizada com a rotina desenvolvida nesse trabalho.

A partir dos ajustes, foi obtido o ganho de gás para diferentes configurações de potencial aplicadas no GEM. Elas foram escolhidas segundo aquelas aplicadas experimentalmente no triplo GEM padrão do CERN (Apêndice A). Os ganhos obtidos podem ser observados na Figura 5.20. Nota-se como o ganho sem levar em conta o efeito Penning é consideravelmente menor do que levando em conta esse fenômeno, como já havia sido reportado na literatura. No caso do presente trabalho, a fração relativa a esse efeito ( $\left.r_{\text {Pen }}\right)$ que melhor adequou as simulações aos resultados experimentais foi 0,38.

É importante ressaltar que é válido tomar como o ganho de gás simulado o valor médio da distribuição de elétrons, isto é, considerando um grande número de avalanches. Isso é verdade porque o ganho experimental obtido tanto a partir de medições da corrente e da taxa de contagens de eventos sob exposição a uma fonte de raios X (Pulkkinen, 2013; Sales, 2015) quanto pelo pico do espectro de uma fonte radioativa (Burns et al., 2017; Patra, Singaraju, Biswas, Viyogi, \& Nayak, 2018) são medidos considerando um grande número de eventos. 


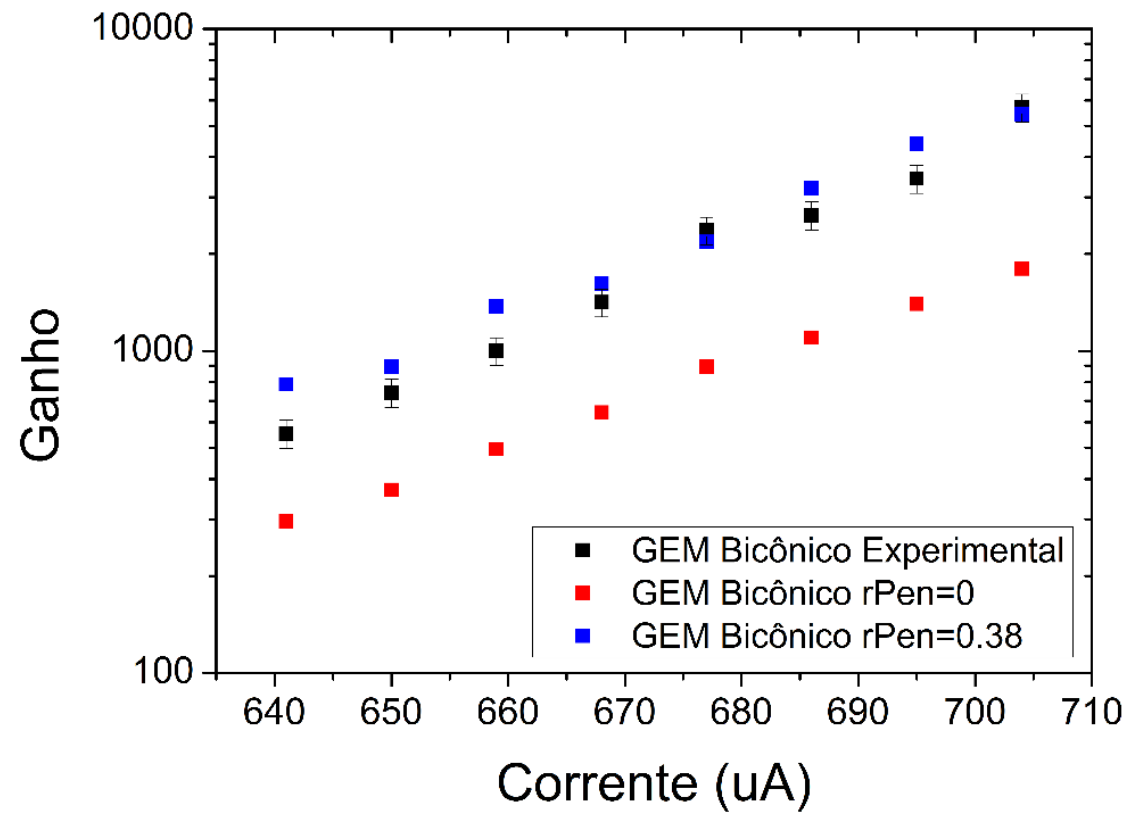

Figura 5.20: Ganho efetivo simulado de um triplo GEM padrão bicônico do CERN e a respectiva comparação com aquele obtido experimentalmente sob as mesmas configurações de campo e potencial. Nota-se como a simulação sem levar em conta o efeito Penning ( $\left.r_{\text {Pen }}=0\right)$ não é capaz de se ajustar aos dados experimentais, mostrando valores menores para o ganho. O valor do ganho nas simulações é dado pelo número médio de elétrons na avalanche, determinado a partir do ajuste pela distribuição de Polya.

\subsection{Eficiência de Coleta, Eficiência de Extração e Resolução Espacial}

Além da quantidade de elétrons secundários gerados no efeito avalanche, é possível obter como resultado da simulação a posição final $\left(\mathrm{x}_{1}, \mathrm{y}_{1}, \mathrm{z}_{1}\right)$ de cada um dos elétrons, tanto os iniciais (liberados em $x_{0}$, yo e $z_{0}$ ) quanto os secundários (gerados na avalanche). Na Figura 4.4 pode-se notar que o triplo GEM possui as seguintes estruturas:

- Plano de Deriva: eletrodo com maior potencial em módulo, responsável por acelerar os elétrons na direção do primeiro GEM (GEM 1) e coletar os íons produzidos na avalanche que não foram coletados nos demais eletrodos;

- GEM 1 Top: Eletrodo superior do primeiro GEM;

- GEM 1 Bottom: Eletrodo inferior do primeiro GEM;

- GEM 2 Top: Eletrodo superior do segundo GEM;

- GEM 2 Bottom: Eletrodo inferior do segundo GEM;

- GEM 3 Top: Eletrodo superior do terceiro GEM; 
- GEM 3 Bottom: Eletrodo inferior do terceiro GEM;

- Plano de Leitura (ReadOut): Eletrodo com menor potencial em módulo (terra), onde os sinais elétricos são coletados e enviados para a eletrônica de aquisição.

Uma vez que temos acesso às posições finais de cada um dos elétrons, é possível fazer a análise das cargas coletadas em cada um dos oito eletrodos citados acima, pois são conhecidas as posições ao longo do eixo $Z$ de cada um deles (Figura 5.1). Procedendo dessa maneira, podemos observar na Figura 5.21 a posição final dos elétrons em cada um dos três GEM's e no ReadOut em uma visão tridimensional.

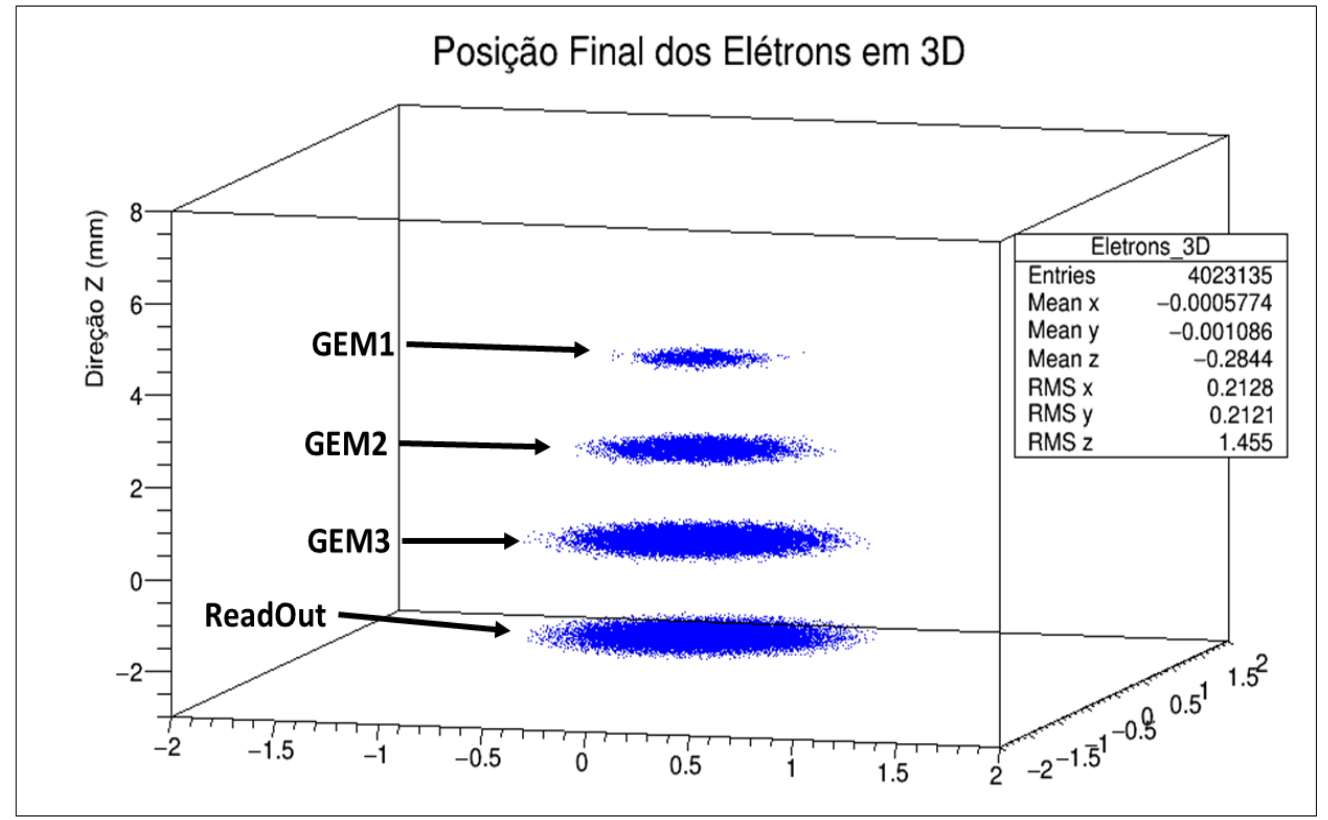

Figura 5.21: Posição final dos elétrons em uma visão em 3D, mostrando o aumento da avalanche até chegar no plano de leitura de sinais. Percebe-se que nenhum elétron se dirige ao plano de deriva $(Z=7 \mathrm{~mm})$.

Na sequência (Figura 5.22 até Figura 5.31), são apresentadas separadamente a distribuição espacial no plano X-Y dos elétrons para cada um dos eletrodos, além daqueles que acabam sendo parados na camada de Kapton. Note a ausência do eletrodo Plano de Deriva, pois nessa estrutura está aplicado o maior potencial negativo do detector, afastando dele todos os elétrons. 


\section{Distribuição de Elétrons no GEM 1 Top}

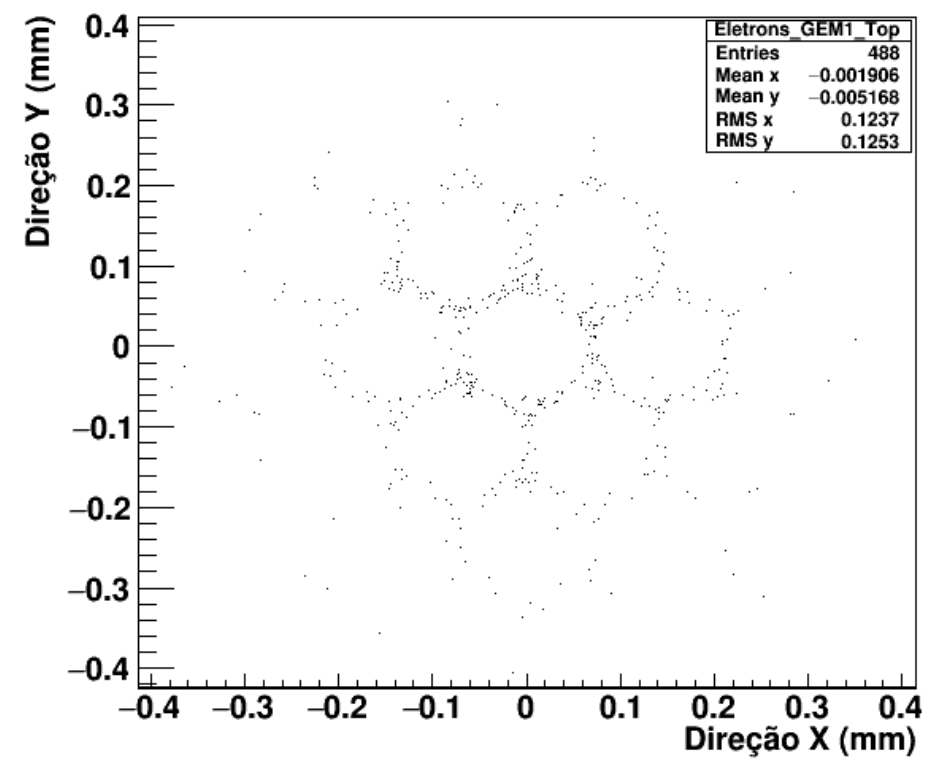

Figura 5.22: Posição final dos elétrons no plano X-Y na superfície superior do primeiro GEM. Essa distribuição mostra os elétrons que foram arremessados contra a parte superior do primeiro GEM pelo campo de deriva e, assim, não contribuem para o sinal observado pela eletrônica, que geralmente capta o sinal do ReadOut ou do GEM3 Bottom, apenas.



Figura 5.23: Distribuição dos elétrons no Kapton do primeiro GEM 1. Parte dos elétrons se distribui na camada do polímero que forma a conicidade dos orifícios. 


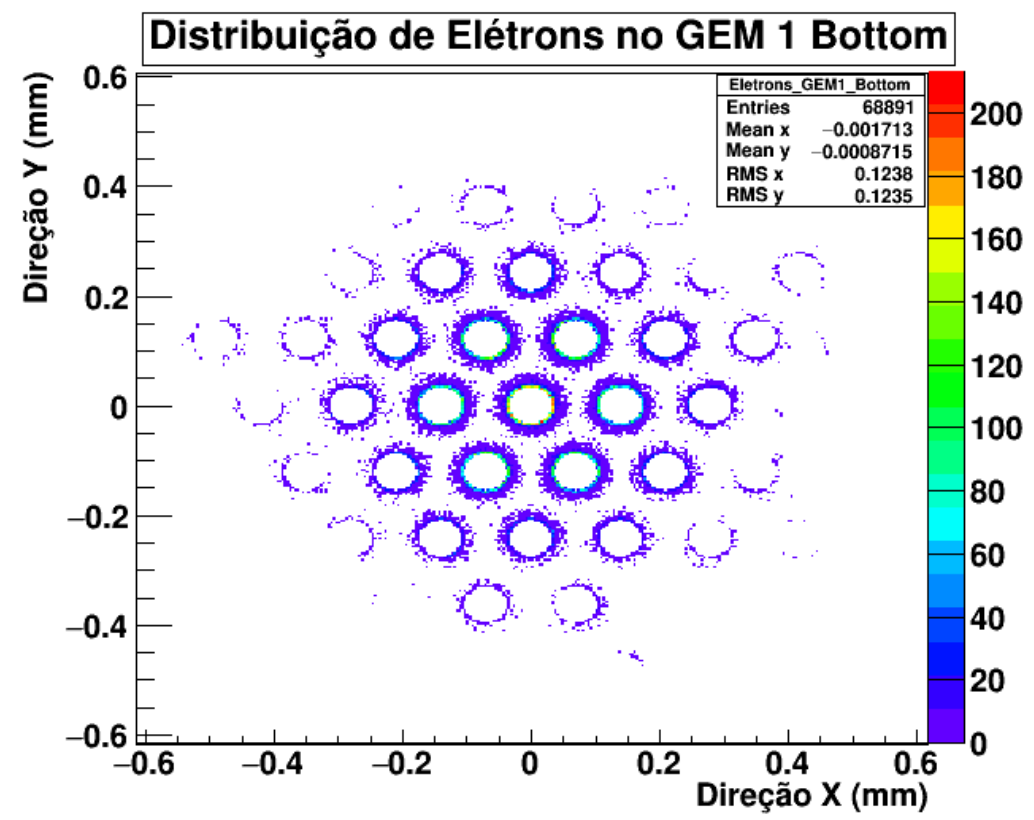

Figura 5.24: Distribuição da posição final dos elétrons na superfície inferior do primeiro GEM. Nesse caso, é observado que os elétrons se distribuem nas proximidades dos orifícios devido ao rearranjo de cargas que ocorre nessa região (Bouianov, Bouianov, Orava, Semenov, \& Tikhonov, 2000; Tikhonov \& Veenhof, 2002).

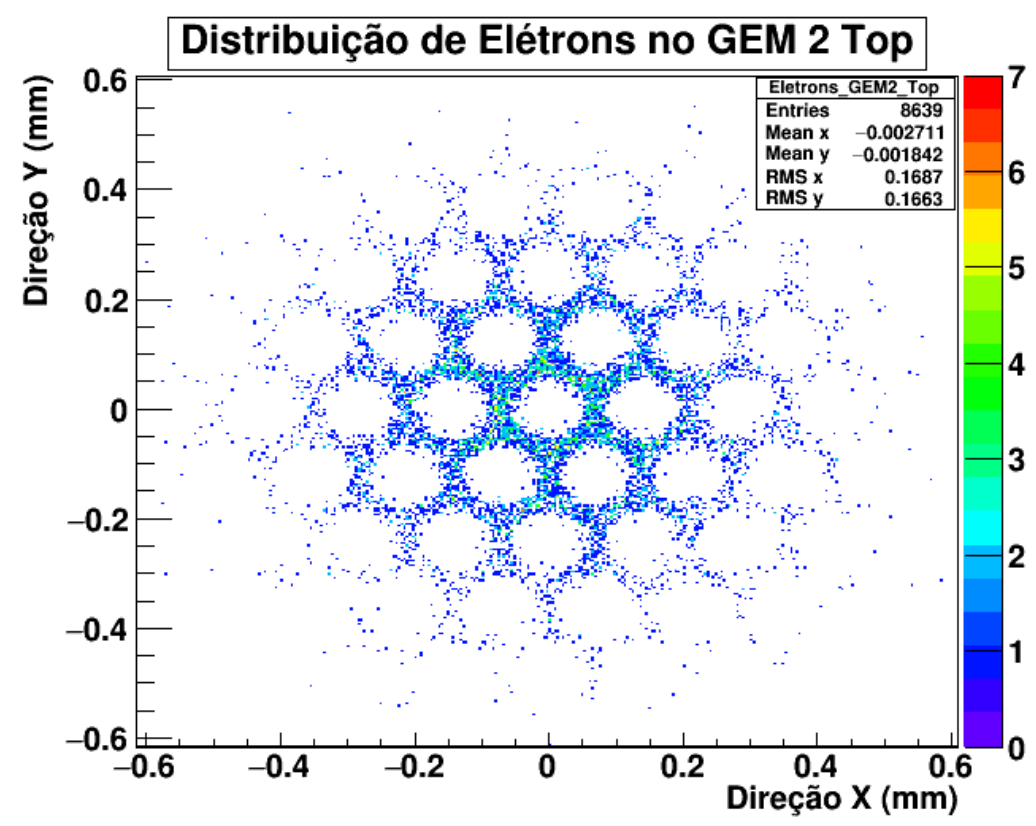

Figura 5.25: Posição final dos elétrons na superfície superior do segundo GEM. Os elétrons arremessados pelo campo contra a superfície superior acabam se distribuindo continuamente, enquanto que na superfície inferior tendem a se concentrar nas proximidades dos orifícios. 




Figura 5.26: Distribuição dos elétrons no Kapton do segundo GEM. Nota-se um aumento na dispersão transversal no plano $X-Y$, aumentando o número de furos ao redor dos quais as cargas acabam sendo depositadas.

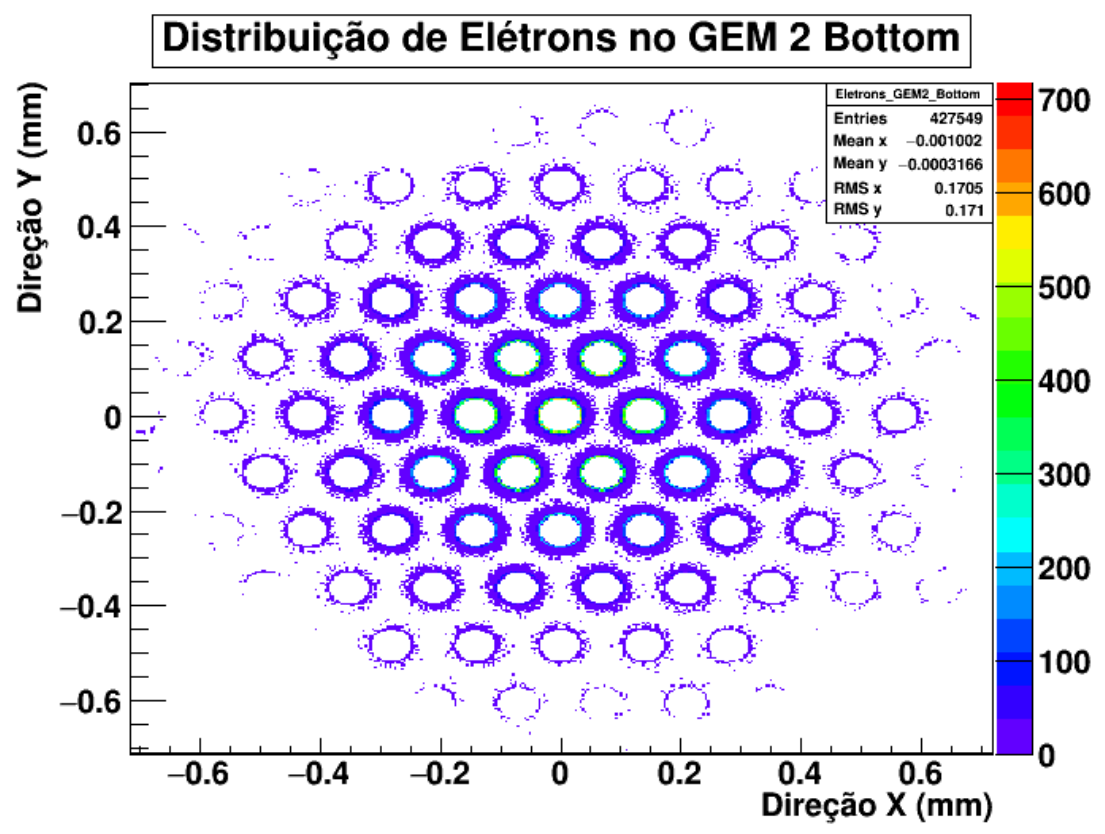

Figura 5.27: Posição final dos elétrons no plano X-Y na superfície inferior do segundo GEM. São observadas as mesmas características apresentadas na respectiva figura do primeiro GEM, mas com maior alargamento da distribuição refletindo um aumento espacial da avalanche no plano. 


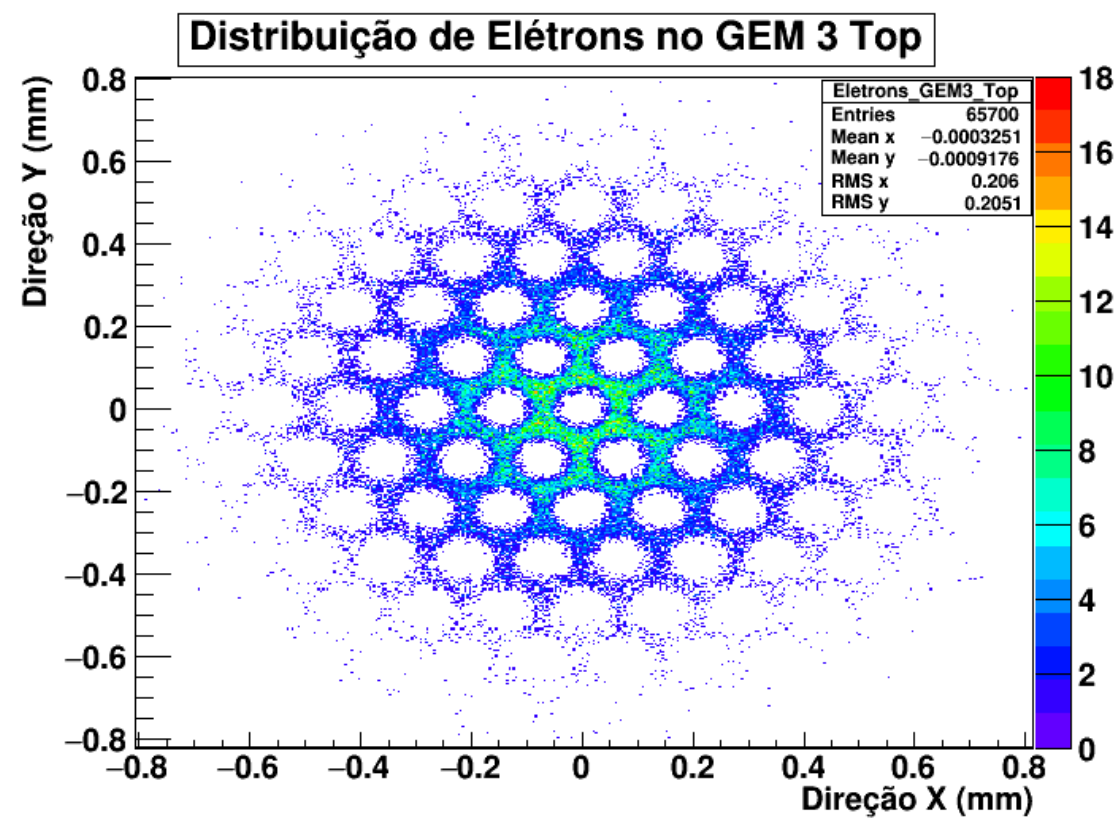

Figura 5.28: Posição final dos elétrons na superfície superior do terceiro GEM. Conforme se avança nos eletrodos ao longo do eixo Z, observa-se um aumento na dispersão transversal no plano, elevando a quantidade de furos ao redor dos quais os elétrons são depositados.

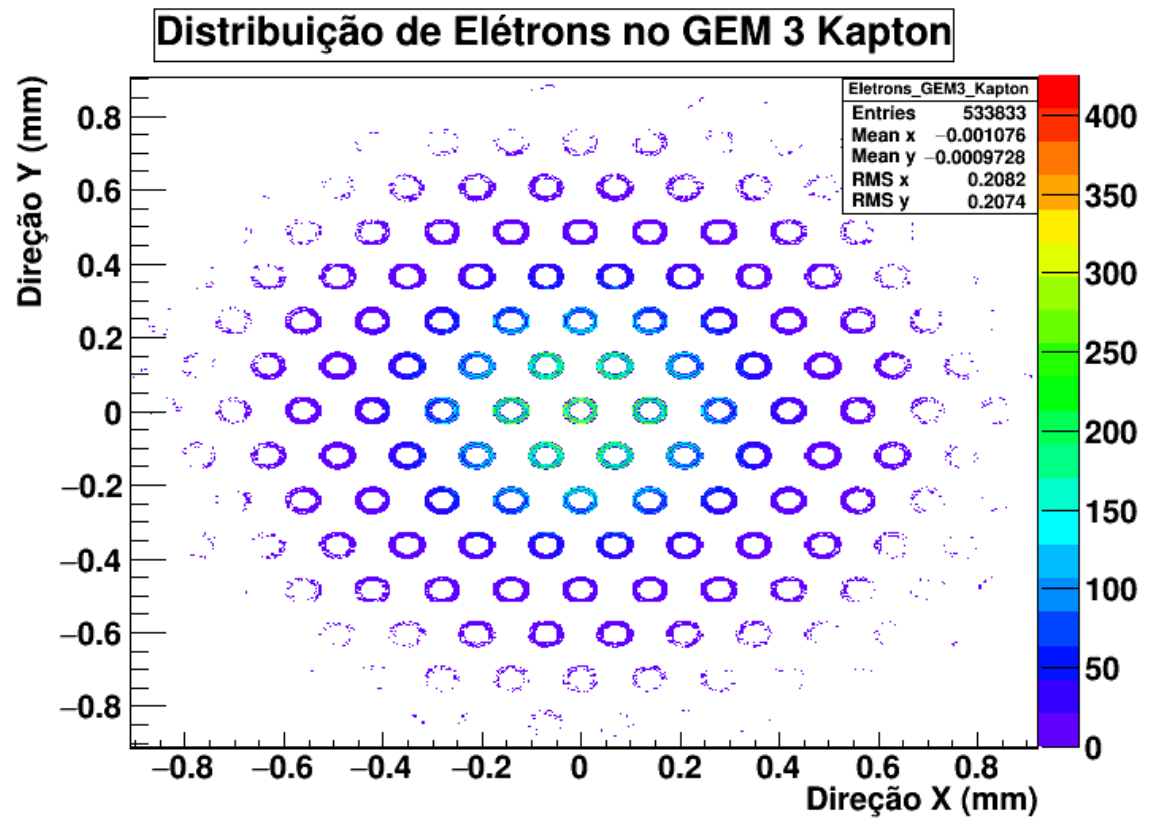

Figura 5.29: Posição final dos elétrons no Kapton do terceiro GEM. É notável uma concentração maior no centro da imagem, cuja intensidade se atenua conforme se afasta do centro da distribuição. 


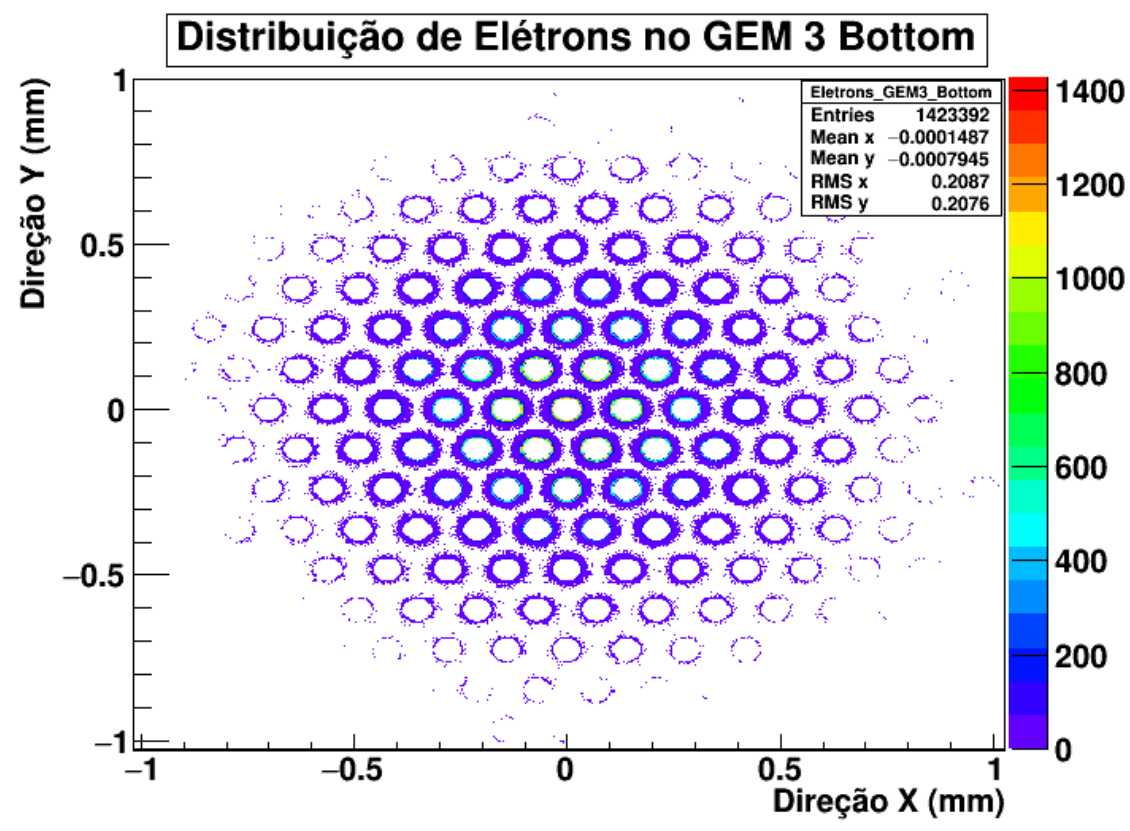

Figura 5.30: Posição final dos elétrons no plano X-Y na superfície inferior do terceiro GEM.

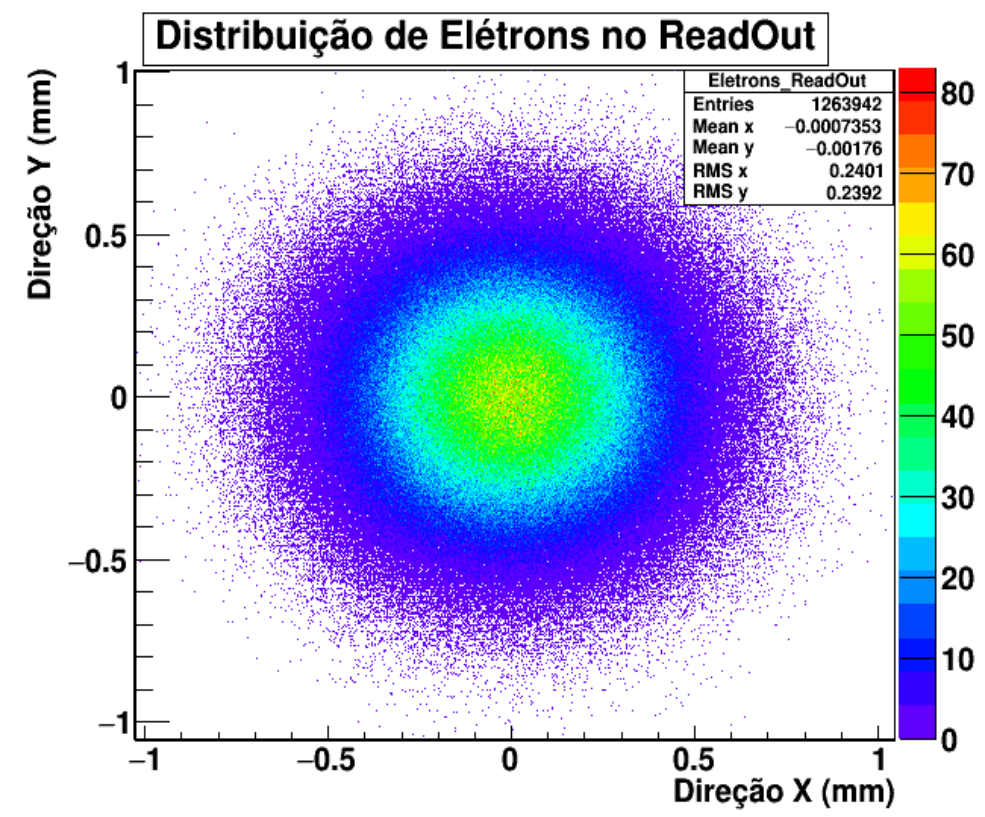

Figura 5.31: Posição final dos elétrons no plano X-Y no eletrodo de leitura (ReadOut). Pode-se observar que nesse eletrodo a distribuição espacial obtida não mostra a posição dos furos, diferentemente dos anteriores.

A eficiência de coleta dos elétrons $\left(E_{C}\right)$ - ou transparência de elétrons - representa a fração de todos os elétrons que se dirigem ao orifício do GEM ( $\boldsymbol{N}_{\text {Inicial }}$ ) e que são efetivamente coletados e entram no furo $\left(\boldsymbol{N}_{\text {coletado }}\right)$. Assim, ela considera os elétrons que não ficaram presos na superfície superior do GEM. Essa grandeza é definida como (Hallermann, 2010): 


$$
E_{C}=\frac{N_{\text {Coletado }}}{N_{\text {Inicial }}}=1-\frac{N_{\text {Top }}}{N_{\text {Inicial }}}
$$

onde $\mathrm{N}_{\text {Top }}$ é a quantidade de carga que foi depositada na superfície superior do GEM.

A eficiência de extração $\left(E_{E x t}\right)$ representa os elétrons que são capazes de sair dos orifícios sem serem coletados na superfície inferior do GEM e pode ser definida por (Hallermann, 2010):

$$
E_{\text {Ext }}=\frac{N_{\text {Extraido }}}{N_{\text {Produzido }}}=\frac{N_{\text {ReadOut }}}{N_{\text {Readout }}+N_{\text {Bottom }}}
$$

onde $\boldsymbol{N}_{\text {Extraido }}$ é o número de elétrons que deixa o GEM sem ficar preso em sua superfície

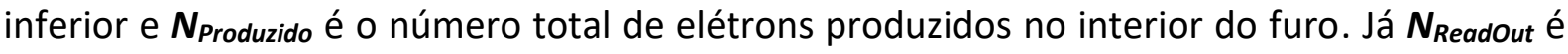
o número de elétrons no plano de leitura, enquanto $\boldsymbol{N}_{\text {Bottom }}$ são os elétrons presos na superfície inferior do GEM.

A eficiência da coleta é de aproximadamente 1 (todos os elétrons coletados pelos furos do GEM) em caso de campo de deriva de módulo baixo, começando a diminuir após cerca de $0,5 \mathrm{kV} / \mathrm{cm}$ (Wang et al., 2019). Já a eficiência de extração, por outro lado, tende a crescer em função do incremento no módulo do campo de indução (Hallermann, 2010).

A partir da distribuição da posição final dos elétrons no plano de leitura (Figura 5.31), pode-se tomar as projeções nas direções $\mathrm{X}$ e $\mathrm{Y}$, ajustar uma Gaussiana e assim obter a partir desse ajuste sua largura a meia altura. Esse parâmetro fornecerá o valor intrínseco da resolução espacial do detector, ou seja, a melhor possível para esse dispositivo nas configurações geométricas, de potenciais e campos estudados. Essa resolução é uma consequência do movimento dos elétrons na direção transversal, provocando um aumento espacial da avalanche no plano X-Y. As projeções a partir da Figura 5.31, com o ajuste e os parâmetros, podem ser observadas nas Figura 5.32 e Figura 5.33. Para a condição simulada e mostrada nas figuras anteriormente, a resolução espacial considerando a largura a meia altura foi de $(0,558 \pm 0,003) \mathrm{mm}$ na direção $X$ e de $(0,560 \pm 0,002) \mathrm{mm}$ na direção $Y$. Os valores de resolução encontrados estão de acordo com os valores típicos encontrados na literatura (Azevedo et al., 2015), além de serem iguais entre elas, considerando as incertezas do ajuste. 


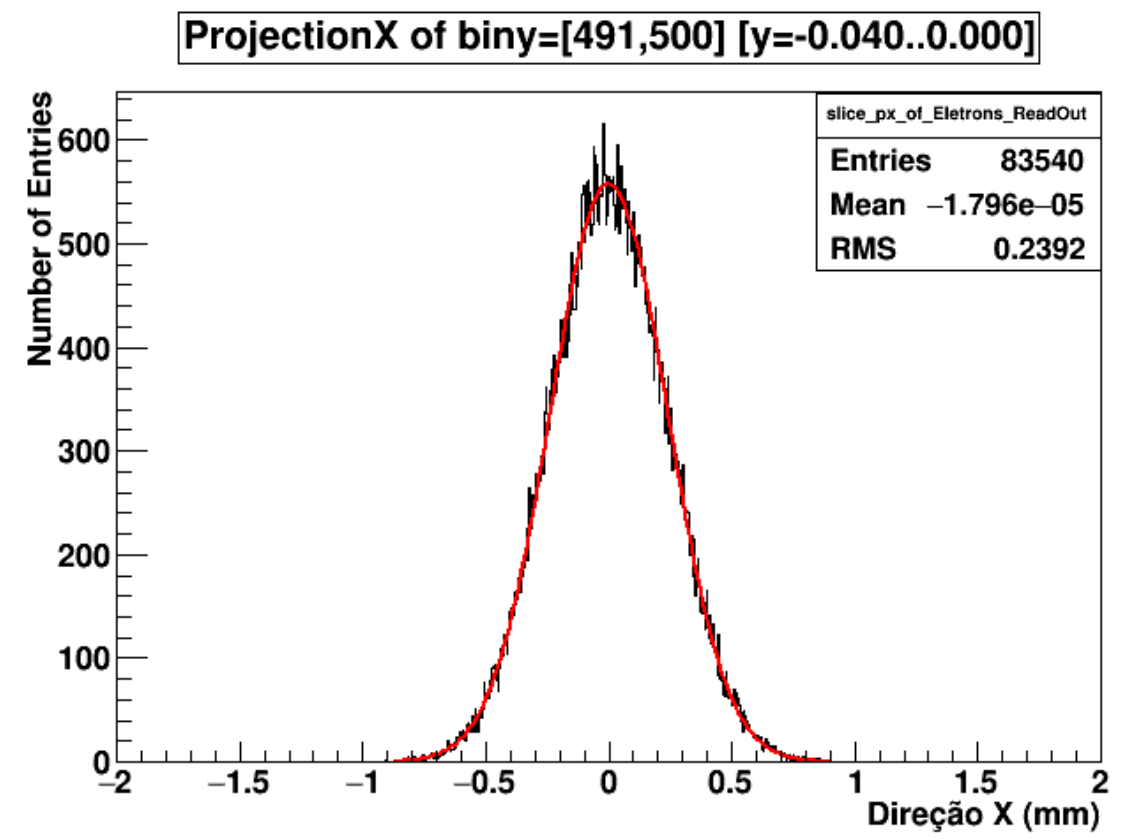

Figura 5.32: Projeção na direção $X$ da distribuição da posição final dos elétrons observada na Figura 5.31. A resolução obtida para essa configuração foi de $(558 \pm 3) \mu \mathrm{m}$.

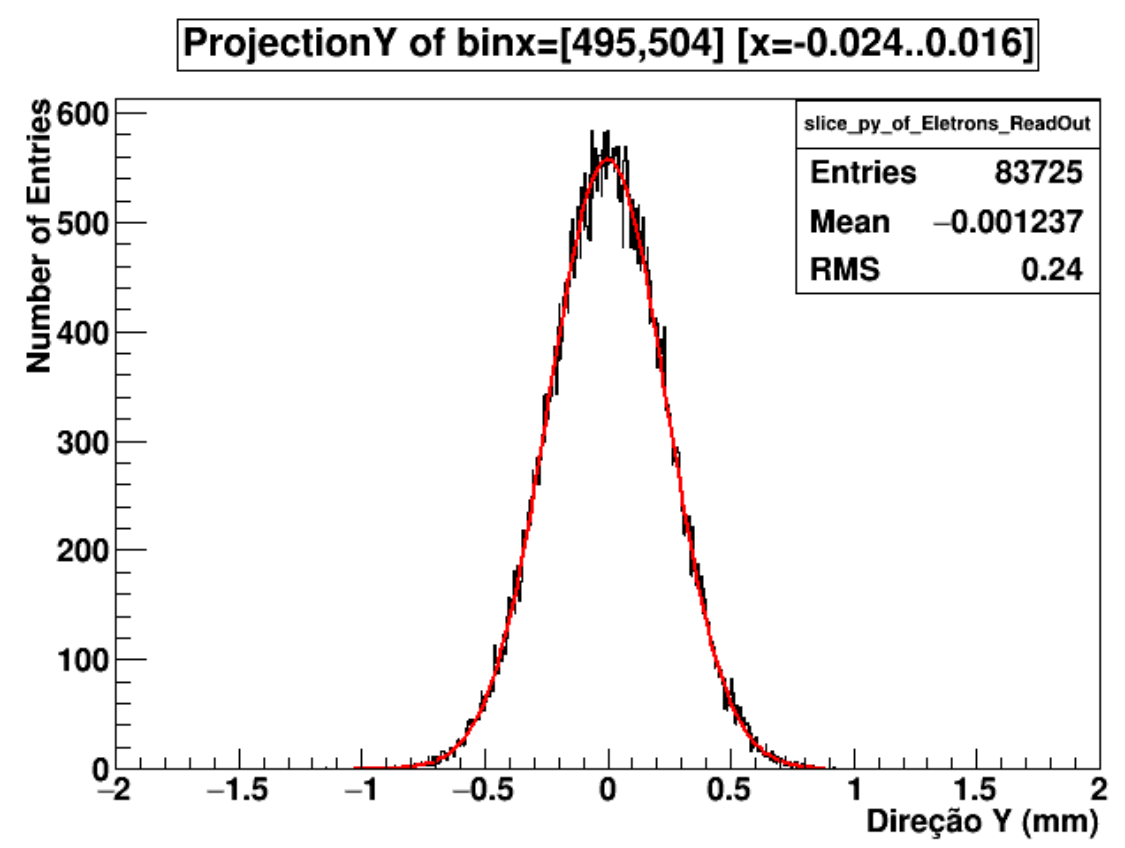

Figura 5.33: Projeção na direção $Y$ da distribuição da posição final dos elétron observada na Figura 5.31. A resolução obtida para essa configuração foi de $(560 \pm 2) \mu \mathrm{m}$. 


\subsection{Simulação do Espectro e Resolução em Energia da Fonte de ${ }^{55} \mathrm{Fe}$}

Para realizar a simulação da resolução em energia (seção 2.4) da fonte de raios $X$ provenientes da ${ }^{55} \mathrm{Fe}$ (seção 3.3), primeiramente foi necessário modelar a fonte no Garfield++, pois no programa não há um algoritmo para essa finalidade. Essa tarefa foi realizada aplicando as intensidades relativas de ocorrência de cada uma das energias indicadas na Tabela 3.1 para a energia dos fótons. Foram excluídos os raios $\mathrm{X}$ provenientes das emissões a partir da camada $\mathrm{L}$ (cerca de $0,6 \mathrm{keV}$ ), pois usualmente não aparecem em um espectro experimental da fonte de ${ }^{55} \mathrm{Fe}$ (Schötzig, 2000).

O pseudocódigo aplicado na simulação pode ser observado na Figura 5.34, onde a variável prob recebe um valor entre 0 e 181, de acordo com o retorno da função RndmUniform (entre zero e um), multiplicada pelo número 181. Esse valor é a soma das intensidades relativas das possíveis energias do fóton emitido pelo átomo excitado de $\mathrm{Mn}$ após o decaimento do ${ }^{55} \mathrm{Fe}: \mathrm{K} \alpha_{1}(100), K \alpha_{2}$ (50) e $K \beta_{1}$ (17) acrescido do valor que corresponde à intensidade relativa do pico de escape do argônio (14) (Watanabe, Schnopper, \& Cirillo, 1962), cuja energia é de 2900 eV.

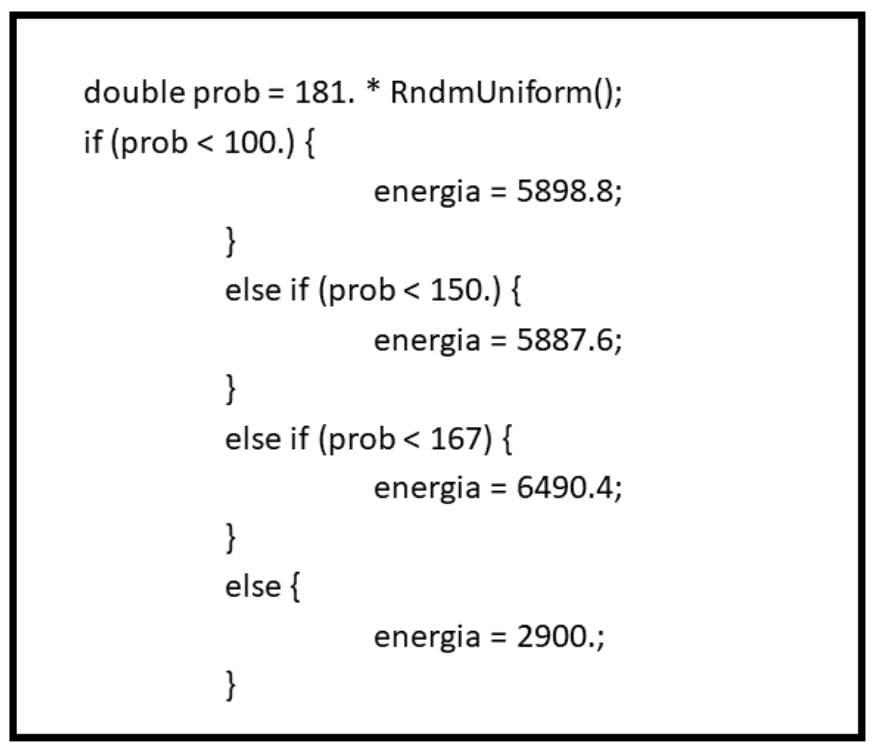

Figura 5.34: Pseudocódigo utilizado para reproduzir nas simulações o espectro da fonte de ${ }^{55} \mathrm{Fe}$. A variável prob representa a intensidade relativa de ocorrência obtida a partir da função RndmUniform (que retorna um valor double com iguais probabilidades entre 0 e 1), multiplicada pelo valor 181 (soma das intensidades relativas para todas as energias possíveis). 
O gráfico da intensidade relativa em função da energia obtido com a aplicação do pseudocódigo descrito anteriormente é mostrado na Figura 5.35, onde são destacadas as linhas correspondentes às emissões de $K \alpha_{1}, K \alpha_{2}, K \beta_{1}$ e o pico de escape do argônio.

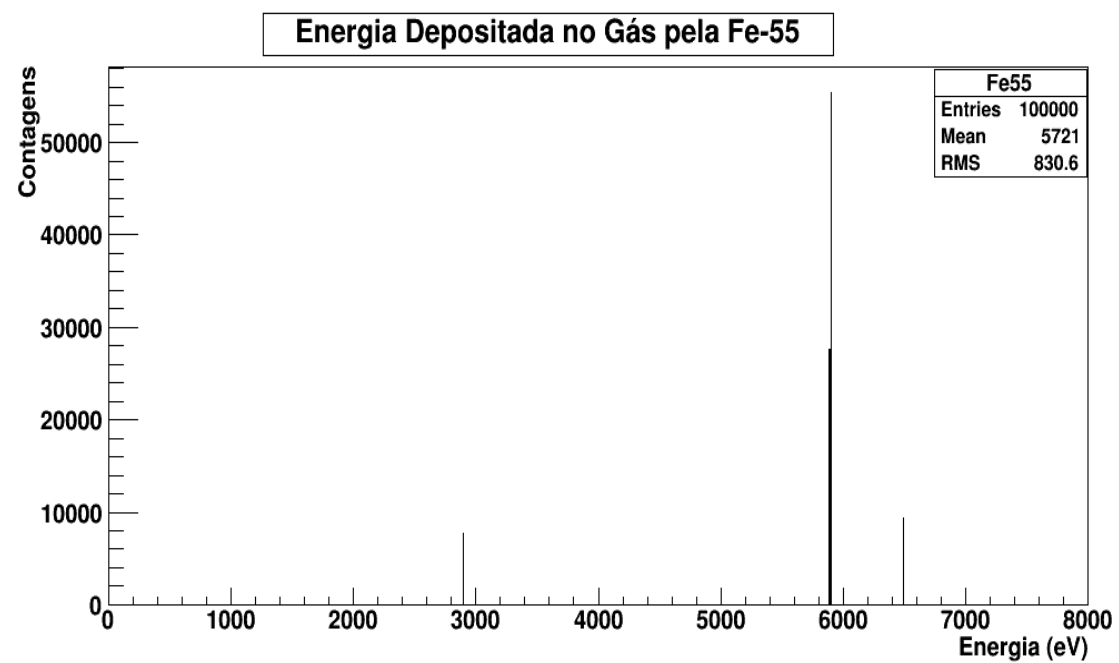

Figura 5.35: Linhas de intensidade relativa para todas as possíveis energias depositadas no gás pela fonte de ${ }^{55} \mathrm{Fe}$.

Após obter o valor de energia a ser depositada no gás (Figura 5.35), realizou-se a simulação do transporte de fóton no Garfield++, que retorna o número de pares de elétrons-íons criados para cada valor de energia, um por vez. Os resultados para $1 \times 10^{5}$ eventos podem ser observados na Figura 5.36.

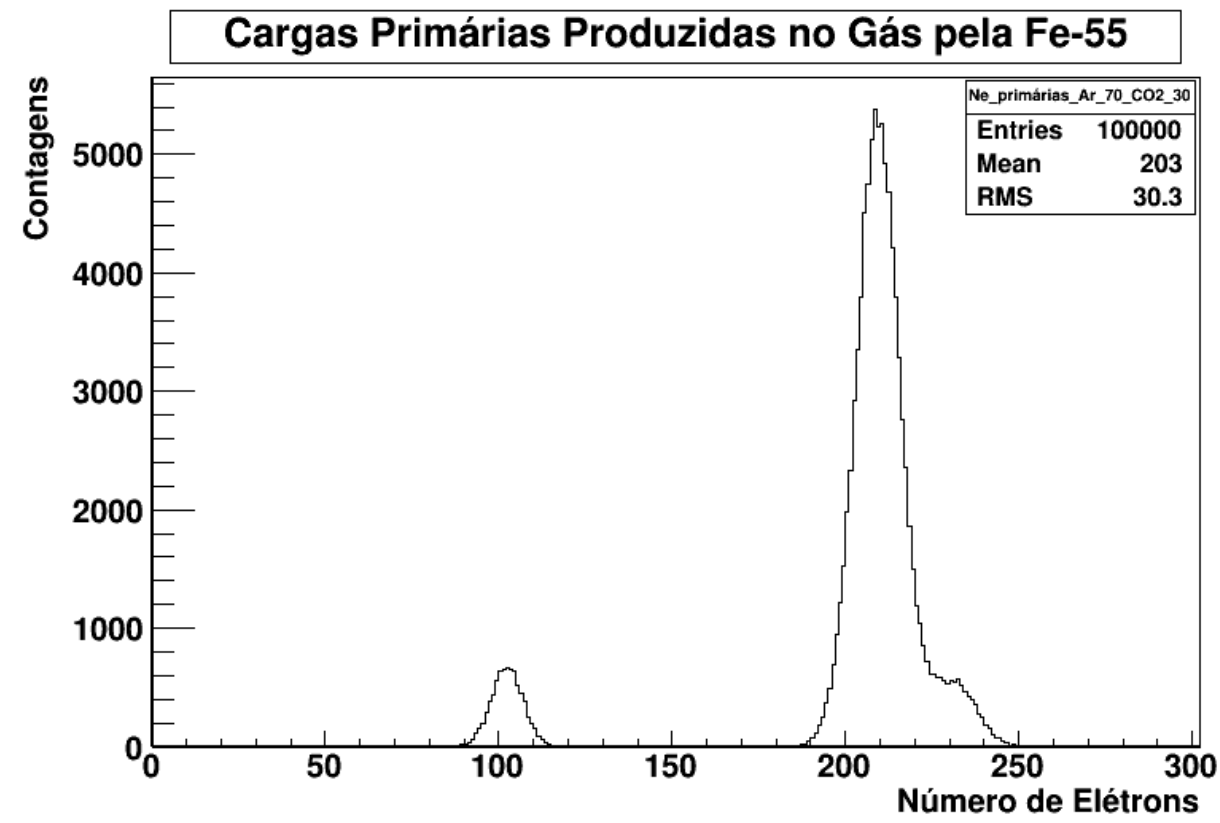

Figura 5.36: Número de ocorrências (contagens) em função do número de elétrons criados pela deposição da energia da radiação no gás (cargas primárias), para a mistura de $70 \%$ de $\mathrm{Ar}$ e $30 \%$ de $\mathrm{CO}_{2}$. 
A partir da equação (2.1) pôde-se calcular o número de pares de cargas primárias criado. Nesse cálculo, foram utilizados os valores de energia correspondentes às transições da camada K do Mn e também do pico de escape do argônio. Além disso, foram aplicados os valores das energias médias para produção de um par de íons para os dois gases: $\mathrm{W}_{\mathrm{Ar}}=26$ eV e $W_{\mathrm{CO} 2}=33$ eV (Grupen \& Shwartz, 2008). Os resultados são apresentados na Tabela 5.2, onde nota-se que eles estão de acordo com aqueles mostrados na Figura 5.36. Lembrando que o processo de produção de pares de elétrons-íons para uma dada deposição de energia é um processo estatístico. Desse modo, caso fossem produzidos em média $\boldsymbol{n}$ pares, seria esperado uma flutuação de acordo com as estatísticas de Poisson com um erro de $\sqrt{n}$. Contudo, essa flutuação em torno do valor médio acaba sendo menor, dada por $\sqrt{n \cdot F}$, sendo $\boldsymbol{F}$ o fator de Fano (Fano, 1963; Grupen \& Shwartz, 2008). O valor estimado para esse fator é de 0,16 para elétrons no argônio (Doke, Ishida, \& Kase, 1992).

Observando a Figura 5.36, fica evidenciado que devido às flutuações estatísticas no número de pares de elétrons-íons, não é possível obter uma resolução em energia que permita separar as energias correspondentes a $K \alpha_{1}, K \alpha_{2}$ e $K \beta_{1}$ para esse tipo de detector a gás. Repare que isso independe do ruído eletrônico ou outras flutuações na amplitude do sinal, que certamente irão alargar ainda mais o espectro da fonte de ${ }^{55} \mathrm{Fe}$. Note que nesse ponto da simulação ainda não foram consideradas as flutuações inerentes ao processo de avalanche eletrônica, como discutido na seção 2.4, ou seja, o espectro experimental será mais largo, prejudicando ainda mais a resolução em energia.

Tabela 5.2: Número de pares de elétrons-íons produzidos no gás em função da energia depositada. Cálculo realizado segundo a equação (2.1) para as energias correspondentes às transições $K \alpha_{1}$, $K \alpha_{2}$ e $K \beta_{1}$ do manganês, além do pico de escape do argônio.

\begin{tabular}{|c|c|}
\hline Energia Depositada no Gás (eV) & Pares de elétrons-íons criados \\
\hline 2900,00 & 104,4 \\
\hline 5887,65 & 212,0 \\
\hline 5898,75 & 212,4 \\
\hline 6490,45 & 233,7 \\
\hline
\end{tabular}


A partir do número de pares elétrons-íons criados (Figura 5.36), foi programado um laço sobre cada um dos elétrons onde em cada iteração foi liberada cada uma dessas cargas a partir da posição inicial de sua criação, sendo produzida uma avalanche eletrônica para cada um deles. Para cada elétron presente na avalanche foi registrada sua posição final. Os elétrons que atingiram o eletrodo de leitura (ReadOut) foram contabilizados e agrupados por avalanche, de modo a reproduzir o espectro da fonte de ${ }^{55} \mathrm{Fe}$, como mostra a Figura 5.37 .



Figura 5.37: Espectro da fonte de ${ }^{55} \mathrm{Fe}$ criada a partir da liberação dos pares de cargas primárias estimadas para a deposição de energia pelos fótons no gás.

Podemos estimar a resolução em energia para o espectro da Figura 5.37 através de um ajuste Gaussiano em torno do pico principal do espectro (Figura 5.38), cujos parâmetros do ajuste são apresentados na Tabela 5.3. A partir do ajuste e aplicando a equação (2.17), foi possível calcular a resolução em energia desse detector. 0 resultado obtido foi de $14,9 \%$, o que está de acordo com aqueles obtidos experimentalmente para um detector triplo GEM (Biswas et al., 2016). 


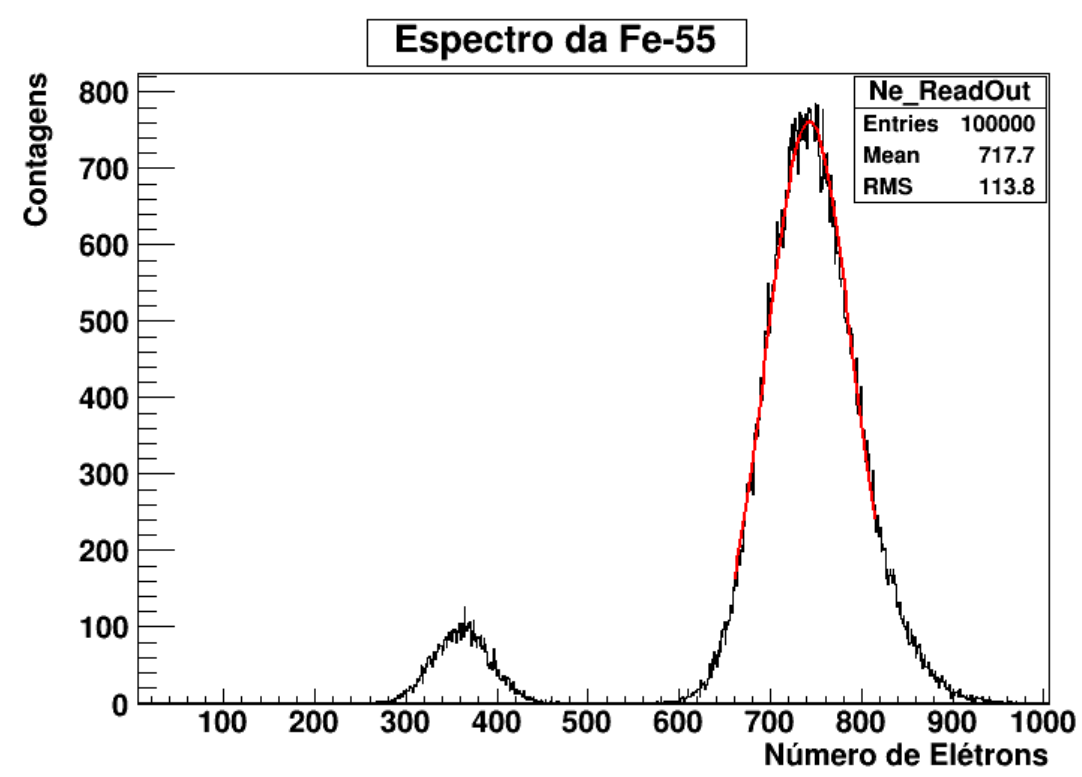

Figura 5.38: Ajuste Gaussiano do pico principal do espectro simulado da fonte de raios X de ${ }^{55} \mathrm{Fe}$ para cálculo da resolução em energia.

Tabela 5.3: Parâmetros do ajuste Gaussiano observado na Figura 5.38 para o espectro sem adição de ruídos.

\begin{tabular}{|c|c|c|c|}
\hline \multicolumn{4}{|c|}{ Espectro ${ }^{55} \mathrm{Fe}$ no ReadOut } \\
\hline Média & $\sigma$ & FWHM & Resolução em Energia \\
\hline $742,7 \pm 0,2$ & $47,2 \pm 0,2$ & 110,9 & $14,9 \%$ \\
\hline
\end{tabular}

O espectro mostrado na Figura 5.38 representa a melhor resolução em energia possível para o triplo GEM, pois considera apenas as flutuações inerentes aos processos de criação dos pares de elétrons-íons na formação da avalanche e diminuição no número de elétrons que chega ao ReadOut ao pararem nos eletrodos acima deste e que assim não contribuem para o sinal observado. No caso de um espectro experimental, é esperado um alargamento na curva com consequente deterioração na resolução. Esse efeito ocorre devido aos ruídos que se sobrepõem ao sinal e assim acabam sendo fontes de flutuação na amplitude do mesmo, alargando o espectro.

É possível simular esse alargamento do espectro levando em consideração um ruído no número de elétrons que chega até o eletrodo ReadOut. O ruído escolhido para essa finalidade foi um ruído do tipo Gaussiano branco, ou seja, que possui uma distribuição Gaussiana cujo desvio padrão é proporcional ao valor médio. Já a média dessa distribuição, por sua vez, é o valor esperado (sem ruído) para o número de elétrons ( $\boldsymbol{n}_{\text {final }}$ ). O trecho de código utilizado pode ser observado na Figura 5.39, onde considera-se uma dispersão em relação ao valor original dada por uma distribuição do tipo Gauss(média, $\sigma$ ). Foram 
simuladas ao todo quatro distribuições com diferentes porcentagens de flutuação em relação ao valor esperado, desde $5 \%$ até $20 \%$ de flutuação do valor original.

$$
\begin{aligned}
& \text { int nfinal_Disp5 }=\text { gRandom }->\text { Gaus(nfinal, } 0.05 * \text { nfinal); } \\
& \text { int nfinal_Disp10 }=\text { gRandom }->\text { Gaus(nfinal, } 0.10 * \text { nfinal); } \\
& \text { int nfinal_Disp15 }=\text { gRandom }->\text { Gaus(nfinal, } 0.15 * \text { nfinal); } \\
& \text { int nfinal_Disp20 }=\text { gRandom }->\text { Gaus(nfinal, } 0.20 * \text { nfinal); }
\end{aligned}
$$

Figura 5.39: Trecho de código utilizado para reproduzir o espectro da fonte de raios $X$ com alargamento do mesmo devido a fontes de ruído que não estão ligadas diretamente aos processos estatísticos no gás, como ruído eletrônico, por exemplo.

Os espectros considerando o ruído Gaussiano são mostrados na Figura 5.40, enquanto os parâmetros de ajuste e respectivas resoluções em energia para cada caso considerado são mostrados na Tabela 5.4.

Tabela 5.4: Resumo dos parâmetros de ajuste, largura a meia altura e resolução em energia dos espectros para os diferentes níveis de ruído Gaussiano considerados.

\begin{tabular}{|c|c|c|c|c|}
\hline$\sigma$ do Ruído & Média do Ajuste & $\sigma$ do Ajuste & FWHM & Resolução em Energia \\
\hline $0 * n_{\text {final }}$ & $742,7 \pm 0,2$ & $47,2 \pm 0,2$ & 110,9 & $14,9 \%$ \\
\hline $0,05 * n_{\text {final }}$ & $741,2 \pm 0,3$ & $59,8 \pm 0,4$ & 140,8 & $19,0 \%$ \\
\hline $0,10 * n_{\text {final }}$ & $740,1 \pm 0,5$ & $88,0 \pm 0,6$ & 207,2 & $28,0 \%$ \\
\hline $0,15 * n_{\text {final }}$ & $740,9 \pm 0,7$ & $121,0 \pm 0,8$ & 285,0 & $38,5 \%$ \\
\hline $0,20 * n_{\text {final }}$ & $740,0 \pm 0,9$ & $157 \pm 1$ & 369,6 & $49,9 \%$ \\
\hline
\end{tabular}




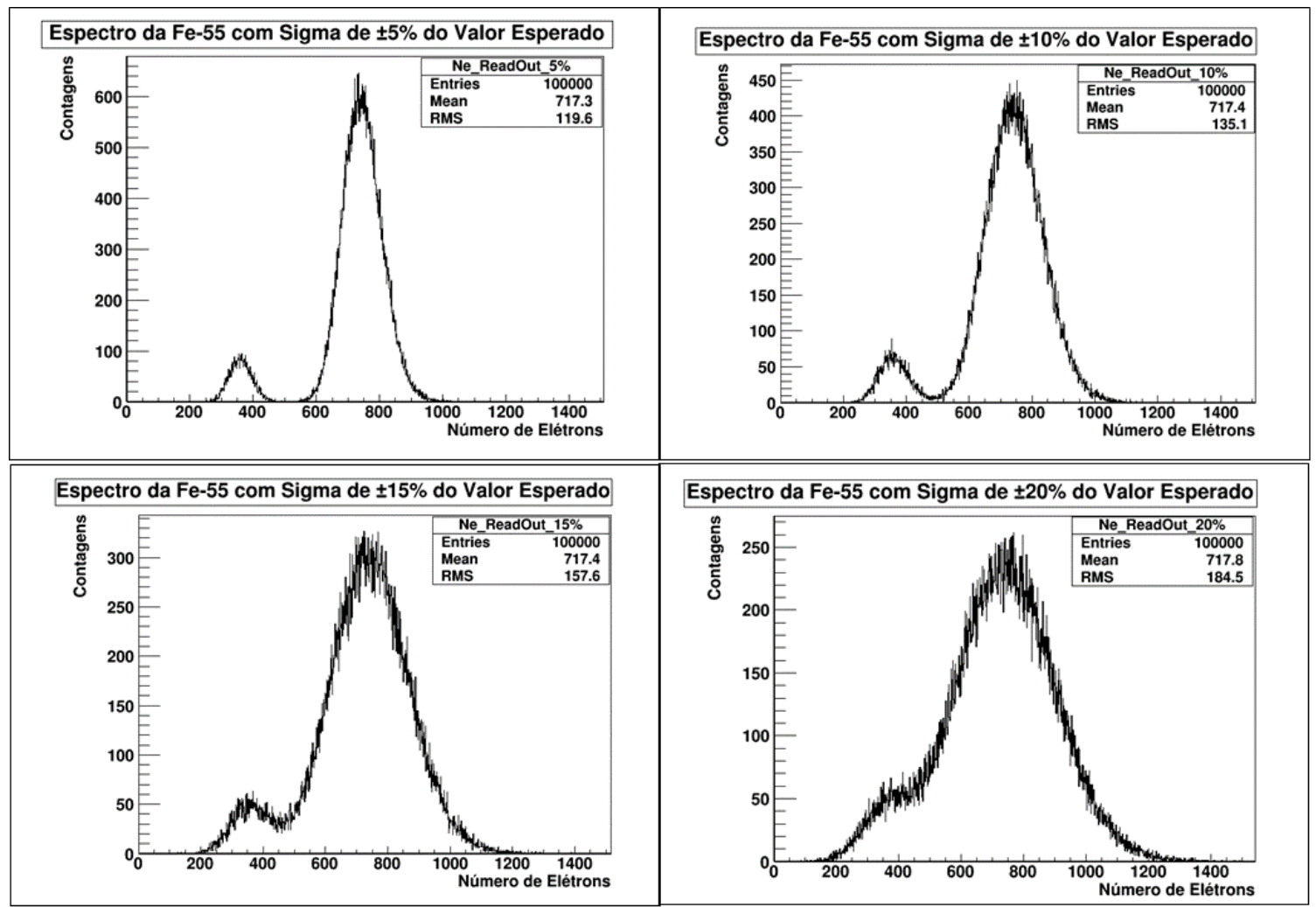

Figura 5.40: Espectros da fonte de raios $X$ com diferentes níveis de ruído branco Gaussiano causando alargamento dos mesmos. Nota-se um progressivo alargamento da curva com o respectivo aumento do nível de ruído. No caso de $20 \%$ de flutuação do valor esperado, praticamente não é possível distinguir o pico principal da fonte de ${ }^{55} \mathrm{Fe}$ do pico de escape do argônio.

\subsection{Movimento Retrógrado de Íons}

Uma vez que todos os potenciais aplicados no triplo GEM (exceto o aterramento no ReadOut) são negativos, todos os eletrodos acima do ReadOut são capazes de captar os íons positivos. A despeito disso, uma porção dessas cargas acaba chegando até o plano de deriva.

A fração do fluxo retrógrado de íons (IBF - lon Back Flow) é a fração das cargas positivas que chegam até a região de deriva do triplo GEM, ou seja, a região compreendida entre o eletrodo GEM1 Top e o eletrodo de deriva da Figura 4.4. Os íons gerados nas avalanches que retornam ao plano de deriva são capazes de alterar a homogeneidade do campo de deriva e gerar uma distorção no comportamento do detector, prejudicando o funcionamento normal do dispositivo (Purba Bhattacharya et al., 2017). Além disso, esse efeito pode limitar drasticamente a operação e a vida útil do detector (Mörmann, Breskin, Chechik, \& Bloch, 2004). Os efeitos do IBF sobre a carga espacial com o respectivo efeito 
sobre o campo elétrico foi bastante explorado no trabalho de Thuiner et al. (Thuiner et al., 2018).

A fração do fluxo retrógrado de íons pode ser descrito matematicamente como (Purba Bhattacharya et al., 2017):

$$
I B F=\frac{N_{\text {Ions }}+1}{G}
$$

onde $\boldsymbol{N}_{\text {lons }}$ é o número de íons positivos que voltam até a região de deriva por cada elétron recebido e $\boldsymbol{G}$ é o ganho do detector. Há trabalhos que preferem normalizar o IBF pela quantidade total de íons produzidos no processo de multiplicação. No presente trabalho, optou-se por fazer a normalização pelo ganho efetivo, pois o IBF ou o $\boldsymbol{N}_{\text {Ions }}$ por si só não são capazes de fornecer informações suficientes para descrever o desempenho do detector, sendo preciso ser complementado com a informação do ganho (Alexeev et al., 2013).

No presente trabalho foi estudada a fração de íons positivos coletados em cada um dos eletrodos do triplo GEM, incluindo a camada de Kapton que forma o furo cônico do detector. Um exemplo da posição final em 3D dos íons no triplo GEM de referência (bicônico) pode ser observado na Figura 5.41. É possível notar que o campo de indução afasta do ReadOut todos os íons, que são observados apenas nos três GEM's e no plano de deriva.



Figura 5.41: Posição final dos íons positivos ao longo do triplo GEM. Percebe-se que nenhuma dessas cargas chega até o plano de leitura $(Z=-2 \mathrm{~mm})$. 
A seguir, são apresentadas as imagens das posições finais dos íons positivos, mostrando como se distribuem em cada um dos eletrodos a partir de projeções no plano XY. Não foi observado nenhum íon na superfície inferior do terceiro GEM (GEM3 bottom), pois o campo elétrico acabou por afastar todas essas cargas desse eletrodo. A distribuição de íons na camada de Kapton do terceiro GEM é mostrada na Figura 5.42.

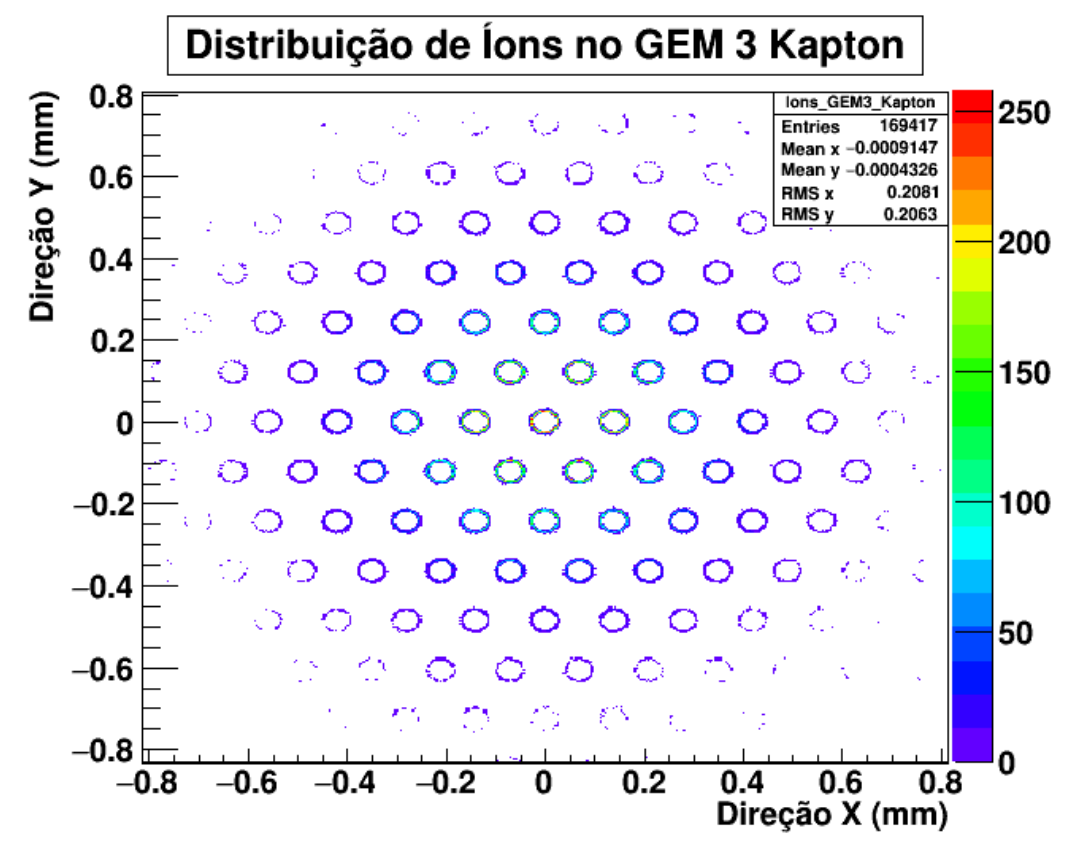

Figura 5.42: Distribuição da posição final dos íons no Kapton do terceiro GEM. Os íons se distribuem ao longo do polímero em cada orifício de modo que a maior parte das cargas se concentra no centro da imagem.

A distribuição dos íons na superfície superior do terceiro GEM pode ser observada na Figura 5.43. Nesse caso, as cargas são depositadas nas proximidades dos furos, não se distribuindo uniformemente na superfície de cobre. 


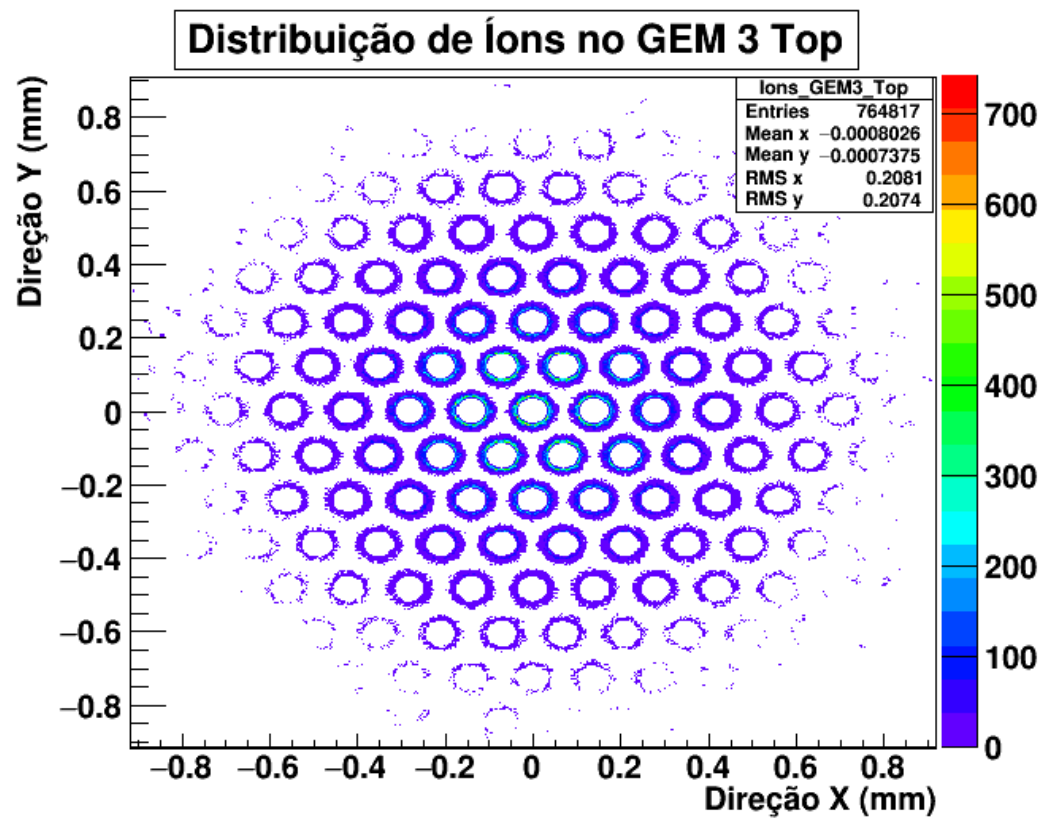

Figura 5.43: Distribuição dos íons que param na superfície superior do terceiro GEM, sendo paradas nas proximidades dos furos.

Os íons positivos que tiveram sua posição final na superfície inferior do segundo GEM são mostrados na Figura 5.44. Nesse caso, essas cargas são distribuídas continuamente ao longo da superfície do GEM, não se concentrado nas proximidades dos orifícios.

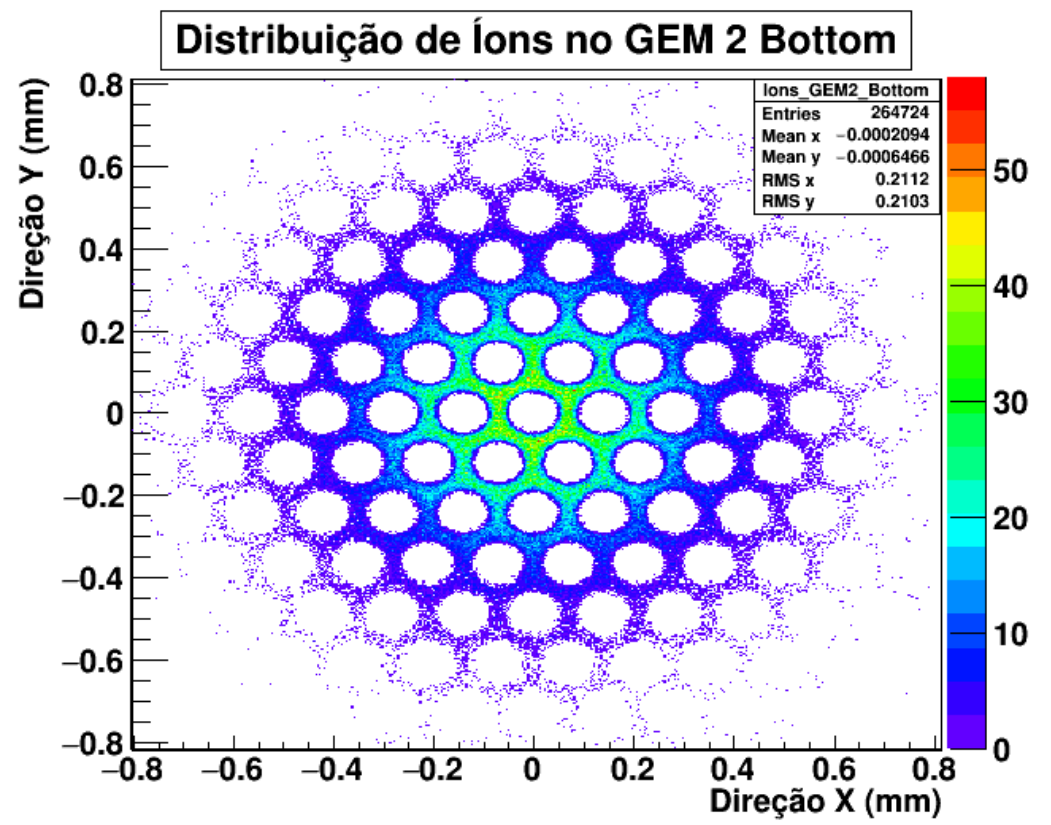

Figura 5.44: Posição final dos íons na superfície inferior do segundo GEM. Nesse caso, as cargas se distribuem continuamente ao longo da superfície de cobre, com maior concentração no centro da distribuição. 
A imagem das posições finais dos íons no Kapton do segundo GEM é mostrado na Figura 5.45. Esse resultado é similar ao observado no Kapton do GEM3, porém com alargamento menor ao longo do plano X-Y.

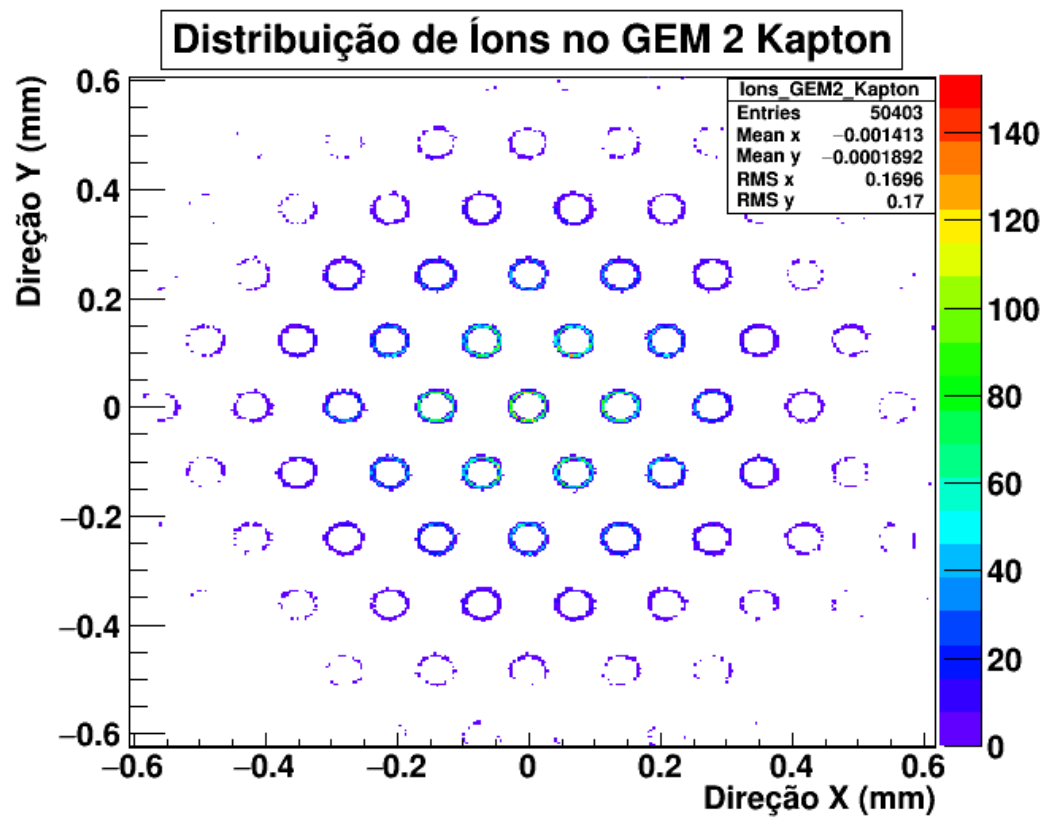

Figura 5.45: Posição final dos íons no Kapton do segundo GEM. As características são similares àquela observada no Kapton do terceiro GEM, contudo a distribuição possui um alargamento no plano menor nesse caso

Para a distribuição da posição final dos íons na superfície superior do segundo GEM, observou-se os resultados mostrados na Figura 5.46. Foram observadas características similares àquelas na distribuição da superfície superior do terceiro GEM, mas com menor amplitude no plano. 


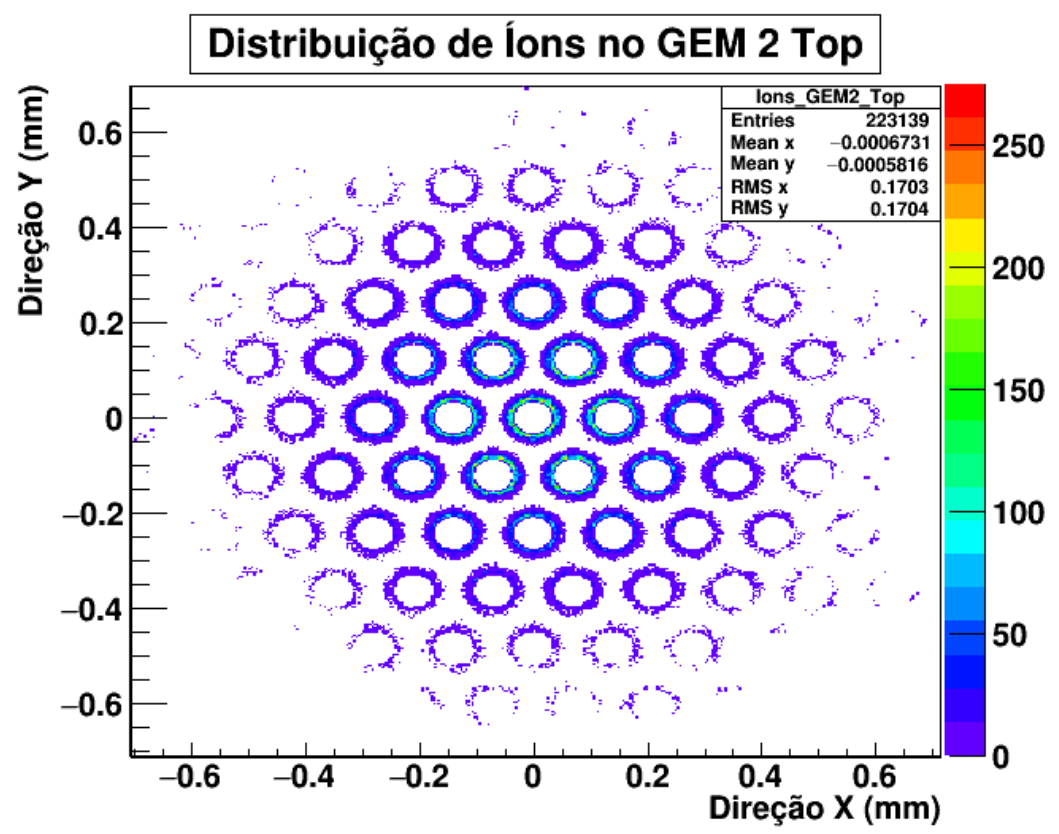

Figura 5.46: Distribuição dos íons na superfície superior do segundo GEM. Foram observadas características similares com a distribuição equivalente no terceiro GEM, mas com menor alcance ao longo do plano, refletindo o fato da avalanche aumentar espacialmente no plano X-Y conforme se dirige ao eletrodo de leitura.

A posição final dos íons na superfície inferior do primeiro GEM é mostrada na Figura 5.47 , onde novamente foram observadas características similares àquelas observadas no segundo GEM.

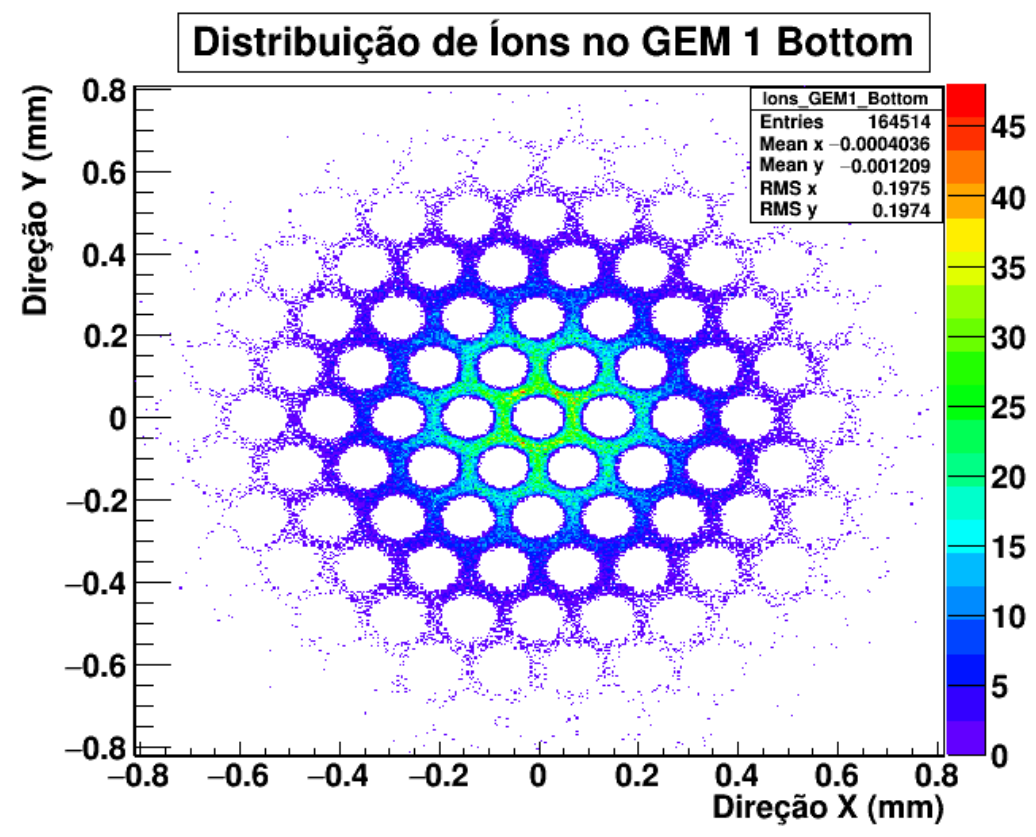

Figura 5.47: Posição dos íons na superfície inferior de cobre do primeiro GEM. Características semelhantes foram observadas no segundo GEM, mas com maior alcance no plano X-Y naquele caso. 
Para a distribuição da posição final dos íons no Kapton do primeiro GEM observou-se os resultados apresentados na Figura 5.48. Em todos os três GEM's pode-se notar que o número de íons coletados no polímero é consideravelmente menor que aquele coletado pelas superfícies de cobre, tanto inferior quanto superior (exceto na parte inferior do terceiro GEM, onde nenhum íon foi coletado).

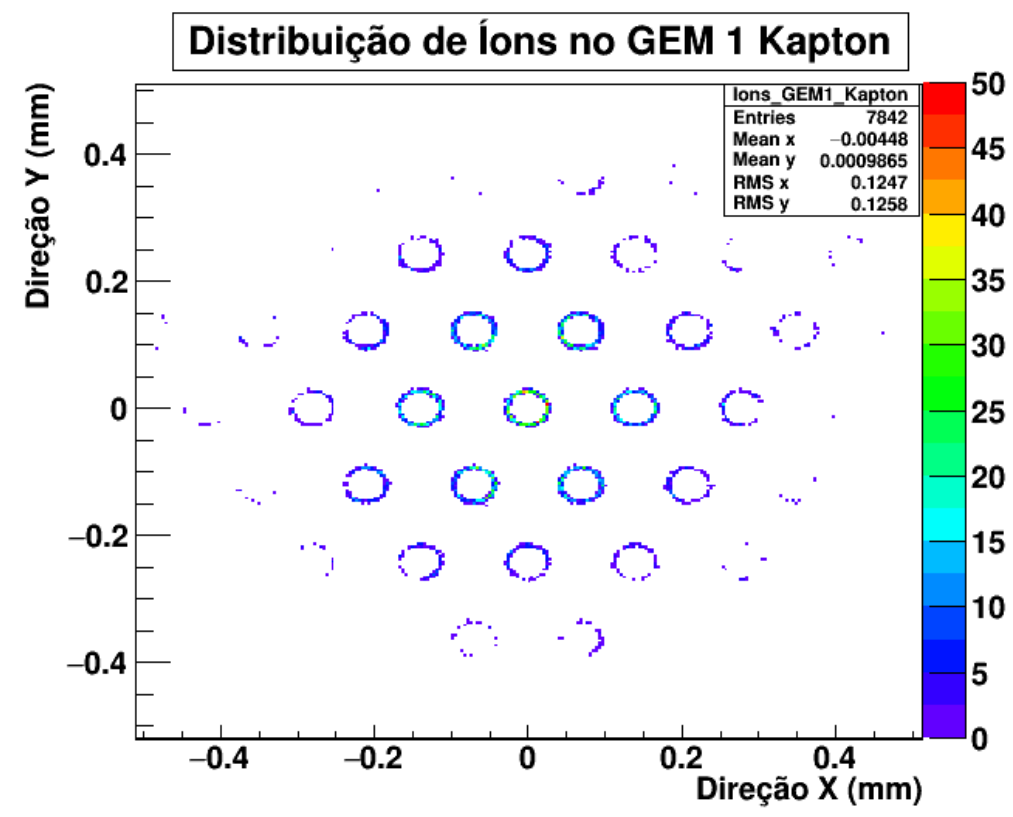

Figura 5.48: Posição final dos íons no Kapton do primeiro GEM. A amplitude reduzida ao longo do plano reflete o fato da amplitude da avalanche ser menor no primeiro GEM. Nota-se que em todos os GEM's o número de íons coletados no polímero é muito menor que aquele coletado nas respectivas superfícies de cobre.

Já a distribuição dos íons coletados na superfície superior do terceiro GEM é mostrada na Figura 5.49, onde nota-se uma distribuição bastante concentrada em um espaço de cerca de $0,4 \mathrm{~mm} \times 0,4 \mathrm{~mm}$ no plano X-Y. 




Figura 5.49: Íons coletados na superfície superior do primeiro GEM, mostrando uma concentração no centro da imagem ao longo de um intervalo de cerca de $0,4 \mathrm{~mm}$ nas direções $\mathrm{X}$ e $\mathrm{Y}$.

A distribuição dos íons que chegam até o eletrodo de deriva e que de fato contribuem para o chamado movimento retrógrado de íns ${ }^{7}$, pode ser observada na Figura 5.50.

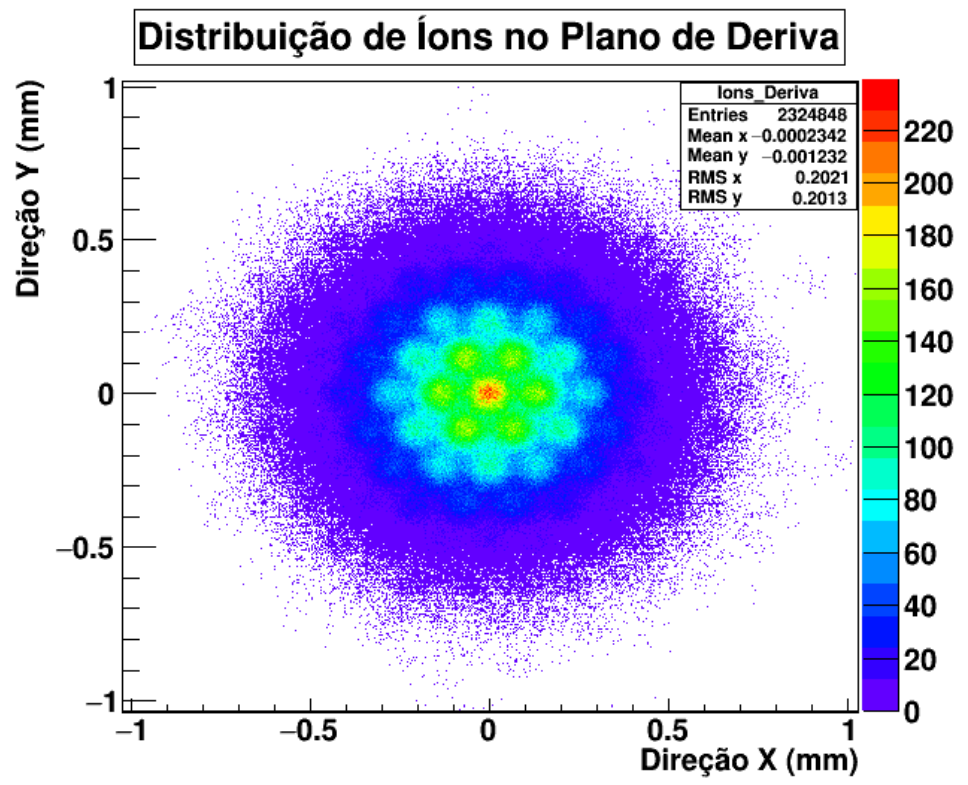

Figura 5.50: Distribuição dos íons no eletrodo de deriva. Percebe-se como essas cargas se distribuem, revelando os contornos dos furos, ou seja, não derivam de maneira contínua como fazem os elétrons no ReadOut, estando assim relacionada com os furos no GEM.

\footnotetext{
${ }^{7}$ Os íons que chegam à superfície superior do primeiro GEM também são depositados na região de deriva, assim também contribuem para o índice IBF. Contudo, a quantidade dessas cargas que se depositam nesse eletrodo é frequentemente muito menor que aquelas no plano de deriva. Repare no número total de cargas na Figura $5.49\left(5,3 \times 10^{4}\right)$ em comparação com a Figura $5.50\left(2,3 \times 10^{6}\right)$, cerca de cinquenta vezes maior.
} 
Para cada configuração simulada do triplo GEM, foi registrada a posição final tanto dos elétrons quanto dos íons positivos para cada uma das cargas geradas na avalanche eletrônica. A partir desse registro, foi possível analisar qual a fração de íons que chegou à região de deriva, a fim de identificar qual seria a configuração que minimiza o IBF. Os resultados para o triplo GEM de referência com as configurações apresentadas no Apêndice A são mostrados na Figura 5.51, onde pode ser observado que a fração de íons que retorna à região de deriva tende a diminuir conforme o ganho efetivo cresce.



Figura 5.51: Fração de íons na região de deriva (IBF) segundo a equação (5.3) em função da corrente aplicada pela fonte de alta tensão. Pode-se verificar como há uma tendência de queda no IBF conforme aumenta-se o ganho do detector. 


\section{Simulações Parte III: O GEM Cônico de Máscara Simples}

Nesse capítulo são apresentadas simulações do triplo GEM de furos cônicos (com a conicidade na borda do furo). Essa geometria foi desenvolvida visando à obtenção de folhas GEM de grandes áreas (maiores que $40 \mathrm{~cm}$ ), devido ao fato dessas estruturas grandes não poderem ser fabricadas com a geometria original (bicônico), pois o processo de fabricação do padrão bicônico se torna muito difícil quando aplicado em folhas de grandes áreas (Villa et al., 2011).

A maioria dos resultados nesse capítulo é apresentada juntamente com aqueles do GEM bicônico. O objetivo dessa estratégia é fazer uma comparação entre as duas geometrias, ao mesmo tempo em que as simulações irão buscar a caracterização dos dispositivos de modo a definir uma configuração que seja mais adequada segundo alguma métrica específica. Por exemplo, pode-se desejar um dispositivo que busque minimizar o movimento retrógrado de íons, caso se esteja trabalhando em um regime de grande fluxo de contagens, de modo que as cargas positivas possam prejudicar o funcionamento do detector. Outra hipótese é a busca por um dispositivo que aperfeiçoe a resolução (energia, espacial ou ambas), ou que maximize o ganho visando trabalhar com tensões mais baixas a fim de prevenir descargas elétricas. De qualquer forma, a ideia é que as simulações aqui apresentadas sirvam como suporte para a construção de um detector baseado na tecnologia GEM com as especificações desejadas.

\subsection{Geometria e Malha de Elementos Finitos}

Igualmente ao processo de simulação do GEM bicônico, inicialmente foi criada a geometria com a respectiva malha de elementos finitos do GEM de conicidade simples (GEM cônico) no Gmsh. A "célula" básica desse dispositivo pode ser observada na Figura 6.1, já a estrutura em detalhe de uma folha de GEM é mostrada na Figura 6.2. 


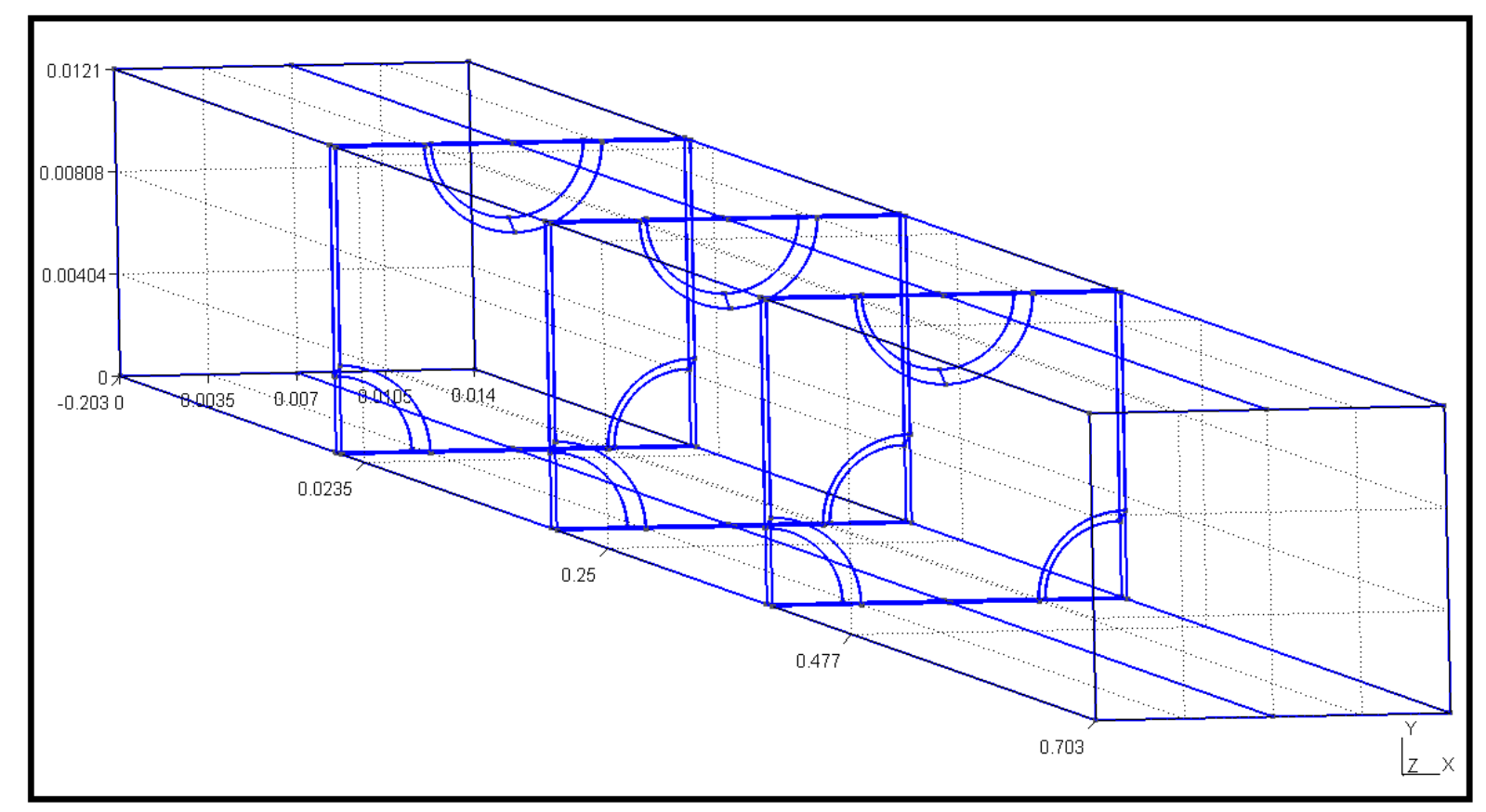

Figura 6.1: Célula básica do triplo GEM cônico criada no Gmsh. Observam-se as três folhas com os furos, delimitadas na direção longitudinal pelos eletrodos de deriva e leitura (ReadOut). As dimensões estão em centímetro.

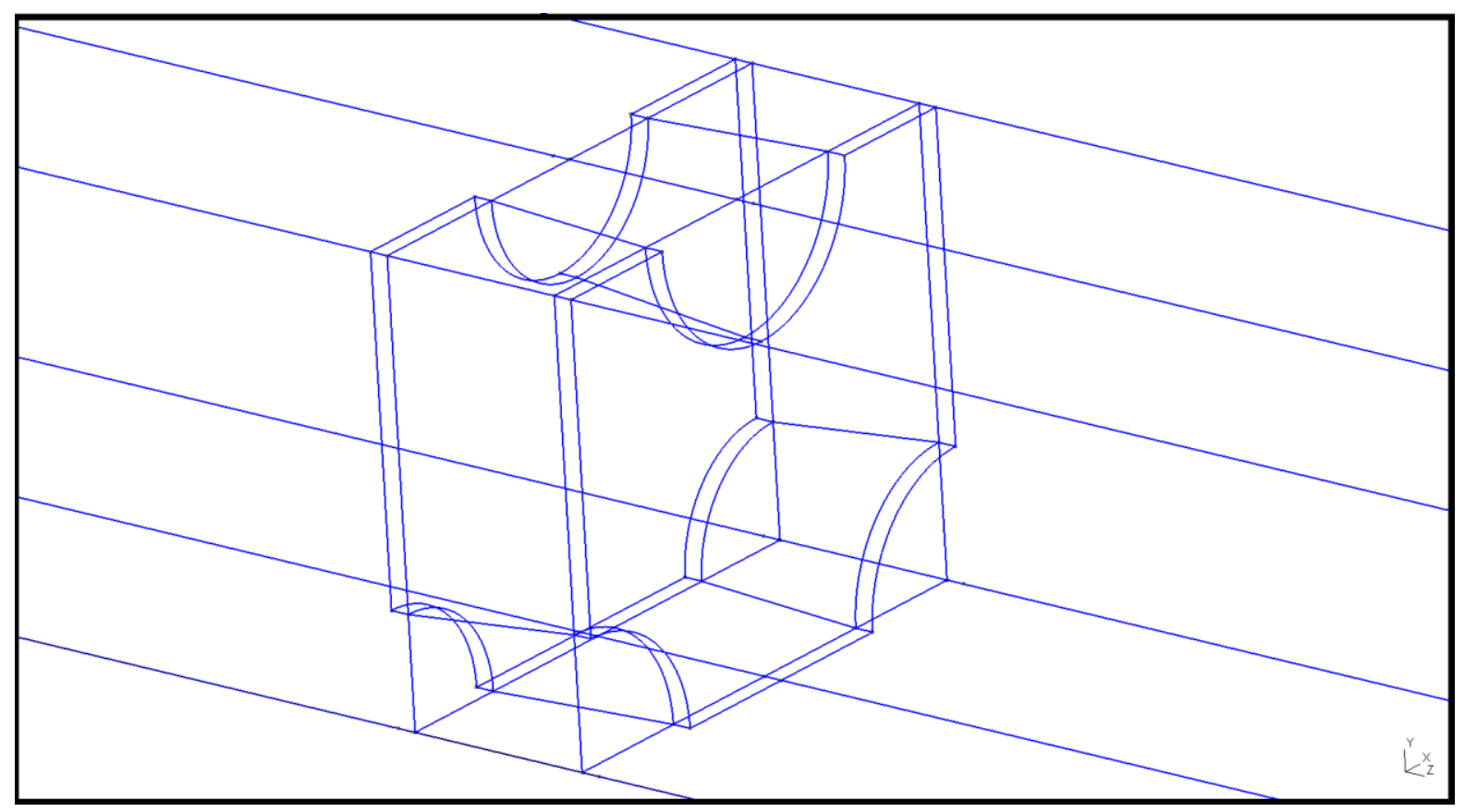

Figura 6.2: Detalhe da estrutura básica do GEM cônico mostrando os furos da folha.

A malha de elementos finitos é apresentada na Figura 6.3, já na Figura 6.4 pode-se observar o detalhe da geometria do GEM cônico, onde é possível observar o mosaico formado pelos elementos finitos (a), bem como a geometria cônica dos furos sem identificar 
os elementos finitos (b). As superfícies laterais das folhas são recobertas por uma camada de cobre de $5 \mu \mathrm{m}$.

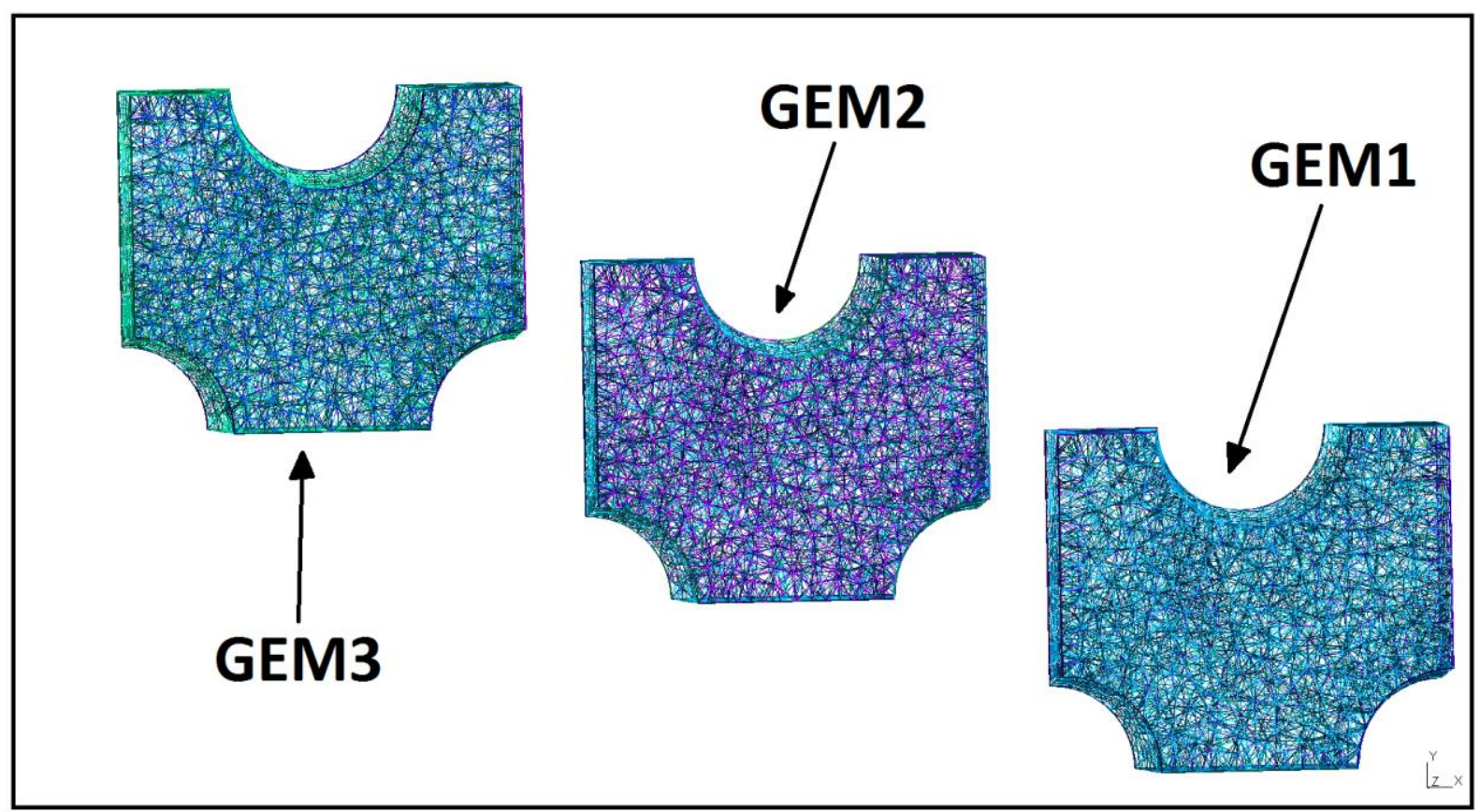

Figura 6.3: Malha do GEM cônico criada no Gmsh composta de um mosaico de estruturas que dividem a geometria em pequenos componentes. Os eletrodos de deriva, de leitura e as superfícies de fronteira foram ocultadas da figura para maior clareza da imagem.
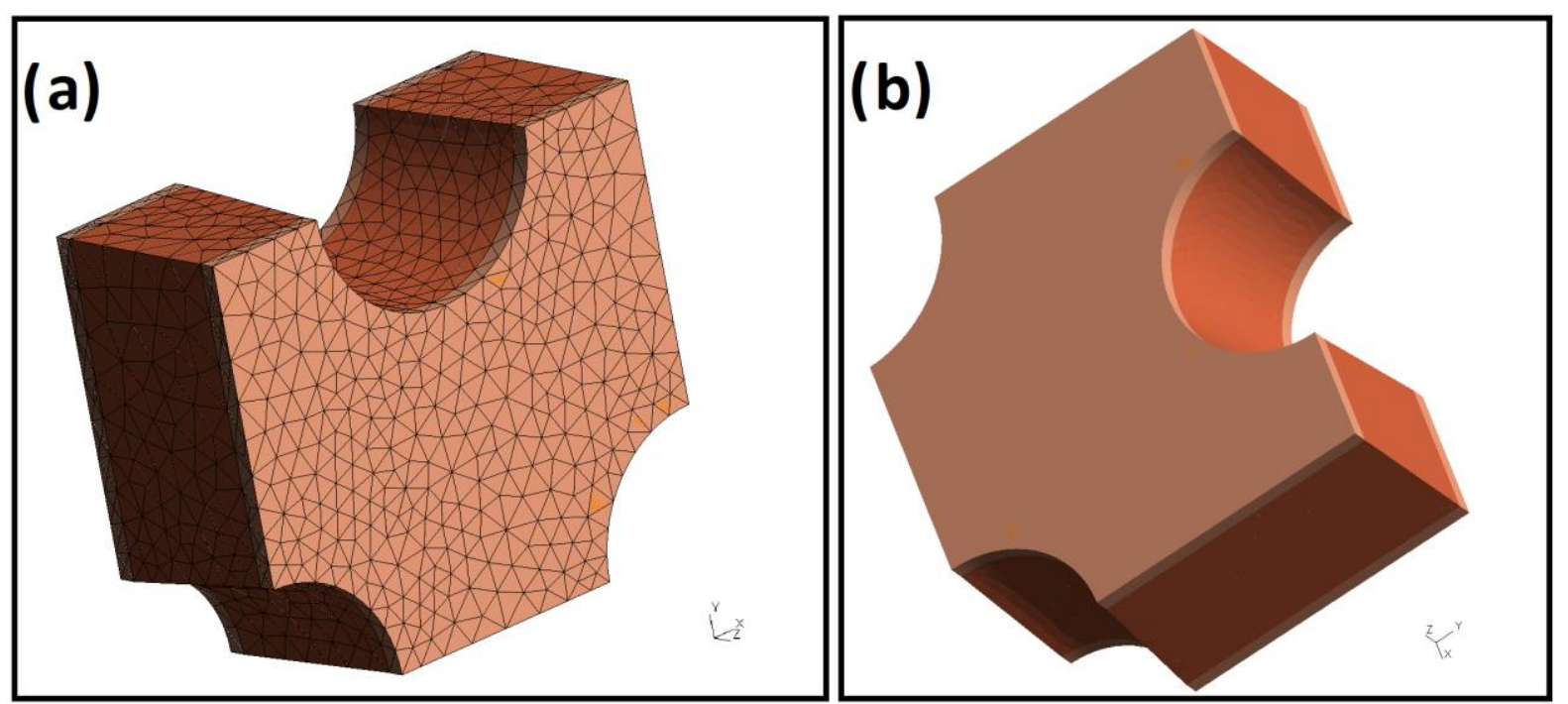

Figura 6.4: Célula do GEM mostrando o mosaico de elementos criados pelo Gmsh para a aplicação do método de elementos finitos (a). Além da mesma imagem sem mostrar os contornos dos elementos, destacando apenas a geometria (b). 
Na sequência, foram realizados os mesmos procedimentos descritos nas simulações do triplo GEM de geometria bicônica (Capítulo 5). A seguir, são apresentados alguns exemplos de simulações de alguns aspectos relevantes para o funcionamento do GEM.

\subsection{Potencial Eletrostático e Campo Elétrico do Triplo GEM Cônico}

Assim como no caso do GEM bicônico, foi observado o resultado da simulação do potencial através de um mapa mostrando o perfil dessa grandeza. No entanto, não se observou diferenças marcantes em suas características em comparação com o GEM cônico (Figura 5.6), assim optou-se por não mostrar a figura para a essa geometria devido às similaridades. Desse modo, a discussão das características do potencial se aplica no caso do GEM cônico da mesma forma que no caso do bicônico.

Em relação ao mapa do campo elétrico, foram observadas algumas diferenças na região próxima aos orifícios, como retratado na Figura 6.5. Essa figura mostra uma variação mais suave do campo na transição entre o Kapton e o gás em comparação com o mapa de campo do GEM bicônico (Figura 5.8).

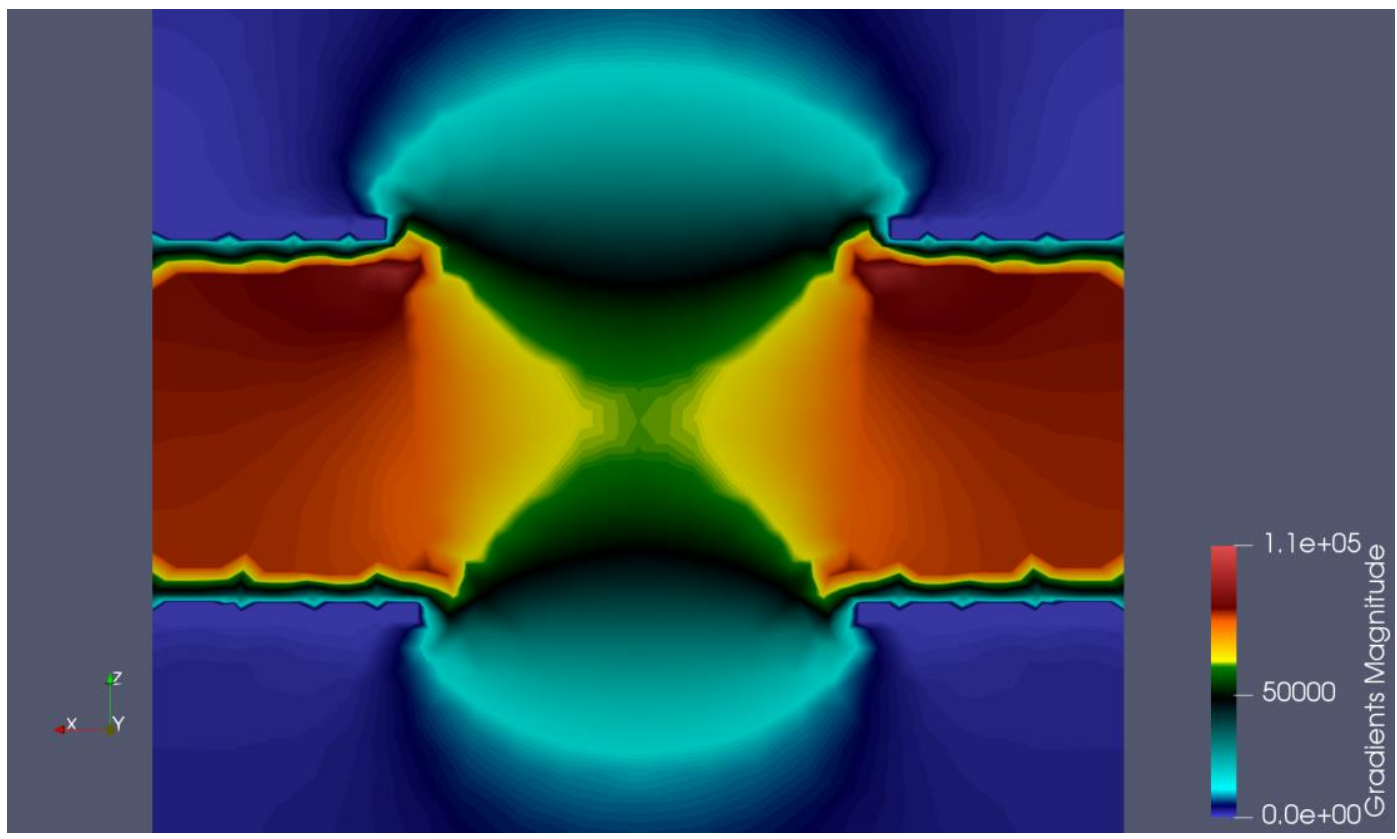

Figura 6.5: Mapa do campo elétrico ao redor do furo do GEM cônico através de uma projeção no plano Z-X, perpendicular ao plano da folha do detector. O código de cores revela como o módulo campo é mais intenso na região dos orifícios em comparação com o campo na região externa. A região marcada com a cor preta indica o limiar para formação da avalanche (Sauli, 2014). 
Optou-se por apresentar os gráficos do campo elétrico seguindo as mesmas direções de plotagem mostradas na Tabela 5.1, mas mostrando os resultados tanto para o GEM cônico quanto para o bicônico, a fim de compará-los. São mostrados os resultados a seguir, com uma breve discussão sobre a comparação entre os dois tipos de GEM submetidos a uma mesma configuração de campos e potenciais.

- DIR 1: O perfil do campo elétrico nos pontos afastados das folhas de GEM é similar para as duas geometrias, contudo nas proximidades dos orifícios o módulo do campo é mais intenso no GEM cônico. Veremos posteriormente que esse detalhe será importante para o ganho de gás de cada um deles;

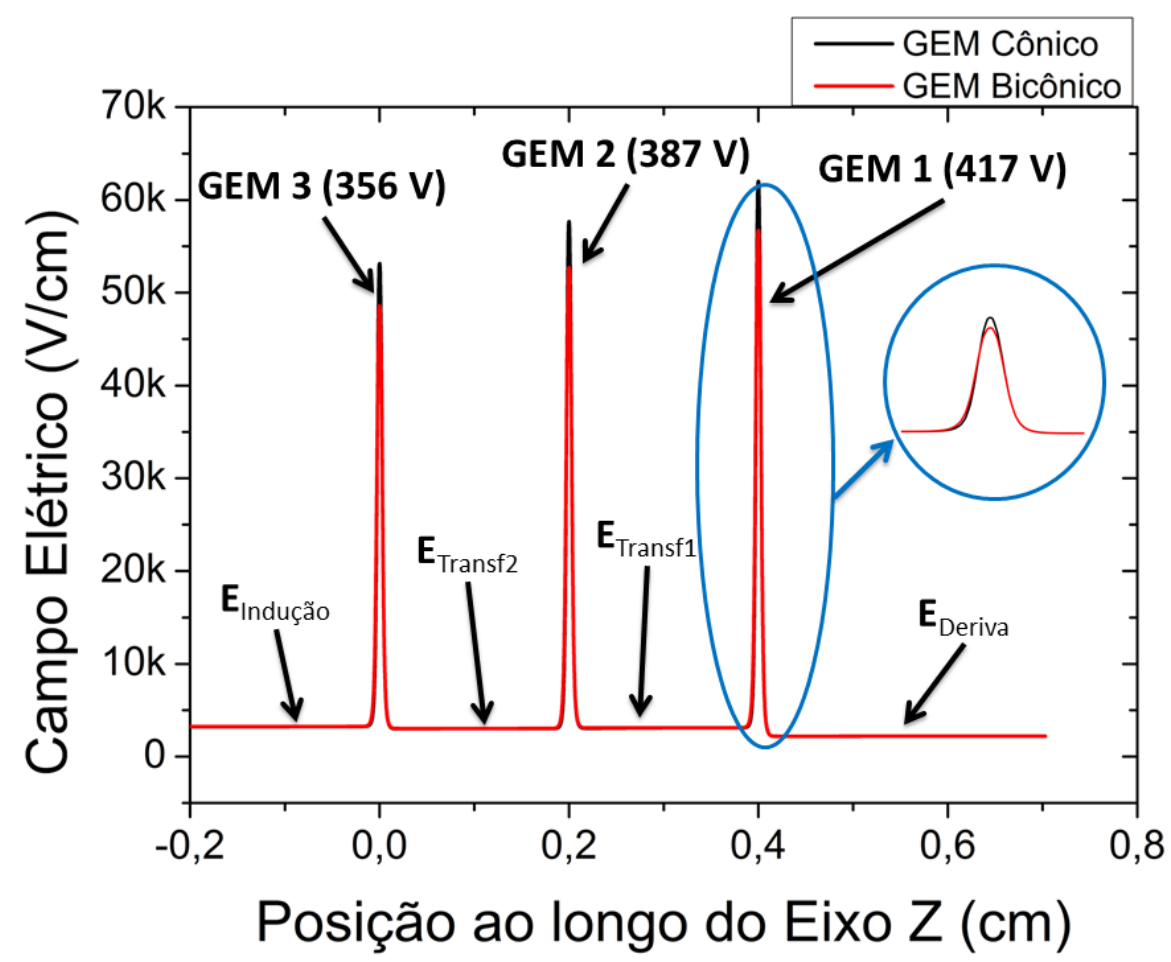

Figura 6.6: Campo elétrico das duas geometrias ao longo da direção perpendicular ao plano das folhas do GEM, passando pelo centro dos furos (DIR1).

- DIR 2: Nesse caso o módulo do campo é maior para a geometria bicônica, com uma pequena diferença de $59 \mathrm{~V} / \mathrm{cm}$ no pico da curva em relação à geometria cônica; 


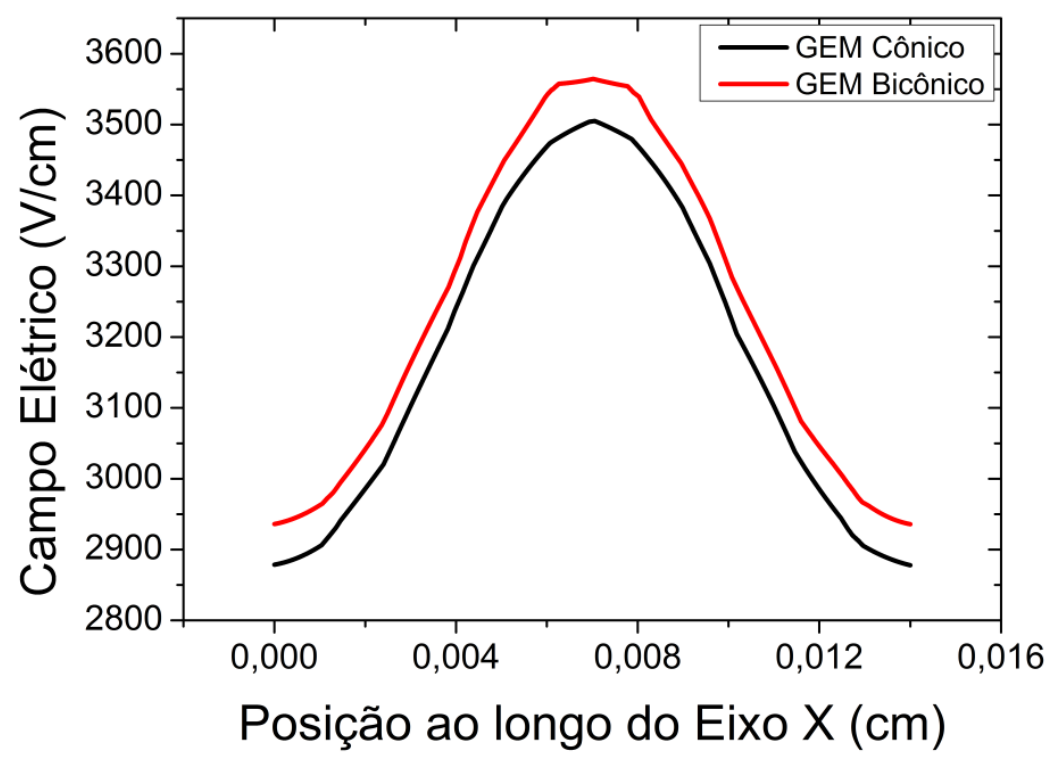

Figura 6.7: Campo elétrico para as duas geometrias do GEM ao longo da direção $X$, paralela ao plano do detector e nas proximidades do GEM1 (DIR2). Para planos cuja coordenada Z maiores o campo torna-se uniforme para ambas.

- DIR 3: Não foi observado nenhuma diferença entre as duas geometrias;

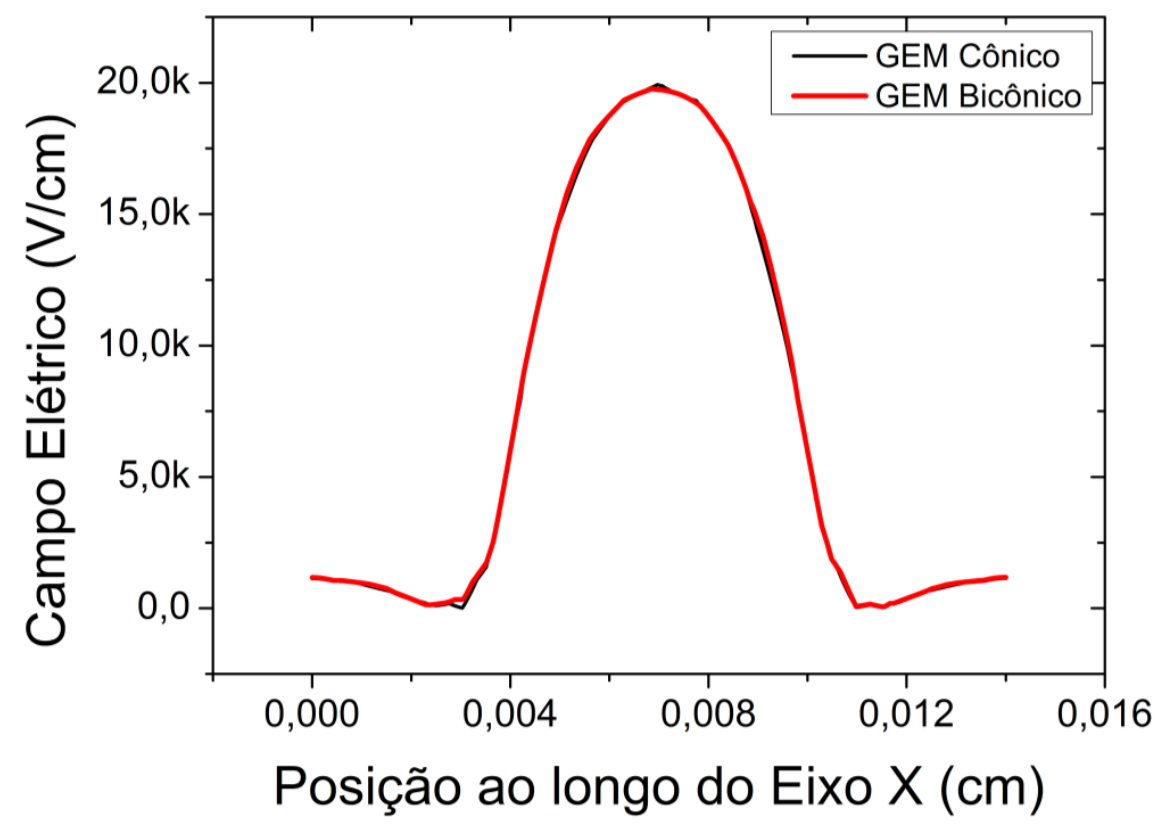

Figura 6.8: Campo elétrico para as duas geometrias estudadas ao longo da direção X, paralela ao plano do detector e nas proximidades do GEM1 (DIR3).

- DIR 4: Nesse caso, observou-se diferenças mínimas que podem ser devido às aproximações realizadas durante a solução do problema pelo MEF; 


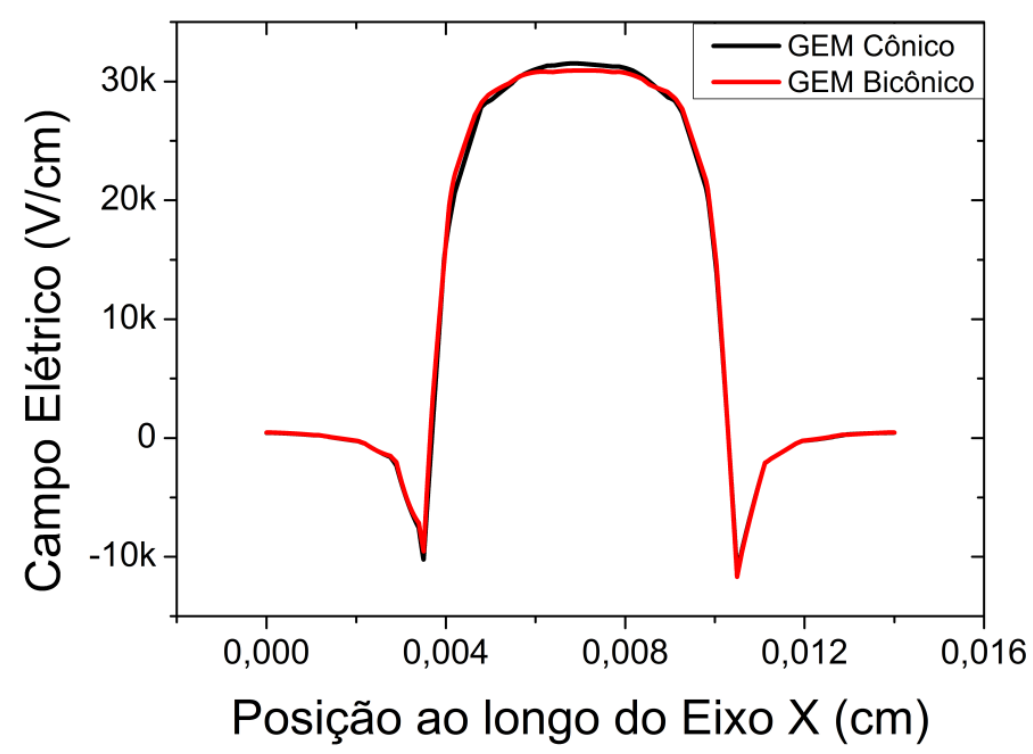

Figura 6.9: Campo elétrico ao longo da direção $X$, paralela ao plano do detector e passando pelo interior da camada condutora de cobre para o GEM cônico e bicônico (DIR4).

- DIR 5: Essa projeção corrobora para o argumento citado anteriormente, quando mostrado o mapa do campo, pois pode-se constatar claramente como a geometria cônica apresenta um comportamento mais suave na transição entre o gás e o Kapton. Esse detalhe provavelmente vem do fato do polímero formar a conicidade no centro da folha na geometria bicônica, favorecendo o rearranjo das cargas nessa região. Acredita-se que o comportamento mais suavizado irá interferir na forma como os elétrons derivam nessa região, alterando características importantes para o funcionamento do detector, como o movimento dos íons. Foi observado ainda que o módulo do campo no ponto de mínimo da curva é de 3,8 kV maior para o GEM cônico, o que deve favorecer o ganho em relação ao bicônico; 


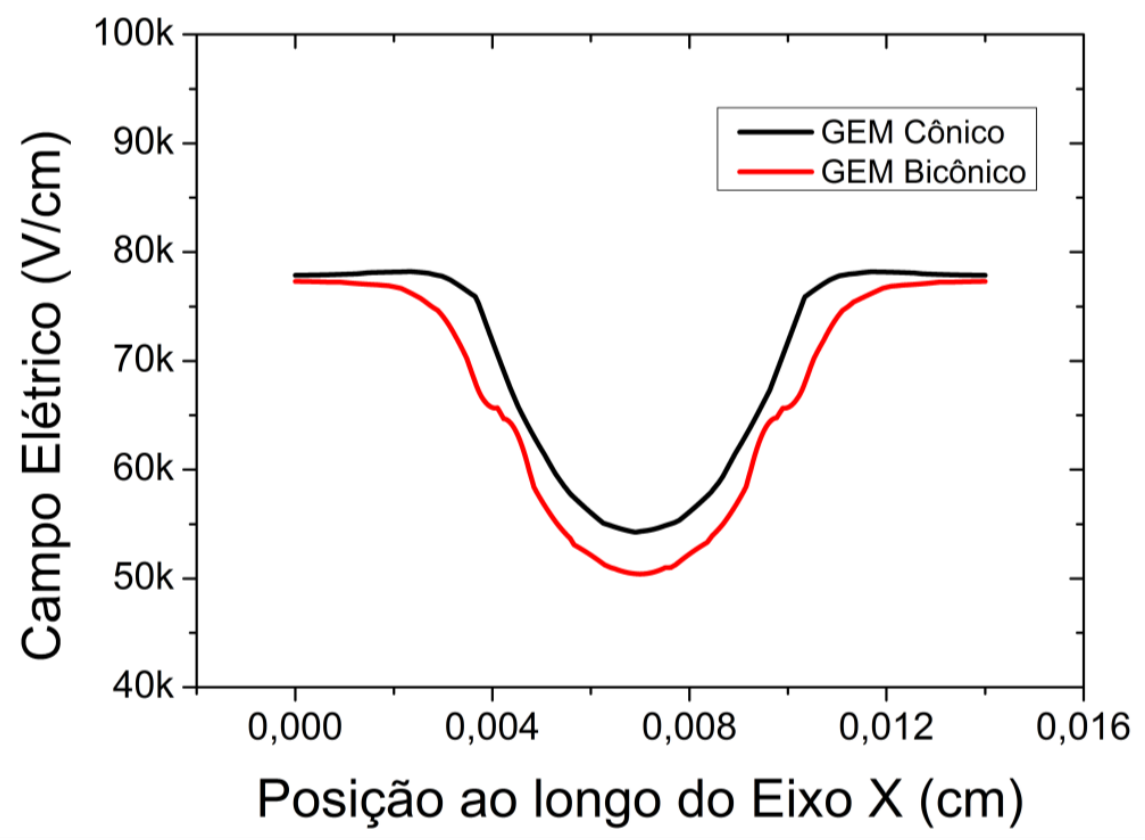

Figura 6.10: Campo elétrico ao longo da direção $X$, paralela ao plano do detector e passando pelo interior do Kapton (DIR5).

- DIR 6: Novamente o campo do GEM cônico apresentou-se mais suave nessa projeção. As depressões laterais no campo do GEM bicônico possivelmente são decorrência da protuberância do Kapton, uma vez que essa projeção passa pelo ponto onde há a extremidade formando a conicidade do furo no centro da folha. No centro da curva, o módulo do campo para o GEM cônico é de 5,0 kV/cm maior que aquele da geometria bicônica. 


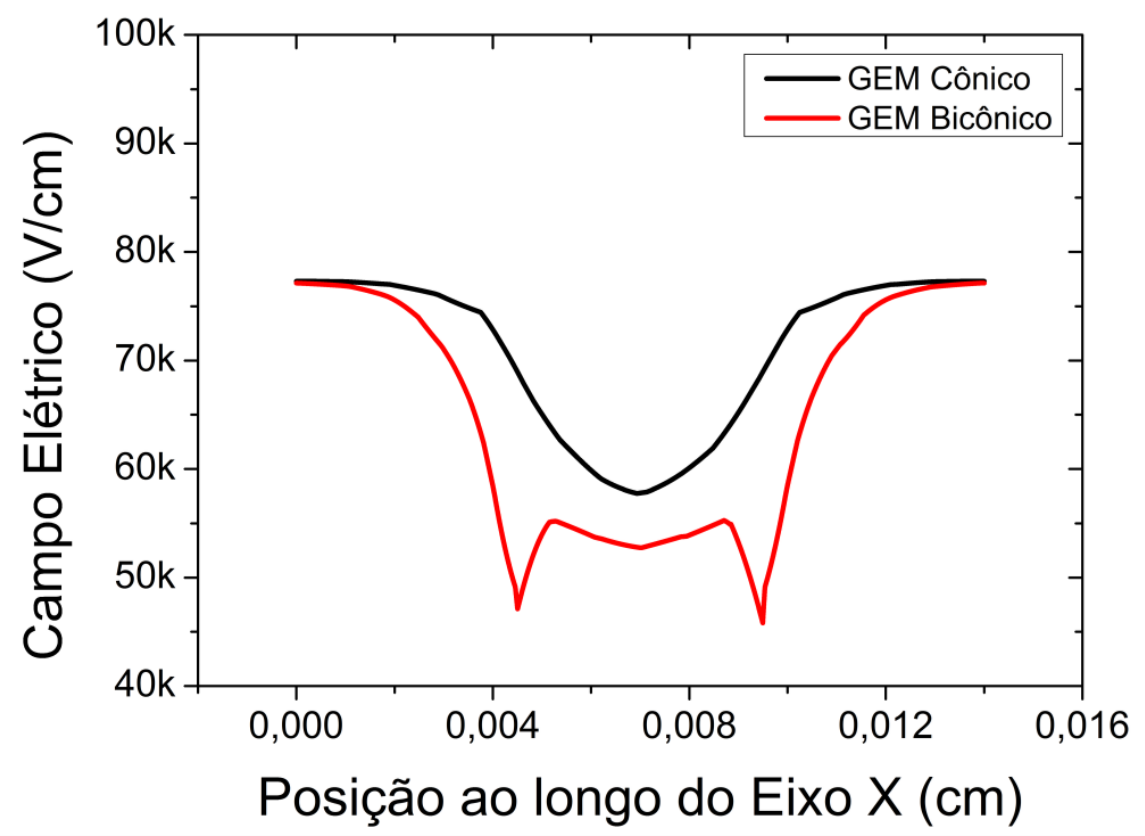

Figura 6.11: Campo elétrico ao longo da direção $X$, paralela ao plano do detector e localizado no centro do GEM (DIR6).

Apesar da geometria cônica não apresentar simetria no eixo Z, para cortes com essa coordenada abaixo de DIR 6, os resultados observados são bastante similares a esse corte, mas cujo módulo do campo é menor.

Na sequência é mostrada a comparação entre os dois tipos de geometria do GEM abordadas, mostrando o campo elétrico ao longo da direção perpendicular ao plano do detector (eixo Z), passando pelo centro do furo. Os resultados apresentados foram resultado de uma simulação com as mesmas configurações de campo e potencial, ou seja, as diferenças são causadas apenas pela geometria dos furos. 


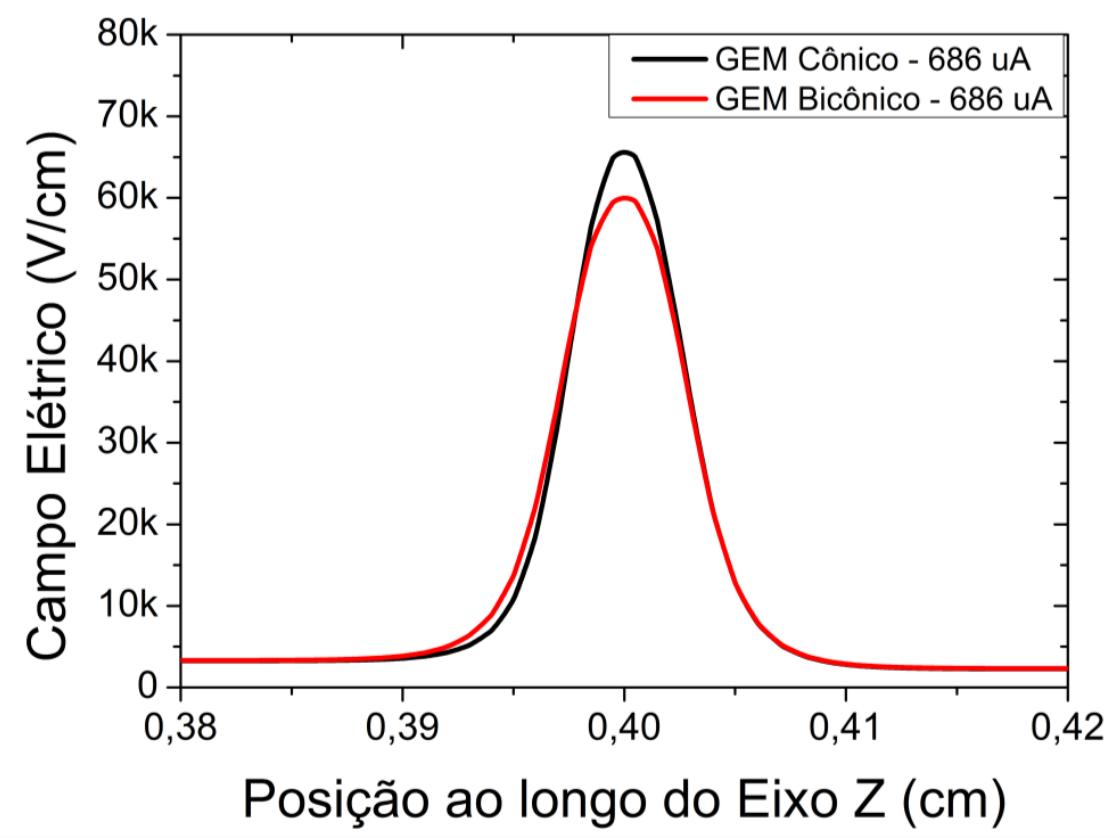

Figura 6.12: Campo elétrico na direção Z, passando pelo centro do orifício similar a DIR1, mas destacando os detalhes do campo nas proximidades do orifício do primeiro GEM (GEM1). A diferença entre o módulo do campo elétrico das duas geometrias no centro da curva foi de cerca de $6 \mathrm{kV} / \mathrm{cm}$, sendo maior no caso do GEM cônico.

\subsection{Ganho de Gás}

O ganho de gás do detector com furos em geometria cônica é apresentado na Figura 6.13 juntamente com aquele obtido com o GEM bicônico, mostrando que o ganho é maior para o GEM cônico em cerca de 30\%. Esse resultado é coerente com o que foi observado nas figuras do campo elétrico no interior dos orifícios, cujo módulo é sistematicamente maior para o caso do GEM cônico em relação ao bicônico. Uma vez que o efeito avalanche é provocado pela aceleração que o campo elétrico causa nos elétrons, um campo mais intenso irá aumentar o número de cargas na avalanche, aumentando também o ganho de gás. Foi reportado na literatura um comportamento que corrobora para o resultado apresentado no presente trabalho, onde Biswas et al. (Biswas et al., 2016) mostram que o ganho no GEM cônico (ou GEM de máscara simples) é maior que no bicônico (máscara dupla). 


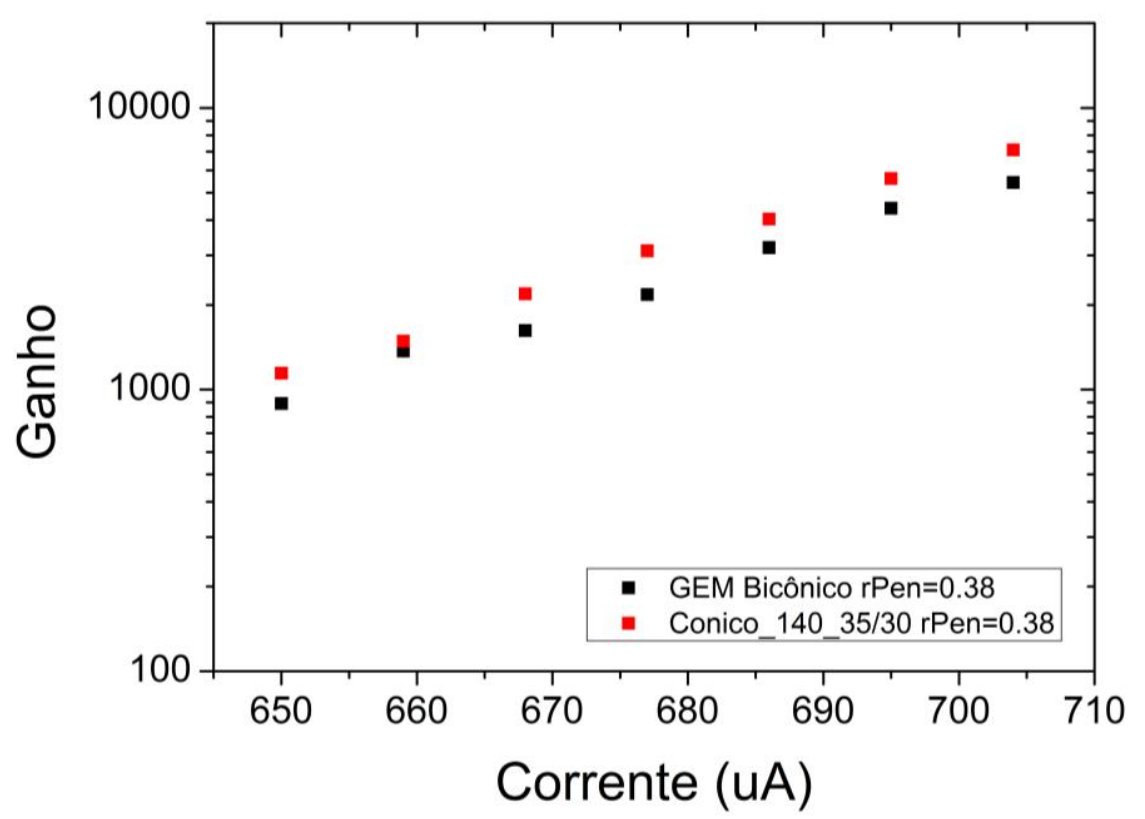

Figura 6.13: Ganho simulado do triplo GEM de geometria cônica em comparação com a bicônica. Nota-se como o ganho do GEM cônico é maior em comparação com o bicônico para uma mesma configuração de potencial, considerando os parâmetros geométricos mostrados nas figuras Figura 4.2 e Figura 4.3.

O termo máscara simples e dupla para essas duas geometrias tem origem no modo como essas estruturas são fabricadas. Inclusive, o fato das estruturas cônicas serem mais fáceis de serem construídas em grandes áreas vem do fato de que no processo de litografia ser utilizada apenas uma máscara para fabricação do GEM cônico, contra a necessidade de duas máscaras no GEM bicônico, com seu respectivo alinhamento (Villa et al., 2011).

\subsection{Variação do Ganho em Função de Parâmetros Geométricos}

Foi estudado como o ganho do triplo GEM cônico muda em função da variação de alguns parâmetros, como a diferença entre o raio da superfície superior (Top) e inferior (Bottom) e o espaçamento entre os furos. Lembrando que o espaçamento padrão desse dispositivo é de $140 \mu \mathrm{m}$ e a diferença entre os raios é de $5 \mu \mathrm{m}\left(R_{\text {sup }}=35 \mu \mathrm{m}\right.$ e $\left.R_{\text {inf }}=30 \mu \mathrm{m}\right)$. O ganho efetivo do detector de geometria cônica em função da diferença entre os raios e normalizado pelo ganho do GEM bicônico (padrão) é mostrado na Figura 6.14.

É notável como o ganho tende a diminuir consideravelmente conforme aumenta-se o módulo da diferença entre o diâmetro dos furos. Por outro lado, o ganho atinge um patamar máximo para o caso cilíndrico $\left(R_{\text {sup }}=R_{\text {inf }}\right)$, assim como para os casos onde o raio inferior é 
até $5 \mu \mathrm{m}$ maior que o raio superior. Considerando esse patamar de máximo, observa-se que o ganho do detector nessas condições geométricas é cerca de $60 \%$ maior que o ganho de um GEM bicônico padrão.

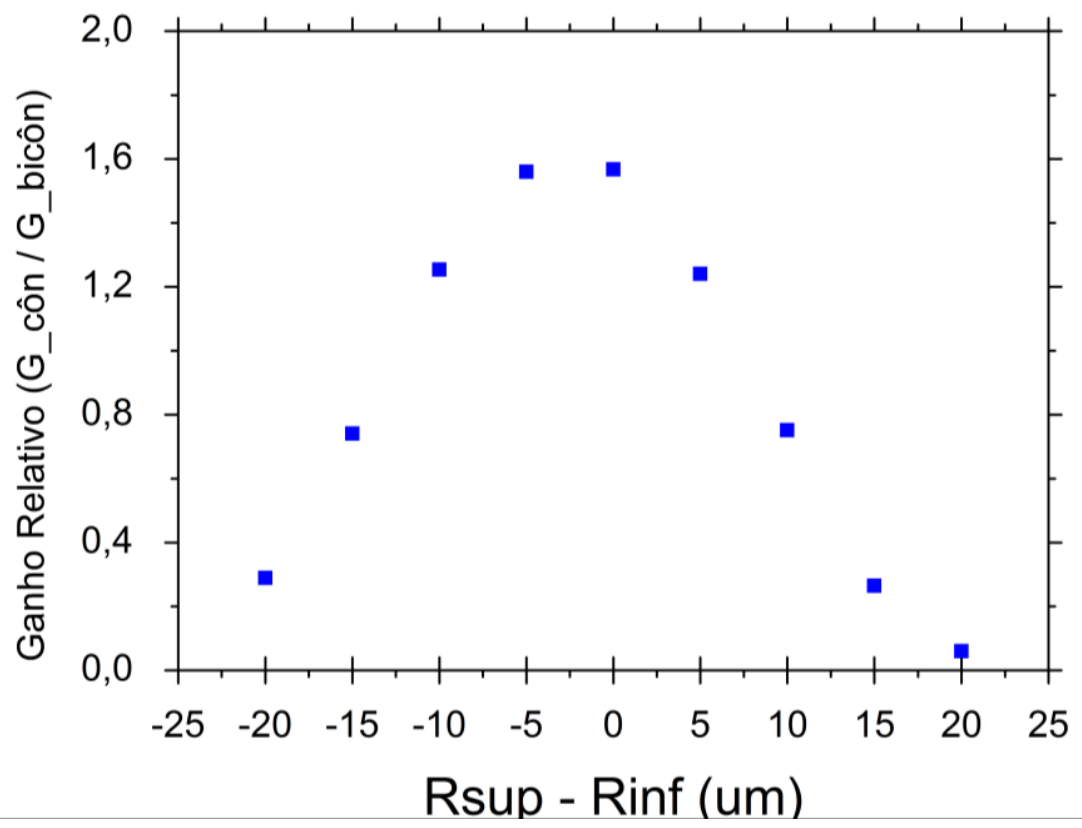

Figura 6.14: Ganho do GEM cônico em função da diferença entre os raios superior e inferior (Rsup - Rinf). Esse resultado é relativo ao GEM bicônico padrão, isto é, o ganho obtido foi normalizado pelo ganho desse detector (seção 5.3). O espaçamento entre os furos foi mantido constante, assim como a configuração de potenciais e campos, utilizando aquela mostrada na Tabela 10.2 .

Ainda considerando o estudo variando o diâmetro relativo dos orifícios, mas olhando para a fração de íons na região de deriva (IBF), temos o resultado revelado na Figura 6.15. Observa-se que há uma tendência clara de diminuição dessa grandeza quanto maior for o valor do raio do orifício inferior em relação ao superior. No caso de uma aplicação prática, é interessante levar em consideração não apenas a fração de íons na zona de deriva, como também o ganho, que diminui de forma abundante nessas condições, como mostra a Figura 6.14 . 


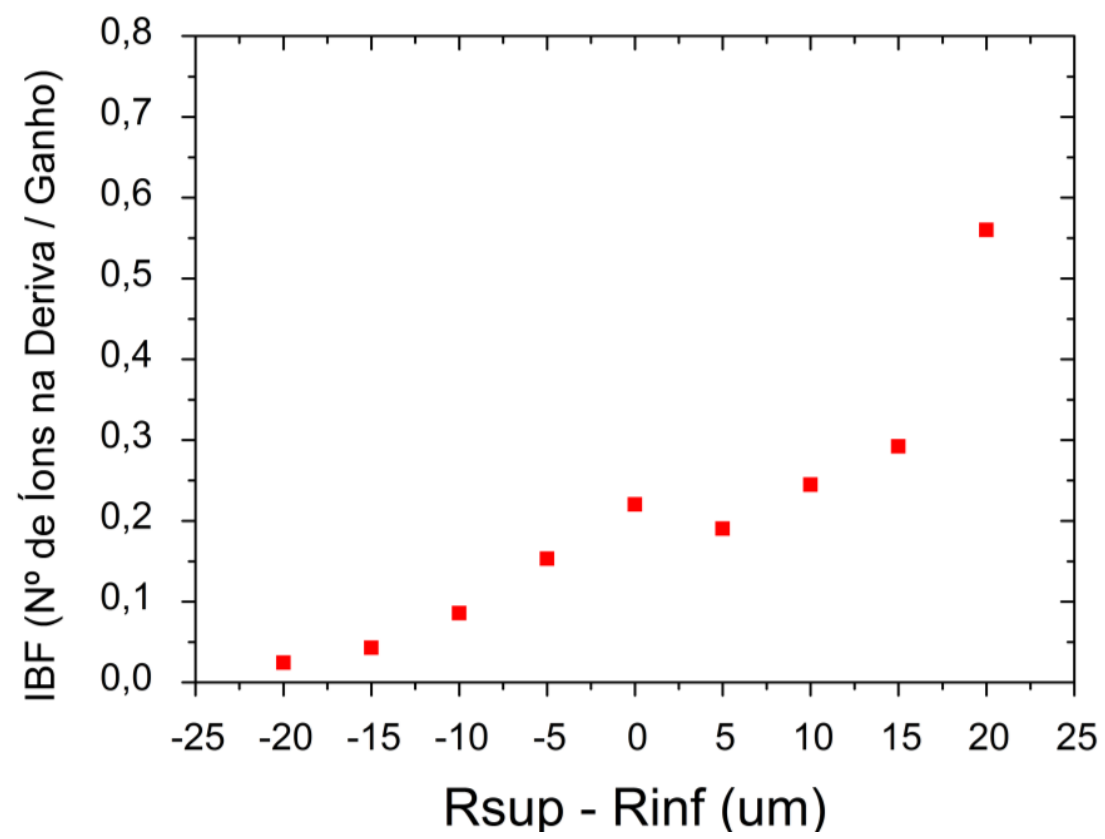

Figura 6.15: Fração de íons na zona de deriva em função da variação relativa entre o diâmetro dos orifícios do GEM cônico. Nota-se que quanto maior o valor do raio do furo inferior em relação ao superior, mais eficiente será o detector em evitar que as cargas positivas cheguem até a região de deriva.

Foi avaliado também como o ganho muda em função do espaçamento entre os furos, variando essa grandeza desde um espaçamento de $80 \mu \mathrm{m}$ (furos praticamente juntos uns aos outros) até $280 \mu \mathrm{m}$ (duas vezes o espaçamento padrão). Os resultados obtidos são apresentados na Figura 6.16, onde observa-se como essa grandeza apresenta um máximo para um espaçamento de $120 \mu \mathrm{m}$. Nessa condição, foi observado um ganho de cerca de $70 \%$ maior que o GEM bicônico com espaçamento de $140 \mu \mathrm{m}$. 




Figura 6.16: Ganho em função do espaçamento entre os orifícios para o triplo GEM cônico normalizado pelo ganho do GEM bicônico na configuração padrão, com espaçamento de $140 \mu \mathrm{m}$ e furos de $70 \mu \mathrm{m}$ nas superfícies superior e inferior e de $50 \mu \mathrm{m}$ no centro da folha de Kapton.

Foi investigado também como se comporta o índice IBF em função do espaçamento entre os furos. Os resultados (expostos na Figura 6.17) revelam como esse índice tende a diminuir conforme aumenta-se a distância entre os orifícios. Esse efeito significa que quanto maior a área exposta de cobre na superfície do GEM, maior será a probabilidade dos íons serem atraídos e consequentemente capturados pela camada condutora, diminuindo a chance de que atravessem as folhas e cheguem até a região de deriva. 


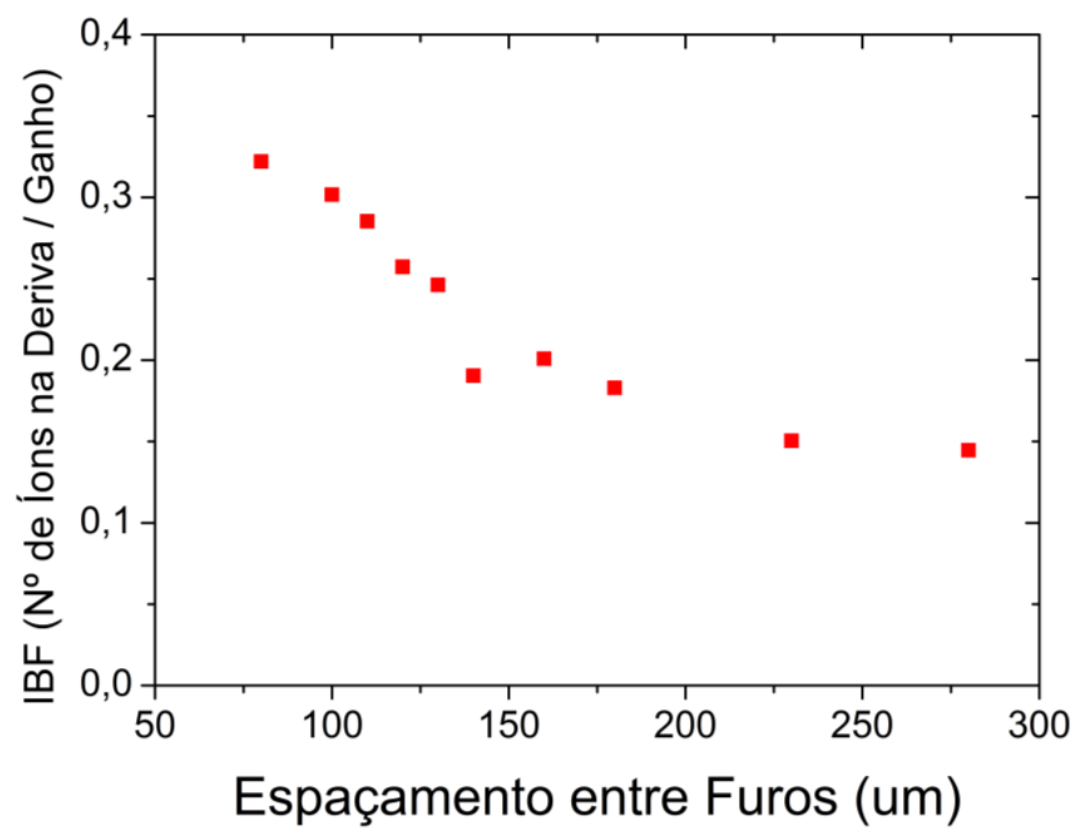

Figura 6.17: IBF em função do espaçamento entre os furos. A fração de íons na zona de deriva normalizada pelo ganho é tanto menor quanto maior o espaçamento entre os furos.

\subsection{GEM Cônico com Espaçamento e Diâmetro de Furos para Maximização do Ganho}

A partir dos resultados mostrados na seção 6.4, foram realizadas simulações cujos parâmetros maximizam o ganho do detector. A ideia foi determinar quais resultados seriam obtidos no caso da construção de um dispositivo com essas características. É interessante incrementar o ganho pelo fato de que quanto maior for essa grandeza, melhor será a relação sinal-ruído, o que pode implicar em melhor resolução espacial por tornar o ruído menos relevante. Além disso, pode-se trabalhar com menores valores de tensão, o que acarreta em menores probabilidades de ocorrência de descargas elétricas que, por sua vez, podem provocar danos ao detector.

Os parâmetros escolhidos para esse GEM aprimorado foram aqueles que correspondem ao máximo nas curvas de ganho (Figura 6.14 e Figura 6.16), isto é, espaçamento de $120 \mu \mathrm{m}$, raio do furo superior de $30 \mu \mathrm{m}$ e raio inferior de $35 \mu \mathrm{m}$. A correspondente geometria é mostrada na Figura 6.18, onde é possível notar o orifício com diâmetro maior na região inferior da estrutura, o que segundo os resultados obtidos na seção 6.4, é capaz de aumentar o ganho em relação à configuração usual para os mesmos potenciais. Outra possibilidade seria utilizar uma geometria onde os furos superior e inferior 
possuíssem o mesmo diâmetro. No entanto, segundo observado na Figura 6.15, essa configuração apresenta maior IBF.
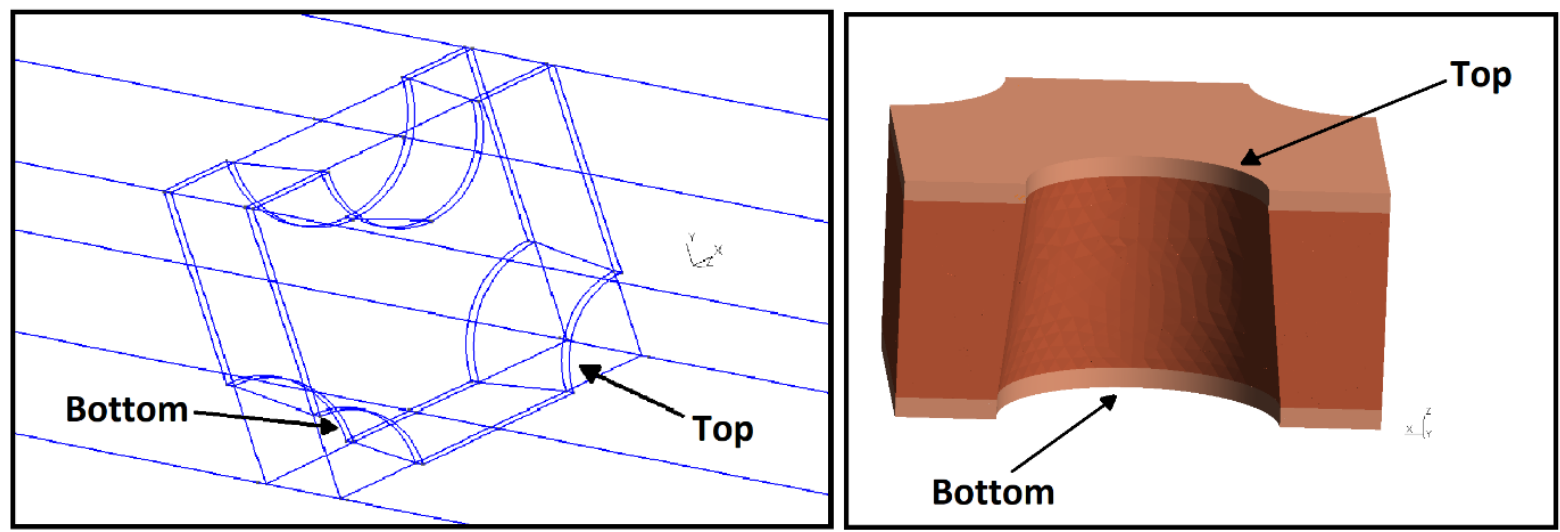

Figura 6.18: Geometria do GEM cônico aprimorado para maximização do ganho, com diâmetro superior de 60 $\mu \mathrm{m}$ e inferior de $70 \mu \mathrm{m}$, enquanto o espaçamento entre furos é de $120 \mu \mathrm{m}$.

Os resultados obtidos para o ganho com geometria otimizada são mostrados na Figura 6.19, onde é mostrado também o ganho do GEM bicônico padrão e cônico com espaçamento de $140 \mu \mathrm{m}$, raio do orifício superior de $35 \mu \mathrm{m}$ e inferior de $30 \mu \mathrm{m}$. Todos os arranjos foram submetidos à mesma configuração de potencial, assim como o valor da fração r Pen referente ao efeito Penning.

Os resultados confirmaram as expectativas para o ganho, ou seja, essa configuração geométrica foi capaz de obter um ganho maior tanto em relação ao GEM bicônico quanto ao cônico em um arranjo usual. Em relação ao GEM bicônico, o incremento no ganho foi superior a $120 \%$ em todos os pontos estudados. Já em relação ao cônico sem otimização dos parâmetros geométricos, o incremento foi da ordem de 75\%. Dessa forma, essa nova configuração proposta tem potencial para até dobrar o valor do ganho, apenas ajustando tanto o espaçamento quanto o diâmetro dos furos. 




Figura 6.19: Ganho do GEM de geometria aprimorada para maximização dessa grandeza em comparação com o GEM bicônico padrão e cônico com espaçamento de $140 \mu \mathrm{m}$, raio do orifício superior de $35 \mu \mathrm{m}$ e inferior de $30 \mu \mathrm{m}$.

O índice IBF obtido para o GEM proposto é mostrado na Figura 6.20, juntamente com os índices para o GEM bicônico e cônico ambos em configuração padrão. Esse resultado mostra que a otimização do ganho não altera significativamente o IBF do detector, uma vez que esse índice é similar para os três dispositivos diferentes.

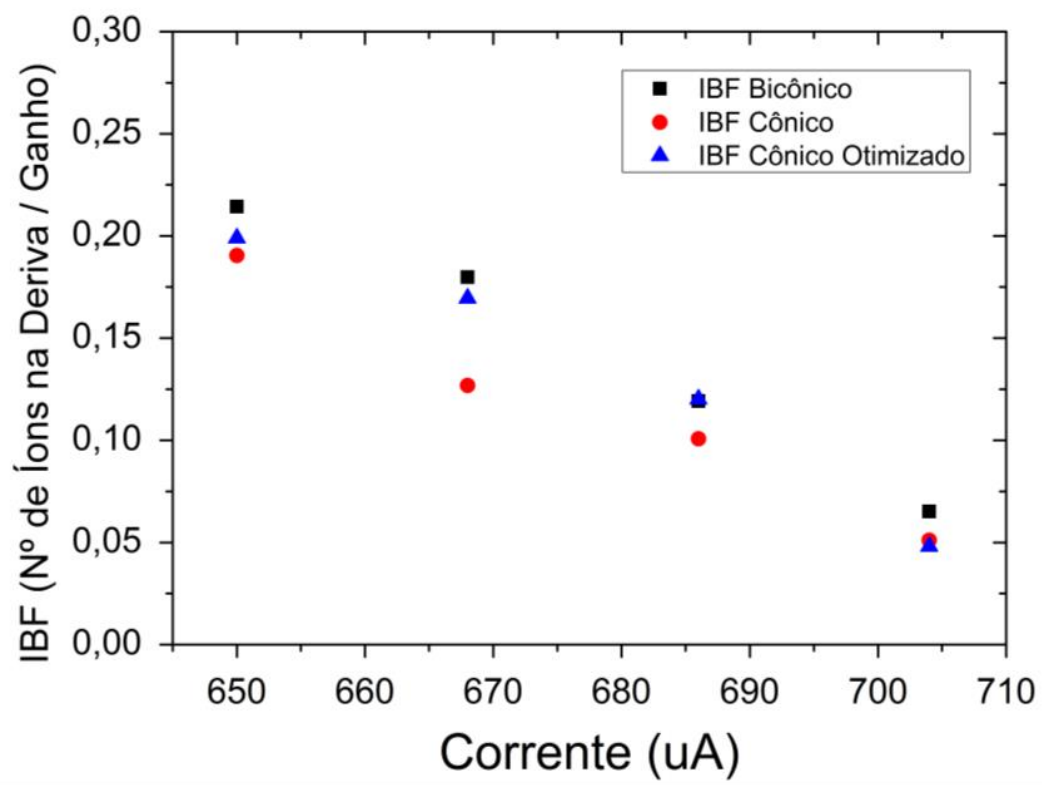

Figura 6.20: Índice de íons na região de deriva normalizado pelo ganho, para o GEM proposto para otimização de ganho, e GEM padrão cônico e bicônico. Os três detectores se mostraram similares em relação a essa grandeza, com pequena vantagem para o GEM cônico padrão. 


\section{Resultados com o Detector}

A seguir, apresentam-se alguns resultados relacionados a um detector MWPC (descrito na seção 2.3) e a um detector triplo GEM pertencente ao Departamento de Física Nuclear do IFUSP. Esses resultados englobam alguns experimentos com uma fonte de ${ }^{55} \mathrm{Fe}$.

Para realizar a aquisição dos dados foi utilizado o programa SPMRoot, do pacote PelRoot (http://sampa.if.usp.br/ suaide/pelletron/) que possui interface com o programa ROOT (Brun \& Rademakers, 1997), que por sua vez foi empregado na criação dos histogramas e ajuste dos dados. Também usamos o Origin para criação de gráficos e ajustes dos dados em algumas situações.

\subsection{Caracterização do MWPC com uma Fonte de ${ }^{55} \mathrm{Fe}$}

Experimentos foram realizados com uma fonte de ${ }^{55} \mathrm{Fe}$ adquirida da empresa Eckert \& Ziegler $^{\mathrm{TM}}$ (California, USA). Essa fonte possuía na época do teste uma atividade de cerca de $100 \mu \mathrm{Ci}$ (micro Curie), correspondendo a aproximadamente $3,7 \mathrm{MBq}\left(3,7 \times 10^{6}\right.$ desintegrações por segundo). Ela emite fótons cujo comprimento de onda possui aproximadamente $2 \AA$, correspondendo a uma energia de 5,9 keV (ver seção 3.3 para mais detalhes sobre essa fonte).

Posicionou-se a fonte de ${ }^{55} \mathrm{Fe}$ a uma certa distância da superfície do detector e utilizou-se de um colimador em formato de disco com um orifício central cujo diâmetro é de $1 \mathrm{~mm}$. Preencheu-se o detector com a mistura de gases composta por 70 \% de Argônio e 30 $\%$ de $\mathrm{CO}_{2}$ a $1 \mathrm{~atm}$. Foi aplicado um potencial positivo na grade de fios do anodo e os catodos foram aterrados, bem como a carcaça do detector.

Foram coletados os sinais elétricos em cada extremidade das grades dos catodos e um sinal do anodo e enviados aos módulos eletrônicos (pré-amplificadores, amplificadores, etc.) para o respectivo processamento do sinal. Nos módulos amplificadores há duas saídas de sinais, um sinal rápido que é utilizado para o gatilho de eventos (para disparar o sistema de aquisição) e um sinal lento que contém informações sobre a amplitude do pulso (utilizado para o cálculo da posição, como mostrado na seção 2.3 ). Toda a eletrônica associada é baseada no padrão NIM e CAMAC (Sales, 2015). 


\subsubsection{Resolução em Energia do MWPC}

Para obter-se a resolução em energia realizou-se um ajuste de uma função Gaussiana na curva referente ao espectro de energia da fonte de ${ }^{55} \mathrm{Fe}$. A partir desse ajuste, pode-se obter o desvio padrão $(\sigma)$, a largura a meia altura (FWHM), bem como o valor médio $\left(H_{0}\right)$, que foram utilizados na equação (2.17) para se calcular a resolução em energia do detector. Na Figura 7.1 pode se observar um exemplo do ajuste do pico principal da fonte de raios $X$ realizada no programa Root.

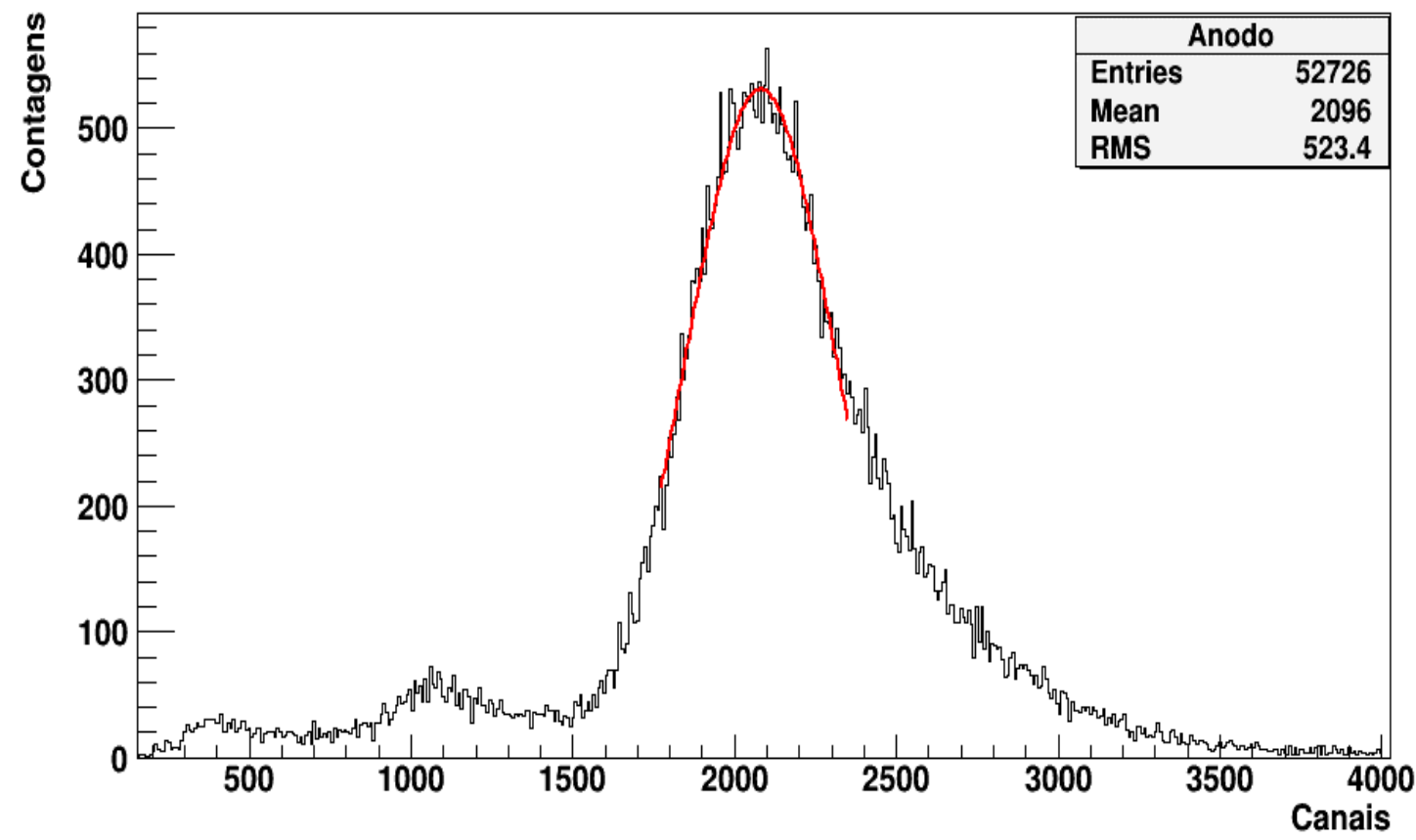

Figura 7.1: Espectro de energia da Fonte de ${ }^{55} \mathrm{Fe}$ com um ajuste Gaussiano do pico principal dessa fonte de radiação. $O$ ajuste fornece o desvio padrão e a largura a meia altura (não mostrados na figura), que foram empregados no cálculo da resolução em energia.

Na Figura 7.2 apresentam-se os resultados obtidos para e resolução em energia do detector multifilar em função da diferença de potencial aplicada nos eletrodos, seguindo a metodologia descrita acima. 


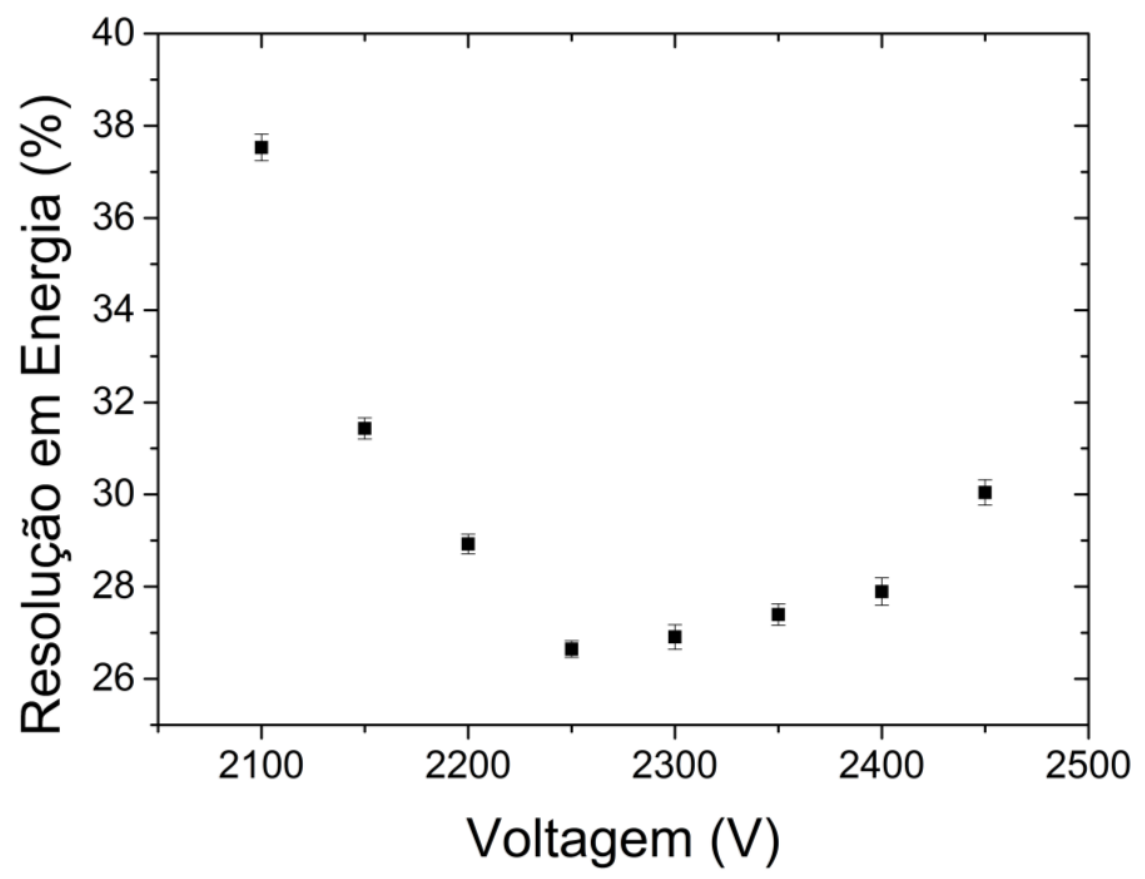

Figura 7.2: Resolução em energia do detector multifilar em função da diferença de potencial entre os eletrodos. A partir do ajuste Gaussiano do espectro de energia da fonte de ferro, obteve-se a largura a meia altura, que empregada na equação (2.17) forneceu a resolução.

\subsubsection{Ganho do MWPC}

Através do ajuste do pico no espectro de energia da fonte de ${ }^{55} \mathrm{Fe}$ (assim como mostra a Figura 7.1), pôde-se obter o ganho do detector, como mostra a Figura 7.3. Como mostrado na figura, o ganho aumenta exponencialmente conforme se incrementa a diferença de potencial nos eletrodos, o que é característico dos detectores proporcionais.

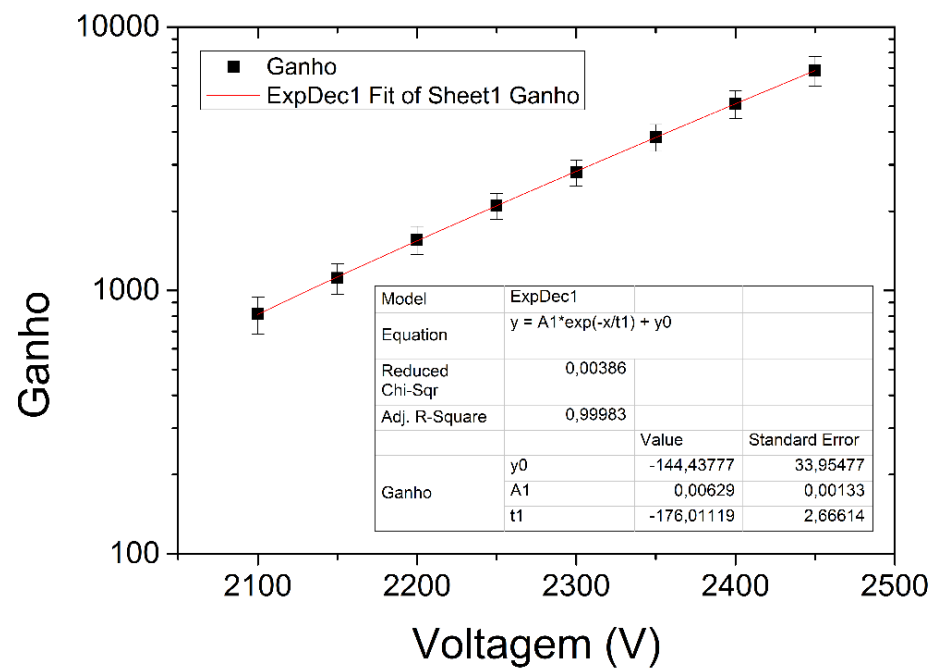

Figura 7.3: Ganho medido no MWPC em função da diferença de potencial aplicada. Pode-se notar que essa grandeza é bem descrita por um ajuste exponencial, mostrando que o detector se encontra na região proporcional. 


\subsection{Caracterização do GEM com a Fonte de ${ }^{55 F e}$}

Foi utilizado um detector GEM pertencente ao grupo HEPIC (High Energy Physics and Instrumentation Center) do Departamento de Física Nuclear do IFUSP para obtenção de dados que corroborem os resultados simulados. Esse dispositivo consiste de um detector com três estágios de multiplicação similar ao esquema do triplo GEM mostrado na Figura 4.4, com a diferença de não utilizar uma cadeia de resistores para distribuição das tensões, mas aplicação de oito canais de alta tensão, permitindo controlar o valor do potencial diretamente em cada um dos eletrodos.

Uma imagem do arranjo experimental utilizado é mostrada na Figura 7.4, onde é possível notar a fonte de raios $\mathrm{X}$ utilizada no experimento, assim como as conexões dos canais de alta tensão que alimentam cada um dos eletrodos do GEM.

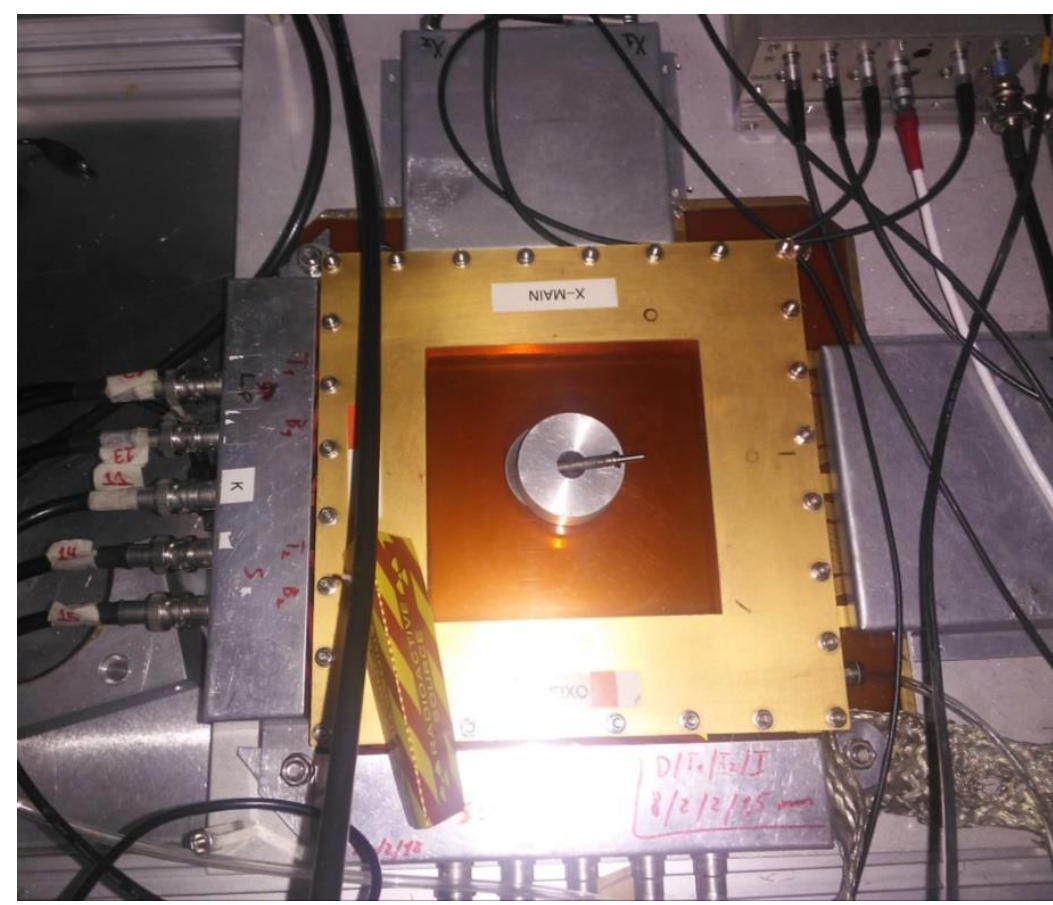

Figura 7.4: Detector triplo GEM utilizado para medidas de ganho de gás e resolução em energia. No centro do dispositivo pode-se perceber a fonte de ${ }^{55} \mathrm{Fe}$ utilizada no experimento.

\subsubsection{Resolução em Energia do GEM}

A eletrônica aplicada, assim como o sistema de aquisição e os procedimentos experimentais, foram praticamente os mesmos dos experimentos com o detector multifilar descrita na seção 7.1. A diferença se deu na aplicação dos potenciais, que foi realizada através de uma fonte de alta tensão com vários canais, onde era possível modificar o valor 
do potencial diretamente em cada um dos eletrodos. Outra diferença foi em relação à coleta dos sinais, que ao contrário do que ocorreu com o GEM de referência do CERN, foram coletados no eletrodo GEM3 Bottom ao invés do ReadOut. Esse artifício tem o objetivo de coletar também os elétrons que são depositados na superfície inferior do terceiro GEM e, dessa maneira, não chegam ao plano de leitura. Os resultados para a resolução em energia são apresentados na Figura 7.5.

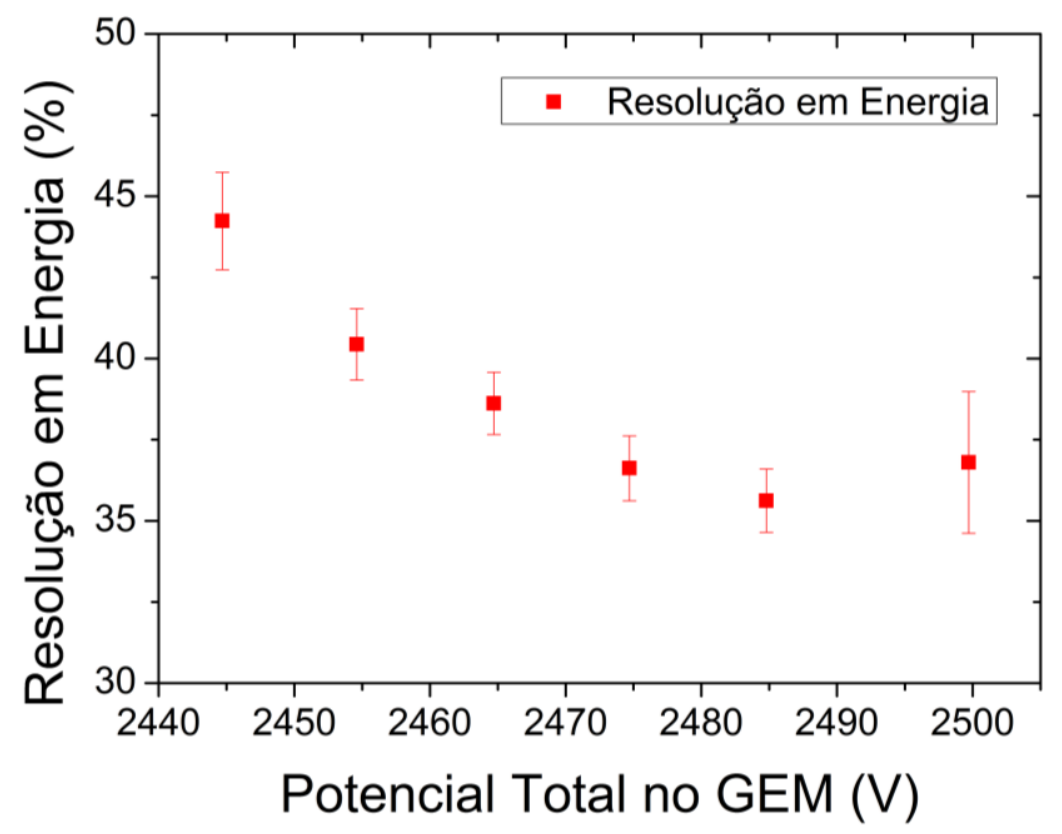

Figura 7.5: Resolução em energia em função do potencial global aplicado no triplo GEM do grupo HEPIC em comparação com a obtida pelo triplo GEM padrão do CERN (Sales, 2015).

Pode ser observado como a resolução em energia obtida para o GEM é bastante distante daquela apontada pelas simulações como sendo a ideal para esse sistema (cerca de 15\%). Esse resultado mostra uma importante influência no ruído eletrônico, o que também ocorreu para o MWPC, mas foi menos acentuado naquele caso.

\subsubsection{Ganho do GEM}

Para medir o ganho desse detector, primeiro foi preciso fazer uma calibração através da introdução de pulsos elétricos de amplitudes conhecidas na entrada de testes do préamplificador com auxílio de um pulsador. Há um capacitor de entrada de $1 \mathrm{pF}$, o que permitiu calcular a carga introduzida no pré-amplificador através da relação entre a diferença de potencial (amplitude do pulso), carga elétrica e capacitância. Na sequência, o valor de carga calculado foi convertido no número de pares de elétrons-íons usando a 
energia de ionização da mistura de gases que preenche o detector e a energia de 5,89 keV dos raios $X$ incidentes aplicando a equação (2.1). O ganho foi determinado através do cálculo da razão entre o número de pares elétron-íon pelo número inicial, o que leva ao resultado mostrado na Figura 7.6, que correlaciona a amplitude do pulso com a carga coletada no detector.

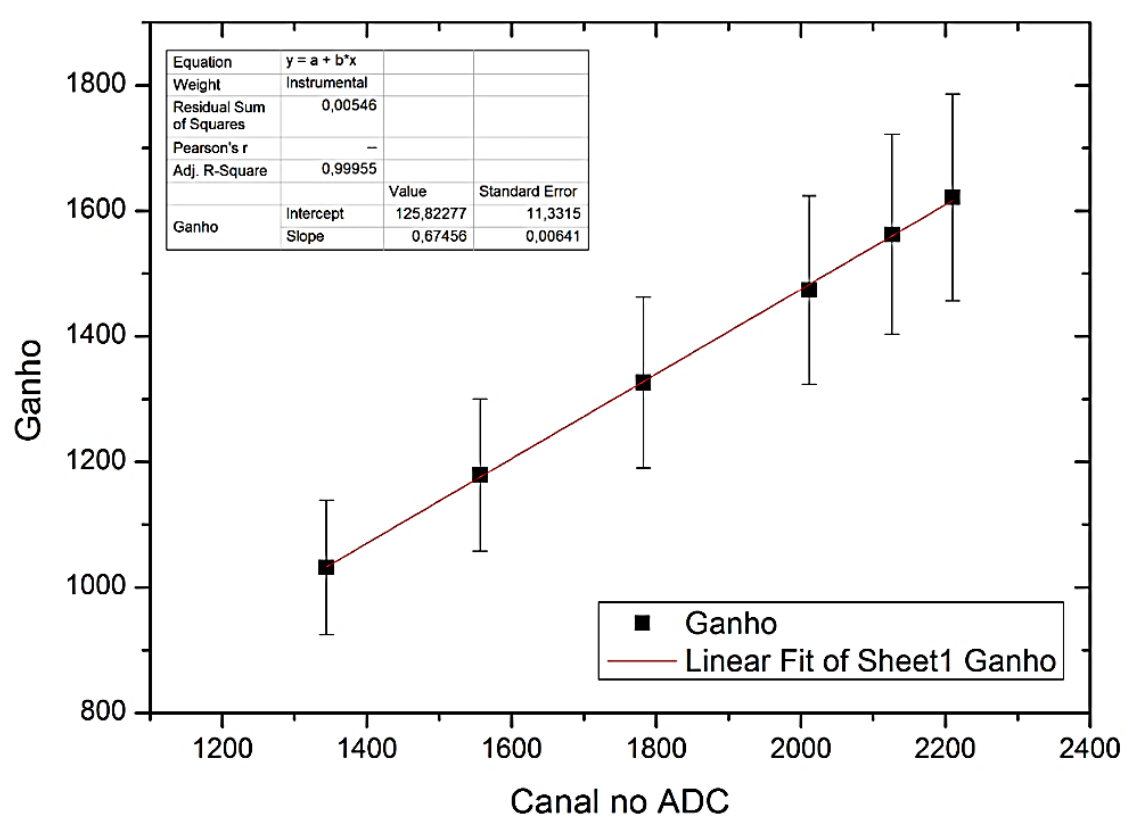

Figura 7.6: Calibração de ganho para o GEM, mostrando a correlação entre o ganho e o canal observado no ADC.

Após a calibração, realizou-se a aquisição do espectro da fonte de raios $\mathrm{X}$ para diferentes configurações de potenciais e campos no GEM. Na sequência, foi realizado um ajuste do pico principal do espectro, cujo valor médio do canal foi aplicado na determinação do ganho aplicando a calibração. O ganho obtido é mostrado na Figura 7.7, onde nota-se o comportamento exponencial dessa grandeza em função do potencial aplicado. 


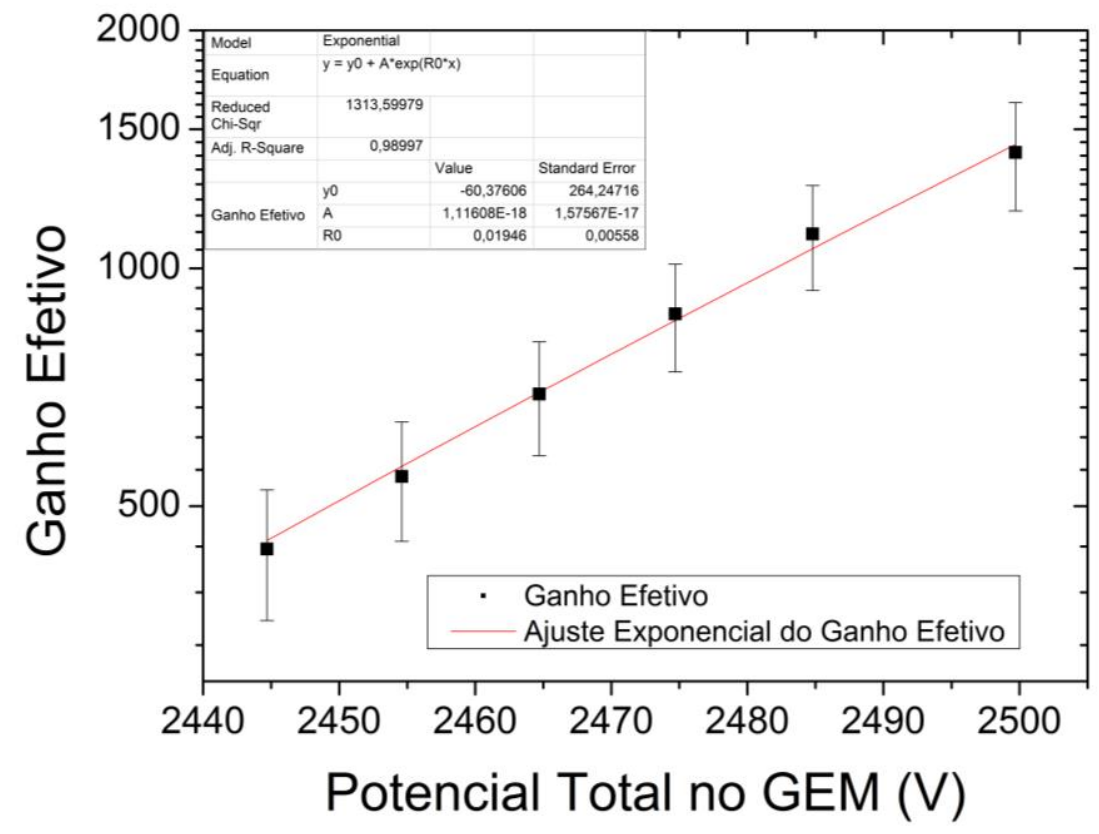

Figura 7.7: Ganho do GEM em função do potencial global aplicado no triplo GEM.

O ganho obtido tanto para o GEM quanto para o MWPC apresenta claramente um comportamento exponencial, como era esperado pelo fato de ser o efeito causado pela avalanche eletrônica estudada nas simulações. Se compararmos os ganhos entre os dois detectores, vemos que o ganho no MWPC é maior que para o GEM, porém essa diferença não deve ser interpretada como uma limitação do GEM. Na realidade, o GEM pode alcançar ganhos muito maiores de acordo com a configuração de campos e potenciais aplicados. 


\section{Conclusões e Perspectivas}

Foram apresentadas nesse trabalho algumas estratégias interessantes para a assimilação de alguns dos princípios de funcionamento e características dos detectores a gás. Foram abordados detalhes sobre a obtenção do ganho do detector experimentalmente (a partir do espectro de energia) e pelas simulações através do ajuste de Polya da distribuição do número de elétrons na avalanche. Os parâmetros obtidos desse ajuste foram empregados na determinação do ganho do detector que, por sua vez, mostrou-se aumentar exponencialmente em função do acréscimo na diferença de potencial aplicada, característica típica dos detectores proporcionais. Esse comportamento exponencial no ganho também foi observado para a caracterização tanto do detector multifilar quanto para o GEM do grupo HEPIC.

Dado que esse trabalho utilizou softwares de livre acesso para simular o GEM, há a possibilidade de uma ampla utilização por parte de futuros trabalhos, que podem analisar sistemas usando o presente estudo como referência, sem ter a preocupação de adquirir a licença de utilização de um programa do tipo proprietário. Para facilitar futuros trabalhos que pretendam simular detectores triplo GEM, foi desenvolvido uma ferramenta através de uma série de arquivos executáveis que são capazes de configurar os arquivos de entrada para todos os programas utilizados nas simulações. Essa abordagem deixa bastante simples e rápida a tarefa de simular um detector ao realizar toda a parte braçal que demanda boa parte do tempo necessário para simular um detector. Destaca-se que não foi encontrado nenhuma iniciativa desse tipo na literatura atualmente. Talvez uma explicação para esse fato é que a maioria dos usuários do Garfield++ acabam optando por ferramentas do tipo proprietário, que necessitam de uma onerosa licença de utilização, como o Ansys, por exemplo. Este procedimento automatizado de simulação pode ser incorporado com rotinas de otimização que possam buscar condições ideais de funcionamento do GEM variando os parâmetros no espaço de configurações. Métodos de Monte Carlo podem ser empregados para esse fim, fazendo uma busca no espaço de parâmetros.

Os resultados obtidos para o potencial elétrico do GEM bicônico revelaram, através de uma projeção ao longo da direção perpendicular ao plano das folhas, que ele se assemelha ao comportamento de um conjunto de capacitores de placas paralelas na região 
afastada dos furos. Já no que se refere ao campo elétrico, a mesma projeção revelou um campo constante nessa região longe dos orifícios, enquanto em suas proximidades observou-se um módulo bastante elevado, se aproximando de $100 \mathrm{kV} / \mathrm{cm}$ em algumas configurações. As linhas de campo, por sua vez, evidenciaram o direcionamento dos elétrons para a região interna dos furos. Ainda em relação ao campo, foi constado como o perfil do mesmo (e não somente o módulo) varia em função da posição conforme a projeção escolhida se aproxima dos furos, revelando as características das transições entre o gás e o polímero (Kapton), além da constatação de um campo nulo no interior do condutor, como era esperado. Foi observado nas bordas da folha que o campo elétrico tem seu sentido invertido, o que caracteriza uma região de atração de elétrons e é um dos motivos pelo qual parte dessas cargas são aprisionadas nessa região.

O potencial elétrico do GEM cônico não mostrou grandes diferenças em relação ao bicônico, enquanto o perfil do campo nas proximidades dos furos se mostrou mais suave na transição entre o gás e o polímero. Na comparação com o GEM bicônico, foi verificado que nas regiões afastadas das folhas o módulo do campo é basicamente o mesmo para as duas geometrias, mas na região interna o campo do GEM cônico é mais intenso.

Em relação ao ganho simulado, foi verificado uma boa concordância entre a simulação com aquele obtido experimentalmente para o triplo GEM bicônico após a adição do efeito Penning no modelo, cujo fator $\boldsymbol{r}_{\text {Pen }}$ com que se obteve melhor concordância com os dados experimentais foi de 0,38. Já a comparação entre as duas geometrias mostrou que o GEM cônico apresenta maior ganho que o bicônico, provavelmente devido à maior intensidade do campo na região dos orifícios.

Foi possível realizar a simulação da deposição de energia no gás por fótons emitidos por uma fonte de ${ }^{55} \mathrm{Fe}$ e o respectivo espectro, que revelou uma resolução em energia mínima possível para o detector de cerca de 15\%. Essa resolução intrínseca considera apenas as flutuações no fator de ganho do detector, sem levar em conta outras fontes de flutuações, como ruído eletrônico, por exemplo. Supondo um ruído eletrônico do tipo Gaussiano branco, foi possível obter um alargamento no espectro que se assemelhou ao obtido experimentalmente. 
A partir da posição final dos elétrons no plano de leitura, foi possível estimar a resolução espacial intrínseca do dispositivo, calculada através de um ajuste Gaussiano da distribuição em cerca de $0,560 \mathrm{~mm}$. Foi estudado também o movimento retrógrado de íons para as mesmas configurações utilizadas na construção da curva de ganho. Os resultados estavam em acordo com aqueles reportados na literatura, ou seja, uma fração de IBF entre 0,2 e 0,05 (normalizada pelo ganho do detector).

Foi investigado também como as propriedades do funcionamento do detector variam em função de parâmetros geométricos do GEM. Foi escolhido fazer o estudo para diferentes diâmetros dos furos e espaçamento entre os mesmos no caso da geometria cônica. No que se refere à resolução em energia e posição, não foi encontrado nenhuma diferença variando os parâmetros geométricos estudados. Verificou-se que, em relação ao ganho, este é tanto maior quanto menor a diferença entre o diâmetro superior e inferior do orifício, isto é, quanto mais o furo se aproxima de uma geometria cilíndrica, ou no caso onde o raio do orifício inferior é até $5 \mu \mathrm{m}$ maior que o superior. Variando o espaçamento entre orifícios, verificou-se que o ganho atinge um valor máximo para um espaçamento de $120 \mu \mathrm{m}$, diminuindo de forma bastante abrupta para valores tanto menores quanto maiores de espaçamentos. No caso de espaçamentos grandes, esse efeito é atribuído à maior área disponível de cobre na superfície, o que diminui a densidade das linhas de campo e pode favorecer a aceleração dos elétrons contra a superfície superior do GEM.

Foi simulado um GEM de geometria cônica aplicando os parâmetros que maximizam o ganho, isto é, com espaçamento de $120 \mu \mathrm{m}$, raio do furo superior de $30 \mu \mathrm{m}$ e inferior de $35 \mu \mathrm{m}$. Os resultados obtidos mostraram claramente como essa configuração foi mais eficiente para o ganho, sendo este cerca de $120 \%$ maior que o GEM bicônico padrão e cerca de $75 \%$ maior que o cônico com geometria usual.

Em relação ao índice IBF, foi constatado que este é tanto menor quanto maior o raio do furo inferior em relação ao superior. Para valores maiores do raio do furo superior, a fração de íons normalizada pelo ganho tende a crescer. Já no caso do espaçamento entre furos, foi constatada uma tendência de queda em função do aumento no passo dentro do intervalo estudado. 
As principais perspectivas do trabalho estão ligadas à fabricação de um protótipo do GEM com as características geométricas que foram estudadas de modo a favorecer uma determinada característica. Por exemplo, no caso de necessidade de diminuir o IBF, pode-se sugerir uma geometria cujo diâmetro do furo inferior seja maior que o superior, enquanto o espaçamento entre os orifícios seja aumentado acima de $150 \mu \mathrm{m}$. Por outro lado, caso se deseje priorizar o ganho, a sugestão construir um GEM com os parâmetros geométricos do detector simulado na seção 6.5 .

O grupo do professor Alexandre Suaide et al. do departamento de Física Nuclear do IFUSP (grupo HEPIC) trabalha com detectores GEM. Entre seus projetos, está previsto o desenvolvimento de folhas GEM em colaboração com o Departamento de Microeletrônica da Escola Politécnica da USP, coordenado pelo professor Marcelo Nelson Páez Carreño. Dessa maneira, os estudos de simulações apresentadas no presente trabalho poderão guiar os desenvolvimentos de folhas GEM, no sentido de apontar os parâmetros ótimos visando favorecer determinada característica de funcionamento do detector. Além disso, os procedimentos de automatização das simulações podem beneficiar pesquisadores desta área no design rápido e eficiente de detectores GEM. 


\section{Bibliografia}

Ahrens, J., Bauer, A., Boeckel, B., Choudhary, A., DeMarle, D., Geveci, B., . . . Zagaris, G. (2019). The ParaView Guide. In (pp. 274). United States of America.: Kitware Inc.

Alexeev, M., Birsa, R., Bradamante, F., Bressan, A., Chiosso, M., Ciliberti, P., . . . Veloso, J. F. C. A. (2013). Ion backflow in thick GEM-based detectors of single photons. IOP Publishing, Journal of Instrumentation, 8, P01021-P01021. doi:10.1088/1748-0221/8/01/p01021

Alkaa, A., Mitev, K., \& Segur, P. (2007). A fast technique for Monte Carlo simulation of the process of gas multiplication in cylindrical proportional counters. Nuclear Instruments \& Methods in Physics Research Section a-Accelerators Spectrometers Detectors and Associated Equipment, 580(1), 161-164. doi:10.1016/j.nima.2007.05.074

Ayachit, U. (2015). The ParaView Guide: A Parallel Visualization Application. In. Clifton Park, NY, USA: Kitware, Inc.

Azevedo, C. D. R., Biagi, S., Veenhof, R., Correia, P. M., Silva, A. L. M., Carramate, L. F. N. D., \& Veloso, J. F. C. A. (2015). Position resolution limits in pure noble gaseous detectors for X-ray energies from 1 to 60 keV. Physics Letters B, 741, $272 \quad-\quad 275$. doi:https://doi.org/10.1016/j.physletb.2014.12.054

Azevedo, C. D. R., Correia, P. M. M., Carramate, L. F. N. D., Silva, A. L. M., \& Veloso, J. F. C. A. (2016). THGEM gain calculations using Garfield++: solving discrepancies between simulation and experimental data. In (Vol. 11, pp. P08018--P08018): IOP Publishing.

Barrett, R., Berry, M., Chan, T. F., Demmel, J., Donato, J. M., Eijkhout, V., . . . Vorst, H. V. d. (1994). Templates for the Solution of Linear Systems: Building Blocks for Iterative Methods. Philadelphia: SIAM.

Bateman, J. E., Connolly, J. F., Stephenson, R., \& Tappern, G. J. (1981). A HIGH-RESOLUTION POSITION-SENSITIVE X-RAY MWPC FOR SMALLANGLE X-RAY-DIFFRACTION. Nuclear Instruments \& Methods in Physics Research, 190(2), 385-394. doi:10.1016/0029554x(81)90303-7

Bencivenni, G., Bonivento, W., Cardini, A., De Simone, P., Deplano, C., Murtas, F., ... Raspino, D. (2002). A comparison between GEM-based detector simulation and experimental measurements. Nuclear Instruments \& Methods in Physics Research Section a-Accelerators Spectrometers Detectors and Associated Equipment, 494(1-3), 233-235. doi:10.1016/s0168-9002(02)01472-9 
Benlloch, J., Bressan, A., Buttner, C., Capeans, M., Gruwe, M., Hoch, M., . . . Veenhof, R. (1998). Development of the gas electron multiplier (GEM). Ieee Transactions on Nuclear Science, 45(3), 234-243. doi:10.1109/23.682386

Benlloch, J., Bressan, A., Capeans, M., Gruwe, M., Hoch, M., Labbe, J. C., . . . Sauli, F. (1998). Further developments and beam tests of the gas electron multiplier (GEM). Nuclear Instruments \& Methods in Physics Research Section a-Accelerators Spectrometers Detectors and Associated Equipment, 419(2-3), 410-417. doi:10.1016/s01689002(98)00816-X

Berners-Lee, T., \& Groff, J.-F. (1992). WWW. SIGBIO Newsl., 12, 37-40.

Betts, W. J. (1996). Studies of Several Wire and Pad Configurations for the STAR TPC. (Master), University of Texas, Austin.

Bhattacharya, P., Mohanty, B., Mukhopadhyay, S., Majumdar, N., \& Luz, H. N. d. (2017). 3D simulation of electron and ion transmission of GEMbased detectors. In (Vol. A, pp. 64-72): Nuclear Inst. and Methods in Physics Research.

Bhattacharya, P., Mukhopadhyay, S., Majumdar, N., \& Bhattacharya, S. (2012). A comparative numerical study on GEM, MHSP and MSGC. Journal of Instrumentation, 7. doi:10.1088/1748-0221/7/09/P09007

Biagi, S. (1995). Magboltz - transport of electrons in gas mixtures (Version 11.2, 3.2): CERN (European Organization for Nuclear Research). Retrieved from http://magboltz.web.cern.ch/magboltz/

Biswas, S., Schmidt, D. J., Abuhoza, A., Frankenfeld, U., Garabatos, C., Hehner, J., . . . Wiechula, J. (2016). Systematic measurements of the gain and the energy resolution of single and double mask GEM detectors. Nuclear Instruments \& Methods in Physics Research Section aAccelerators Spectrometers Detectors and Associated Equipment, 824, 504-506. doi:10.1016/j.nima.2015.11.086

Blum, W., Riegler, W., \& Rolandi, L. (2008). Particle Detection with Drift Chambers. Berlin: Springer-Verlag Berlin Heidelberg.

Bouianov, O., Bouianov, M., Orava, R., Semenov, P., \& Tikhonov, V. (2000). Progress in GEM simulation. Nuclear Instruments and Methods in Physics Research Section A: Accelerators, Spectrometers, Detectors and Associated Equipment, 450(2), 277 - 287. doi:https://doi.org/10.1016/S0168-9002(00)00257-6

Boulin, C. J., Kempf, R., Gabriel, A., \& Koch, M. H. J. (1988). DATA ACQUISITION-SYSTEMS FOR LINEAR AND AREA X-RAY-DETECTORS USING DELAY-LINE READOUT. Nuclear Instruments \& Methods in Physics Research Section a-Accelerators Spectrometers Detectors and Associated Equipment, 269(1), 312-320. doi:10.1016/01689002(88)90895-9 
Brun, R., \& Rademakers, F. (1997). ROOT - An object oriented data analysis framework. Nuclear Instruments \& Methods in Physics Research Section a-Accelerators Spectrometers Detectors and Associated Equipment, 389(1-2), 81-86. doi:10.1016/s0168-9002(97)00048-x

Burns, J., Crane, T., Ezeribe, A. C., Grove, C., Lynch, W., Scarff, A., . . . Steer, C. (2017). Characterisation of Large Area THGEMs and Experimental Measurement of the Townsend Coefficients for CF4. In: British Crown Owned.

Bé, M. M., \& Chisté, V. (2006). Table de Radionucléides 55Fe. In (pp. 5): Laboratoire National Henri Becquerel (LNE-LNHB).

CERN. (2019a). The birth of the Web. Retrieved from https://home.cern/science/computing/birth-web

CERN. (2019b). Where the web was born. Retrieved from https://home.cern/science/computing/where-web-was-born

Charles, M. W. (1972). GAS GAIN MEASUREMENTS IN PROPORTIONAL COUNTERS. Journal of Physics E-Scientific Instruments, 5(1), 95-\&. doi:10.1088/0022-3735/5/1/031

Charpak, G., Bouclier, R., Bressani, T., Favier, J., \& Zupancic, C. (1968). USE OF MULTIWIRE PROPORTIONAL COUNTERS TO SELECT AND LOCALIZE CHARGED PARTICLES. Nuclear Instruments \& Methods, 62(3), 262-\&. doi:10.1016/0029-554x(68)90371-6

Choudhury, R. K. (1999). Experimental techniques in nuclear physics. In (pp. 38). Mumbai: Bhabha Atomic Research Centre.

Cook, R. D., Witt, R. J., Malkus, D. S., \& Plesha, M. E. (2002). Concepts And Applications Of Finite Element Analysis (4Th ed.): John Wiley \& Sons.

Correia, P. M. M., Pitt, M., Azevedo, C. D. R., Breskin, A., Bressler, S., Oliveira, C. A. B., . . Veloso, J. F. C. A. (2018). Simulation of gain stability of THGEM gas-avalanche particle detectors. In (Vol. 13, pp. P01015): Journal of Instrumentation.

Croci, G., Ropelewski, L., Sauli, F., \& Solevi, P. (2007a). Depth of interaction determination in GEM-based multi-layer PET detectors. Nuclear Instruments \& Methods in Physics Research Section a-Accelerators Spectrometers Detectors and Associated Equipment, 582(2), 693-695. doi:10.1016/j.nima.2007.08.244

Croci, G., Ropelewski, L., Sauli, F., \& Solevi, P. (2007b). Depth of Interaction determination in GEM-based multilayer PET detectors. In (pp. 7): Nuclear Instruments and Methods in Physics Research Section A Accelerators Spectrometers Detectors and Associated Equipment.

Date, H., Kondo, K., Shimozuma, M., \& Tagashira, H. (2000). Electron kinetics in proportional counters. Nuclear Instruments \& Methods in Physics Research Section a-Accelerators Spectrometers Detectors and 
Associated Equipment, 451(3), 588-595. doi:10.1016/s01689002(00)00331-4

de Moura, M. M., Suaide, A. A. P., Souza, F. A., Alonso, E. E., Fujii, R. J., Meyknecht, A. B., ... Carlin, N. (1999). A large area two-dimensional position sensitive multiwire proportional detector. Nuclear Instruments \& Methods in Physics Research Section a-Accelerators Spectrometers Detectors and Associated Equipment, 433(3), 623-629. doi:10.1016/s0168-9002(99)00387-3

Delaney, C. F. G., \& Finch, E. C. (1992). Radiation detectors : physical principles and applications. Oxford: Clarendon Press.

Dildick, S. (2011). Gas gain in a single GEM: parameter space. Paper presented at the RD51 mini-week.

Doke, T., Ishida, N., \& Kase, M. (1992). Fano factors in rare gases and their mixtures. Nuclear Instruments and Methods in Physics Research Section B: Beam Interactions with Materials and Atoms, 63, 373 - 376. doi:https://doi.org/10.1016/0168-583X(92)95207-8

Druyvesteyn, M. J., \& Penning, F. M. (1940). The Mechanism of Electrical Discharges in Gases of Low Pressure. In (Vol. 12, pp. 87): Rev. Mod. Phys. (Reprinted from: Erratum Rev. Mod. Phys. 13, 72 (1941)).

Fano, U. (1963). Penetration of Protons, Alpha Particles, and Mesons. Annual Review of Nuclear Science, 13, 1-66. doi:10.1146/annurev.ns.13.120163.000245.

Fehlberg, E. (1969). Low order Runge-Kutta formulas with step control for heat transfer problems. Retrieved from NASA Marshall Space Flight Center, WASHINGTON, United States:

Ferretti, A., De Nardo, L., \& Lombardi, M. (2009). Preliminary study of a leak microstructure detector as a new single-electron counter for STARTRACK experiment. Nuclear Instruments \& Methods in Physics Research Section a-Accelerators Spectrometers Detectors and Associated Equipment, 599(2-3), 215-220. doi:10.1016/j.nima.2008.11.093

Filliatre, P., Jammes, C., Geslot, B., \& Veenhof, R. (2012). A Monte Carlo simulation of the fission chambers neutron-induced pulse shape using the GARFIELD suite. Nuclear Instruments \& Methods in Physics Research Section a-Accelerators Spectrometers Detectors and Associated Equipment, 678, 139-147. doi:10.1016/j.nima.2012.03.020

Fourme, R. (1997). Position-sensitive gas detectors: MWPCs and their gifted descendants. Nuclear Instruments \& Methods in Physics Research Section a-Accelerators Spectrometers Detectors and Associated Equipment, 392(1-3), 1-11. doi:10.1016/s0168-9002(97)00284-2

Gabriel, A. (1977). POSITION-SENSITIVE X-RAY DETECTOR. Review of Scientific Instruments, 48(10), 1303-1305. doi:10.1063/1.1134870 
Gabriel, A., Dauvergne, F., \& Rosenbaum, G. (1978). LINEAR, CIRCULAR AND 2 DIMENSIONAL POSITION-SENSITIVE DETECTORS. Nuclear Instruments \& Methods, 152(1), 191-194. doi:10.1016/0029554x(78)90263-x

Geuzaine, C., \& Remacle, J. F. (2009). Gmsh: a three-dimensional finite element mesh generator with built-in pre- and post-processing facilities In (Vol. 79, pp. 1309-1331): International Journal for Numerical Methods in Engineering

Giomataris, Y., Rebourgeard, P., Robert, J. P., \& Charpak, G. (1996). MICROMEGAS: A high-granularity position-sensitive gaseous detector for high particle-flux environments. Nuclear Instruments \& Methods in Physics Research Section a-Accelerators Spectrometers Detectors and Associated Equipment, 376(1), 29-35. doi:10.1016/01689002(96)00175-1

Golub, G., Greenbaum, A., \& Luskin, M. (1994). Recent Advances in Iterative Methods (Vol. 60). New York: Springer-Verlag.

GRIPER. (2019). SAMPA (Sistema de Análise e Multi-Processamento Avançado). Retrieved from http://hepic.if.usp.br/?q=pt-br/infraestrutura-computacional

Grupen, C., \& Shwartz, B. (2008). Particle detectors (Second ed.). Cambridge ; New York: Cambridge University Press.

Guérard, B. (2019). An inspirational inventor: Anton Oed 1933-2018.

Hallermann, L. (2010). Analysis of GEM Properties and Development of a GEM Support Structure for the ILD Time Projection Chamber. (Doutorado), Universität Hamburg, Hamburg, Germany.

Henke, B. L., Gullikson, E. M., \& Davis, J. C. (1993). X-ray interactions: photoabsorption, scattering, transmission, and reflection at $E=50$ $30000 \mathrm{eV}, \quad Z=1-92$. Vol. 54. Retrieved from http://henke.lbl.gov/optical constants/index.html

Hippel, E. V. (2001). Innovation by User Communities: Learning from OpenSource Software. In (pp. 82-86): MIT SLOAN MANAGEMENT REVIEW. Johnson, N. L., Kemp, A. W., \& Kotz, S. (1992). Univariate Discrete Distributions (Second ed.). New York: John Wiley \& Sons, Inc.

Jucker, M. (2014). Scientific Visualisation of Atmospheric Data with ParaView. In (pp. 4): Journal of Open Research Software.

Kadilar, G. Ö., \& İnal, C. (2010). The probability function of a geometric Poisson distribution. Journal of Statistical Computation and Simulation - J STAT COMPUT SIM, 80, 479-487. doi:10.1080/00949650802711925.

Karadzhinova, A., Nolvi, A., Veenhof, R., Tuominen, E., Haeggstrom, E., \& Kassamakov, I. (2015). Impact of GEM foil hole geometry on GEM 
detector gain. Journal of Instrumentation, 10. doi:10.1088/17480221/10/12/p12014

Knoll, G. F. (1979). Radiation detection and measurement. New York: Wiley. Kudryavtsev, V. N., Maltsev, T. V., \& Shekhtman, L. I. (2019). Spatial resolution of triple-GEM detectors. In (Vol. 936, pp. 482-484): Nuclear Inst. and Methods in Physics Research, A.

Lepage, P. G. (1978). A new algorithm for adaptive multidimensional integration. Journal of Computational Physics, 27(2), 192-203. doi:https://doi.org/10.1016/0021-9991(78)90004-9

Lessig, L., \& Stallman, R. M. (2004). Free Software, Free Society: Selected Essays of Richard M. Stallman (J. Gay Ed. 2nd ed.). Boston, MA USA: GNU Press.

Liu, Q., Li, J., \& Liu, J. (2017). ParaView visualization of Abaqus output on the mechanical deformation of complex microstructures. Computers \& Geosciences, 99, 135-144. doi:https://doi.org/10.1016/j.cageo.2016.11.008

Lutz , G. (2007). Semiconductor Radiation Detectors. Leipzig: SpringerVerlag Berlin Heidelberg.

Lyon, A. L., Kowalkowski, J. B., \& Jones, C. D. (2017). Integrating Visualization Applications, such as ParaView, into HEP Software Frameworks for In-situ Event Displays. Journal of Physics: Conference Series, 898, 072041. doi:10.1088/1742-6596/898/7/072041

Maghrbi, Y., Bouhali, 0., \& Ieee. (2013, Dec 03-05). Gain uniformity of trapezoidal triple-GEM detectors. Paper presented at the 7 th International Conference on Sensing Technology (ICST), Wellington, NEW ZEALAND.

Majewski, P. (1996). Multiwire Proportional Chamber for the fast RICH detector for the ALICE experiment at LHC. (Master), Warsaw University,

Malinowski, K., Chernyshova, M., Czarski, T., Kowalska-Strzeciwilk, E., Linczuk, P., Wojenski, A., . . . Gaska, M. (2018). Simulation of energy spectrum of GEM detector from an x-ray quantum. Journal of Instrumentation, 13, 10.

Marinho, P. R. B. (2001). Projeto e Construção de um Detector de Raios Cósmicos com Localização Tridimensional. (Mestrado), CENTRO BRASILEIRO DE PESQUISAS FÍSICAS, Rio de Janeiro.

Matoba, M., Hirose, T., Sakae, T., \& Kametani, H. (1985). 3-DIMENSIONAL MONTE-CARLO SIMULATION OF THE ELECTRON AVALANCHE AROUND AN ANODE WIRE OF A PROPORTIONAL COUNTER. Ieee Transactions on Nuclear Science, 32(1), 541-544. doi:10.1109/tns.1985.4336890 
Mukhopadhay, S., \& Majumdar, N. (2009). A nearly exact Boundary Element Method (Version 1.8.13). Retrieved from http://nebem.web.cern.ch/nebem/

Murello, A., \& Milotti, E. (2013). Using a free software tool for the visualization of complicated electromagnetic fields. European Journal of Physics, 35(1), 015014. doi:10.1088/0143-0807/35/1/015014

Murtas, F. (2002). Development of a gaseous detector based on Gas Electron Multiplier (GEM)

Technology. In SRG Lab Seminar. Frascati: Instituto Nazionale di Fisica Nucleare.

Mörmann, D., Breskin, A., Chechik, R., \& Bloch, D. (2004). Evaluation and reduction of ion back-flow in multi-GEM detectors. Nuclear Instruments and Methods in Physics Research Section A: Accelerators, Spectrometers, Detectors and Associated Equipment, 516, 315 - 326. doi:https://doi.org/10.1016/j.nima.2003.08.156

Nemallapudi, M. V. (2012). Gain of a Single Gas Electron Multiplier. (Master), University of Arkansas, Fayetteville.

NIST. (2006). Dataplot PAPPDF.

Nuel, G. (2008). Cumulative Distribution Function of a Geometric Poisson Distribution. Journal of Statistical Computation and Simulation, 78, 385-394. doi:10.1080/10629360600997371

Oed, A. (1988). POSITION-SENSITIVE DETECTOR WITH MICROSTRIP ANODE FOR ELECTRON MULTIPLICATION WITH GASES. Nuclear Instruments \& Methods in Physics Research Section a-Accelerators Spectrometers Detectors and Associated Equipment, 263(2-3), 351359. doi:10.1016/0168-9002(88)90970-9

Ogawa, T., \& Aoki, Y. (2017). Simulation study on impact of GEM geometry for gas gain uniformity. In (pp. 10): Journal of LATEX Templates.

Oliveira, C. A. B. (2011). Estudo de Monte Carlo da electroluminescência em detectores gasosos. (Doutorado), Universidade de Aveiro, Aveiro, Portugal.

Oliveira, C. L. P. (1998). OBTENÇÃO DE IMAGENS BIDIMENSIONAIS DE ESPECTROS DE DIFRAÇÃO DE RAIOS X USANDO PLACAS DE FÓSFORO SENSÍVEL E LEITURA DIGITAL. Retrieved from Campinas, SP:

Patra, R. N., Singaraju, R. N., Biswas, S., Viyogi, Y. P., \& Nayak, T. K. (2018). Characteristic study of a quadruple GEM detector and its comparison with a triple GEM detector. Nuclear Instruments and Methods in Physics Research Section A: Accelerators, Spectrometers, Detectors and Associated Equipment, 906, 37-42. doi:https://doi.org/10.1016/j.nima.2018.08.023. 
Penning, F. M. (1928). Uber den Einfluß sehr geringer Beimischungen auf die Zundspannung der Edelgase. In (Vol. 46, pp. 335): Z. Physik.

Penning, F. M. (1934). The starting potential of the glow discharge in neon argon mixtures between large parallel plates: II. Discussion of the ionisation and excitation by electrons and metastable atoms. In (Vol. 1, pp. 1028-1044). Eindhoven/Holland, Netherlands: Physica.

Polycarpou, A. C. (2006). Introduction to the Finite Element Method in Electromagnetics. United States of America: Morgan \& Claypool Publishers.

Price, W. J. (1964). Nuclear radiation detection (2d ed.). New York,: McGrawHill.

Pulkkinen, H. (2013). Basic properties of Gas Electron Multipliers and different methods to calculate the centroid of a cluster. Retrieved from

Renner, J. (2015). Detector Simulation in Garfield++ with Open-Source Finite Element Electrostatics. In.

Ropelewski, L. (2011a). Gas Detectors Development Group. Retrieved from http://gdd.web.cern.ch/GDD/

Ropelewski, L. (2011b). Gas Detectors Development Group. Retrieved from http://gdd.web.cern.ch/GDD/

Ruokolainen, J., Malinen, M., Råback , P., Zwinger, T., Pursula, A., \& Byckling, M. (2019). ElmerSolver Manual. In: CSC - IT Center for Science.

Ryne, R. D. (1993). ADVANCED COMPUTERS AND SIMULATION. Proceedings of the 1993 Particle Accelerator Conference, Vols 1-5, 3229-3233. doi:10.1109/pac.1993.309609

Råback, P., \& Malinen, M. (2019). Overview of Elmer. In: CSC - IT Center for Science.

Råback , P., Malinen, M., Ruokolainen, J., Pursula, A., \& Zwinger, T. (2020). Elmer Models Manual In: CSC - IT Center for Science.

Saad, Y. (2003). Iterative Methods for Sparse Linear Systems (Second ed.): Society for Industrial and Applied Mathematics.

Sahin, O., Tapan, I., Ozmutlua, E. N., \& Veenhof, R. (2010). Penning transfer in argon-based gas mixtures. Journal of Instrumentation, 5, P05002-P05002. doi:10.1088/1748-0221/5/05/p05002

Sales, E. (2015). Desenvolvimento de Detectores a Gás Multifilares para Raios $X$. (Mestrado), Universidade de São Paulo, São Paulo. (USP/IF/SBI$041 / 2015)$

Sauli, F. (1977). Principles of Operation of Multiwire Proportional and Drift Chambers. In Lectures given in the Academic Training Programme of CERN (pp. 92). Geneva: CERN (European Organization for Nuclear Research).

Sauli, F. (1997). GEM: A new concept for electron amplification in gas detectors. Nuclear Instruments \& Methods in Physics Research Section 
a-Accelerators Spectrometers Detectors and Associated Equipment, 386(2-3), 531-534. doi:10.1016/s0168-9002(96)01172-2

Sauli, F. (1999). Recent developments and applications of fast positionsensitive gas detectors. Nuclear Instruments \& Methods in Physics Research Section a-Accelerators Spectrometers Detectors and Associated Equipment, 422(1-3), 257-262. doi:10.1016/s01689002(98)00953-X

Sauli, F. (2014). Gaseous radiation detectors : fundamentals and applications. Cambridge: Cambridge University Press.

Schindler, H. (2019). Garfield++ User Guide. In (2019.6 ed., pp. 76).

Schindler, H., Veenhof, R., Renner, J., Baraka, K., Folkestad, A., Heijhoff, K., . . . Zenker, K. (2015). Garfield++. Retrieved from http://garfieldpp.web.cern.ch/garfieldpp

Schötzig, U. (2000). Half-life and X-ray emission probabilities of $55 \mathrm{Fe}$. Applied Radiation and Isotopes, Volume 53(Issue 3), 469-472. doi:https://doi.org/10.1016/S0969-8043(00)00166-4

Segal, B. (1995). A Short History of Internet Protocols at CERN. Retrieved from http://ben.web.cern.ch/ben/TCPHIST.html

Segrè, E. (1987). Dos Raios X aos Quarks Físicos Modernos e suas Descobertas. Brasília: Editora Universidade de Brasília.

Shohani, M. E., Golgoun, S. M., Aminipour, M., Shabani, A., Mazoochi, A. R., Akbari, R. M., ... Jafari, A. (2016). Study and full simulation of ten different gases on sealed Multi-Wire Proportional Counter(MWPC) by using Garfield and Maxwell codes. Elsevier Ltd., 115, 289-294. doi:http://dx.doi.org/10.1016/j.apradiso.2016.07.005

Sipaj, A. (2012). Simulation, Design and Construction of a Gas Electron Multiplier for Particle Tracking. (Master), University of Ontario Institute of Technology, Ontario.

Smirnov, I. (1995). HEED - Interactions of particles with gases (Version 1.01): CERN (European Organization for Nuclear Research). Retrieved from http://heed.web.cern.ch/heed/

Stamelos, I., Angelis, L., Oikonomou, A., \& Bleris, G. L. (2002). Code quality analysis in open source software development. Information Systems Journal(12), 43-60.

Stéphan, C. (1997). Gas Filled Detectors. In D. N. Poenaru (Ed.), Experimental Techniques in Nuclear Physics (pp. 57). Berlin: Walter de Gruyter.

Sundaresan, M. K. (2001). Handbook of particle physics. Boca Raton, Fla.: CRC Press.

Supriya, D. (2016). Study of gain variation as a function of physical parameters of GEM foil. In (pp. 518-520): Nuclear Instruments and Methods in Physics Research A. 
Takada, A., Tanimori, T., Kubo, H., Parker, J. D., Mizumoto, T., Mizumura, Y., . .. Kurosawa, S. (2013). Simulation of gas avalanche in a micro pixel chamber using Garfield plus. Journal of Instrumentation, 8. doi:10.1088/1748-0221/8/10/c10023

Thompson, A., Attwood, D., Gullikson, E., Howells, M., Kim, K.-J., Kirz, J., . . . Winick, H. (2009). X-ray Data Booklet. In (Vol. 14, pp. 176): Lawrence Berkley National Laboratory.

Thuiner, P., Resnati, F., Franchino, S., Diaz, G. D., Hall-Wilton, R., Muller, H., . . . Veenhof, R. (2018). Multi-GEM Detectors in High Particle Fluxes. EPJ Web of Conferences, 174, 05001. doi:10.1051/epjconf/201817405001.

Tikhonov, V., \& Veenhof, R. (2002). GEM simulation methods development. In (Vol. 478, pp. 452-459): Nuclear Instruments and Methods in Physics Research Section A: Accelerators, Spectrometers, Detectors and Associated Equipment,.

Tsoulfanidis, N. (1995). Measurement and detection of radiation (2nd ed ed.). Washington, D.C ; London: Taylor \& Francis.

Veenhof, R. (1984). Garfield - simulation of gaseous detectors (Version 9). Genève, Suisse: CERN (European Organization for Nuclear Research). Retrieved from http://garfield.web.cern.ch/garfield/

Veenhof, R. (1993). Garfield, a drift-chamber simulation program - User's guide. In (Version 4.29 ed.).

Veenhof, R. (1998). GARFIELD, recent developments. Nuclear Instruments \& Methods in Physics Research Section a-Accelerators Spectrometers Detectors and Associated Equipment, 419(2-3), 726-730. doi:10.1016/s0168-9002(98)00851-1

Veenhof, R. (2009). Numerical methods in the simulation of gas-based detectors. Journal of Instrumentation, 4, 12. doi:10.1088/17480221/4/12/p12017

Veenhof, R. (2014). Deriva de Cargas em Gases - Comunicação Particular. In. Ven, K., Verelst, J., \& Mannaert, H. (2008). Should You Adopt Open Source Software? In (Vol. 25, pp. 54-59): IEEE Software.

Villa, M., Pinto, S. D., Alfonsi, M., Brock, I., Croci, G., David, E., ... van Stenis, M. (2011). Progress on large area GEMs. Nuclear Instruments \& Methods in Physics Research Section a-Accelerators Spectrometers Detectors and Associated Equipment, 628(1), 182-186. doi:10.1016/j.nima.2010.06.312

Wang, S., Shen, F., Zhao, X., Zhu, Z., Kong, F., Li, C., ... Zhu, C. (2019). Studies on ion back-flow of Time Projection Chamber based on GEM and anode wire grid. In: Preprint submitted to Nuclear Instruments and Methods in Physics Research Section A. 
Watanabe, T., Schnopper, H. W., \& Cirillo, F. N. (1962). K X-Ray Fluorescence Yield of Argon. Phys. Rev. American Physical Society, 127(6), 20552057. doi:10.1103/PhysRev.127.2055.

Weck, O., \& Kim, Y. I. (2005). Finite Element Method - Engineering Design and Rapid Prototyping. In (pp. 28): Massachusetts Institute of Technology.

Wheeler, D. A. (2015). Why Open Source Software / Free Software (OSS/FS, FLOSS, or FOSS)? Look at the Numbers! Retrieved from https://dwheeler.com/oss fs why.html

Woodring, J., Heitmann, K., Ahrens, J., Fasel, P., Hsu, C.-H., Habib, S., \& Pope, A. (2011). ANALYZING AND VISUALIZING COSMOLOGICAL SIMULATIONS WITH ParaView. The Astrophysical Journal Supplement Series, 195(1), 11. doi:10.1088/0067-0049/195/1/11

Ziegler, J. F., Biersack, J., \& Littmark, U. (1985). The Stopping and Range of Ions in Matter. In: Pergamon Press.

Zuydtwyck, D. H. v. (2010). DEVELOPMENT OF MICRO-PATTERN GASEOUS DETECTORS - GEM. (Phd), Ludwig-Maximilians-Universit"at of Munich,

Đurković, J., Vuković, V., \& Raković, L. (2008). Open Source Approach in Software Development - Advantages and Disadvantages. Management Information Systems, Vol. 3(No. 2), p. 029-033.

Žlimen, I., Browne, E., Chan, Y., da Cruz, M. T. F., García, A., Larimer, R. M., . . . Wietfeldt, F. E. (1992). Second-forbidden electron-capture decay of 55Fe. Physical Review C, 46(3), 1136-1138. doi:10.1103/PhysRevC.46.1136 


\section{Apêndice A - Configurações de Potencial e Campo Elétrico do Triplo GEM Padrão}

São apresentadas a seguir todas as configurações do potencial e campo elétrico que foram utilizadas como entrada para as condições de contorno das simulações do triplo GEM de referência, aplicado na validação das simulações do presente trabalho, assim como para alguns estudos envolvendo o triplo GEM cônico.

Tabela 10.1: Configuração de potenciais e campos para o primeiro ponto da curva de ganho efetivo (Corrente aplicada de $641 \mu \mathrm{A})$.

\begin{tabular}{|c|c|c|c|c|c|c|}
\hline \multicolumn{7}{|c|}{ Ponto 1 da Curva de Ganho Efetivo } \\
\hline Corrente $(\mu \mathrm{A})$ & Eletrodo & \multirow{2}{*}{$\begin{array}{c}\text { Potencial (V) } \\
0,0\end{array}$} & \multicolumn{2}{|c|}{ Campos Elétricos } & \multicolumn{2}{|c|}{ Potenciais no GEM } \\
\hline \multirow{8}{*}{641} & \multirow{2}{*}{$\begin{array}{l}V_{\text {Ground }} \\
\text { VG3 }_{\text {Bottom }}\end{array}$} & & Nome & $E(V / c m)$ & GEM & $\Delta \mathrm{V}(\mathrm{V})$ \\
\hline & & -632 & EDeriva & 2132 & GEM3 & 351 \\
\hline & VG3 ${ }_{\text {Top }}$ & -983 & $E_{\text {Transf1 }}$ & 2885 & GEM2 & 382 \\
\hline & VG2 Bottom $_{\text {}}$ & -1547 & $E_{\text {Transf2 }}$ & 2820 & GEM1 & 412 \\
\hline & VG2 ${ }_{\text {Top }}$ & -1929 & $E_{\text {Indução }}$ & 3160 & & \\
\hline & VG1 $1_{\text {Bottom }}$ & -2506 & & & & \\
\hline & VG1 $1_{\text {Top }}$ & -2918 & & & & \\
\hline & $V_{\text {Deriva }}$ & -3557 & & & & \\
\hline
\end{tabular}

Tabela 10.2: Configuração de potenciais e campos para o segundo ponto da curva de ganho efetivo (Corrente aplicada de $650 \mu \mathrm{A})$.

\begin{tabular}{|c|c|c|c|c|c|c|}
\hline \multicolumn{7}{|c|}{ Ponto 2 da Curva de Ganho Efetivo } \\
\hline Corrente $(\mu \mathrm{A})$ & Eletrodo & Potencial (V) & Campo & Elétricos & Poten & no GEM \\
\hline \multirow{8}{*}{650} & $V_{\text {Ground }}$ & 0,0 & Nome & $E(V / c m)$ & GEM & $\Delta V(V)$ \\
\hline & VG3 Bottom $_{1}$ & -641 & E Eeriva & 2162 & GEM3 & 356 \\
\hline & VG3 Top $_{\text {T }}$ & -997 & $E_{\text {Transf1 }}$ & 2925 & GEM2 & 387 \\
\hline & VG2 Bottom $_{\text {B }}$ & -1569 & $E_{\text {Transf2 }}$ & 2860 & GEM1 & 417 \\
\hline & VG2 ${ }_{\text {Top }}$ & -1956 & EIndução & 3205 & & \\
\hline & VG1 $_{\text {Bottom }}$ & -2541 & & & & \\
\hline & VG1 ${ }_{\text {Top }}$ & -2959 & & & & \\
\hline & $V_{\text {Deriva }}$ & -3607 & & & & \\
\hline
\end{tabular}


Tabela 10.3: Configuração de potenciais e campos para o terceiro ponto da curva de ganho efetivo (Corrente aplicada de $659 \mu \mathrm{A}$ ).

\begin{tabular}{|c|c|c|c|c|c|c|}
\hline \multicolumn{7}{|c|}{ Ponto 3 da Curva de Ganho Efetivo } \\
\hline Corrente $(\mu \mathrm{A})$ & Eletrodo & Potencial (V) & \multicolumn{2}{|c|}{ Campos Elétricos } & \multicolumn{2}{|c|}{ Potenciais no GEM } \\
\hline \multirow{8}{*}{659} & \multirow{4}{*}{\begin{tabular}{|l|}
$V_{\text {Ground }}$ \\
VG3 \\
Bottom \\
VG3 \\
VGop \\
VGottom
\end{tabular}} & 0 & Nome & $E(V / c m)$ & GEM & $\Delta \mathrm{V}(\mathrm{V})$ \\
\hline & & -650 & E Eeriva & 2192 & GEM3 & 361 \\
\hline & & -1011 & $E_{\text {Transf1 }}$ & 2966 & GEM2 & 392 \\
\hline & & -1591 & $E_{\text {Transf2 }}$ & 2900 & GEM1 & 423 \\
\hline & VG2 ${ }_{\text {Top }}$ & -1983 & Elndução & 3249 & & \\
\hline & VG1 $1_{\text {Bottom }}$ & -2576 & & & & \\
\hline & VG1 $1_{\text {Top }}$ & -3000 & & & & \\
\hline & $V_{\text {Deriva }}$ & -3657 & & & & \\
\hline
\end{tabular}

Tabela 10.4: Configuração de potenciais e campos para o quarto ponto da curva de ganho efetivo (Corrente aplicada de $668 \mu \mathrm{A})$.

\begin{tabular}{|c|c|c|c|c|c|c|}
\hline \multicolumn{7}{|c|}{ Ponto 4 da Curva de Ganho Efetivo } \\
\hline Corrente $(\mu \mathrm{A})$ & Eletrodo & Potencial (V) & Campc & Elétricos & Poten & no GEM \\
\hline \multirow{8}{*}{668} & $\mathbf{V}_{\text {Ground }}$ & 0 & Nome & $E(V / c m)$ & GEM & $\Delta V(V)$ \\
\hline & VG3 Bottom $_{1}$ & -659 & E Eeriva & 2222 & GEM3 & 366 \\
\hline & VG3 & -1025 & $E_{\text {Transf1 }}$ & 3006 & GEM2 & 398 \\
\hline & VG2 Bottom & -1613 & $\mathrm{E}_{\text {Transf2 }}$ & 2939 & GEM1 & 429 \\
\hline & VG2 ${ }_{\text {Top }}$ & -2010 & $E_{\text {Indução }}$ & 3293 & & \\
\hline & VG1 $1_{\text {Bottom }}$ & -2612 & & & & \\
\hline & VG1 $1_{\text {Top }}$ & -3041 & & & & \\
\hline & $V_{\text {Deriva }}$ & -3707 & & & & \\
\hline
\end{tabular}

Tabela 10.5: Configuração de potenciais e campos para o quinto ponto da curva de ganho efetivo (Corrente aplicada de $677 \mu \mathrm{A})$.

\begin{tabular}{|c|c|c|c|c|c|c|}
\hline \multicolumn{7}{|c|}{ Ponto 5 da Curva de Ganho Efetivo } \\
\hline Corrente $(\mu \mathrm{A})$ & Eletrodo & Potencial (V) & Campc & Elétricos & Poten & no GEM \\
\hline \multirow{8}{*}{677} & $V_{\text {Ground }}$ & 0 & Nome & $\mathrm{E}(\mathrm{V} / \mathrm{cm})$ & GEM & $\Delta V(V)$ \\
\hline & VG3 ${ }_{\text {Bottom }}$ & -668 & E Eeriva & 2251 & GEM3 & 371 \\
\hline & VG3 Top & -1039 & $E_{\text {Transf1 }}$ & 3047 & GEM2 & 403 \\
\hline & VG2 ${ }_{\text {Bottom }}$ & -1634 & $E_{\text {Transf2 }}$ & 2979 & GEM1 & 435 \\
\hline & VG2 & -2037 & Elndução & 3338 & & \\
\hline & VG1 $1_{\text {Bottom }}$ & -2647 & & & & \\
\hline & VG1 $_{\text {Top }}$ & -3082 & & & & \\
\hline & $V_{\text {Deriva }}$ & -3757 & & & & \\
\hline
\end{tabular}


Tabela 10.6: Configuração de potenciais e campos para o sexto ponto da curva de ganho efetivo (Corrente aplicada de $686 \mu \mathrm{A})$.

\begin{tabular}{|c|c|c|c|c|c|c|}
\hline \multicolumn{7}{|c|}{ Ponto 6 da Curva de Ganho Efetivo } \\
\hline Corrente $(\mu \mathrm{A})$ & Eletrodo & Potencial (V) & \multicolumn{2}{|c|}{ Campos Elétricos } & \multicolumn{2}{|c|}{ Potenciais no GEM } \\
\hline \multirow{8}{*}{686} & \multirow{2}{*}{$\begin{array}{l}\text { V }_{\text {Ground }} \\
\text { VG3 }_{\text {Bottom }}\end{array}$} & \multirow{2}{*}{$\begin{array}{c}0 \\
-676\end{array}$} & Nome & $E(V / c m)$ & GEM & $\Delta V(V)$ \\
\hline & & & E Eeriva & 2281 & GEM3 & 376 \\
\hline & VG3 & -1052 & $E_{\text {Transf1 }}$ & 3087 & GEM2 & 409 \\
\hline & VG2 Bottom $_{\text {}}$ & -1656 & $E_{\text {Transf2 }}$ & 3018 & GEM1 & 441 \\
\hline & VG2 ${ }_{\text {Top }}$ & -2065 & EIndução & 3382 & & \\
\hline & VG1 $1_{\text {Bottom }}$ & -2682 & & & & \\
\hline & VG1 $1_{\text {Top }}$ & -3122 & & & & \\
\hline & $V_{\text {Deriva }}$ & -3807 & & & & \\
\hline
\end{tabular}

Tabela 10.7: Configuração de potenciais e campos para o sétimo ponto da curva de ganho efetivo (Corrente aplicada de $695 \mu \mathrm{A})$.

\begin{tabular}{|c|c|c|c|c|c|c|}
\hline \multicolumn{7}{|c|}{ Ponto 7 da Curva de Ganho Efetivo } \\
\hline Corrente $(\mu \mathrm{A})$ & Eletrodo & Potencial (V) & \multicolumn{2}{|c|}{ Campos Elétricos } & \multicolumn{2}{|c|}{ Potenciais no GEM } \\
\hline \multirow{8}{*}{695} & \multirow{2}{*}{\begin{tabular}{|l}
$V_{\text {Ground }}$ \\
VG3 $_{\text {Bottom }}$
\end{tabular}} & 0 & Nome & $E(V / c m)$ & GEM & $\Delta V(V)$ \\
\hline & & -685 & E Eeriva & 2311 & GEM3 & 381 \\
\hline & VG3 & -1066 & $E_{\text {Transf1 }}$ & 3128 & GEM2 & 414 \\
\hline & VG2 Bottom $_{\text {B }}$ & -1678 & $\mathrm{E}_{\text {Transf2 }}$ & 3058 & GEM1 & 446 \\
\hline & VG2 ${ }_{\text {Top }}$ & -2092 & $E_{\text {Indução }}$ & 3426 & & \\
\hline & VG1 $1_{\text {Bottom }}$ & -2717 & & & & \\
\hline & VG1 $1_{\text {Top }}$ & -3163 & & & & \\
\hline & $V_{\text {Deriva }}$ & -3857 & & & & \\
\hline
\end{tabular}

Tabela 10.8: Configuração de potenciais e campos para o oitavo ponto da curva de ganho efetivo (Corrente aplicada de $704 \mu \mathrm{A})$.

\begin{tabular}{|c|c|c|c|c|c|c|}
\hline \multicolumn{7}{|c|}{ Ponto 8 da Curva de Ganho Efetivo } \\
\hline Corrente $(\mu \mathrm{A})$ & Eletrodo & Potencial (V) & Campc & Elétricos & Poten & no GEM \\
\hline \multirow{8}{*}{704} & $V_{\text {Ground }}$ & 0 & Nome & $\mathrm{E}(\mathrm{V} / \mathrm{cm})$ & GEM & $\Delta V(V)$ \\
\hline & VG3 ${ }_{\text {Bottom }}$ & -694 & E Eeriva & 2341 & GEM3 & 386 \\
\hline & VG3 Top & -1080 & $E_{\text {Transf1 }}$ & 3168 & GEM2 & 419 \\
\hline & VG2 ${ }_{\text {Bottom }}$ & -1699 & $E_{\text {Transf2 }}$ & 3098 & GEM1 & 452 \\
\hline & VG2 & -2119 & Elndução & 3471 & & \\
\hline & VG1 $1_{\text {Bottom }}$ & -2752 & & & & \\
\hline & VG1 $_{\text {Top }}$ & -3204 & & & & \\
\hline & $V_{\text {Deriva }}$ & -3907 & & & & \\
\hline
\end{tabular}




\section{Apêndice B - Ajuste da Distribuição do Número de Elétrons na Avalanche}

Simulou-se o ganho do gás (ou ganho efetivo da avalanche) no Garfield++ para diferentes configurações de potencial aplicadas nos eletrodos do triplo GEM (Apêndice A). Programou-se um laço onde em cada iteração simulou-se uma avalanche a partir da liberação de um elétron em uma dada posição afastada do GEM 1 (próximo ao eletrodo de deriva), permitindo-se que o elétron tivesse um valor randômico em sua velocidade inicial. $A$ partir da liberação dos elétrons, foi registrada a posição final de todas as cargas. Em seguida, construiu-se um histograma com a distribuição do número de elétrons na avalanche que chegaram à zona de indução, isto é, abaixo do terceiro GEM e que assim contribuem efetivamente para o sinal elétrico que seria medido em um sistema de detecção real. Um exemplo do histograma obtido pode ser observado na Figura 11.1.

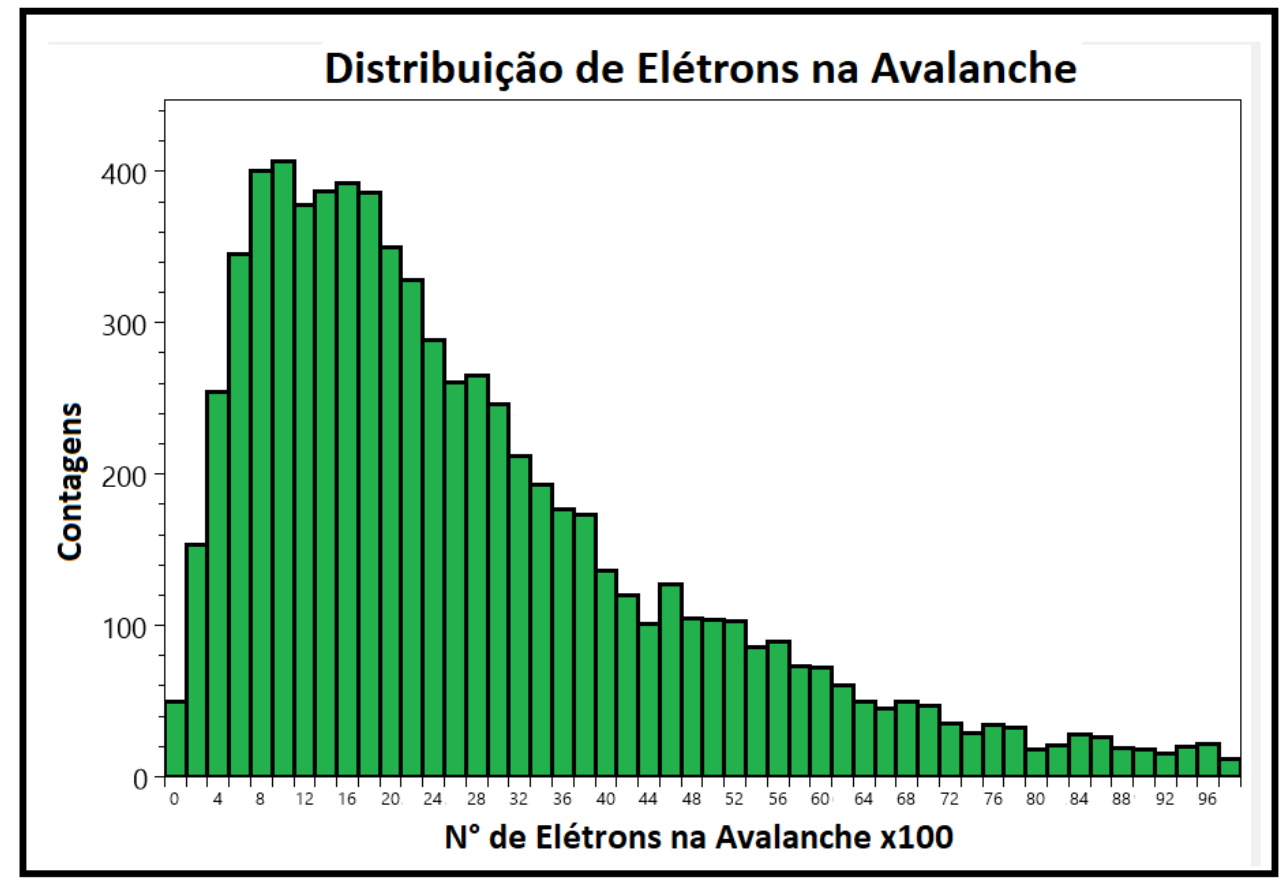

Figura 11.1: Histograma da distribuição do número de elétrons na avalanche para uma diferença de potencial de $400 \mathrm{~V}$ na folha do GEM, um campo de deriva de $500 \mathrm{~V} / \mathrm{cm}$ e um campo de indução de $1 \mathrm{kV} / \mathrm{cm}$.

O histograma do número de elétrons na avalanche segue uma distribuição conhecida como distribuição de Polya (Johnson, Kemp, \& Kotz, 1992; Kadilar \& İnal, 2010; NIST, 2006; Nuel, 2008). Desse modo, para encontrar o número médio de elétrons na avalanche e assim 
determinar o ganho de gás, foi realizado um ajuste com essa distribuição utilizando um programa desenvolvido especificamente para essa finalidade, como mostra a Figura 11.2.

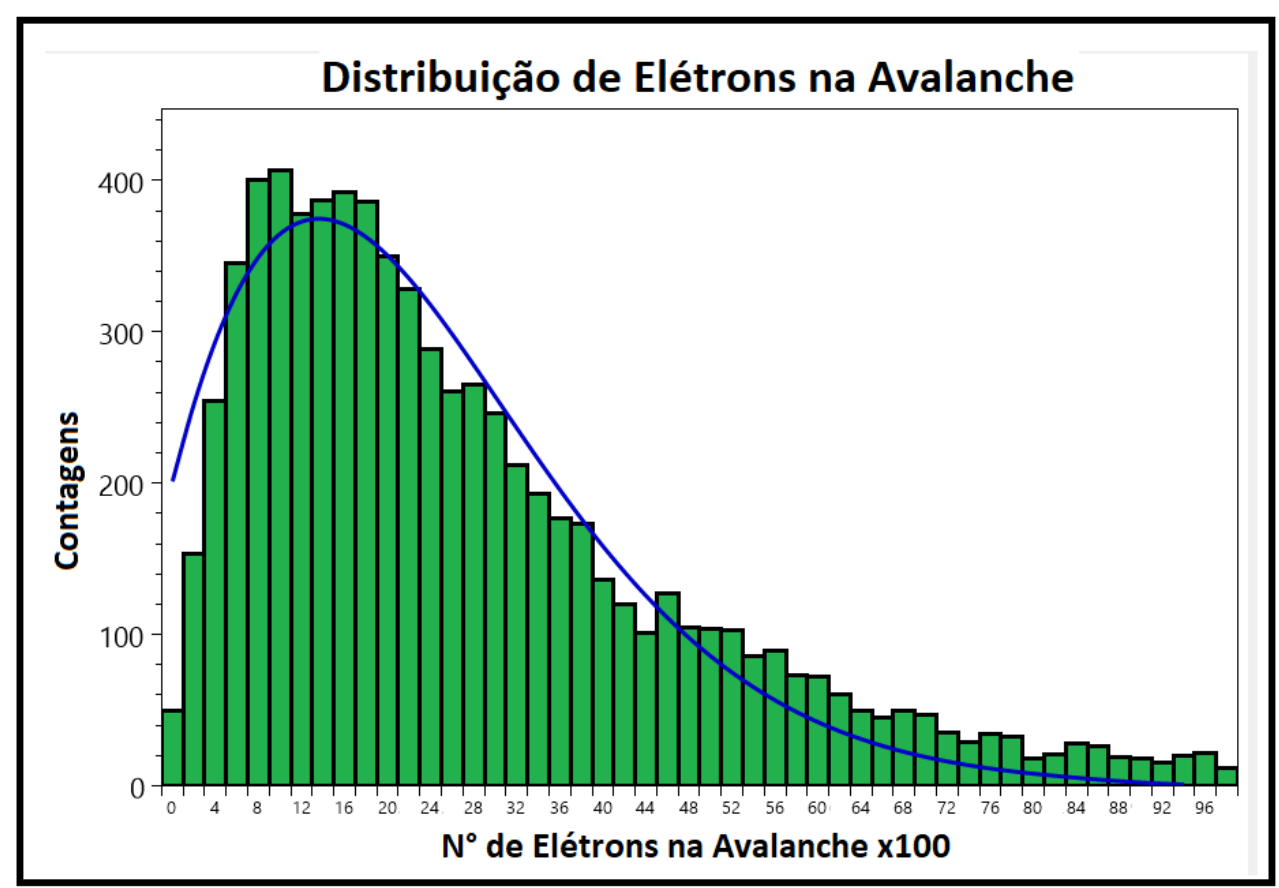

Figura 11.2: Um exemplo do ajuste da distribuição do número de elétrons na avalanche através de uma distribuição de Polya realizada no programa desenvolvido nesse trabalho.

O programa de ajuste desenvolvido considera uma distribuição de Polya (também chamada de Polya-Aeppli), dada pela seguinte expressão (Johnson et al., 1992):

$$
\begin{gathered}
p(x ; \theta, p)=e^{-\theta} \\
p(x ; \theta, p)=e^{-\theta} p^{x} \sum_{j=1}^{x}\left(\frac{x-1}{j-1}\right) \frac{(\theta(1-p) / p)^{j}}{j !} \\
0<p=1,2, \ldots
\end{gathered}
$$

onde $\boldsymbol{\theta}$ e $\mathbf{p}$ os representam os parâmetros de forma da distribuição. A distribuição PolyaAeppli propõe um modelo de distribuição que supõe que o número de objetos em estudo (que podem ser contabilizados) ocorrem em aglomerados (clusters). O número de 
aglomerados segue uma distribuição de Poisson com o parâmetro de forma $\boldsymbol{\theta}$, já o número de objetos dentro de um cluster segue uma distribuição geométrica com o parâmetro de forma $\mathbf{p}$ (Johnson et al., 1992). Por este motivo, esta distribuição é por vezes referida como uma distribuição geométrica de Poisson (NIST, 2006).

Os momentos desta distribuição são dados por (Johnson et al., 1992; NIST, 2006):

$$
\begin{aligned}
& \text { Média }=\frac{\theta}{1-p} \\
& \text { Variância }=\frac{\theta(1+p)}{(1-p)^{2}} \\
& \text { Assimetria }=\frac{\left(1+4 p+p^{2}\right)^{2}}{(1+p)^{3} \theta} \\
& \text { Achatamento }=3+\frac{\left(1+11 p+11 p^{2}+p^{3}\right)}{(1+p)^{2} \theta}
\end{aligned}
$$

Na rotina de ajuste desenvolvida nesse trabalho, foi implementada a equação (11.1), onde ela faz uma estimativa inicial dos parâmetros $\boldsymbol{\theta}$ e $\mathbf{p}$ a partir dos estimadores de momento, dados por (NIST, 2006):

$$
\begin{aligned}
& \hat{\theta}=\frac{2 \bar{x}^{2}}{s^{2}+\bar{x}} \\
& \hat{p}=\frac{s^{2}-\bar{x}}{s^{2}+\bar{x}}
\end{aligned}
$$

onde $\bar{x}$ e $s^{2}$ representam a média e a variância amostral da distribuição, respectivamente. Na sequência é possível fazer um ajuste fino desses parâmetros de modo a obter o melhor ajuste possível do histograma.

Uma vez ajustada a curva, os valores de $\boldsymbol{\theta}$ e $\boldsymbol{p}$ obtidos são aplicados na equação (11.2) e calculado a média, variância, etc. A média do ajuste da distribuição do número de elétrons na avalanche corresponde ao ganho do gás, isto é, o número médio de elétrons produzidos pelo efeito avalanche. 


\section{Apêndice C - Exemplos de Utilização da Rotina de Automatização das Simulações}

São apresentados a seguir exemplos da sequência de comandos aplicados para utilizar a rotina que automatiza as simulações (seção 4.3).






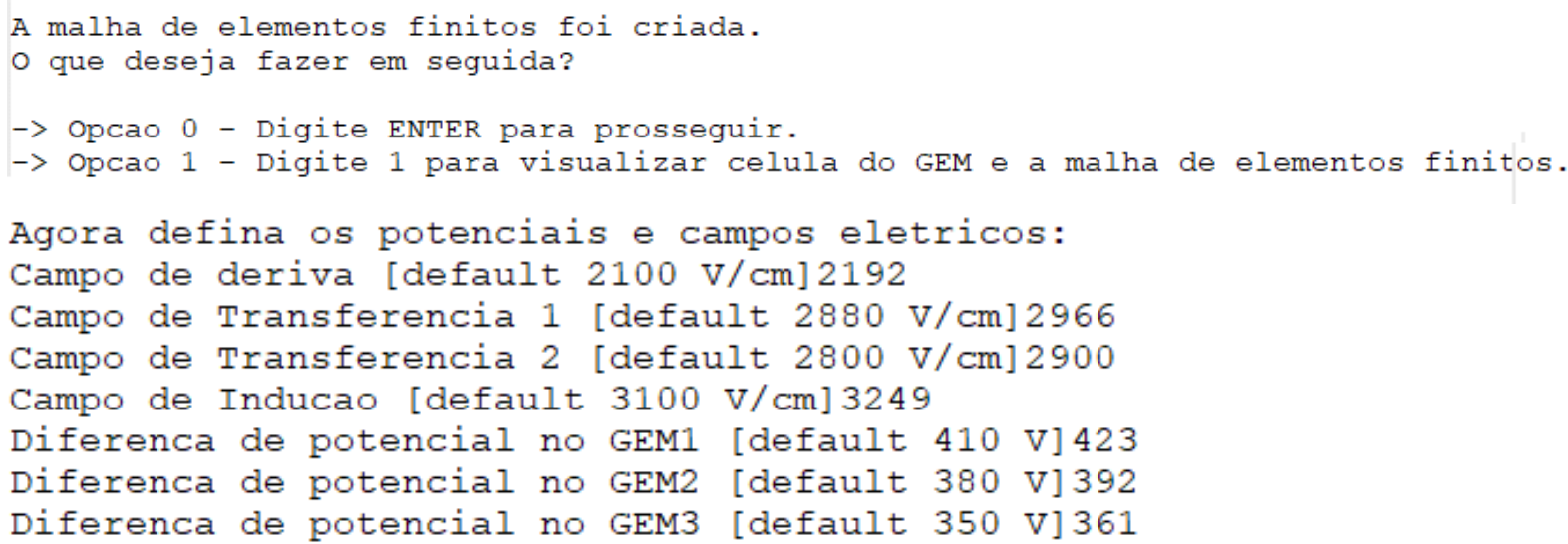

Voce escolheu os seguintes valores para os campos e potenciais:

Campo de deriva: $2192 \mathrm{~V} / \mathrm{cm}$

Campo de transferencia 1: $2966 \mathrm{~V} / \mathrm{cm}$

Campo de transferencia 2: $2900 \mathrm{~V} / \mathrm{cm}$

Campo de Inducao: $3249 \mathrm{~V} / \mathrm{cm}$

Delta V GEM 1: $423 \mathrm{~V}$

Delta V GEM 2: $392 \mathrm{~V}$

Delta V GEM 3: $361 \mathrm{~V}$

-> Opcao 1 - Digite ENTER para prosseguir.

-> Opcao 2 - Digite 2 para reconfigurar os parametros.

Vamos definir alguns parametros fisicos comuns a todos os tipos de simulacao. Digite 0 (zero) e ENTER para carregar o valor default.

Temperatura do gas [default $293.15 \mathrm{~K}$ ]:

Pressao do gas [default 740 torr]: 0

Concentracao de Argonio [default 70 \%]: 0

Concentracao de $\mathrm{CO} 2$ [default 30 \%] : 0

Fracao para efeito Penning [default 0 / sem Penning]: 0

Selecione o tipo de simulacao que deseja realizar:

-> Digite 1 para simular e visualizar uma avalanche.

-> Digite 2 para ganho e resolucao em posicao (multiplas avalanches - sem visual izacao) .

-> Digite 3 para resolucao em energia (espectro da fonte de raios $\mathrm{x} 55-\mathrm{Fe}$ ).

Escolha: 3 